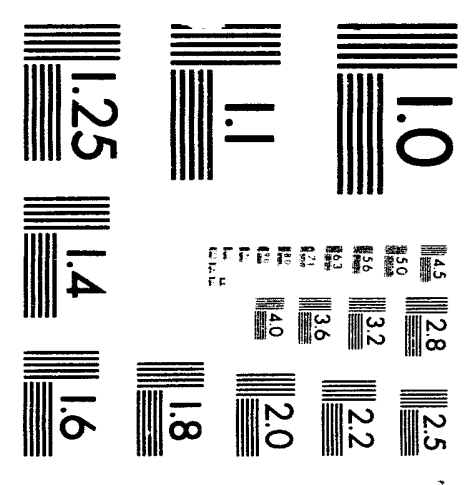



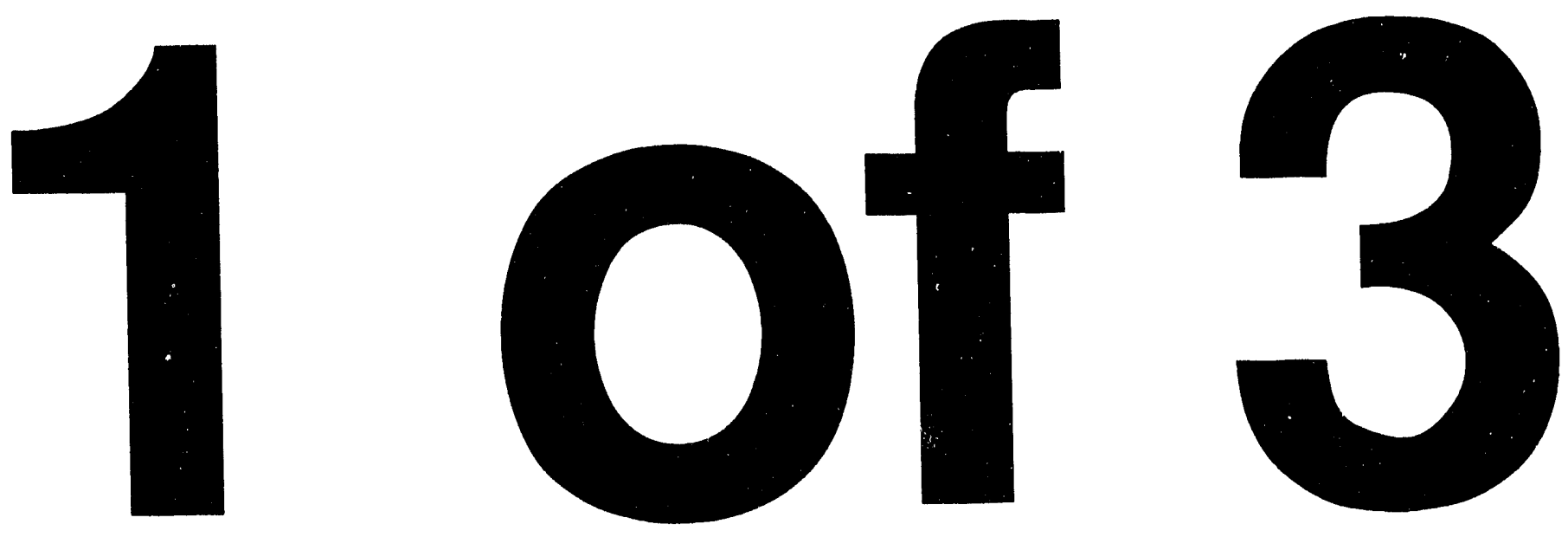
Distribution

Category UC-610

SAND93-1475

Unlimited Release

Printed October 1993

\title{
MELCOR 1.8.2 Assessment: IET Direct Containment Heating Tests
}

\author{
L. N. Kimetyk \\ Thermal/Hydraulic Analysis Department \\ Sandia National Laboratories \\ Albuquerque, NM 87185
}

\begin{abstract}
MELCOR is a fully integrated, engineering-level computer code, being developed at Sandia National Laboratories for the USNRC, that models the entire spectrum of severe accident phenomena in a unified framework for both BWRs and PWRs. As part of an ongoing assessment program, the MELCOR computer code has been used to analyze several of the IET direct containment heating experiments done at 1:10 linear scale in the Surtsey test facility at Sandia and at 1:40 linear scale in the corium-water thermal interactions (CWTI) COREXIT test facility at Argonne National Laboratory. These MELCOR calculations were done as an open post-test study, with both the experimental data and CONTAIN results available to guide the selection of code input.

Basecase MELCOR results are compared to test data in order to evaluate the new HPME DCH model recently added in MELCOR version 1.8.2. The effect of various userinput parameters in the HPME model, which define both the initial debris source and the subsequent debris interaction, were investigated in sensitivity studies. In addition, several other non-default input modelling changes involving other MLLCOR code packages were required in our IET assessment analyses in order to reproduce the observed experiment behavior. Several calcalations were done to identify whother any numeric effects cxist in our DCH IET assessment analyses.
\end{abstract}




\section{Contents}

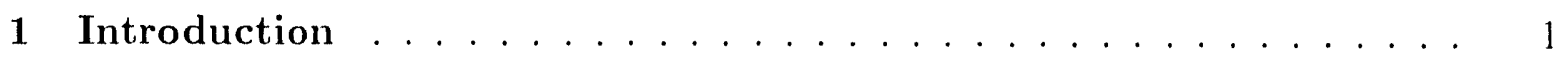

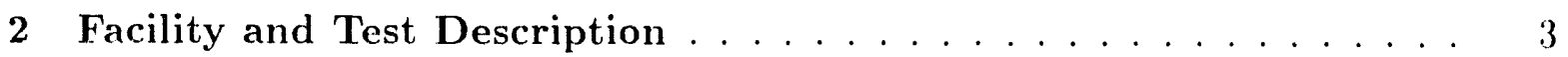

$2.1 \quad$ 1:10 Linear Scale Surtsey DCH Test Facility . . . . . . . . . 3

2.2 1:40 Linear Scale COREXIT/CWTI DCH Test Facility . . . . . 12

3 MELCOR Computer Model . . . . . . . . . . . . . . . . . . . 19

$3.1 \quad 1: 10-$ Scale Surtsey Test Facility MELCOR Model . . . . . . . 19

$3.2 \quad$ 1:40-Scale COREXIT Test Facility MELCOR Model . . . . . 26

4 Reference Calculation Results . . . . . . . . . . . . . . . 28

5 Experiment Uncertainty Studies . . . . . . . . . . . . . . . . . . 45

5.1 Steam Blowdown . . . . . . . . . . . . . . . . . . 45

5.2 Melt Injection Timing $\ldots \ldots \ldots \ldots \ldots$

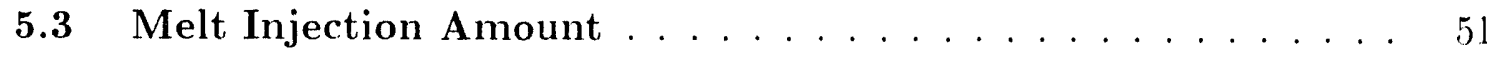

5.4 Melt Injection Temperature . . . . . . . . . . . . . . . 55

5.5 Melt Injection Distribution _. . . . . . . . . . . . . . . . 55

6 DCH Modelling Studies . . . . . . . . . . . . . . . . . . . 67

6.1 Airborne Debris Oxidation Characteristic Time . . . . . . . 67

6.2 Airborne Debris Heat Transfer Characteristic Time . . . . . . 70

6.3 Airborne Debris Settling Chararteristic Time . . . . . . . . . 75

6.4 Deposited Debris Oxidation Characteristic Time . . . . . . . 75

6.5 Deposited Debris Heat Transfer Coefficient . . . . . . . . . . 80

7 Other Modelling Studies . . . . . . . . . . . . . . . . . . . 86

7.1 Hydrogen Combustion . . . . . . . . . . . . . 86

7.2 Heat Transfer to Structures . . . . . . . . . . . . . . . . . . 90

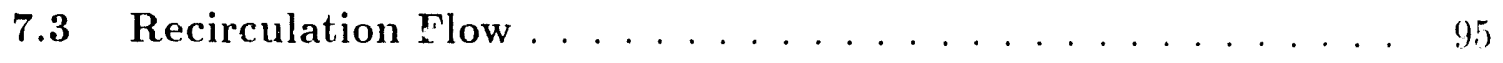

8 Scaling Sensitivity Study . . . . . . . . . . . . . . . . 10.1

8.1 Facility and Data Scaling Background Discussion . . . . . . 10.4

8.2 Scaling Facility Geometry and Test Conditions . . . . . . . . 109

8.3 Scaling Characteristic Interaction Times . . . . . . . . . . . 111

8.4 Varying Hydrogen Combustion Parameters . . . . . . . . . . 119

8.5 Varying Convective Heat Transfer . . . . . . . . . . . . . . . 120 
8.6 Varying Recirculation Flow . . . . . . . . . . . . . 123

9 Time Step Effects and Machine Dependency . . . . . . . . . . . . . 127

9.1 Machine Dependencies . . . . . . . . . . . . . . 127

9.2 Time Step Effects . . . . . . . . . . . . . . . 127

10 Comparison to CONTAIN . . . . . . . . . . . . . . 139

11 Code Problems Identified . . . . . . . . . . . . . . . . . . . . . . 144

11.1 Debris Material and Source Input . . . . . . . . . . . . . 144

11.2 Debris Interaction with Structures . . . . . . . . . . . . . . 145

11.3 Hydrogen Combustion during DCH . . . . . . . . . . . 145

11.4 Additional Output . . . . . . . . . . . . . . . 146

11.5 Debris Heat Transfer . . . . . . . . . . . . . . . 146

11.6 Cavity Condensate Water . . . . . . . . . . . . . . . . . 148

12 Summary and Conclusions . . . . . . . . . . . . . . . 149

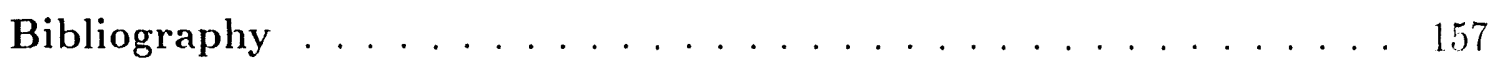

A MELCOR FDI package HPME/DCH Model . . . . . . . . . . 161

B SNL/IET-1 Reference Calculation Input Deck . . . . . . . . . . . 169 


\section{List of Figures}

2.1.1 Surtsey Vessel, HPME Ejection System and Instrumentation Ports Used in the SNL/IET Experiments . . . . . . . . . . . . . . 4

2.1.2 HPME Ejection System (High-Pressure Steam Boiler, Steam Accumulator, Melt Generator), Cavity and Instrument Chute Used in the SNL IET Ex-

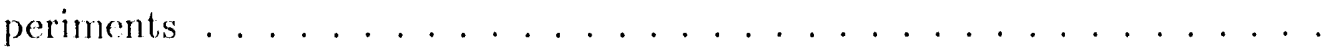

2.1.3 Cross-Sectional View of Subcompartments in Surtsey Vessel Used in the SNL/IET Experiments . . . . . . . . . . . . . . .

2.1.4 Isometric View of Subcompartments in Surtsey Vessel Used in the SNL/IET Experiments ....................... 7

2.2.1 COREXI'T Facility Used in the $\Lambda$ NL/IET Experiments . . . . . . . . 13

2.2.2 HPME System, Cavity and Inst mument (hute Used in the ANL/IET Experiments .......................... 14

2.2.3 Cross-Sectional Views of Subcompartments in $\Lambda \mathrm{NL}$ Vessel Used in the $\Lambda \mathrm{NL} / \mathrm{IET}$ Experiments ................... 15

3.1 .1 Reference MELCOR Model for SNL/IET Experiment Analyses . . . . . 20

4.1 Aluminum and Fe/Cr Masses Oxidized, and Oxygen and Steam Masses Reacted for SNL/LET Experiments .. Reference Calculation . . . . . . . . 29

4.2 Hydrogen Production for SNL/IET Experiments - Reference Calculation . 32

4.3 Iydrogen Combustion for SNL/IET Experiments - Reference (alculation 33

4.4 Hydrogen Mole Fractions in the Subcompartments and Dome for SNI/IET' Experiments ... Reference Calculation . . . . . . . . . . .

4.5 Oxygen Mole Fractions in the Subcompartments and Dome for SNL/IE'T Experiments Reference (alculation . . . . . . . . . . . . 36

4.6 Vessel Pressures for SNL/IET Experiments Reference Calculation . . . 39

4.7 Subcompartment Temperatures for Experiments SNL/IET-1, SNI/ILT-1R and SNI/IET-5 - Reference Calculation . . . . . . . . . . .

4.8 Subcompartment Temperatures for Fxperiments SNL/IET'-3, SNI/IET-4, SNL/IEI-6 and SNJ/IET'7 - Reference Calculation . . . . . . . . .

4.9 Dome Temperatures for Experiments SNL/IET-1 and SNL/IET-5 Refor-

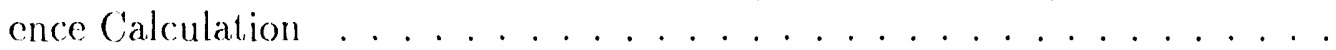

4.10 Dome Temperatures for Experiments SNL/IET-3, SNL/IET-4, SNI/IET'-6 and SNL/IET-7 Reference Calculation . . . . . . . . . . . . 44

5.1.1 Steam Accumulator Pressures for SNL/IET Experiments Using Valve Opening Times of $0.5 \mathrm{~s}, 1 \mathrm{~s}, 2 \mathrm{~s}$ and $4 \mathrm{~s}$ - Steam Blowdown Sensitivity Study . . . 
5.1.2 Vessel Pressures for SNL/IET Experiments Using Valve Opening Times of $0.5 \mathrm{~s}, 1 \mathrm{~s}, 2 \mathrm{~s}$ and $4 \mathrm{~s}$ - Steam Blowdown Sensitivity Study . . . . . . .

5.2.1 Vessel Pressures for SNL/IET Experiments Using Melt Injection Times of $0.1 \mathrm{~s}, 0.5 \mathrm{~s}, 1 \mathrm{~s}$ and $2.5 \mathrm{~s}$ - Melt Injection Timing Sensitivity Study . . . . . .

5.2.2 Subcompartment Temperatures for SNL/IET Experiments Using Melt Injection Times of $0.1 \mathrm{~s}, 0.5 \mathrm{~s}, 1 \mathrm{~s}$ and $2.5 \mathrm{~s}$ - Melt Injection Timing Sensitivity

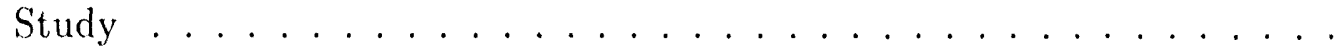

5.3.1 Vessel Pressures for SNL/IET Experiments Using Melt Masses of 80\%, 90\%, $100 \%$ and $110 \%$ the Initial Charge - Mclt Injection Amount Sensitivity Study 56

5.3.2 Subcompartment Temperatures for SNL/IET Experiments Using Melt Masses of $80 \%, 90 \%, 100 \%$ and $110 \%$ the Initial Charge -.- Melt Injection Amount Sensitivity Study . . . . . . . . . . . . . . . . .

5.4.1 Vessel Pressures for SNL/IET Experiments Using Melt Temperatures of 2000K, 2300K, 2500K and 3000K - Melt Temperature Sensitivity Study .

5.4.2 Subcompartment Temperatures for SNL/IET Experiments Using Melt Temperatures of $2000 \mathrm{~K}, 2300 \mathrm{~K}, 2500 \mathrm{~K}$ and $3000 \mathrm{~K}$ - Melt Temperature Sensitivity Study . . . . . . . . . . . . . . . . . .

5.5.1 Vessel Pressures for SNL/IET Experiments Using Basecase Melt Distribution, Experimental Melt Distribution, Melt Mostly into Cavity and Melt Mostly into Dome -- Melt Distribution Sensitivity Study . . . . . . . . .

5.5.2 Subcompartment Temperatures for SNL/IET Experiments Using Basecase Melt Distribution, Experimental Melt Distribution, Melt Mostly into Cavity and Melt Mostly into Dome - Melt Distribution Sensitivity Study . . . . .

6.1.1 Vessel Pressures for SNL/IET Experiments Using Airborne Debris Characteristic Oxidation Times of $0.5 \mathrm{~s}, 0.1 \mathrm{~s}, 0.05 \mathrm{~s}$ and $0.01 \mathrm{~s}$ - Airborne Debris Oxidation (haracteristic Time Sensitivity Study . . . . . . . . . .

6.1.2 Subcompartment 'Temperatures for SNI./IE'T Experiments Using Airborne Debris Oxidation Characteristic Times of $0.5 \mathrm{~s}, 0.1 \mathrm{~s}, 0.05 \mathrm{~s}$ and $0.01 \mathrm{~s} \cdots$ Airborne Debris Oxidation (Characteristic Time Sensitivity Study . . . . . .

6.2.1 Vessel Pressures for SNL/IET Experiments Using Airborne Debris Characteristic Heat Transfer Times of $1 \mathrm{~s}, 0.5 \mathrm{~s}, 0.25 \mathrm{~s}$ and $0.1 \mathrm{~s}$ Airborne Debris

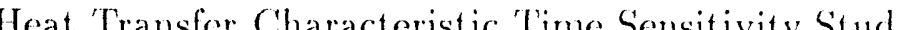

6.2.2 Subcompartment Temperatures for SNL/IET Experiments Using Airborne Debris Characteristic Heat Transfer Times of $1 \mathrm{~s}, 0.5 \mathrm{~s}, 0.25 \mathrm{~s}$ and $0.1 \mathrm{~s}$ Airborne Debris Heat 'Transfer (haracteristic Time Sensitivity Study . .

6.3.1 Vessel Pressures for SNI/IFT Experiments Using Airborno Debris (haracteristic Settling Times of $1 \mathrm{~s}, 0.5 \mathrm{~s}, 0.25 \mathrm{~s}$ and $0.1 \mathrm{~s}$ Airborne Debris Settling Characteristic 'Time Sensitivity Study 
6.3.2 Subcompartment Temperatures for SNL/IET Experiments Using Airborne Debris (haracteristic Settling Thimes of $1 \mathrm{~s}, 0.5 \mathrm{~s}, 0.25 \mathrm{~s}$ and $0.1 \mathrm{~s}$ Airborne Debris Settling Heat 'Transfer Characteristic 'Time Sensitivity Study . . . .

6.4.1 Vessel Pressures for SNL/IET Experiments Using Deposited Debris (haracteristic Oxidation Times of $10 \mathrm{~s}, 60 \mathrm{~s}, 600 \mathrm{~s}$ and $1800 \mathrm{~s}-1$ )eposited Dobris Oxidation ('haracteristic 'Time Sensitivity Study . . . . . . . .

6.4.2 Subcompartment 'Temperatures for SNL/IET Experinents Using I)eposited Debris Characteristic Oxidation Times of $10 \mathrm{~s}, 60 \mathrm{~s}, 600 \mathrm{~s}$ and $1800 \mathrm{~s}-1$ Deposited Debris Oxidation Characteristic 'Time Sensitivity Study . . . . . .

6.5.1 Vessel Pressures for SNL/IET Experiments Using Deposited Debris Heat, Transfer Coefficient of $1 \mathrm{w} / \mathrm{m}^{2}-\mathrm{K}, 10 \mathrm{w} / \mathrm{m}^{2}-\mathrm{K}, 100 \mathrm{w} / \mathrm{m}^{2}-\mathrm{K}$ and $1000 \mathrm{w} / \mathrm{m}^{2}-\mathrm{K}$ Deposited Debris Heat Transfer Coefficient Sensitivity Study . . . . . . .

6.5.2 Subcompartment Temperatures for SNL/IE'T Experiments Using IDeposited Debris Heat Transfer Coefficient of $1 \mathrm{w} / \mathrm{m}^{2}-\mathrm{K}, 10 \mathrm{w} / \mathrm{m}^{2}-\mathrm{K}, 100 \mathrm{w} / \mathrm{m}^{2}-\mathrm{K}$ and $1000 \mathrm{w} / \mathrm{m}^{2}-\mathrm{K}$ - Deposited Debris Heat Transfer Coefficient Sensitivity Study

7.1.1 Vessel Pressures for SNL/IEI Experiments with Default Burn Parameters, Basecase with Burn in the Dome Only with Zero Ignition Limit and (ombustion Completeness of (), with Burn in all Volumes with Zero Ignition Limit and (Combustion Completeness of 0 and with Burn in the Dome Only with Zero Ignition limit but Combustion Completeness of 1 - Iydrogen Combustion Sensitivity Study . . . . . . . . . . . . . .

7.1.2 Subcompartment, Temperatures for SNL/IET Experiments with Default Burn Paraneters, Basecase with Burn in the Dome Only with Zero Ignition Limit and (ombustion Completeness of 0, with Burn in all Volumes with Zero Ignition Limit and Combustion Completeness of 0 and with Burn in the Dome: Only with Zero Ignition Limit but Combustion Completeness of 1 - Hydrogen Combustion Sensitivity Study . . . . . . . . . .

7.2.1 Subcompartment Atmosphere-to-Structure Ileat Transfer Coefficients for SNL/IET Experiments Using Jefault Volume Flow Areas/Velocities Convective Heat Transfer Sensitivity Study . . . . . . . . . . . . .

7.2.2 Subcompartment Atmosphere-to-Structure Ileat Transfer Coefficients for SNI/IET Lxperiments Using I)efault Volume Flow Areas/Velocities, $0.1 \times$ Volume Flow Areas, $0.01 \times$ Volume llow Areas and $0.001 \times$ Volume Flow Areas - Convective Heat Transfer Sensitivity Study . . . . . . . . .

7.2.3 Vessel Pressures for SNI/IET Experiments Using Default Volume Flow Areas/Velocities, $0.1 \times$ Volume Flow Areas, $0.01 \times$ Volume Flow Areas and $0.001 \times$ Volume Flow Areas - Convective Heat Transfer Sensitivity Study ......................... 
7.2.4 Subcompartment 'l'emperatures for SNI/IVT Experiments Ising Default Volume Flow Areas/Velocities, $0.1 \times$ Volume Flow Areas, $0.01 \times$ Volume Flow Areas and $0.001 \times$ Volume Flow Areas Convective Heat Transfer Sonsitivity Study . . . . . . . . . . . . . .

7.3.1 Vessel Pressures for SNI./LET Rxperiments for No Recirculation, $0.1 \times$ Basecase, Basecase and $10 \times$ Basecase - Recirculation Flow Sensitivity Study 99

7.3.2 Flows into and out of the Vessel Dome and Dome Inside Surface Ileat Transfer Coefficients for SNL/IET Experiments for Basecase and $10 \times$ Basecase

Recirculation Flow Sensitivity Stıdy . . . . . . . . . . . . .

7.3.3 Subcompartment. Temperatures for SNL/IET Experiments for No Recirculation, $0.1 \times$ Basecase, Basecase and $10 \times$ Basecase Recirculation Flow Sensitivity Study . . . . . . . . . . . . . . .

8.1.1 Scaled, Measured Steam Accumulator Pressures for SNI, and $\Lambda$ NI, (ounterpart IST Experiments Scaling Study . . . . . . . . . . . .

8.1.2 Scaled, Measured Vessel Pressures for SNI and ANI, Counterpart IFI Wx-

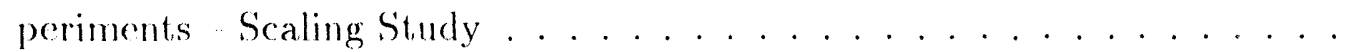
108

8.2.1 Scaled Vessel Pressures for SNL and ANI, Counterpart IEI Experiments Scaling Facility Ceometry and Test Conditions . . . . . . . . . . . .

8.3.1 Scaled Vessel Pressures for SNL and ANL Counterpart IET Experiments Scaling Airborne-Debris Sottling (haracteristic Interaction Times . . . . .

8.3.2 Scaled Vessel Pressures for SNI, and ANI, Counterpart IET Experiments Scaling Airborne-Debris Oxidation and Settling ('haracteristic Interaction Times . . . . . . . . . . . . . . . . . .

8.3.3 Scaled Vessel Pressures for SNI, and ANI. ('onnterpart IET Experiments Scaling Airbornc-bebris Heat l'ransfer and Settling ('haracteristic Interaction Times

8.3.4 Scaled Vessel Pressures for SNL, and ANL ('ommlerpart IVI Experiments Scaling All Characteristic Interaction l'imes . . . . . . . . . . .

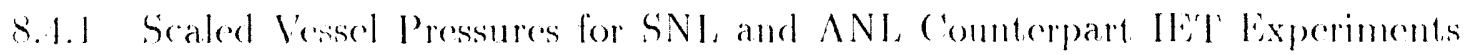
I'sing Hydrogon Molo livaction Ignition limits of $0.01,0.02,0.03$ and 0.04 for the $\mathrm{N}$ N Experiment Simulations Varying Hydrogen ('ombustion l'arameters . . . . . . . . . . . . . . . . .

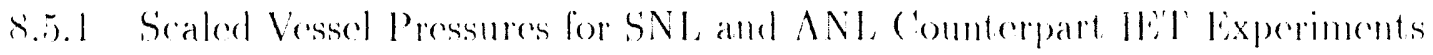
Varying convective lleat l'ransfer . . . . . . . . . . . . . .

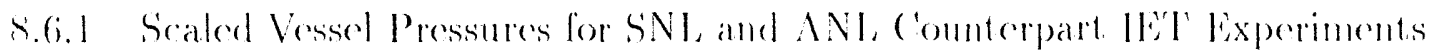
Increasing and Reducing Recirculation Flow . . . . . . . . . . . . .

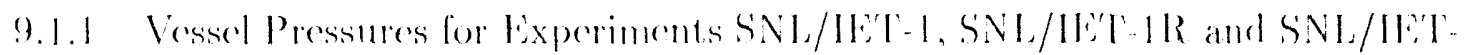
5 Machine Dependency Sonsitivity Study . . . . . . . . . . 
9.1.2 Vessel Pressures for Experiments SNL/IET-3, SNL/IET-4, SNL/IET-6 and SNL/IET-7 - Machine Dependency Sensitivity Sturly . . . . . . . . . . . . 129

9.1.3 Total Run Times and Time Step Histories for SNI/IET-I and SNL/IE'T-6 Experiment, Analyses -.. Machine Dependency Sensitivity Study . . . . . . 131

9.2.1 Vessel Pressures for Experiments SNL/IET-1, SNI/IET-1R and SNL/IET5 -Time Step Sensitivity Study . . . . . . . . . . . . . . 1333

9.2.2 Vessel Pressures for Experiments SNL/IET-3, SNL/IET-1, SNI/IET-6 and SNL/IET'-7 —. Time Step Sensitivity Study . . . . . . . . . . . . . . 134

9.2.3 Hydrogen Combustion for Experiments SNL/IET-3, SNL/IET-4, SNL/IET'6 and SNL/IET- 7 - Time Step Sensitivity Study . . . . . . . . . . . 136

9.2.4 Total Run Times and Time Step Histories for SNL/IET-1 and SNL/IET-1R Experiment Analyses - Time Step Sensitivity Study . . . . . . . . . . 137

9.2.5 'Total Run Times and Time Step Histories for SNI/IET-6 and SNL/IET'-7 Experiment Analyses - Time Step Sensitivity Study . . . . . . . . 138 


\section{List of Tables}

2.1.1 Common Initial Conditions for the SNL/IET Experiments . . . . . . . . 9

2.1.2 Individual Experiment Initial Conditions for the SNL/IET Experiments . 9

2.1.3 Debris Masses Recovered for the SNL/IET Experiments . . . . . . . . . 11

2.1.4 Results Summary for the SNL/IET Experiments . . . . . . . . . . . 11

2.2.1 Common Initial Conditions for the ANL/IET Experiments . . . . . . . . . 17

2.2.2 Individual Experiment Initial Conditions for the ANL/IET Experiments . 17

2.2.3 Debris Masses Recovered for the ANL/IET Experiments . . . . . . . . 18

2.2.4 Results Summary for the ANL/IET Experiments . . . . . . . . . . . 18

3.1.1 MELCOR FDI/HPME Debris Input Parameters Used for the SNL/IET Experiments .......................... 23

3.1.2 Characteristic Interaction Times Used in Reference MELCOR Model for SNL IE $\mathrm{T}$ Experiment Analyses . . . . . . . . . . . . . . . .

4.1 Calculated HPME/DCH Mass Results Summary for the SNL/IET Experiments - Reference Calculation . . . . . . . . . . . . . . 31

4.2 Calculated Hydrogen Results Summary for the SNL/IET Experiments Reference Calculation ................. 31

4.3 Hydrogen Results for the SNL/IET Experiments - Reference Calculation . 38

4.4 Peak Pressures for the SNL/IET Experiments - Reference Calculation . . 38

5.1.1 Hydrogen Generation for the SNL/IET Experiments - Steam Blowdown Sensitivity Study . . . . . . . . . . . . . . .

5.1.2 Hydrogen Combustion for the SNL/IET Experiments - Steam Blowdown

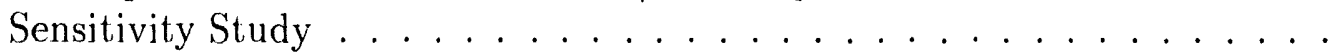

5.2.1 Hydrogen Generation for the SNL/IET Experiments - Melt Injection Timing Sensitivity Study . . . . . . . . . . . . . . . .

5.2.2 Hydrogen Combustion for the SNL/IET Experiments - Melt Injection Timing Sensitivity Study . . . . . . . . . . . . . . . .

5.3.1 Debris Masses for the SNL/IET Experiments - Melt Injection Amount Sen-

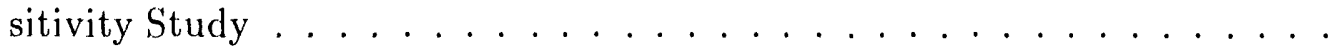

5.3.2 Hydrogen Generation for the SNL/IET Experiments - Meli Injection Amount Sensitivity Study . . . . . . . . . . . . . . . . . .

5.3.3 Hydrogen Combustion for the SNL/IET Experiments - Melt Injection Amount Sensitivity Study . . . . . . . . . . . . . . .

5.4.1 Hydrogen Generation for the SNL/IET Experiments - Melt Temperature

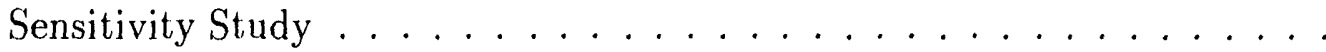


5.4.2 Hydrogen Combustion for the SNL/IET Experiments - Melt Temperature Sensitivity Study . . . . . . . . . . . . . . .

5.5.1 Debris Masses for the SNL/IET Experiments - Debris Distribution Sensi-

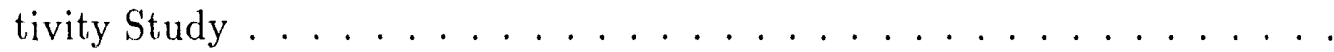

5.5.2 Hydrogen Generation for the SNL/IET Experiments - Melt Distribution Sensitivity Study . . . . . . . . . . . . . . .

5.5.3 Hydrogen Combustion for the SNL/IET Experiments - Melt Distribution Sensitivity Study . . . . . . . . . . . . . . . .

6.1.1 Hydrogen Generation for the SNL/IET Experiments - Airborne Debris Oxidation Characteristic Time Sensitivity Study . . . . . . . . . . .

6.1.2 Hydrogen Combustion for the SNL/IET Experiments - Airborne Debris Oxidation Characteristic Time Sensitivity Study . . . . . . . . . .

6.2.1 Hydrogen Generation for the SNL/IET Experiments - Airborne Debris Heat Transfer Charasteristic Time Sensitivity Study . . . . . . . . . . . .

6.2.2 Hydrogen Combustion for the SNL/IET Experiments - Airborne Debris Heat Transfer Characteristic Time Sensitivity Study . . . . . . . . . .

6.3.1 Hydrogen Generation for the SNL/IET Experiments - Airborne Debris Settling Characteristic Time Sensitivity Study . . . . . . . . . . . .

6.3.2 Hydrogen Combustion for the SNL/IET Experiments - Airborne Debris Settling Characteristic Time Sensitivity Study . . . . . . . . . . . .

6.4.1 Hydrogen Generation for the SNL/IET Experiments -- Deposited Debris Oxidation Characteristic Time Sensitivity Study

6.4.2 Hydrogen Combustion for the SNL/IET Experiments - Deposited Debris Oxidation Characteristic Time Sensitivity Study . . . . . . . . . . .

6.5.1 Hydrogen Generation for the SNL/IET Experiments - Deposited Debris Heat 'Transfer C'oefficient Sensitivity Study . . . . . . . . . . . . .

6.5.2 Hydrogen Combustion for the SNL/IET Experiments - Deposited Debris Heat Transfer Coefficient Sensitivity Study . . . . . . . . . . . . .

7.1.1 Hydrogen Generation for the SNL/IET Experiments - Hydrogen Combustion Sensitivity Study . . . . . . . . . . . . . .

7.1.2 Hydrogen Combustion for the SNL/IET Experiments - Hydrogen Combustion Sensitivity Study . . . . . . . . . . . . . . .

7.2.1 Hydrogen Generation for the SNL/IET Experiments -.. Convective Heat Transfer Sensitivity Study . . . . . . . . . . . . . . .

7.2.2 Hydrogen Combustion for the SNL/IET Experiments - Convective Heat Transfer Sensitivity Study . . . . . . . . . . . . . . . . .

7.3.1 Hydrogen Generation for the SNL/IET Experiments -.. Recirculation Flow Sensitivity Study . . . . . . . . . . . . . . 102 
7.3.2 Hydrogen Combustion for the SNL/IET Experiments - Recirculation Flow Sensitivity Study . . . . . . . . . . . . . . . . 102

8.1.1 Facility Scaling for the SNL and ANL IET Experiments . . . . . . . . 106

8.1.2 Scaled, Measured Hydrogen Generation for SNL and ANL, Counterpart IET Experiments - Scaling Study . . . . . . . . . . . . 110

8.1.3 Scaled, Measured Hydrogen Combustion for SNL and ANL Counterpart IET Experiments - Scaling Study . . . . . . . . . . . . . . . 110

8.3.1 Hydrogen Generation for the ANL/IET Experiments - Scaling Facility Geometry and Test Conditions, and Characteristic Interaction Times . . . . .

8.3.2 Hydrogen Combustion for the ANL/IE'T Experiments - Scaling Facility Geometry and Test Conditions, and Characteristic Interaction Times . . . 118

8.4.1 Hydrogen Generation for the ANL/IET Experiments - Varying Hydrogen Combustion Parameters . . . . . . . . . . . . . 122

8.4.2 Hydrogen Combustion for the ANL/IET Experiments - Varying Hydrogen Combustion Parameters . . . . . . . . . . . . . . . . 122

9.1.1 Hydrogen Generation for the SNL/IET Experiments -- Machine Dependency Sensitivity Study . . . . . . . . . . . . . . . .

9.1.2 Machine Dependency for the SNL/IET Experiments - Machine Dependency Sensitivity Study . . . . . . . . . . . . . . .

9.2.1 Hydrogen Generation for the SNL/IET Experiments - Time Step Sensitivity Study

9.2.2 Hydrogen Combustion for the SNL/IET Experiments - Time Step Sensitivity Study . . . . . . . . . . . . . . . . . . 135

10.1 Peak Pressures for the SNL/IET Experiments - Code Comparison Study . 140

10.2 Hydrogen Generation for the SNL/IET Experiments - Code Comparison Study ............................. 141

10.3 Hydrogen Combustion for the SNL/IET Experiments - Code Comparison

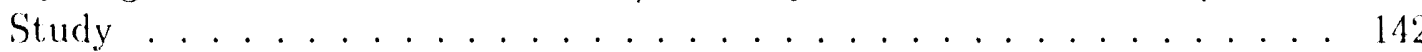




\section{Acknowledgements}

The author would like to acknowledge a number of individuals who contributed significantly to this report. Mike Allen and the other experimenters provided high-quality, rapid and extensive documentation of the Sandia IE $T$ experiment results. Russ Smith of the MELCOR development team helped with both input model setup and code problem diagnosis and correction. Sam Thompson provided the code on various platforms on demand and friendly plot programs. Dave Williams and Richard Griffith provided information on the CONTAIN model and calculations, and Dave Williams provided copies of the ANL test data letter reports and the CONTAIN analysis letter reports. Susan Dingman and Dave Williams helped with interpretation of the results in many fruitful and informative discussions. Russ Smith and Dave Williams provided the final, formal technical review, which resulted in a large number of improvements and clarifications to the text; Sam Thompson, Randy Summers, Susan Dingman and Dr. Sud Basu of the NRC also reviewed the report and suggested a number of additional improvements, all of which were incorporated in the final product.

This work was funded by the Office of Research, U. S. Nuclear Regulatory Commission. 


\section{Introduction}

MELCOR [1] is a fully integrated, engineering-level computer code, being developed at Sandia National Laboratories for the U.S. Nuclear Regulatory Commission (USNIRC), that models the progression of severe accidents in light water reactor (LWR) nuclear power plants. The entire spectrum of severe accident phenomena, including reactor coolant system and containment thermal/hydraulic response, core heatup, degradation and relocation, and fission product release and transport, is treated in MELCOR in a unified framework for both boiling water reactors and pressurized water reactors.

The MELC(P. computer code has been developed to the point that it is now being successfully applied in severe accident analyses. Some limited technical assessment activities were performed early in the MELCOR development process [2]; more recently, a more extensive, systematic program of verification and validation has been underway. 'To this end, a number of assessment calculations have been and are being done [3-9]. One of these assessment activities is analysis of some of the IET direct containment heating experiments done at 1:10 linear scale in the Surtsey test facility at Sandia [10-17] and at 1:40 linear scale in the corium-water thermal interactions (CW'TI) test facility at Argonne National Laboratory (ANL) [18-24], to evaluate the new high-pressure melt ejection (HPME) direct containment heating (DCH) model [25] added to the Fuel Dispersal Interactions (FDI) package [26] in MELCOR 1.8.2. This report documents the results of those analyses. (This report assumes familiarity with the MELCOR FDI/HPME/I)CH model, its terminology and modelling assumptions, and its input requirements. A brief description of the model, excerpted from [26], is included in Appendix A for the convenience of interested readers.)

Our original intent was to model three of the Sandia Surtsey experiments (SNL/IET1, SNL/IET-3 and SNL/IET-6), together with one of the ANL counterpart experiments (ANL/IET-6). These particular tests were chosen to provide a base case (SNI/IE'-1), to investigate the effects of hydrogen combustion in the presence of pre-existing oxygen (SNL/IET-3) and also pre-existing hydrogen (IEI-6), and to investigate the effects of scaling (ANL/IET-6 at ANL). After we began work, we soon expanded our plans to include most of the Sandia Surtsey experiments (adding SNL/IET-1R, SNL/IET-4, SNL/IET-5 and SNL/IET-7) and the rest of the ANL counterpart experiments (ANL/IET$1 \mathrm{RR}$ and $\mathrm{ANL} / \mathrm{IET}-3)$. This was done because the controlled variations done by the experimentalists in these tests (presence $v s$ absence of pre-existing hydrogen and presence $v$ s absence of basement condensate water) made little difference and required minor input changes, while the range of final melt distributions (i.e., amounts of debris collected in various locations in the containment) observed in the tests created a significant. uncertainty in specification of the MELCOR debris source. We chose to use reasonable, representative values for the debris mass and distribution for the Surtsey IET experiments, and address the variation in both total mass and distribution through sensitivity studies and analyses of more experiments.

We did not look at SNL/IET-2 in Surtsey because that was a set of separateeffects experiments on debris temperature measurements. We did not consider analyzing 
SNL/IET-8 and SNL/IET-8B in Surtsey because this test pair involved significantly different phenomena due to the cavity being half filled with water. We did not consider any of the more recent Sandia IET experiments (SNL/IET-9 and SNL/IET-10) because they were done in a different facility at a different scale and for a different plant configuration, thus requiring major input modifications. We did not consider any of the early $A N L$ tests (ANL/IET-1 and ANL/IET-1R) because of problems in the experimental procedure affecting steam/debris blowdown timing; we did not consider any of the later ANL tests (ANL/IET - 7 and ANL/IET- 8 which investigated variations initial atmosphere conditions and most recently $\mathrm{U} 1 \mathrm{~A}, \mathrm{U} 1 \mathrm{~B}$ and $\mathrm{U} 2$ which evaluated the effects of using corium vs thermite melts) because of the different phenomena and more substantial input modifications required.

MELCOR version $1.8 \mathrm{NN}$ was used for all the calculations described in this report. (The release version of MELCOR 1.8.2 was MELCOR 1.8NM. The changes between the release version and version $1.8 \mathrm{NN}$ are discussed briefly in Section 11.) Note that these MELCOR calculations were done as an open post-test study, with both the experimental data and CON'TAIN results [27-33] available to guide the selection of code input.

The Surtsey and CWTI test facilities, experimental configurations and experimental procedures are outlined in Section 2. Section 3 describes the input used for these MELCOR assessment analyses. The results of our reference calculations are given in Section 4 . Sensitivity studies on the high-pressure melt ejection model in MELCOR are presented in Sections 5 and 6 , on user-input parameters controlling the initial debris source and the subsequent debris interaction, respectively; sensitivity studies on other MELCOR modcls affecting direct containment heating are given in Section 7. Results from a scaling study using the 1:40-scale ANL tests are presented in Section 8 . Section 9 contains the results of our time step and machine dependency sensitivity studies. Comparison with results obtained by CONTAIN is done in Section 10. Section 11 summarizes the code and modelling problems identified during these assessment analyses. The conclusions of this MELCOR assessment study are presented in Section 12. A brief description of the MELCOR FDI/HPME/1)CH model is included in Appendix A, and a listing of the input used for the Surtsey IET-1 reference calculation is given in Appendix B. 


\section{Facility and Test Description}

\section{$2.1 \quad$ 1:10 Linear Scale Surtsey DCH Test Facility}

The Surtsey Test facility at Sandia is used to perform scaled experiments that simutate high-pressure melt ejection (HPME) in a nuclear power plant, investigating the pheromena associated with direct containment heating (DCII). In these tests, high-tem;erature, chemically reactive melt is ejected by high-pressure steam into a 1:10 lincar scale model of a reactor cavity. Debris is entrained by the steam blowdown into the Surtsey vessel where specific phenomena, such as the effect of subcompartment structures, water in the cavity, and hydrogen generation and combustion, can be studied.

Figure 2.1.1 gives a composite view of the Surtsey vessel, the IIPME delivery system, and the instrument penetration ports at six levels in the Surtsey vessel. $\Lambda$ more detailed view of the HPME delivery system and of the cavity and instrument chute for these IE: experiments is presented in Figure 2.1.2. (The circled numbers in these and following figures correspond to channel numbers in the data acquisition system. That experimental data identification is not used in this report; therefore, those circled numbers are not identified or discussed further.)

In the Surtsey IET tests [10-17], 1:10 linear scale models of the Zion reactor pressure vessel (RPV), cavity, in-core instrument tunnel, and subcompartment structures were used. The RPV was modelled with a melt generator that consisted of a stecl pressure barrier, a cast, $\mathrm{MgO}$ crucible, and a thin steel liner. The melt-generator/crucible had a hemispherical bottom head containing a graphite limiter plate with a $4 \mathrm{~cm}$ exit hole to simulate the ablated hole in the RPV bottom head that would be formed by ejection of an instrument guide tube and subsequent hole ablation in a severe accident.

The cavity used was a 1:10 linear scale model of the Zion reactor cavity. The inclined portion of the instrument tunnel entered the bottom head of Surtsey at a $26^{\circ}$ incline from vertical, as it does in Zion. A false concrete floor was constructed in the Surtsey vessel similar to the floor of the Zion basement so that the inclined portion of the instrument tunnel was $\sim 2.7$ times the correct scaled length of the Zion instrument tunnel exit. ('This floor was constructed in Surtsey to match the configuration of the $\Lambda$ NL facility, described in the next, subsection.)

'The subcompartment structures, shown in cross-section in Figure 2.1 .3 and illustrated schematically in Figure 2.1.4, included 1:10 linear scale models of the crane wall, four steam generators, four reactor coolant pumps (RCPs), the opening in the floor of the scal table room for the instrument guide tubes, the seal table room, the biological shield, the refueling canal, the radial beams and the gratings at the RCP deck, and the operating deck. The steam generators, RCPs and gratings were made of stecl, and the other structures were constructed of reinforced concrete. All of the structures were painted with an epoxy-base paint.

In the majority of the IET experiments, the steam accumulator tank was pressurized with superheated steam. After the pressurization sequence, the iron-oxide/aluminumi- 


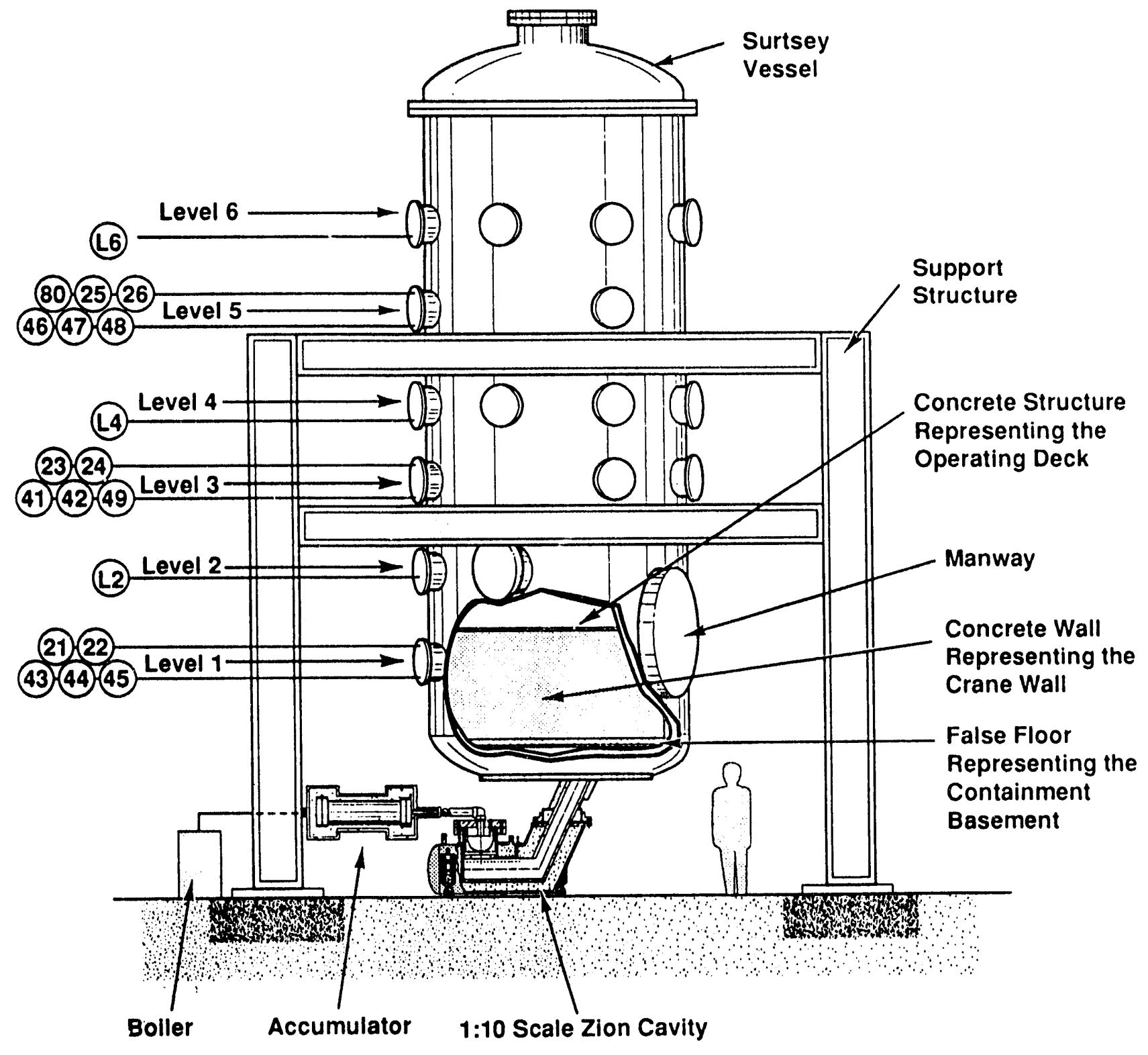

Note: All pressure transducers have Individual penetrations.

Figure 2.1.1. Surtsey Vessel, HPME Ejection System and Instrumentation Ports Used in the SNL/IET Experiments (from [10]) 


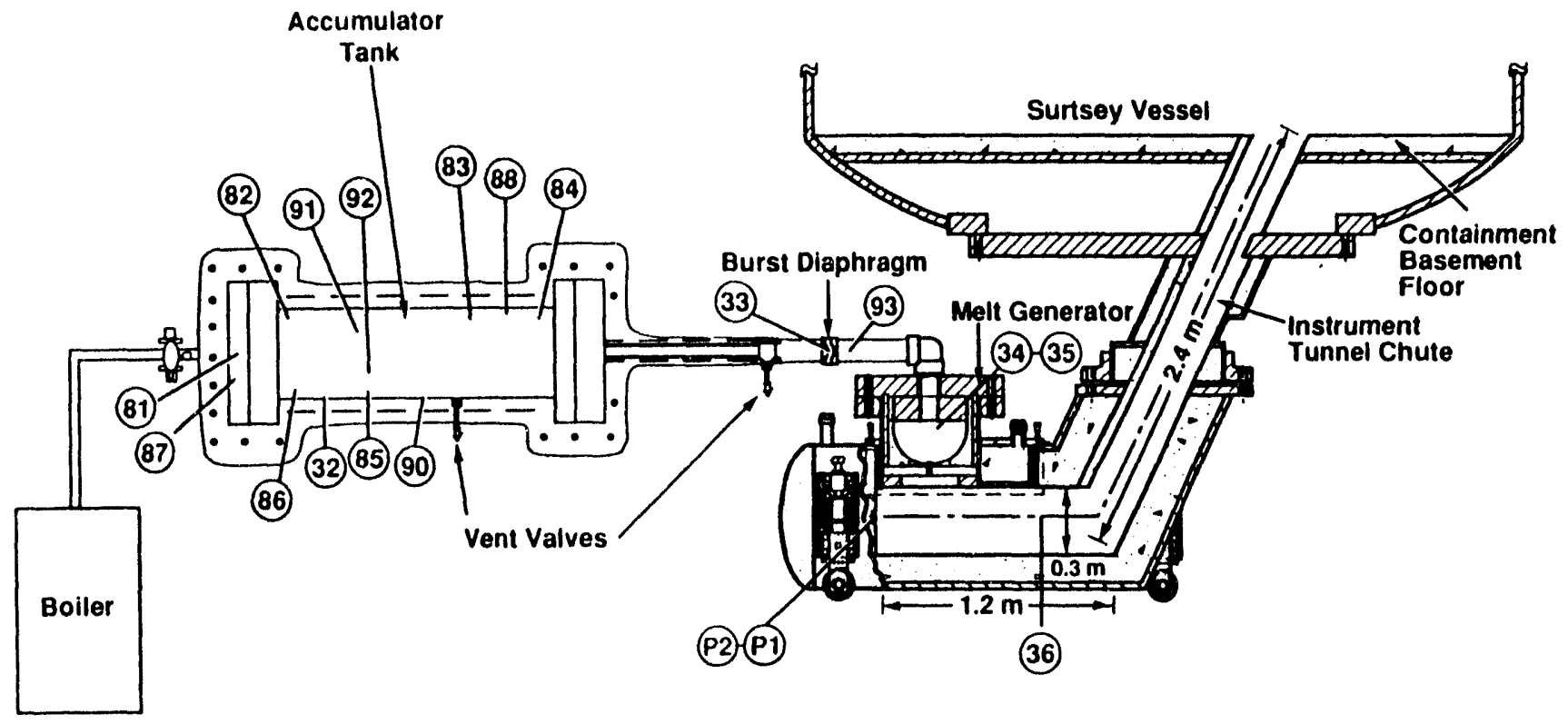

Figure 2.1.2. HPME Ejection System (High-Pressure Steam Boiler, Steam Accumulator, Melt Generator), Cavity and Instrument Chute Used in the SNL IET Experiments (from [10]) 


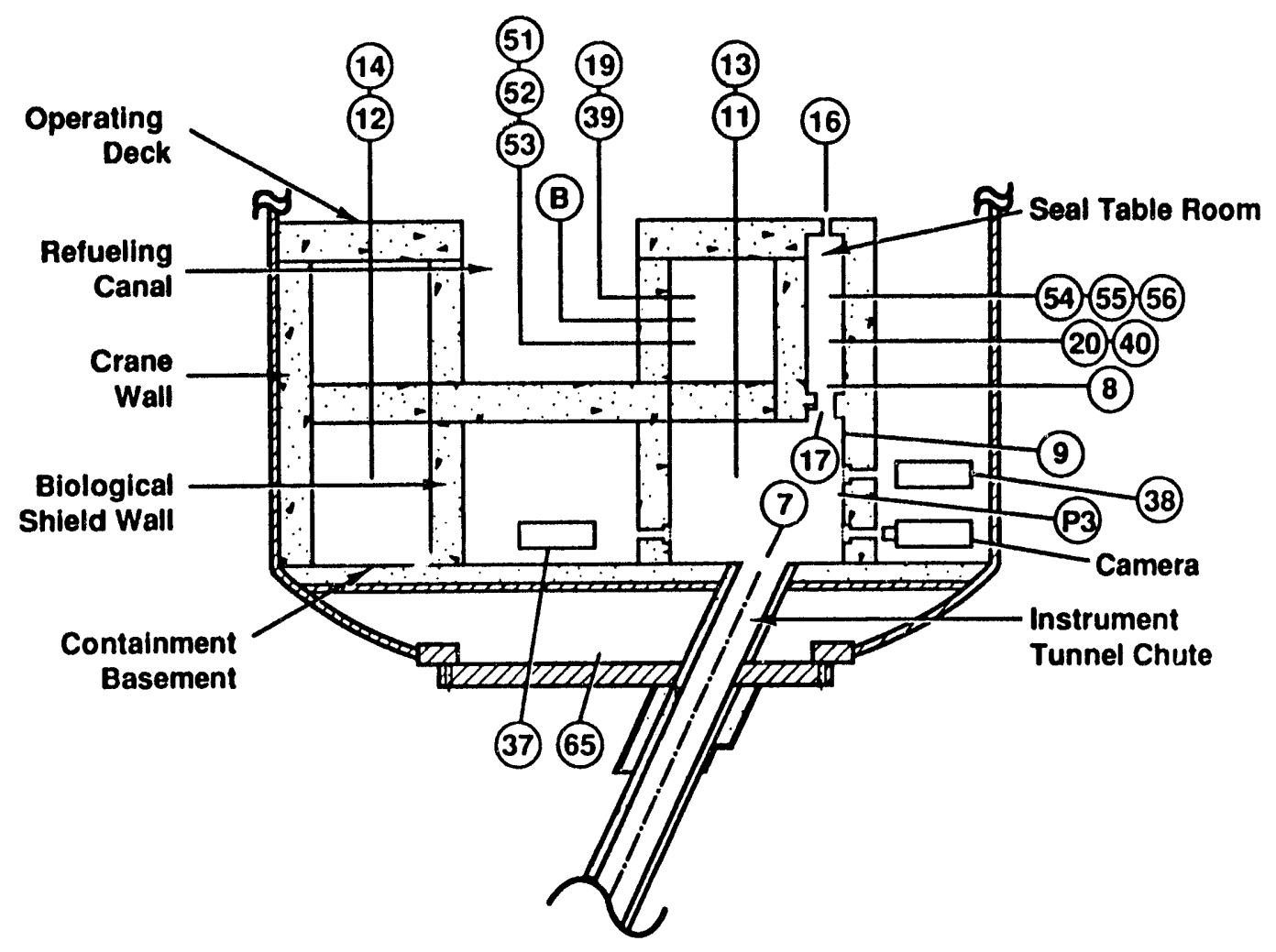

Figure 2.1.3. Cross-Sectional View of Subcompartments in Surtsey Vessel Used in the SNL/IET Experiments (from [10]) 


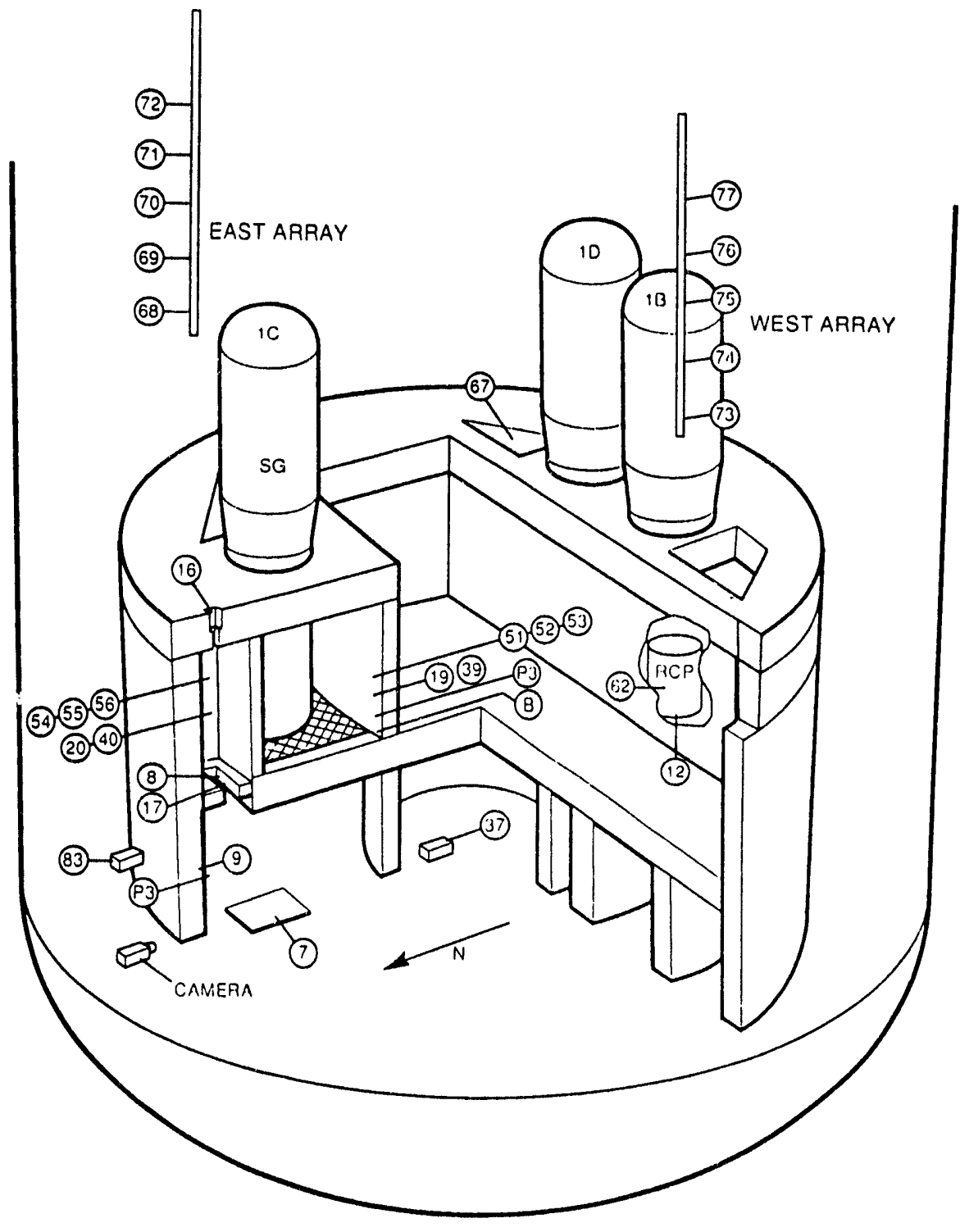

Figure 2.1.4. Isometric View of Subcompartments in Surtsey Vessel Used in the SNL/IET Experiments (from [10]) 
chromium thermite mixture was ignited remotely. After the thermite was ignited, the pressure in the crucible rapidly increased, verifying that the thermite reaction had started and signalling the operator to fail the burst diaphragm separating the steam accumulator tank and the molten thermite in the melt generator, bringing superheated steam into contact with the molten thermite. Zero time for the HPME experiments was set at the time at which the melt in the crucible failed a fusible brass plug at the bottom of the crucible and was expelled by high-pressure steam into the cavity.

A series of experiments were done investigating the effects of high pressure melt ejection on direct containment heating:

1. Test SNL/IET-1 was the baseline test, while test SNL/IET-1R was a replicate test, investigating experiment reproducability [10].

2. Test,(s) SNL/IET-2A, SNL/IET-2B and SNL/IET-2C [11] were a set of separateeffects experiments performed to measure the temperature of molten thermite as it exited the melt generator.

3. Test SNL/IET-3 replicated test. SNL/IET-1 except the vessel contained a mixture of air and nitrogen [12]; no steam explosion occurred in SNL/IET-3 as it had in SNL/IET-1, but instead there was a vigorous hydrogen burn.

4. Test SNI/IET-4 [13] replicated test SNL/IET-3 except the Surtsey vessel contained slightly more pre-existing oxygen and water was placed on the basement floor inside the crane wall.

5. Test SNL/IET'-5 conditions were similar to those in SNL/IET-4, except the vessel atmosphere was classically inert [11], with $\mathrm{CO}_{2}$ used to suppress hydrogen combustion,

6. Test SNL/IET-6 initial conditions [15] were similar to those in SNL/IL'P-3, except the vessel atmosphere contained pre-existing hydrogen to represent partial oxidation of the zirconium in the core.

7. 'Test SNL/IET-7 initial conditions were similar to those in SNL/IET-4, except the vessel atmosphere contained pre-existing hydrogen to represent partial oxidation of the zirconium in the core [16].

8. In SNL/IE'-8 [17], the molten thermite flowed under gravity through the hole in the melt generator into the reactor cavity, which was half filled with water; in SNL/LET-8B, the molten thermite was ejected by high-pressure steam (as in most of the earlier IET tests) into the reactor cavity, which was again half filled with water.

Initial conditions for the SNL/IFI' tests are given in Tables 2.1.1 and 2.1.2; Table 2.1.1 gives initial conditions common to all the Surtsey experiments, while Table 2.1.2 gives initial conditions for those parameters whose values were varied in the Surtsey tests. 
Table 2.1.1. Common Initial Conditions for the SNL/IET Experiments

$\begin{array}{lc}\text { Thermite Total }(\mathrm{kg}) & 4.30 \\ & \\ \text { Surtsey Vessel Volume }\left(\mathrm{m}^{3}\right) & \\ \text { Subcompartments } & 4.65 \\ \text { Upper Dome } & 85.15 \\ \text { Total } & 89.8\end{array}$

Table 2.1.2. Individual Experiment Initial Conditions for the SNL/IET Experiments

\begin{tabular}{|c|c|c|c|c|c|c|c|c|c|}
\hline Parameter & IE $\Gamma-1$ & IET-1R & IET-3 & IET-4 & IE' -5 & IET-6 & IET'-7 & IE $T-8$ & IET-8B \\
\hline \multicolumn{10}{|l|}{ Hole Diarretci $(\mathrm{cm})$} \\
\hline Initial & 3.5 & 3.5 & 3.5 & 3.5 & 3.5 & 3.5 & 3.5 & 3.5 & 3.5 \\
\hline Final & 4.04 & 4.02 & 4.53 & 4.22 & 4.31 & 3.91 & 4.08 & 3.5 & 4.1 \\
\hline \multicolumn{10}{|l|}{ Steam Accumulator } \\
\hline Pressure (MPa) & 7.1 & 6.3 & 6.1 & 6.7 & 6.0 & 6.3 & 5.9 & - & 6.25 \\
\hline Temperature (K) & 600 & 585 & 585 & 555 & 584 & 571 & 599 & & 554 \\
\hline Mass (gm-moles) & 140 & 477 & 456 & 582 & 457 & 505 & 416.4 & .. & 538 \\
\hline \multicolumn{10}{|l|}{ Water Mass $(\mathrm{kg})$} \\
\hline Cavity & 3.48 & 3.48 & 3.48 & 3.48 & 3.48 & 3.48 & 3.48 & 62 & 62 \\
\hline Basement & 0 & 0 & 0 & 71.1 & 71.1 & 0 & 71.1 & 71.1 & 71.1 \\
\hline \multicolumn{10}{|l|}{ Vessel Atmosphere } \\
\hline Pressure (MPa) & 0.20 & 0.20 & 0.19 & 0.20 & 0.20 & 0.198 & 0.21 & 0.20 & 0.203 \\
\hline Temperature (K) & 295 & 295 & 279 & 286 & 303 & 308 & 302.7 & 304.1 & 298 \\
\hline \multicolumn{10}{|c|}{ Composition (mole \%) } \\
\hline $\mathrm{N}_{2}$ & 99.90 & 99.78 & 90.60 & 90.00 & 16.90 & 87.10 & 85.95 & 85.32 & 85.80 \\
\hline $\mathrm{O}_{2}$ & 0.03 & 0.19 & 9.00 & 9.59 & 4.35 & 9.79 & 9.57 & 9.85 & 9.79 \\
\hline $\mathrm{H}_{2}$ & 0 & 0.02 & 0 & 0 & 2.76 & 2.59 & 3.97 & 4.33 & 3.91 \\
\hline $\mathrm{CO}_{2}$ & 0.01 & 0 & 0.02 & 0.02 & 75.80 & 0 & 0.03 & 0.03 & 0.03 \\
\hline other & 0.06 & 0.01 & 0.38 & 0.39 & 0.13 & 0.52 & 0.48 & 0.47 & 0.47 \\
\hline
\end{tabular}


The most significant variables measured in the Surtsey IET tests were the overall increase in pressure and temperature in the Surtsey vessel, the cavity local pressure, the amount of hydrogen generated by the reaction of metallic debris with steam driving gas and with water in the cavity, the debris temperatures as it exited the instrument tunnel and as it struck the crane wall, debris velocities based on breakwires in seal table room openings, and the mass of debris recovered from the Surtsey vessel. In some of the later tests, cameras were used to determine if the subcompartment structures filled immediately with aerosols, and to obtain information about the debris flow regime and velocity; also in some of the later tests, post-test sieve analysis was done on debris recovered from the Surtsey vessel outside the subcompartment structures to determine particle size distribution.

Table 2.1.3 gives a debris recovery summary for the Surtscy IET experiments. The total molten mass available for dispersal into the vessel was usually $\sim 20 \%$ greater than the initial thermite charge due to melting of the inner wall of the crucible, vaporization of the fusible brass plug, ablation of concrete in the cavity and structures, and oxidation of metallic debris.

Table 2.1.4 summarizes the comparative results of the IET' tests for overall vessel pressurization and for hydrogen generation and combustion. The total amount of hydrogen generated hy steam/metal reactions was calculated by subtracting the measured amount of pretest bivlrogen from the sum of the measured amount of posttest hydrogen plus the estimates: amount of hydrogen burned; the hydrogen combustion given was based on the asumplim that all oxygen depletion was due to reaction with hydrogen and was ralculated using the stoichiomertic chemical reaction for the formation of water:

$$
\begin{gathered}
n_{\text {burn }}\left(H_{2}\right)=2\left[n_{0}\left(\mathrm{O}_{2}\right)-n_{f}\left(\mathrm{O}_{2}\right)\right] \\
n_{\text {prod }}\left(H_{2}\right)=n_{\text {burn }}\left(H_{2}\right)+n_{f}\left(H_{2}\right)-n_{0}\left(H_{2}\right)
\end{gathered}
$$

where the n's are the number of moles and the subscripts 0 and $f$ refer to initial and final values, respectively. Final gas concentrations were measured from grab bottle samples mostly taken $30 \mathrm{~min}$ after the HPME transient in all tests, at levels 2,4 and 6 in the Surtsey vessel; in some experiments, gas grab samples were also available 0 - 2 s after the start of the HPME transient (in the cavity), $2-5 \mathrm{~s}$ after the start of the HPME transient (inside the subcompartment structures) and at 2min after the HPME transient (at the. same three levels in the vessel). There was little difference in the gas grab samples taken in the vessel at 2 and $30 \mathrm{~min}$, but there were large differences in gas composition in the cavity and inside the subcompartment structures during the HPME transient, as would be expected.

There is a significant increase in hydrogen combustion from tests SNL/IET-3 and SNL/IEI'-4 (186 and 236 gm-moles, respectively), which had no pre-existing hydrogen, to tests SNL/IET-6 and SNL/IET-7 (335 and 321 gm-moles, respectively), with no preexisting hydrogen. In both tests with pre-existing hydrogen, more hydrogen burned than 
Table 2.1.3. Debris Masses Recovered for the SNL/IET Experiments

$\begin{array}{lccccccccc} & \text { IET-1 } & \text { IET-1R } & \text { IET-3 } & \text { IET-4 } & \text { IET-5 } & \text { IE'T-6 } & \text { IET-7 } & \text { IET-8 } & \text { IET-8B } \\ \text { Initial Thermite (kg) } & 43.0 & 43.0 & 43.0 & 43.0 & 43.0 & 43.0 & 43.0 & 43.0 & 43.0 \\ & & & & & & & & & \\ \text { Recovered Mass (kg) } & & & & & & & & & \\ \quad \text { Crucible } & 4.54 & 4.63 & 4.50 & 4.76 & 2.60 & 2.27 & 6.74 & 0.23 & 2.56 \\ \text { Cavity/Chute } & 7.06 & 13.19 & 16.80 & 9.54 & 20.07 & 8.47 & 13.31 & 42.31 & 5.55 \\ \text { Subcompartment } & 38.03 & 32.41 & 31.30 & 32.67 & 31.22 & 36.60 & 33.99 & 5.81 & 26.99 \\ \text { Dome } & 4.98 & 3.80 & 3.00 & 8.04 & 1.89 & 5.87 & 2.71 & 2.76 & 15.87 \\ \text { Total } & 54.61 & 54.03 & 55.60 & 55.02 & 55.79 & 53.21 & 56.75 & 51.11 & 50.97\end{array}$

Table 2.1.4. Results Summary for the SNL/IET Experiments

IET-1 IET-1R IET-3 IET-4 IET-5 IET-6 IET-7 IET-8 IET-8B

HPME $\triangle \mathrm{P}_{\text {MAX }}(\mathrm{kPa})$

$\begin{array}{llllllllll}\text { Dome } & 98 & 110 & 246 & 262 & 103 & 279 & 271 & 87 & 243\end{array}$

$\mathrm{H}_{2}$ (gm-moles)

Pretest.

Produced

Burned

$\begin{array}{ccccccccc}\sim 0 & \sim 0 & \sim 0 & \sim 0 & 202 & 180 & 284 & 307 & 288 \\ 223 & 252 & 223 & 297 & 313 & 308 & 271 & 107 & 2.17 \\ 1 & 12 & 186 & 236 & 50 & 335 & 321 & 114 & 202\end{array}$


was produced by oxidation during HPME, indicating some of the pre-existing hydrogen was burned. However, there is not a corresponding significant increase in peak vessel pressures measured. Therefore, the pre-existing hydrogen must have recombined on a time scale much longer than the HPME time scale not to have contributed to the peak pre sure increase.

\subsection{1:40 Linear Scale COREXIT/CWTI DCH Test Facility}

Counterpart IET tests are being performed at Sandia in the Surtsey facility $(1: 10$ scale) and at ANL in the Corium Ex-Vessel Interaction (COREXIT) facility (1:40 scale), in an experimental program to investigate the effects of scale on DCH phenomena.

A schematic of the experiment apparatus [18-24] is given in Figure 2.2.1. Major components of the facility include an explosion-resistant containment cell, an expansion vessel and a high-pressure steam boiler. A concrete cavity model is contained within an outer pipe body, as shown in Figure 2.2.2. Bolted on top of the pipe body is a saddle piece, referred to as the top cap, which contains the melt generator and injecter (MGI). The cavity keyway is elongated by a transition chute which connects the cavity to the bottom of the expansion vessel. The elongation is required in order to allow room for the melt generator to fit underneath the expansion vessel; the keyway is thus elongated by 2.7 times its correctly scaled length.

The model used for the Zion subcompartment structures is shown in Figure 2.2.3, and is a scaled-down version of the subcompartments mociel used in the SNL/IET tests. Prominent features which are modelled include the seal table room, refueling canal, biological shield wall, reactor coolant pumps, steam generators, floor grating and operating deck floor. The walls and floors were constructed from concrete and mortar, and the structures painted with epoxy paint. This model was built up from the lower flange of the expansion vessel. The perimeter of the model is defined by a circular concrete wall which simulates the crane wall in the plant.

Test operations were begun by preheating the accumulator, the MGI and all piping associated with the test delivery system, until predetermined temperatures were obtained. If called for by the test, water was added to the cavity. The expansion vessel, steam generator and accumulator were brought to test-specified pressures. Each test was begun by starting the data acquisition system and starting a timer which applied power to an igniter assembly which started the thermite reaction. At a specified time after applying power to the igniter, the isolation steam valve was actuated followed by the steam valve which introduces steam into the MGI. At some time after the steam introduction, the thermite reaction reached and failed the brass plug in the melt generator, which started the high-pressure melt ejection.

A series of experiments were done investigating the effects of high pressure melt ejection on direct containment heating:

1. Test ANL/IET-1 was the baseline test, while test ANL/IET-1R and ANL/IET$1 R R$ were replicate tests investigating experiment reproducability [18, 19]. This 
KNTEI ALI. RIPTUIRF MISTS

AlNI RELI II: VAI VI:S ARI:

VEENIL:II II IIII IIIIISIII:

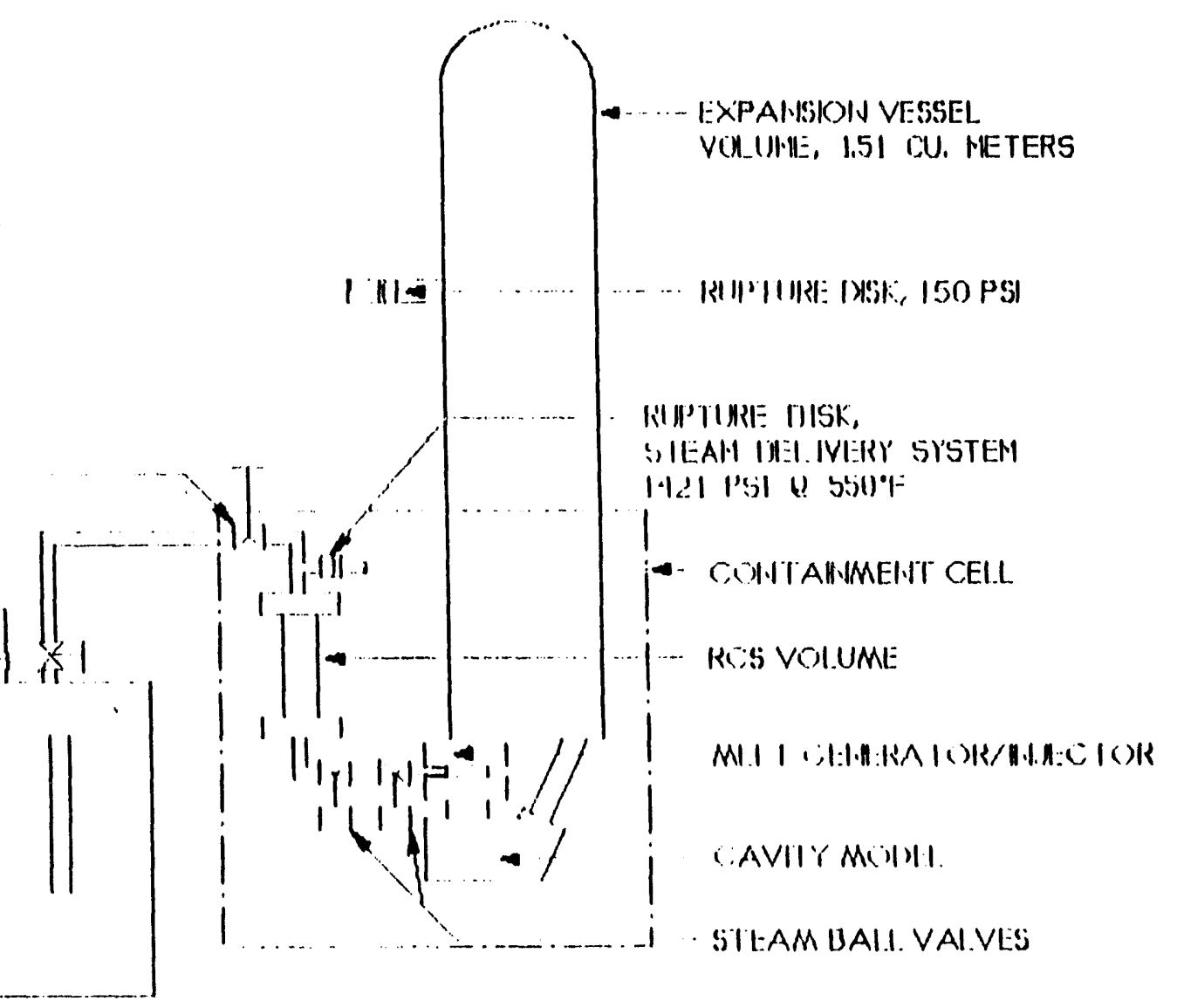

Figure 2.2.1. COREXIT Facility Used in the ANL/IET Experiments (from [19]) 

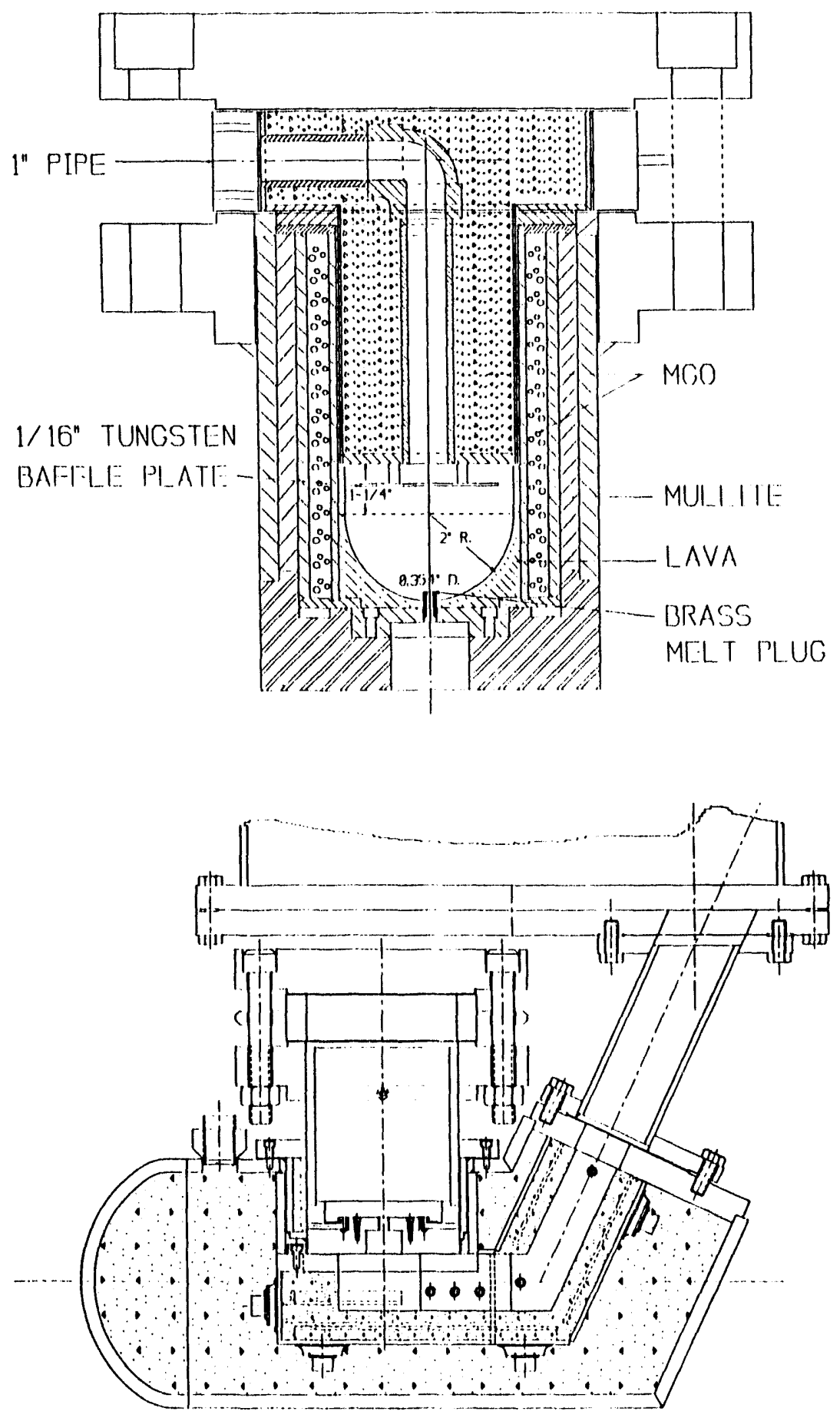

Figure 2.2.2. HPME System, Cavity and Instrument Chute Used in the ANL/IET Experiments (from [19]) 


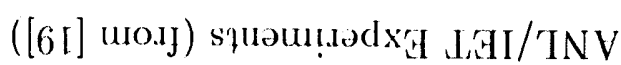

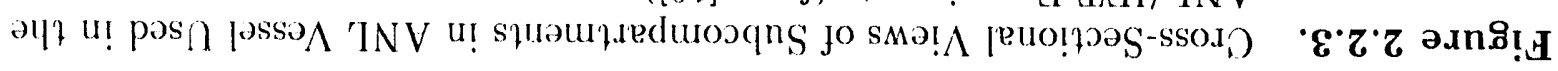
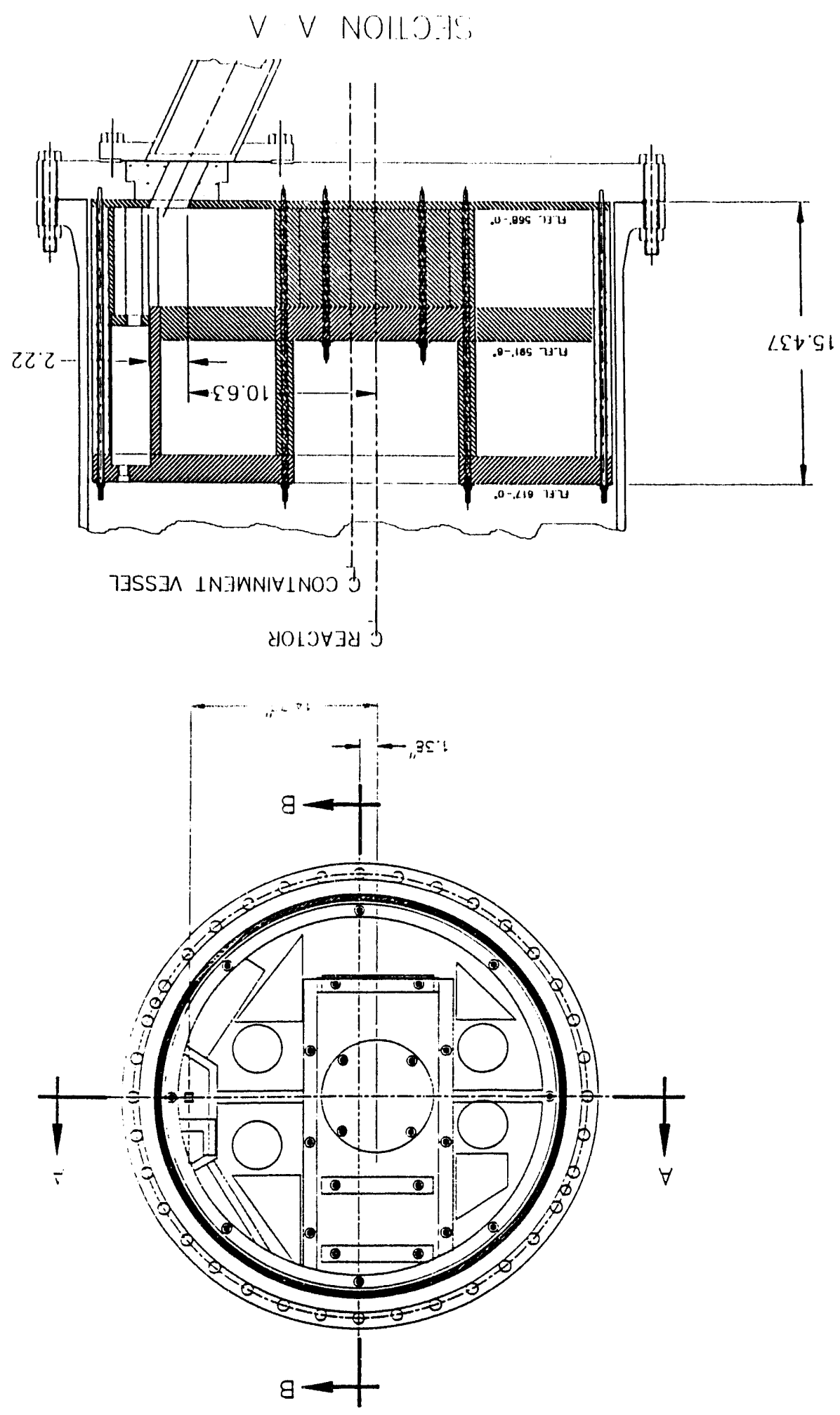
was designed to be a counterpart test to SNL/IET-I and SNL/IE'T-IR (discussed in the previous subsection). In particular, the difficulties with late application of stean and consequent elongation of RCS blowdown time were removed in test ANL/IE'I'- IRR.

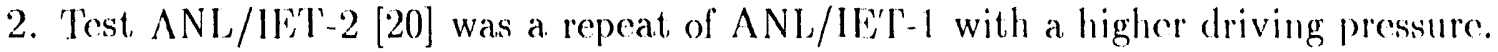

3. Test $\Lambda N L / I F L-3$ nominally repeated the same initial conditions of $A N L / I E T-I$, $A N L / I E I T-I R$ and $A N I / I E T-I R R$, with the exception of the containment almosphere, which contained an equal mixture of air and nitrogen [21].

4. Test $\Lambda$ NL/IE'I'-6 [22] nominally repeated the initial conditions of $\Lambda$ NL/IE'T-3, except the containment atmosphere contained pre-existing hydrogen and a smaller thermite charge was used.

5. 'Test ANL/IET-7 nominally repeated the same initial conditions of $A \mathrm{NL} / \mathrm{IL} / \mathrm{L}^{-}-3$, with the exception that the contaimment pressure was reduced by one-half $[23]$ and a smaller thermite charge was used (as in $\Lambda \mathrm{NI} /\left[\mathrm{E}^{\prime} \mathrm{l}^{\prime}-6\right.$ ).

6. 'T'est, $\Lambda$ NL/IE'T'-8 [24] nominally repeated the same initial conditions of $\Lambda$ NI,/IF'T'-3 with a different containment atmosphere gas composition, and a smaller thermite charge (as in $\Lambda \mathrm{NL} /[\mathrm{HE} / \mathrm{J}-(6)$.

Initial conditions for the $\Lambda$ NL/IET tests are given in Tables 2.2 .1 and 2.2 .2 ; 'Table 2.2 .1 gives initial conditions common to all the $\Lambda$ N , experiments, while Table 2.2 .2 gives intial conditions for those parameters whose values were varied in the $\Lambda \mathrm{NL}$, tests.

'The most significant variables measured in the $\Lambda \mathrm{NL} / \mathrm{W}$ I tests were the overall increase in pressure and temperature in the $\Lambda \mathrm{NL}$ vessel, the cavity local pressure, the amount of hydrogen generated by the reaction of metallic debris with steam driving gas and with water in the cavity, the debris temperatures as it exited the instrument tumnel and as it struck the crane wall, and the mass of debris recovered from the $\Lambda \mathrm{NI}$, vessel.

lable 2.2.3 gives a debris recovery summary for the $\Lambda$ NI/ISI' experiments. (The total molten mass available for dispersal into the vessel was 1 sually $20 \%$ greater than the intitial thermite charge due to melting of the inner wall of the crucible, vaporization of the fusible brass plug, ablation of concrete in the cavity and structures, and oxidation of metallie debris.) 'Table 2.2 .4 summarizes the comparative results of the le't' testes for overall vessed pressurization and for hydrogen generation and combustion. 
Table 2.2.1. Common Initial Conditions for the ANL/IET Experiments

$\begin{array}{lc}\text { ANL Vessel Volume }\left(\mathrm{m}^{3}\right) & \\ \text { Subcompartments } & 0.077 \\ \text { Upper Dome } & 1.43 \\ \text { Total } & 1.51\end{array}$

Table 2.2.2. Individual Experiment Initial Conditions for the ANL/IET Experiments

$\begin{array}{lccccccc}\text { Parameter } & \text { IET-1 } & \text { IET-1R } & \text { IET-1RR } & \text { IET-3 } & \text { IET-6 } & \text { IET-7 } & \text { IET-8 } \\ & & & & & & & \\ \text { Thermite Composition (gm) } & & & & & & & \\ \quad \mathrm{FeO} & 558.0 & 558.0 & 558.0 & 558.0 & 485.2 & 485.2 & 485.2 \\ \mathrm{Cr} & 88.6 & 88.6 & 88.6 & 88.6 & 77.0 & 77.0 & 77.0 \\ \mathrm{Al} & 173.4 & 173.4 & 173.4 & 173.4 & 150.8 & 150.8 & 150.8 \\ \text { Total } & 820.0 & 820.0 & 820.0 & 820.0 & 713.0 & 713.0 & 713.0 \\ & & & & & & & \\ \text { Hole Diameter (cm) } & & & & & & & \\ \quad \text { Initial } & 0.9 & 0.9 & 1.1 & 1.1 & 1.1 & 1.1 & 1.1 \\ \text { Final } & 0.9 & 0.9 & 1.3 & 1.1 & 1.1 & 1.1 & 1.1 \\ & & & & & & & \\ \text { Steam Accumulator } & & & & & & & \\ \text { Pressure (MPa) } & 6.0 & 6.2 & 6.7 & 5.7 & 6.6 & 6.1 & 6.5 \\ \text { Temperature (K) } & 600 & 600 & 600 & 600 & 600 & 600 & 600 \\ \text { Mass (gm-moles) } & 7.44 & 8.55 & 9.84 & 8.43 & 9.65 & 8.88 & 9.36 \\ & & & & & & & \\ \text { Water Mass (gm) } & & & & & & & \\ \text { Cavity } & 55.0 & 55.0 & 55.0 & 55.0 & 55.0 & 55.0 & 55.0 \\ & & & & & & & \\ \text { Vessel Atmosphere } & & & & & & & \\ \text { Pressure (MPa) } & 0.20 & 0.20 & 0.20 & 0.20 & 0.20 & 0.10 & 0.20 \\ \text { Temperature (K) } & 318 & 318 & 318 & 318 & 318 & 318 & 477 \\ \text { Composition (mole \%) } & & & & & & & \\ \quad \mathrm{N}_{2} & 99.4 & 99.9 & 99.9 & 88.8 & 87.5 & 87.5 & 37.9 \\ \quad \mathrm{O}_{2} & 0.5 & 0.0026 & 0.12 & 10.8 & 9.9 & 9.9 & 7.7 \\ \quad \mathrm{H}_{2} & <0.01 & <0.01 & <0.01 & <0.01 & 2.0 & 4.0 & 3.9 \\ \quad \mathrm{CO}{ }_{2} & 0.0048 & 0.004 & 0.011 & 0.011 & 0.013 & 0.013 & - \\ \quad \mathrm{H}_{2} \mathrm{O} & - & - & - & - & - & - & 50.0 \\ \quad \text { other } & <0.01 & <0.006 & <0.005 & <0.02 & <0.01 & 0.47 & 0.5\end{array}$


Table 2.2.3. Debris Masses Recovered for the ANL/IET Experiments

$\begin{array}{lccccccc} & \text { IET-1 } & \text { IE'T-1R } & \text { IET-1RR } & \text { IET-3 } & \text { IET-6 } & \text { IET-7 } & \text { IET-8 } \\ & & & & & & & \\ \text { Initial Thermite }(\mathrm{gm}) & 820.0 & 820.0 & 820.0 & 820.0 & 713.0 & 713.0 & 713.0 \\ & & & & & & & \\ \text { Recovered Mass }(\mathrm{gm}) & & & & & & & \\ \quad \text { MGI } & 87.4 & 4.0 & 43.3 & 67.3 & 30.3 & 4.0 & 11.8 \\ \quad \text { Cavity/Chute } & 541.6 & 197.1 & 260.8 & 232.2 & 262.7 & 153.7 & 179.3 \\ \quad \text { Seal Table Room } & - & - & 148.9 & 163.1 & 167.9 & 113.6 & 158.7 \\ \quad \text { Remaining Subcompartments } & 339.0 & 551.1 & 358.2 & 428.2 & 339.6 & 448.9 & 405.3 \\ \text { Total in Subcompartments } & 339.0 & 551.1 & 507.1 & 591.3 & 507.5 & 562.5 & 564.0 \\ \quad \text { Outside Structures } & 66.7 & 87.7 & 114.6 & 37.8 & 81.3 & 26.2 & 22.6 \dagger \\ \text { Total } & 1034.7 & 839.9 & 925.8 & 928.6 & 881.8 & 746.48 & 804.5\end{array}$

†A unknown amount of debris was lost during the vacuuming procedure.

Table 2.2.4. Results Summary for the ANL/IET Experiments IET'-1 IE'T-1R IET'-1RR IET-3 IE'T-6 IE'T-7 IET-8

$\begin{array}{llllllll}\text { HPME } \triangle P_{M A X}(\mathrm{kPa}) & & & & & & \\ \text { Cavity } & 420 & 920 & 550 & 200 & 480 & 430 & 290 \\ \text { Dome } & 105 & 170 & 150 & 190 & 250 & 166 & 133\end{array}$

$\begin{array}{lccccccc}\mathrm{H}_{2} \text { (gm-moles) } & & & & & & & \\ \text { Pretest } & \sim 0 & \sim 0 & \sim 0 & \sim 0 & 2.28 & \sim 0 & 3.1 \\ \text { Produced } & 1.51 & 4.00 & 4.00 & 4.65 & 4.89 & 5.1 & 5.6 \\ \text { Burned } & \sim 0 & \sim 0 & \sim 0 & 3.50 & 4.22 & 3.66 & 1.0\end{array}$




\section{MELCOR Computer Model}

('This section presupposes some familiarity with the MELCOR FI)/HPME/I)CH model, its terminology and modelling assumptions, and its input requirements. $\Lambda$ brief description of the model, excerpted from [26], is included in Appendix $A$ for the convenience of interested readers.)

Note that most individual parameters in our MELCOR input models were not separately adjusted in each of our MEI, (OR SNL/IE:T and ANL/IET experiment analyses to best match data for each individual experiment. Instead, the basic control-volume/flowpath/heat-structure model was kept the same for all SNL/ILI experiments analyzed, and a single set of debris source, distribution and interaction time paranceters was used for all the SNI/IFT experiments analyzed. Similarly, the basic (VII/FL/HS input model and the debris source, distribution and interaction time parameters was used for all the ANI/IET calculations were the same. The only test-specific changes made were to set. the initial pressures, temperatures, gas composition, and liquid pool lieights to match individual experiment initial conditions.

\subsection{1:10-Scale Surtsey Test Facility MELCOR Model}

The MELCOR input model used for the SNL IET experiment calculations is shown in Figure 3.1.1. Five control volumes, five flow paths, and twelve heat structures were used in the reference MELCOR model. (A copy of the input used for the Surtsey IE:T'-1 reference calculation is given in the appendix, for documentation.)

Two control volumes represent the (horizontal) cavity and (inclined) chute, respecetively. The Surtsey vessel was subdivided into two control volumes, one for the subcompartments and another for the upper dome. The final cont rol volume modelled the steam source. Five flow paths were provided for straight flow throngh the system, and for recirculation from the upper dome to the subcompartment volume. Volumes and heights were generally taken from the test data reports [10-17], while some of the flow path parameters were taken from the CON'TAN input decks [27], berause there was not. enough information in the published test reports to fully define the required input (such as flow area, opening heights, elevations, loss coeflicients).

The control-volume nodalization was set to approximate the level of detail provided in the post-test debris recovery distribution data provided in the test data reports [10-17]; we judged that a finer subdivision in the subcompartments was not warranted because the MELCOR DCH model requires the final debris distribution to be input on a per-volume basis, and there were no data available on a fince scale for either input or comparison. The "recirculation" flow path was provided to allow for the fact that in the artual facility a number of openings exist between the various subcompartments and the vessed dome. with the potential of inflow in some openings and ontlow in others. The area of that recirculation flow path was set to $10 \%$ of the area of the stadight-1hrough flow path from 


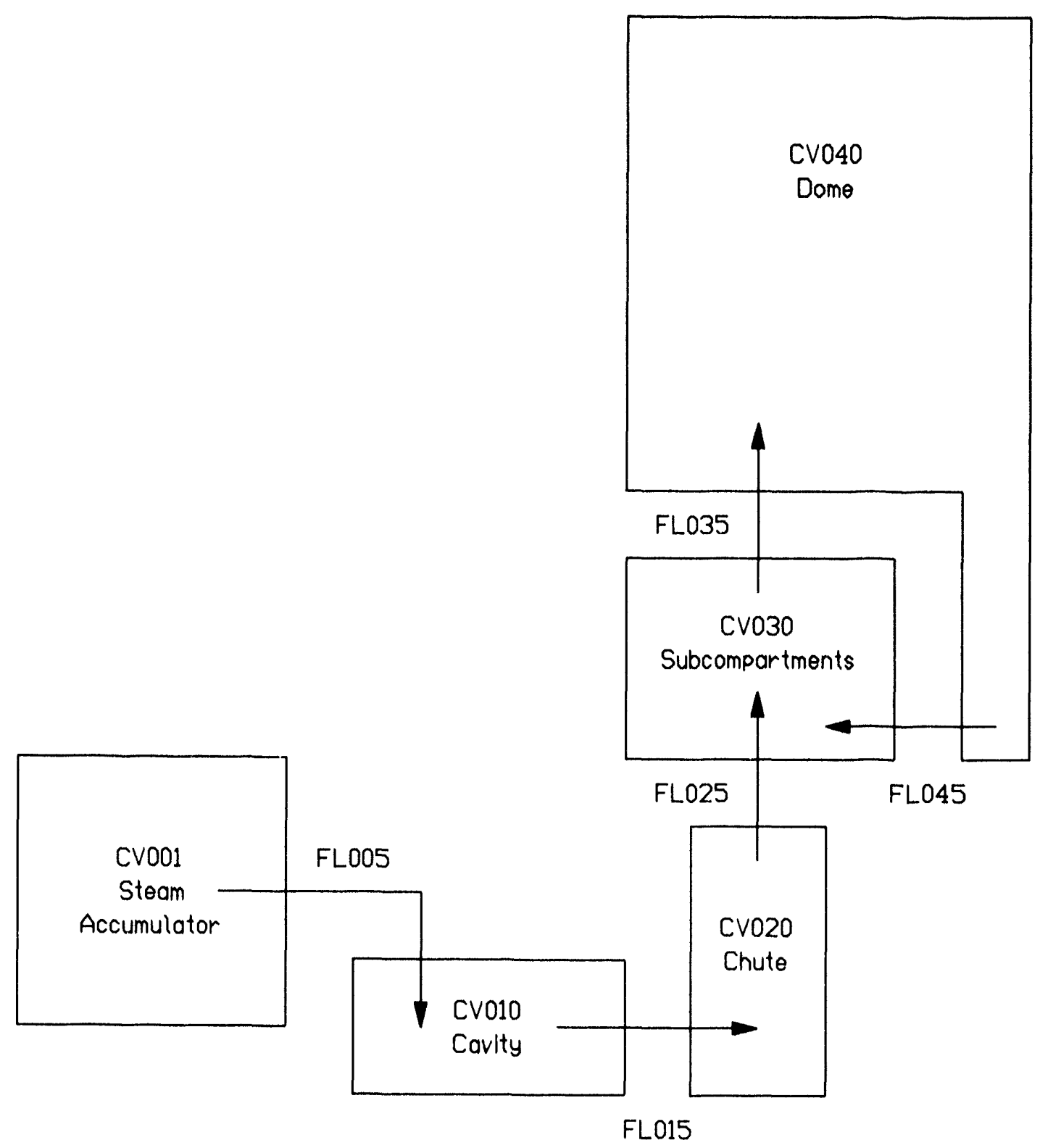

Figure 3.1.1. Reference MELCOR Model for SNL/IET Experiment Analyses 
the subcompartments to the dome. (Sensitivity studies were done with that recirculation flow path area increased and decreased, with results summarized in Section 7.3.)

A valve with a time-dependent area was used in the flow path from the steam accumulator to the cavity to control the rate of steam injection, with the opening rate adjusted to provide a valve opening at a constant rate between 0 and $1 \mathrm{~s}$. Although different final hole diameters were identified in the test reports for the opening from the melt generator to the cavity, the input was kept the same for all the SNL/IEI experiments analyzed for the valve and associated time-dependent area used in the flow path from the steam accumulator to the cavity to control the rate of steam injection. In the experiments the thermite reaction products and the steam were injected through the same opening, with some indication in the data of occasional plugging and flow interruption. In the MELCOR model the debris is inserted separately, directly to its ultimate destination; thus MELCOR does not model any debris blockage or obstruction possibly affecting the steam injection rate. We simply adjusted the opening rate to match the observed steam accumulator depressurization rates in the various tests reasonably well (as discussed in more detail in Section 5.1).

The post-reaction thermite debris was added directly through tabular function input using the FII HPME "stand-alone" mode, rather than input via COR package or TP (Transfer Process) package input. The FI)I input for debris amount, temperature and distribution were kept the same in our MELCOR input for all tests analyzed, although there were differences identified in the test reports in debris distribution. The difficulty here was that, while the original amount of thermite mass was very carefully kept constant. in all experiments, both the amount retained in the molt generator and the excess debris collected post-test (from melting of the inner wall of the crucible, vaporization of the fusible brass plug, ablation of concrete in the cavity and structures, and oxidation of metallic debris) introduce significant uncertainty into the debris source. Wo chose to use reasonable, representative values for the debris mass and distribution for the Surtsey IET experinents, and address the variation in both total mass and distribution through sensitivity studies.

The input parameters for the debris source used in the MELC'OR input are given in Table 3.1.1. The debris amount was kept constant at $43 \mathrm{~kg}$ for all the SNI.IE' experiments analyzed, neglecting both the small excess in and the small variations in total amount of debris collected (summarized in Table 2.1.3). The debris temperature was set to $2300 \mathrm{~K}$ temperature. The final collected dobris distributions given in the test data reports (and in 'lable 2.1.3) was used to estimate a single, average distribution of debris into the various control volumes. The MEL(COR FI)I/HPME model input allows the user to specify debris distribution both into control volume atmospheres and directly onto heat structures (as well as directly into a CORC'ON cavity, not included in these calculations). All of the debris in our IE'T assessment analyses was placed initially into control volume atmospheres and then allowed to settle out; no debris was specified to be deposited immediately directly onto heat structures. A tabular function was used to specify the melt injection as a function of time and was adjusted to try to match the rate of pressure and temperature incerese in the vessel. (Sensitivity studies varying the 
debris total amonnt, temperature, distribution and injection timing within a reasonable range of data uncertainty are presented in Sections 5.3, 5.4, 5.5, and 5.2.)

A single set of characteristic interaction times was specified for all the seven of the 1:10-scale tests analyzed (SNI/LET'- t through SNL/LET'-7). 'The values used in our rof-

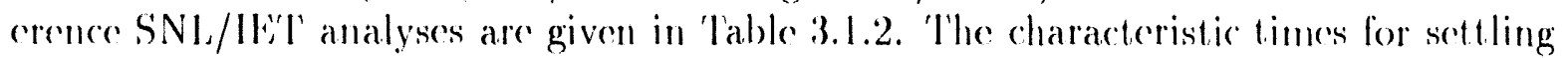
$\left(\tau_{s r t}\right)$ of debris in the control volume atmospheres onto floor heat structures were based upon free-fall times for the varions volume heights, and are therefore proportional to volume heights and ronstant in the varions tests; there could be some terst-to-test variations in turbulent. flow circulation patterns, thermal buoyancy effects, cle, but these were assumed negligible. The characteristic oxidation and heat transfer times were assumed to depend primarily on parameters such as average airborne or deposited particle concentrations, which in a given geometry should be approximately constant for identical melt debris and blowdown steam sourees such as used in the lests analyzed. (Section 6 stmmmarizes sensitivity studies done varying these characteristic interaction lime input. parameters individually over wide ranges of values.)

The characteristic times for oxidation and heat transfer $\left(\tau_{o, x}\right.$ and $\tau_{h e}$, respectively $)$ of debris in the control volume atmospheres, as well as a characteristic time for oxidation of debris deposited on heat structures $\left(\tau_{h s-a r}\right)$, in 'lable 3.1 .2 were selected alter mumerous iterations as giving reasonable agreement with a subset of test data (in particular, vessel pressure, subcompartment temperature and hydrogen production and combustion) in the

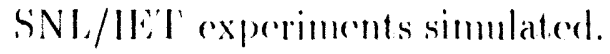

Note that there is no reason to assume that the debris source and interaction input paranoter set given in Tables 3.1 .1 and 3.1 .2 is unique (i.e. the only set to provide reasonable agreement with the selected test data); it is also not guarantered that the iteration procedure followed results in an input paranceter sed that would yield the best agreement with data, or agreement with data for the "correct" reasons (i.t., representing the actual hehavior). For example, freeging some of the parameter values carly in this iterative process undoubtedly affected the values assumed for other patanders. Further, experiment ambignities may have led to incorrect morlelling assumptions which would also affect the values chosen for varions parameters. In particular, the choice of a very short time constant for airborne debris oxidation (0.0)ess in the reference analyses) was driven by trying to match the reported hydrogen production and combustion data; sensitivity study results in Section 6.1 show very little difference in calculated pressures or temperatures for $0.01 \mathrm{~s} \leq \tau_{o x} \leq 0.1 \mathrm{~s}$, and the hydrogen production and combustion later derived from a molar balance assuming only steam/metal reactions (as in the test data analysis) is in better agrement with test data for the longer characteristic oxidation times tried $\left(\tau_{o, r} \sim 0.1 \mathrm{~s}\right)$.

In the majority of our IET analysis calculations, the burn package was activated, but burn was suppressed in all control volumes except the vessel dome. 'The minimum ( (') $)_{2}$ $\left.+\mathrm{I}_{2} \mathrm{O}\right)$ mole fraction limit for inerting volumes was left unchanged from the default value of 0.55 (which was sufficient to prevent hydrogen combustion in $\$ \mathrm{NL}$ / / IF'P'-5, as observed in that experiment). The minimum hydrogen mole fraction in the ignition criterion in the absence of igniters was set to 0.0 , and the combustion completeness was also set to 
Table 3.1.1. MEL(COR FI)/HPME Debris Input Parameters Used for the SNIJ/IEl Exporiments

Debris (omposition (kg)
$\mathrm{Al}_{2} \mathrm{O}_{3}$
16.056
Fes
21.699
$\mathrm{Cr}$
4.649
Al
0.596
'Total
43.00

Debris Temperature (K) 2300

Debris Distribution (\%)

('avity

C'hute

10

Subcompartment

6.5

Dome

10

Debris Injoction 'Timing

(Cumulative Fraction)

$\begin{array}{lc}\text { by } \mathrm{t}=0 \mathrm{~s} & 0 \\ \text { by } \mathrm{t}=0.1 \mathrm{~s} & 0.05 \\ \text { by } \mathrm{t}=0.2 \mathrm{~s} & 0.1 \\ \text { by } \mathrm{t}=0.3 \mathrm{~s} & 0.15 \\ \text { by } \mathrm{t}=0.1 \mathrm{~s} & 0.2 \\ \text { by } \mathrm{t}=0.5 \mathrm{~s} & 0.3 \\ \text { by } \mathrm{t}=0.6 \mathrm{~s} & 0.5 \\ \text { by } \mathrm{t}=0.7 \mathrm{~s} & 0.8 \\ \text { by } \mathrm{t}=0.8 \mathrm{~s} & 0.9 \\ \text { by } \mathrm{t}=0.9 \mathrm{~s} & 0.95 \\ \text { by } \mathrm{t}=1.0 \mathrm{~s} & 1.0\end{array}$


Table 3.1.2. Characteristic Interaction T'imes Used in Reference MELCOR Model for SNL IET Experiment Analyses

$\begin{array}{lc}\text { Interaction Time } & \text { Value }(\mathrm{s}) \\ \begin{array}{l}\text { Airborne Debris: } \\ \text { Oxidation }\end{array} & 0.025 \\ \text { Heat Transfer } & 0.40 \\ \text { Settling } & \\ \quad \text { Cavity } & 0.15 \\ \quad \text { Chute } & 0.35 \\ \quad \text { Subcompartment } & 0.25 \\ \quad \text { Dome } & 0.60 \\ & \\ \text { Deposited Debris: } & \\ \text { Oxidation } & 600.0\end{array}$

0.0. This combination of input prevented the burning of any pre-existing hydrogen, but allowed burning of any additional hydrogen generated during the HPME. This is because a combustion completeness equal to 0.0 does not mean no combustion; instead, specifying a combustion completeness of 0 causes the code logic to try to maintain the mole fractions after the burn equal to the mole fractions before, so that new hydrogen introduced during a time step, either by oxidation or by arlvection, will be burned but pre-existing hydrogen will remain present and generally unreacted. This particular combination of input was found to produce reasonable agreement with test data in all cases. ('The results of sensitivity studies using other possible input settings are described in Section 7.1.)

Note that the combustion completeness did not have to be reset to 0 in the input, because in these problems the Le(thatelier formula $\gamma$ is simply the hydrogen mole fraction $x_{H_{2}}$ (because $x_{C}(0)=0.0$ ) and, with the hydrogen mole fraction ignition limit reset to 0.0 , the Lechatedier formula at the beginning of the burn $\left(Y_{M A X}\right)$ is also 0.0 , and the default correlation used in MEL( $(O)$ gives combustion completeness $C(C=0.0$ for $Y_{M A X} \leq 0.03746$. Therefore, with a hydrogen mole fraction ignition limit of 0.0 , the combustion completeness correlation used in MELC(OR automatically gives a combustion completeness value of 0 .

The heat structure input was generally taken from (ONTAIN input [27], because there was not enough information in the published test reports to fully define the reguired input (such as heat structure surface areas, thicknesses, elevations, etce). The cavity, chute, subempartments and dome control volumes were cach defined to have corresponding floor, wall and roof heat structures, for a total of twelve heat structures. These structures were specified to use "external" heat transfer coefficient correlations on 
the inside surface, with the volume length/height input as the characteristic length, while on their outside surface the heat structures were specified to be adiabatic. The nodes were very closely spaced on the inner surface and moved progressively farther apart in the depths of the structures, to better resolve the steep temperature gradients expected near the surface. Radiation heat transfer using the gray gas model was enabled with an emissivity of 0.8 . All heat structures used MELCOR's steady-state temperature-gradient self-initialization option.

Most of our calculations were run with control volume flow areas reduced by factors of $\geq 10$ from their default values, to enhance convective heat transfer from the control volume atmospheres to the heat structure surfaces. (The control volume flow areas are used only to obtain volume velocities for use in the calculation of convective heat transfer coefficients; changing control volume flow areas does not affect flow path calculations at all.) The convective heat transfer was enhanced for two reasons:

First, our preliminary calculations showed that the flow through the system in these calculations was primarily that associated with the steam blowdown only, flowing from the steam accumulator through the cavity and chute volumes to the subcompartments and then to the dome. The MELCOR FIDIHPME/DCH model does not model transport of dobris between and through volumes but instead deposits the debris directly at its ultimate destination, using the same time-dependent deposition in all volumes regardless of their distance from the debris source. Thus, instead of debris being transported into an "upstream" volume (e.g., the cavity or the subcompartments) with the blowdown steam and the resultant additional heating adding to the driving force pushing flow further "downstream" (c.g., from the cavity to the chute or the subcompartments to the dome), the MELCOR logic does not represent, this additional flow driving force and in contrast has debris appearing "upstream" and heating the atmosphere in upstream volumes, if anything contributing a retarding force to the expected flow. This results in lower velocities, and is more benign than the transient HPME blowdown actually occurring in the experiments, with transport of hot debris together with the steam blowdown.

Decreasing volume flow areas results in increased volume velocities more characteristic of the turbulent conditions that might be expected during HPME, and the associated turbulent forced convection heat transfer to structures. For the subcompartment control volume, in particular, it also reflects the fact that there is not a single, large, open subcompartment volume in the Surtsey facility but instead a collection of subcompartments, each with smaller volume and internal flow area and with smaller-area openings connecting the subcompartments to each other and to the dome. Thus, a (default) volume flow area of $\geq 4.5 \mathrm{~m}^{2}$ obtained using the subcompartment volume of $4.65 \mathrm{~m}^{3}$ and a height of $\geq 1 \mathrm{~m}$ may not be indicative of the actual velocities in the subcompartments.

In addition, the MELCOR FDI/IIPME/DCH model does not account for any radiation directly from airborne debris to surrounding structures (or from deposited debris directly to atmosphere). There is little or no calculated atmosphere-structure radiation heat transfer early in these transients (except in IET-5), because MELCOR only considers radiation heat transfer for steam and/or $\mathrm{CO}_{2}$ in atmospheres. In IET-5, some atmosphere-structure radiation heat transfer is calculated because of the large amount 
of $\mathrm{C}^{\prime} \mathrm{O}_{2}$ used to inert the system; however, in most of the experiment simulations there is very little steam present early in the transient, because any blowdown steam is consumed in debris oxidation soon after arrival, and very little $\mathrm{CO}_{2}$ present at all. The lack of steam and/or $\mathrm{CO}_{2}$ in the atmosphere would if anything enhance radiation heat transfer from airborne debris to structures because there would be little absorption in the intervening atmosphere. Hand calculations indicate that this could be a significant lieat transfer mechanism, early in the transient. Because there is no way in MELCOR to model this cffect, too much energy may be deposited in the atmosphere by the airborne debris; because there is no convenient way to enhance atmosphere-structure radiation heat transfer in general, we relied on increasing convective heat transfer instead to help remove that energy.

For these reasons, most of cur calculations were run with control volume flow areas reduced by factors of $\geq 10$ from their default values, to cbtain volume velocities more characteristic of the turbulent conditions that might be expected during HPME, and the associated turbulent forced convection heat transfer to structures, and to partially account for the lack of any radiation from airborne debris to structures. The results of a sensitivity study showing the effect of increasing volume velocities and hence convective heat transfer coefficients and overall heat transfer to structures are given in Section 7.2.

Our reference MEI, COR IET experiment analyses were run with the coefficient for heat transfer from deposited debris to structure surface reduced to $1 \mathrm{w} / \mathrm{m}^{2}-\mathrm{K}$. This was originally done to avoid temperature iteration convergence problems, and was not, changed when the temperature solution algorithm was improved and made more robust (as discusserl in Section 11). To see what effect this had on our analyses, a set of calculations were run with that heat transfer coefficient progressively increased to $10 \mathrm{w} / \mathrm{m}^{2}-\mathrm{K}$, $100 \mathrm{w} / \mathrm{m}^{2}-K$, and $1000 \mathrm{w} / \mathrm{m}^{2}-K$ (the default value), with results described in Section 6.5 .

The user-specified maximum time step in the reference calculations was 1 s. The code then ran at an internally-determined time step during the high-pressure melt cjection, as discussed in Section 4, and at the user-specified maximum time step later in the transient period analyod. Results of a time-step study on the SNL/IET reference calculations are given in Section 9.2. The majority of these IET I)(H MELCOR calculations were run on a SUN Sparce workstation; results of a machine-dependency study for the SNL/IET reference calculations are given in Section 9.1 .

\subsection{1:40-Scale COREXIT Test Facility MELCOR Model}

The MELCOR input deck for the ANL 1:40-scale test analyses was very similar to that for the Surtsey 1:10-scale facility and tests, shown in Figure 3.1.1. (ontrol volume volumes and heights, and the blowdown orifice flow area, were taken from the test data reports [18-21] whenever possible. Otherwise, the input values used for the SNL/IET analyses were simply adjusted as appropriate by the difference in scale factor between the two facilities (i.e., 1/4 for heights or ! ngths, 1/16 for flow areas or surface areas). The opening time for the steam blowdown valve and for molt injection was scaled by 
$1 / 4$ from the $\mathrm{SNI} / \mathrm{IE} T$ input used, based upon examination of the experimental results. The debris amount and distribution were taken from the test data reports, as were the initial steam and atmosphere conditions. Again, as in our Surtsey IET analyses, most, individual parameters in our MELCOR input model were not separately adjusted in each of our MEI,COR ANI./IET experiment analyses to best match data for cach experiment considered. $\Lambda$ s in our Surtsey IET analyses, the initial pressures, temperatures, gas composition, and liquid pool heights were set, to match individual experiment initial conditions (summarized in Table 2.2.2); however, for the ANL/IET analyses it was also necessary to adjust the total debris mass, which changed from one value in the earlier testis $(820 \mathrm{gm})$ to a smaller value $(713 \mathrm{gm})$ in the later tests.

Our MELCOR assessment analyses for these 1:40-scale ANI/ILT experiments were done in several steps, concentrating on the scaling of the phenomena. First, the $\Lambda \mathrm{NI}$, facility geometry and test conditions were modelled (and/or scaled) as just discussed, with no change in the characteristic interaction times input to the MELC (OR FI)I IIPME model, with results given in Section 8.2. However, there is no reason to expert to match the $\Lambda$ NL/IEl data only scaling the facility geometry and test conditions it secms intuitively obvious that the characteristic interaction time for airborne debris seteling should be sealed as the height of the volume; it is not intuitively obvious whether the characteristic interaction times for oxidation of airborne or deposited debris, or for heat. transfer from airborne debris to atmosphere, should be scaled or not. Therefore, we scaled the various characteristic interaction times also, individually and in combination, in more sets of calculations, with results given in Section 8.3. Finally, the ollare non-standard MELCOR input used for the 1:10-scale SNI / IET experiment analyses (i.e. hydrogen combustion parameters, volume flow areas and velocities used to determine leat transfer correlations, and recirculation from the dome to the subcompartments) were varied and the impact on calculated results covaluated in Sections 8.4 throngh 8.6 . 


\section{Reference Calculation Results}

This section presents MELCOR assessment analysis results for the 1:10 linear scale SNL/IET experiments performed in the Surtsey vessel at Sandia. Results for analyses of the 1:40 linear scale ANL/IET experiments done at Argonne are presented in Section 8, as a scaling sensitivity study.

Figure 4.1 shows the masses of $\mathrm{Al}$ and of Fe and (ir that were oxidized during the transient, together with the masses of oxygen and steam that reacted with the debris. The default assumption in the MEL(COR FI)I/HPME/D) (H model is sequential oxidation. Thus, $\mathrm{Zr}$ (not, present in this case) would be oxidized first, followed by $\Lambda \mathrm{l}$ and then by steel; because the fe and Cr injected are treated as components of injected "stecl" with a user-specified composition, they are assumed to oxidize at the same rale. Similarly, the MEI,COR FDI/HPME/DCH model assumes steam oxidation in a volume only if there is insufficient oxygen available to support the prescribed oxidation rate; oxygen is therefore consumed first whenever available. This hierarchical oxidation model is reflected in the results which show almost all of the $\Delta l$ injected was calculated to be oxidized but only about $45-70 \%$ of the injected Fe and ('r was oxidized. N/most all of the debris oxidation occurs in $\leq 1 \mathrm{~s}$, while the debris is being injected into the system, although there is a small additional amount of oxidation later, between $\sim$ s and $\sim 1$.5s, in the SNL/IE'T-I and SNL/IV:T-IR calculations. 'The plots in the figure show that, in the the SNI/IET'1 and SNL/IE'T-IR calculations, all the available oxygen was depleted within $\leq 0.5 s$, leaving some debris unoxidized until the arrival of sufficient blowdown steam. (Recall that the MEL(OOR FDI/IIPME/I)('II model assumes debris immediatedy transported to its final destination, while the accummlator steam blowdown was modelled as a transicnt process.)

Masses involved in the calculated Fl)I/IIPML/D)(II reactions are summarized in Table 4.1. (The molar balances are not exact because of the limited number of significant digits used and because of using round mumber for molecular weights, for convenience.) These numbers reflect the MELCOR calculation only; there is no experimental data available on how much of the debris collected post-test was oxidized and, as discussed in Section 2.1, the experimenters assumed in their data analysis that debris reacted only with steam, not with free oxygen. (Recall that this is the oppesite of the MELCOR assumption that oxidation of metals with frec oxygen occurs preferentially to oxidation with steam.)

Total amounts of hydrogen generated and buned in these SNI, IFT tests are given in Figures 4.2 and 4.3, respectively. (Note the different time scales on these two ligures.) Almost all of the hydrogen gencrated during debris/steam reactions is gencrated in $\mathrm{t} \leq \mathrm{ls}$, when the debris is being injected into the system; there is a small additional amount of hydrogen generated later (between $\sim 1 \mathrm{~s}$ and $\sim 1.5 \mathrm{~s}$ ) in the SNL/IET-1 and SNL/IET'-1R calculations. No significant amounts of additional hydrogen are generated at later times in these reference calculations. In contrast, about $0.3 \mathrm{~kg}(150 \mathrm{gm}-\mathrm{moles})$ of hydrogen are burned within the first second or two, and anothor $0.03-0.06 \mathrm{~kg}$ (15-30gmmoles) are burned between $\sim 1.5 \mathrm{~s}$ and $\sim 3.5 \mathrm{~s}$. MEI, (OR calculates $11 \mathrm{PME} / \mathrm{D}$ ('I1 to last 

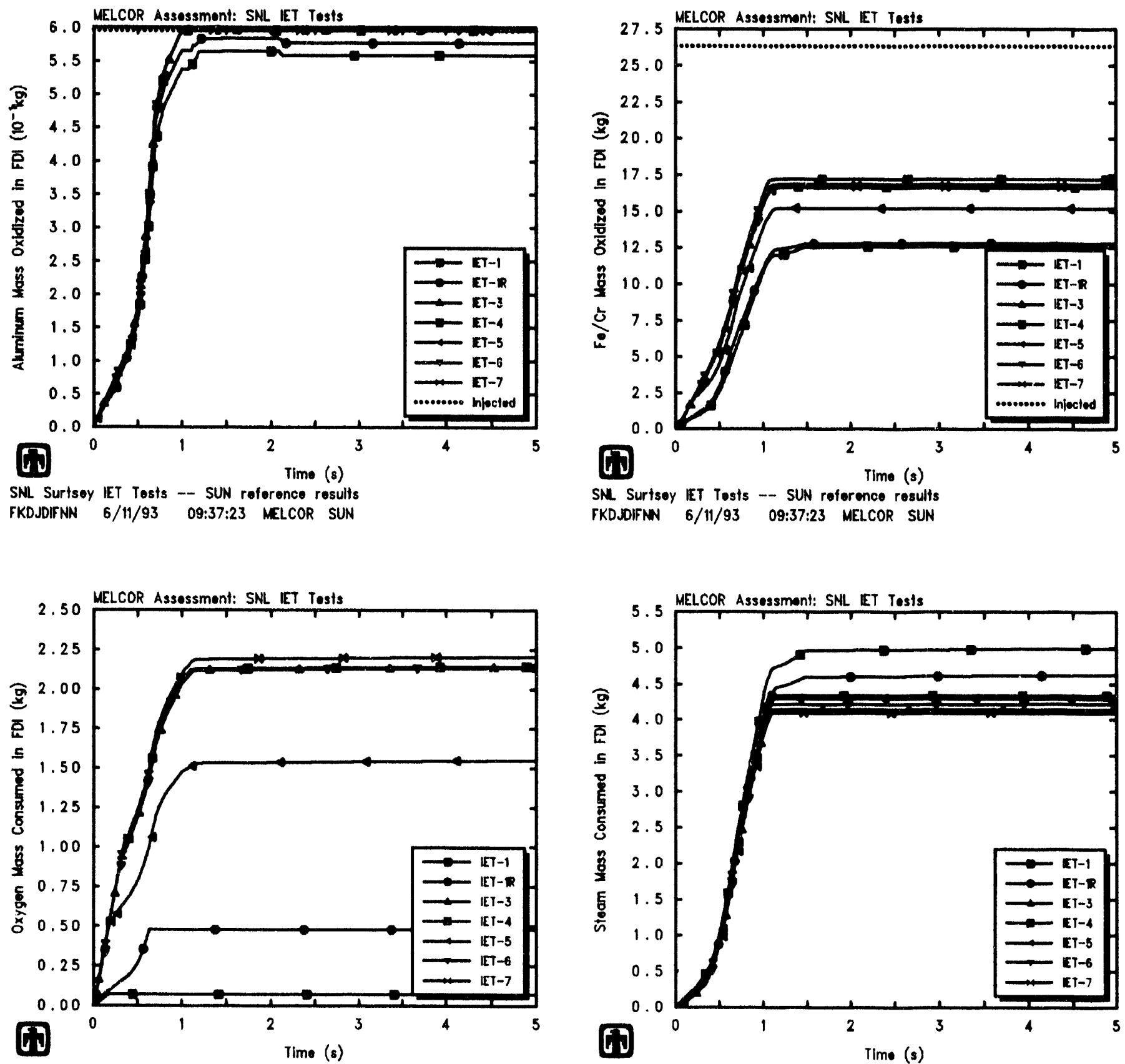

SNL Surtsoy IET Tesis -- SUN roference results FKDJDIFNN 6/11/93 09:37:23 MELCOR SUN

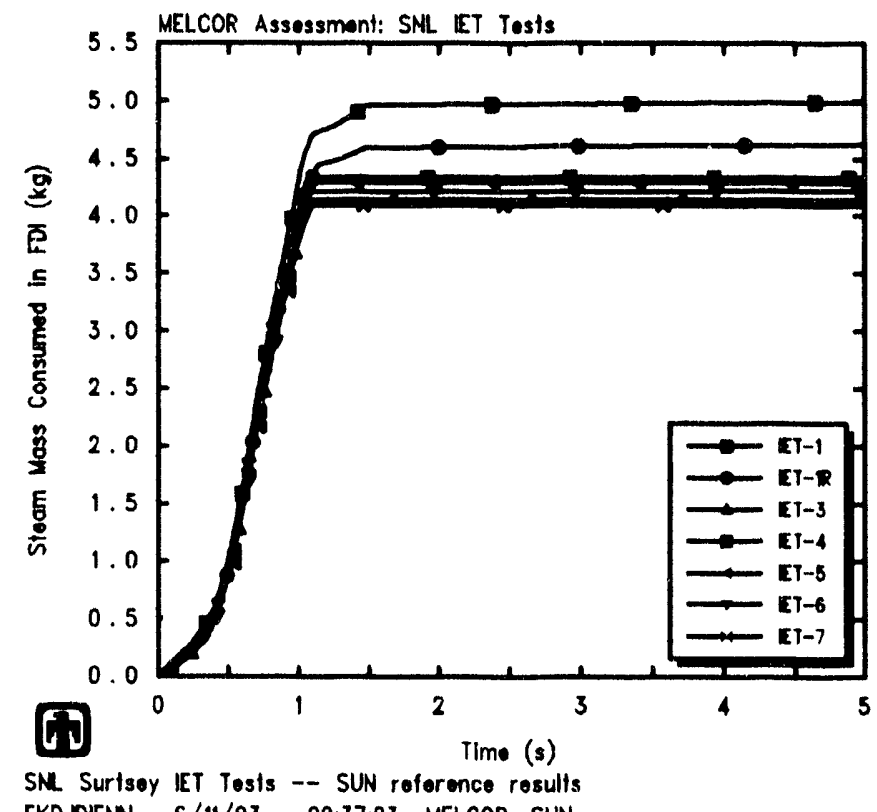

SN Surtsey IET Tosts -- SUN roforence results FKDJDIFNN 6/11/93 09:37:23 MELCOR SUN

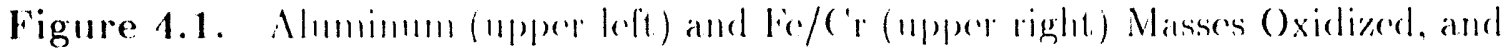
Oxygen (lower lefi) and Steam (lower right) Masses Raacted for SNI./ERT lixperiments Reference ('alculation 
$\leq 4 s$, based upon default criteria in the code for airborne debris temperature, mass and density. However, another $\sim 0.04 \mathrm{~kg}(20 \mathrm{gm}-$ moles) are calculated to be burned later in the SNI./HEI-3 and SNL/IET-6 analyses and another $\leq 0.1 \mathrm{~kg}$ (50)gm-moles) are (alculated to be burned later in the SNL/IET-4 and SNL/IFI'T analyses, as some hydrogen is advected from the subcompartments to the vessed dome where it is assumed to burn. There is thus significant late-time hydrogen burn in our MELCOR calculations for those test simulations where the vessel atmosphere was not inert. (Sections 7.3 and 9.2 will show that both the carly-time and the late-time hydrogen burn is quite sensitive to the recieculation flow between the subcompartments and the vessel dome, while the late-time hydrogen burn is quite sensitive to the time step used.)

The overall hydrogen behavior calculated in these If:l' experiment analyses is summarized in Table 4.2. The values given include the amount of hydrogen pre-existing in the vessel, the amount produced by IIPME steam/metal reactions, the amount burned and the final amount.

It is difficult to quantitatively compare the measured and calculated hydrogen production and combustion because of the basic assumption made by the experimenters that all oxygen depletion was due to reaction with hydrogen. Thus, as discussed in Section 2.1, the experimenters assumed in their data analysis that debris reacted only with steam, not with frec oxygen, which is the opposite of the MELCOR assumption that oxidation of metals with free oxygen occurs preferentially to oxidation with steam. Figure 4.1 and Table 4.1 show that MELC? (OR did predict significant interaction of free oxygen with

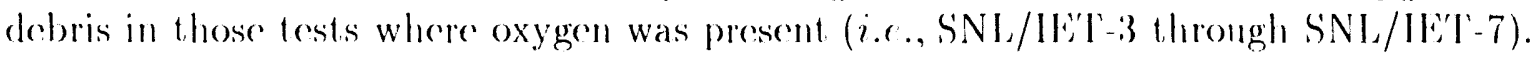

Table 4.3 summarizes the overall hydrogen behavior measured and calculated in these IFT experiments and analyses. For the test data, the total amomnt of hydrogen generated by steam/motal reactions was obtained by subtracting the measured amount of pretest. hydrogen from the sum of the measured amount of post test hydrogen phus the estimated amount of hydrogen bumed; the hydrogen combustion given was based on the assmumption 1.hat all oxygen depletion was due to reaction with hydrogen, as described in Section 2.1 . The MELC OOR values given include both the actual amomuts of hydrogen produced by MPME steam/metal reactions and burned, and the amounts of hydrogen produced and burned that would be calculated using the initial and final oxygen and hydrogen moles from the MEL(COR analyses, using the same formulae as in the experiment data analysis. (IIowever, note that the experimental results come from analyzing gas grab botite samples taken from the Surtsey vessel at 30min, while the MEld OOR results are taken from output. at, 20 s.)

The two sets of MELCOR values differ by twiec the mumber of moles of $\mathrm{O}_{2}$ consumed by direct metal/oxygen reactions. 'There is little difference found in the hydrogen production evaluated using the experimental procedure and actually calculated by MELC(OR in the tests with little or no free oxygen present (i.e., SNI./LI'- and SNI.IE'T-IRR); however, note that, for these two tests and for SNL/IE'T'-5, assuming all oxygen depletion was due to combustion reaction with hydrogen does result in a small mass of hydrogen calculated to be burned, quite similar to the experimental results given. 'The actual moles of hydrogen produced and burned in these MEL(COR analyses appear gener- 
Table 4.1. Calculated HPME/DCH Mass Results Summary for the SNL/IET Experiments - Reference Calculation

\begin{tabular}{lccccc} 
& \multicolumn{5}{c}{ MELCOR (gm-moles) } \\
& Oxidized & \multicolumn{2}{c}{ Reacted } & Produced \\
& & & & & \\
& & & & \\
& & & & \\
IET-1 & 20.9 & 227.7 & 2.2 & 284.2 & 286.2 \\
IET-1R & 21.6 & 231.3 & 15.0 & 263.8 & 265.7 \\
IET-3 & 22.1 & 301.1 & 69.2 & 230.2 & 231.8 \\
IET-4 & 22.1 & 311.3 & 69.2 & 241.1 & 242.8 \\
IET-5 & 22.1 & 275.0 & 51.3 & 238.7 & 240.3 \\
IET-6 & 22.1 & 304.8 & 69.0 & 234.4 & 236.0 \\
IET-7 & 22.1 & 302.6 & 71.3 & 227.6 & 229.2
\end{tabular}

Table 4.2. ('alculated Hydrogen Results Summary for the SNL/IE'T Experiments Reference Calculation

MliscoR Ilydrogen Balance

Experiment (gm-moles)
Pre-existing Produced Burned End-of-calculation

$\begin{array}{lcccc}\text { IET-1 } & 0 & 286 & 0 & 286 \\ \text { IET-1R } & 0 & 266 & 0 & 266 \\ \text { IET-3 } & 0 & 232 & 188 & 44 \\ \text { IET-4 } & 0 & 243 & 209 & 34 \\ \text { IET-5 } & 204 & 240 & 0 & 44 . \\ \text { IET-6 } & 183 & 236 & 218 & 201 \\ \text { IET-7 } & 288 & 229 & 223 & 29.4\end{array}$




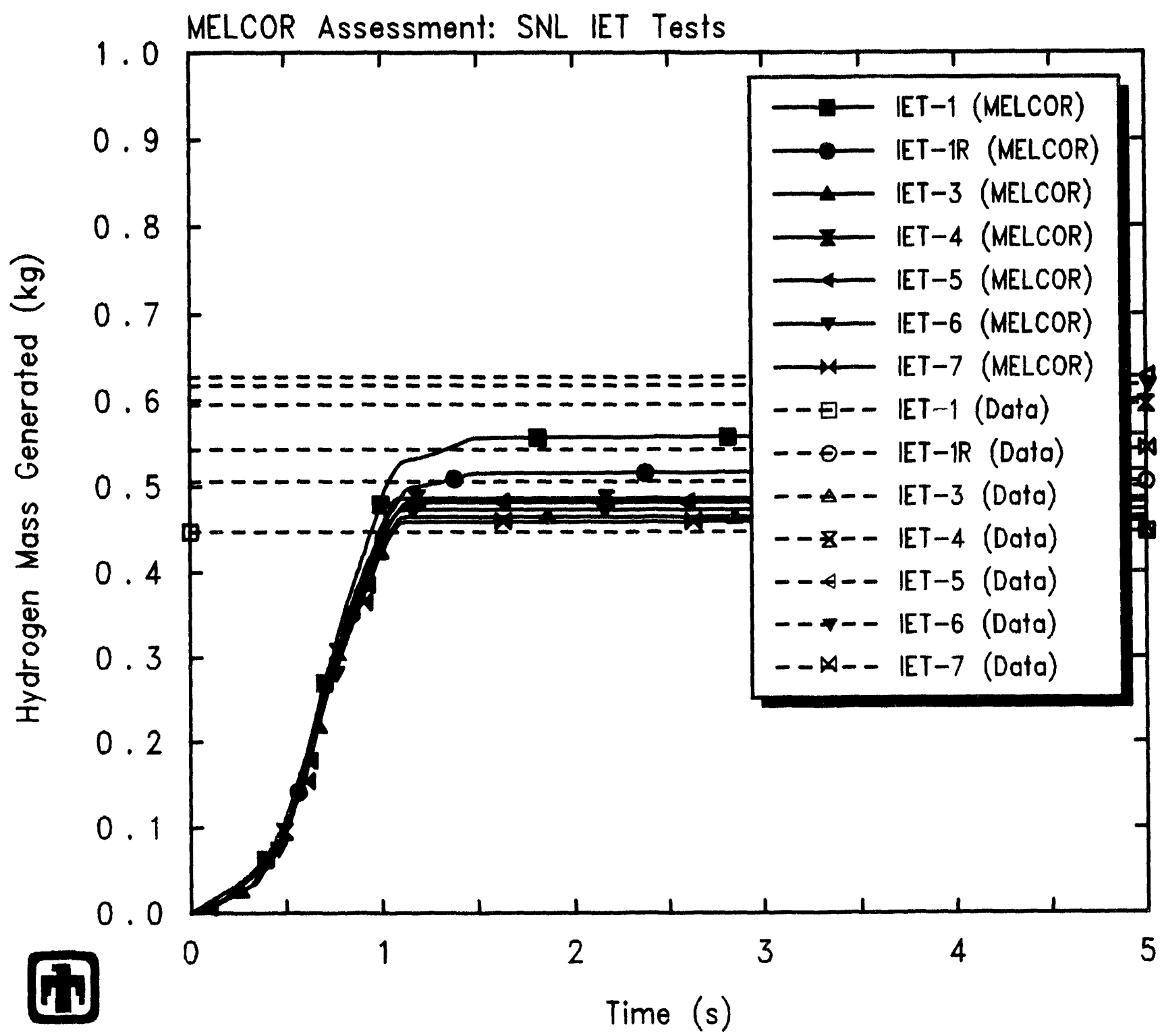

SNL Surtsey IET Tests -- SUN reference results

FIDOBDQNN 6/09/93 14:12:52 MELCOR SUN

Figure 4.2. Hydrogen Production for SNI/IET Experiments Reference Calculation 


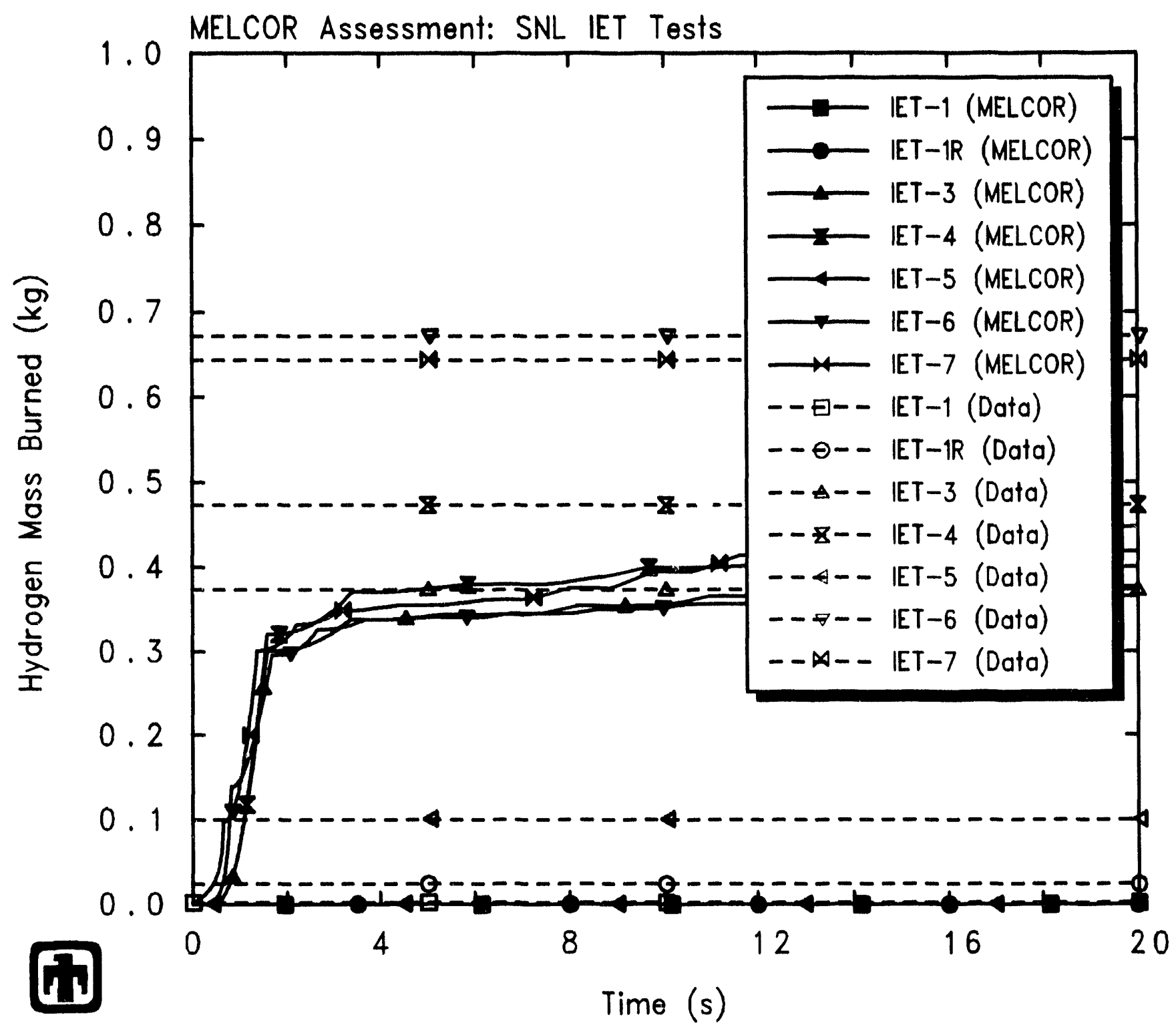

SNL Surtsey IET Tests -- SUN reference results FIDOBDQNN 6/09/93 14:12:52 MELCOR SUN

Figure 4.3. Hydrogen ('ombustion for SNL/IET lixperiments Reference ('alculation 
ally less than measured values, especially in the experiments with hydrogen combustion, while the hydrogen production and combustion calculated using the experimental procerlure on the MEl, (O) results are generally greater than measured. Also, the actual amount of hydrogen calculated to be produced by MELCOOR is lower in the tests with

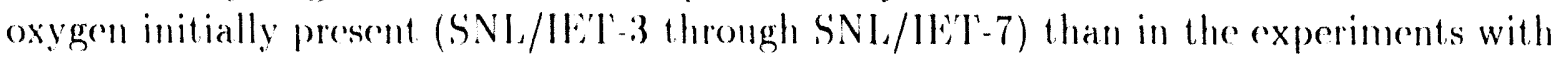
no significant oxygen initially present (SNL/IET-1 and SNI.IET-1R), while deriving the amounts of hydrogen produced and burned assuming only steam/metal reactions yields greater hydrogen production in SNL/IE'-3 through SNI/IE'T'-7 than in SNI/IE'I'-1 and SNI/LET-1R, reproducing the trend seen in the tabulated experimental data.

Overall, the "correct" answers are likely to lie somewhere between the two limiting assumptions. It is molikely that there is no oxiclation of motal with free oxygen at all (as assumed in the experimental analesis protocol). However, MEL(C)R would be expected to exaggerate the relative degree to which metal oxidizes with free oxygen es with steam,

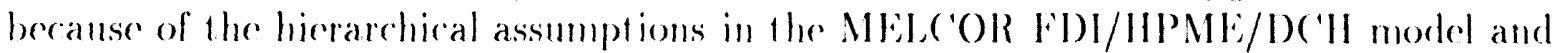
because, in the experiment, the debris transport probably lags the steam/hydrogen mixture flow, so that not much of the debris gets to see much oxygen, while in the MELC(O) model the debris is immediately transported to its ultimate distribution (as discussed in more detail in Sections 3.1 and 5.2) within Is while the steam blowedown is modelled "normally" as a transiont process taking several seconds.

('The quantification of hydrogen production and combustion in the SNL/IF:T experiments assuming that all oxygen depletion was due to reaction with hydrogen had an unforeseen effect on our MLide(O) analyses. In particular, the choice of a very short time constant for airborne debris oxidation (0.025s in the reference analyses) was driven by trying to explicitly match the reported hydrogen production and combustion data: sensitivity study results show very litte difference in calculated pressures or temperatures for $0.01 \mathrm{~s} \leq \tau_{o x} \leq 0.1 \mathrm{~s}$, becanse the oxidation rate is essentially limited by avalability of stram and/or oxygen at the shorter characteristic interaction himes, and the hydrogen production and combustion results later derived from a molar balance assuming only steam/metal reactions (as in the test data analysis) is in better agreement with test data for calculations using longer characteristic airborne-debris oxidation times ( $\left.\tau_{t, r} \geq 0.1 \mathrm{~s}\right)$, which seems a more reasonable value based on physical gromuds.)

Figures 4.4 and 1.5 depict the hydrogen and oxygen mole fractions, respertively, in the subcompartments and dome. The test data comes from gas grab bot te samples taken in the Surtsey vessel at 2 and 30 min, and a data point from a grab bottle sample taken at 2-7s in the subcompartments is included. Note that the data is included primarily to show late-time response and shonld not be interpered as showing constant conditions thronghont the test period: the single data point available in the subempartments at 2-7s indicates substantial atmosphere composition variations occurred early in the transient. The calculations show a rapid transiont during the first few seconds, during HeME, and then generally show a gradual approach to the final, post-test data.

Figure 1.6 compares Surtsey vessel pressures measured in the SNI.IF'l experiments to pressures calculated in onr final, reforence MElo (O) analyses. (The pressures measured at there levels in the Surtsey vessed with three different pressure transducers were 

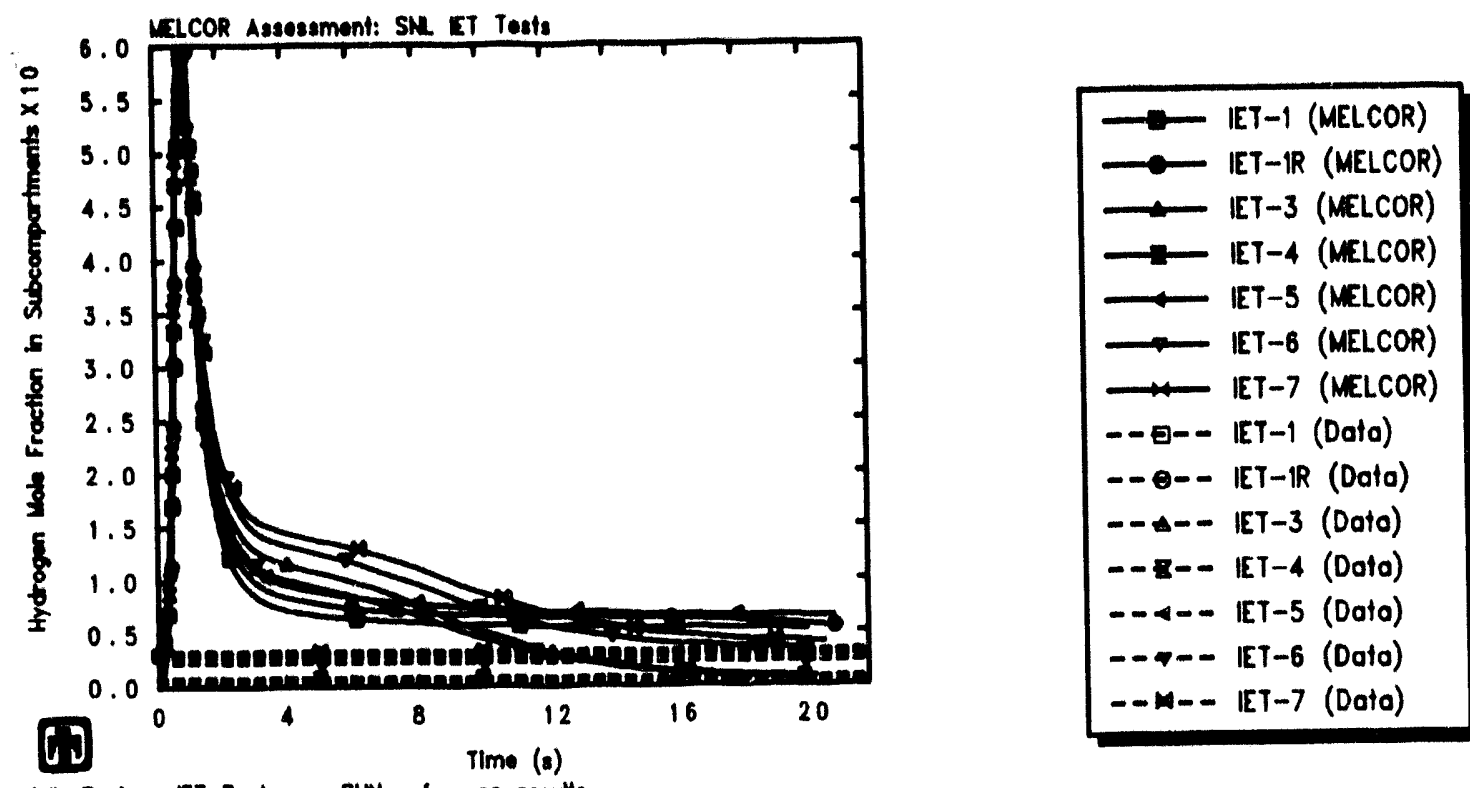

SKL Surtsey ET Tosis -- SUN roference results FKDDIFNN 6/11/93 09:37:23 NELCOR SUN
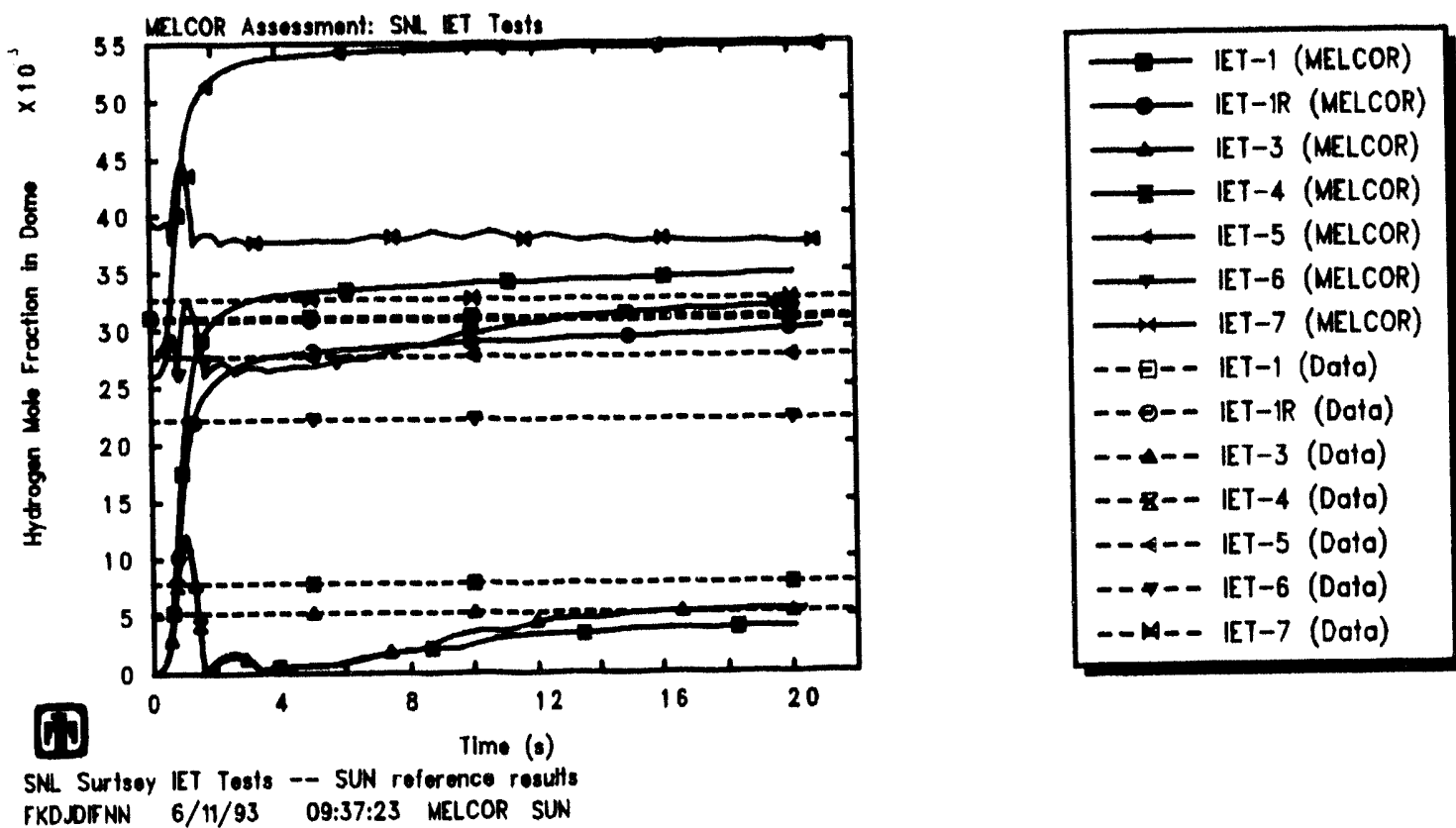

Figure 4.4. Hydrogen Mole liractions in the Subcompartments (top) and Dome

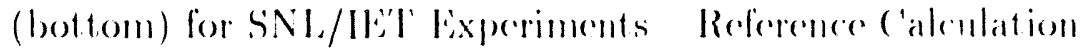



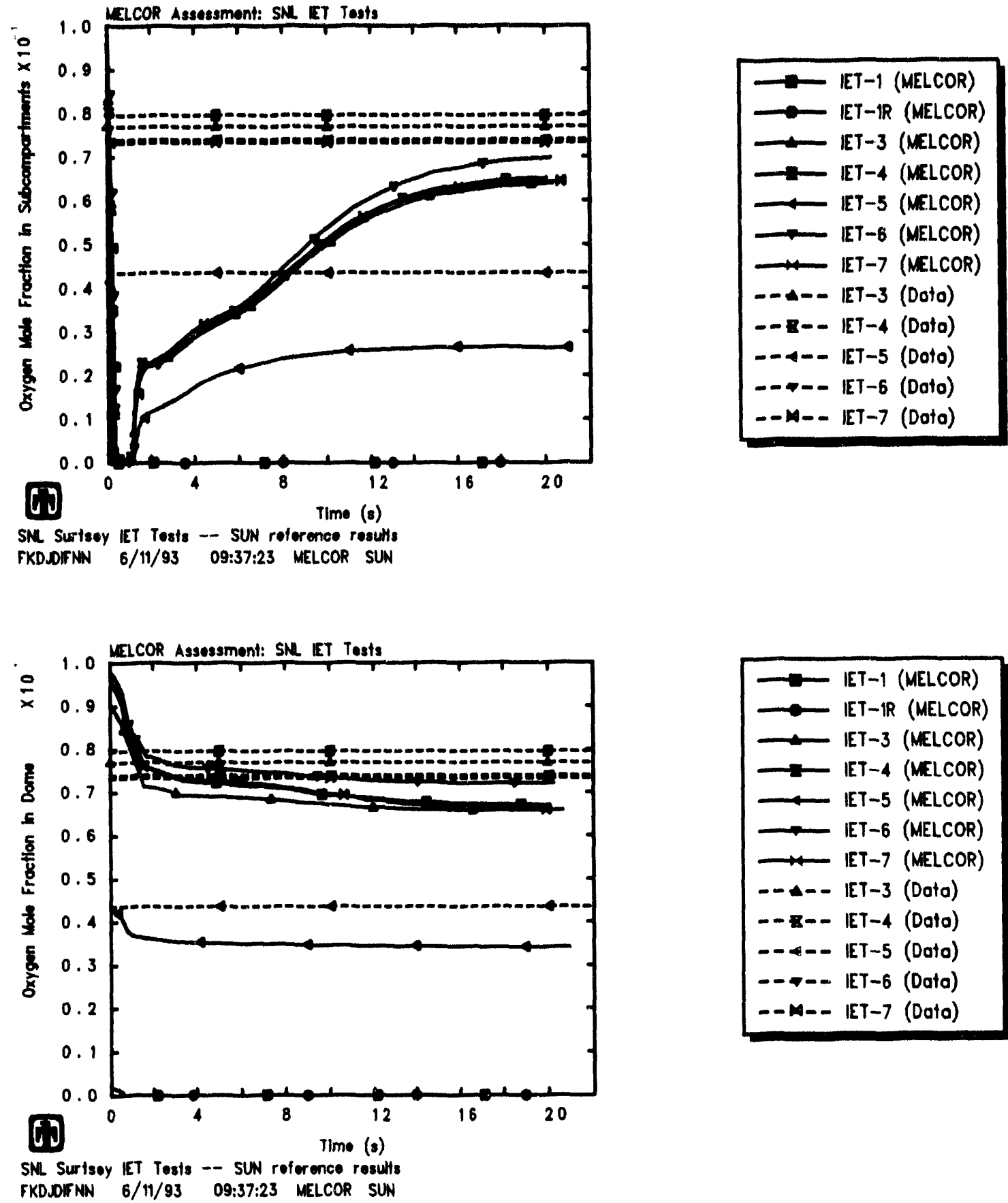

$$
\begin{aligned}
& \text { IET-1 (MELCOR) } \\
& \longrightarrow \text { IET-IR (MELCOR) } \\
& \text { IET-3 (MELCOR) } \\
& \longrightarrow \text { IET-4 (NELCOR) } \\
& \longrightarrow \text { IET-5 (MELCOR) } \\
& \text { IET-6 (MELCOR) } \\
& \text { IET-7 (NELCOR) } \\
& \text { - - - - IET-3 (Data) } \\
& \text { - - E-- IET-4 (Dota) } \\
& \text { - -4-- IET-5 (Dato) } \\
& \text { - - -- IET-6 (Data) } \\
& \text { - - M-- IET-7 (Doto) }
\end{aligned}
$$

Figure 4.5. Oxygen Mole Fractions in the Subcompartments (top) and Dome (bottom) for SNL/IET Experiments Reference ('alculation 
virtually identical; the pressures calculated in the subcompartments cont rol voiume and the uppere dome cont rol volume were also virtually identical.) The pressure signature observed falls into two major subdivisions, caused by the effect of hydrogen rombustion. In tests SNI./LE'I'- and SNL/IEZI'-IR, the vessel was incerted with nitrogen and the hydrogen produced by steam reaction with motallic debris during hlowdown could not burn; in SNL/IE:T'-5, the vessel was "classically inerted" with carbon dioxide and again very little hydrogen combustion occurred. When the hydrogen (preexisting or IIPML-gencrated) was allowed to burn with oxygen in the vessel atmosphere, pressure increases rose from $\sim 10(1 \mathrm{kl}$ 'a to 210 -280kPar, a significant contribution to contaimment pressurization. The lack of substantially higher peak pressures in tests with pre-cexisting hydrogen indicates that combustion of pre-existing hydrogen did not ocent on the same time scale as the IIPME.

Table 1.4 rompares the measured and calculated poak pressures for the tests andlyzed, and also indicates how much of the predicted pressurization was due to the steam blowdown, HPME, reactions and hydrogen combustion, respectively. (The individual pressurization contributions are obtained from sensitivity studies with either no melt

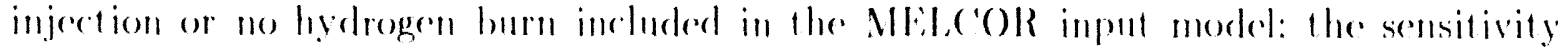
sturlies with no hydrogen burn included are presented in Siection 7.1.)

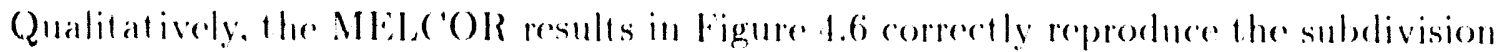
of the pressure response into two major families. aaused by the effect of hydrogen com-

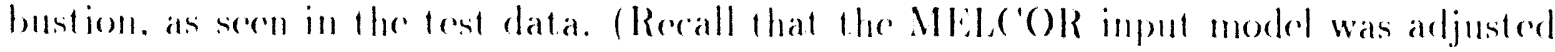
to approximate the observed hydrogen combustion behavion in these I)('ll experiments.

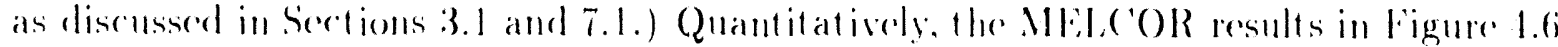

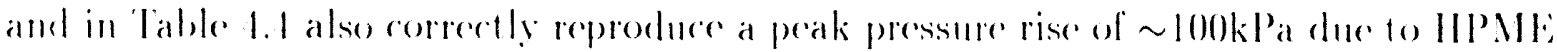

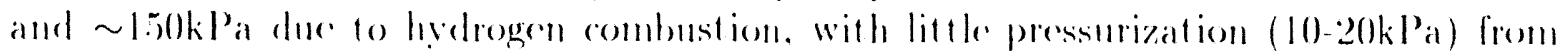
the steam blowelown.

Measured and calculated temperatures in the subcompartments are compared in lighures 1.7 and lis. for the three tests with little or no hedrogen burn and for the four tests in which hydrogen combustion occurred. respectively. Thermoconple results are shown for any data avaibable. including one or more of the following: the temperature inside the sulfeompartment structures, temperatures inside the seal roome the tempera tures in the triangular rent spares abowe the pumpe models, and temperalures measured by thermocomples suspended q focm moler the reactor coolant pump mockups. The single data trace for the temperature inside the subeompartment structures mstally corresponds to three aspitated thermocomples in a thermocouple assembly giedding nearly ielentical temperature es time comves. When multiple measurements are available. they show significant local temperature gradients present. The Mlite (o) results are gernerally judgerd to be in reasomably good agreement with the lest data. Note that, although

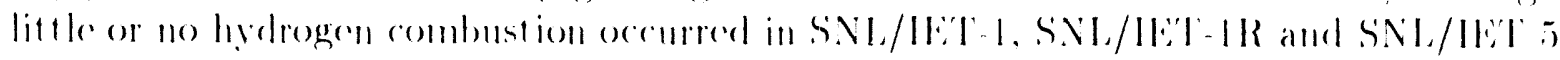

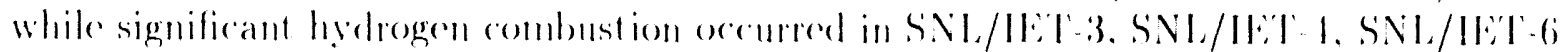

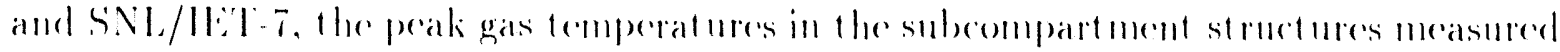
in all these tests were almost identical: this indeates that the primary mechanism for leating the subeompartment atmosplere was probably dehris/gas heat transfer and not 
Table 4.3. Hydrogen Results for the SNL/IE'I Experiments Reference Calculation Fxperiment

$$
\text { Hydrogen (gm-moles) }
$$

Produced
Datat MELCORg MELCOR Datat MELCORg MELCOR

$\begin{array}{lcccccc}\text { IE'T-1 } & 233 & 286 & 266 & 3 & 0 & 4 \\ \text { IE'T-1R } & 248 & 266 & 267 & 11 & 0 & 28 \\ \text { IE'-3 } & 227 & 232 & 352 & 190 & 188 & 313 \\ \text { IE'T-4 } & 303 & 243 & 361 & 240 & 209 & 332 \\ \text { IET-5 } & 319 & 240 & 313 & 53 & 0 & 91 \\ \text { IET- } 6 & 319 & 236 & 354 & 345 & 218 & 307 \\ \text { IE'T-7 } & 274 & 229 & 351 & 323 & 223 & 350\end{array}$

ffrom gas grab bottle samples at $30 \mathrm{~min}$

Tactual end-of-calculation values at 20 s

fcalculated from initial and final oxygen and hydrogen moles assuming only steam/metal reactions

Table 4.4. Prak Pressures for the SNL/IET Experiments - Reference Calculation

\begin{tabular}{|c|c|c|c|c|c|}
\hline \multirow[t]{3}{*}{ Experiment } & \multicolumn{5}{|c|}{$\Delta P_{M A X}(\mathrm{kPa})$} \\
\hline & & Total & Blowdown & HPME & $\mathrm{H}_{2} \mathrm{Burn}$ \\
\hline & Data & MELCOOR & only & only & only \\
\hline WE'T-1 & 98 & 84 & 18 & 66 & () \\
\hline IET-1R & 103 & 102 & 21 & 81 & 0 \\
\hline IE'T-3 & 246 & 276 & 18 & 102 & 156 \\
\hline IE'T-4 & 262 & 285 & 24 & 96 & 15.5 \\
\hline IET-5 & 103 & 93 & 17 & 76 & 0 \\
\hline IET'-6 & 279 & 266 & 16 & 105 & 145 \\
\hline IET'7 & 271 & 264 & 28 & 89 & 147 \\
\hline IE'T-8A & 87 & & & & \\
\hline [ET-8B & 243 & & & & \\
\hline
\end{tabular}




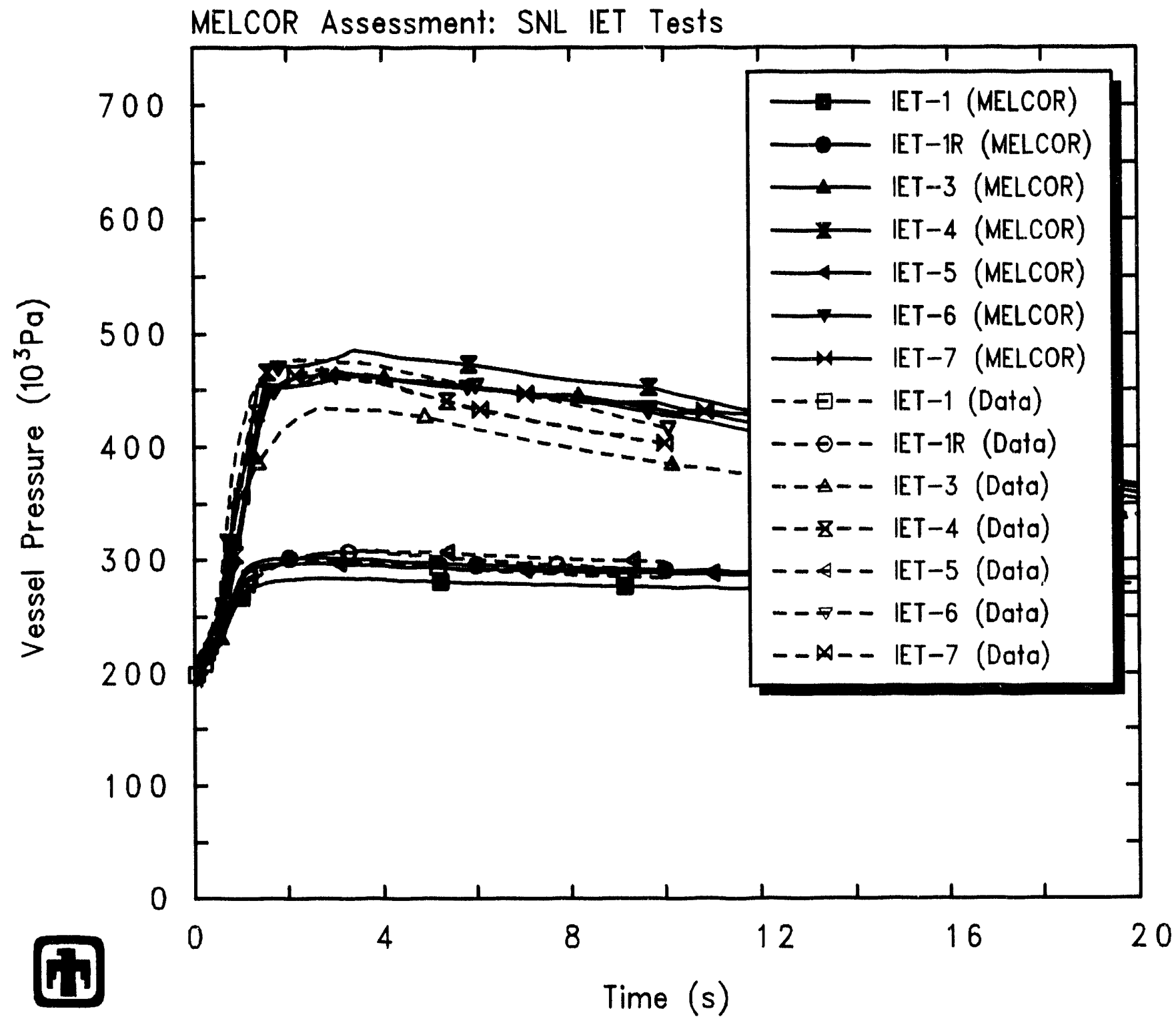

SNL Surtsey IET Tests -- SUN reference results

FIDOBDQNN 6/09/93 14:12:52 MELCOR SUN

Figure 4.6. Vessel Pressures for SNL/IET Experiments - Reference (alculation 
hydrogen combustion. To reproduce this behavior, in the MELCOR input we specified hydrogen combustion to be suppressed in all control volumes except the vessel dome.

Figures 1.9 and 1.10 present observed and predicted temperatures in the upper dome, above the operating deck. for two tests with little or no hydrogen burn and for four tests in which hydrogen combustion occurred respectively. (No test data was available for test S.NI./FE-IR.) Thermocomple results are given for thee levels in the dome, with the levels identified in Figure 2.1.1): measured temperatures typically decreased with increasing elevation. When avalable, additional thermocouple results also are included for arrays in the dome. which moasured temperatures from abont level 3 to halfway between level 5 and 6; those arrays are shown in Figure 2.1.4). The MELCOR vessel dome atmosphere temperature results are generally in good agreement with the test. data, given the localized response of the thermocouples. The significantly higher vessel temperatures observed in the tests with substantial hydrogen combustion (SNL/IET-3,

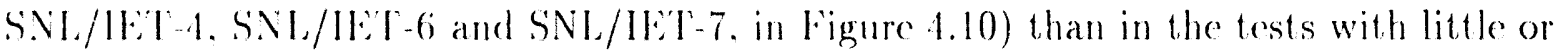
no hydrogen combustion (SNL/IET-I, SNL/IET'IR and SNL/IET-5, in Figure 4.9) are also fond in the MELCOR calculations. This result is expected, because the vessel dome average temperature response is closely compled to the vessel pressure behavior, and thus the reasonably goor! agreement between measurement and calculation for vessel pressures in ligurep-base is reflected in similar good agreement in observed and predicted average vessed tomperatures.

So comparisons are given for the local cavity pressure. Because the MELCOR D(:H model does not model transport of debris into and through the cavity. but instead immedialely places the debris at its ultimate destination. the predicted cavity and chute pressures are hasically the same as the subcompartments and upper vessel pressures. There is aw apability to model transient debris-coolant interactions in the cavity. 

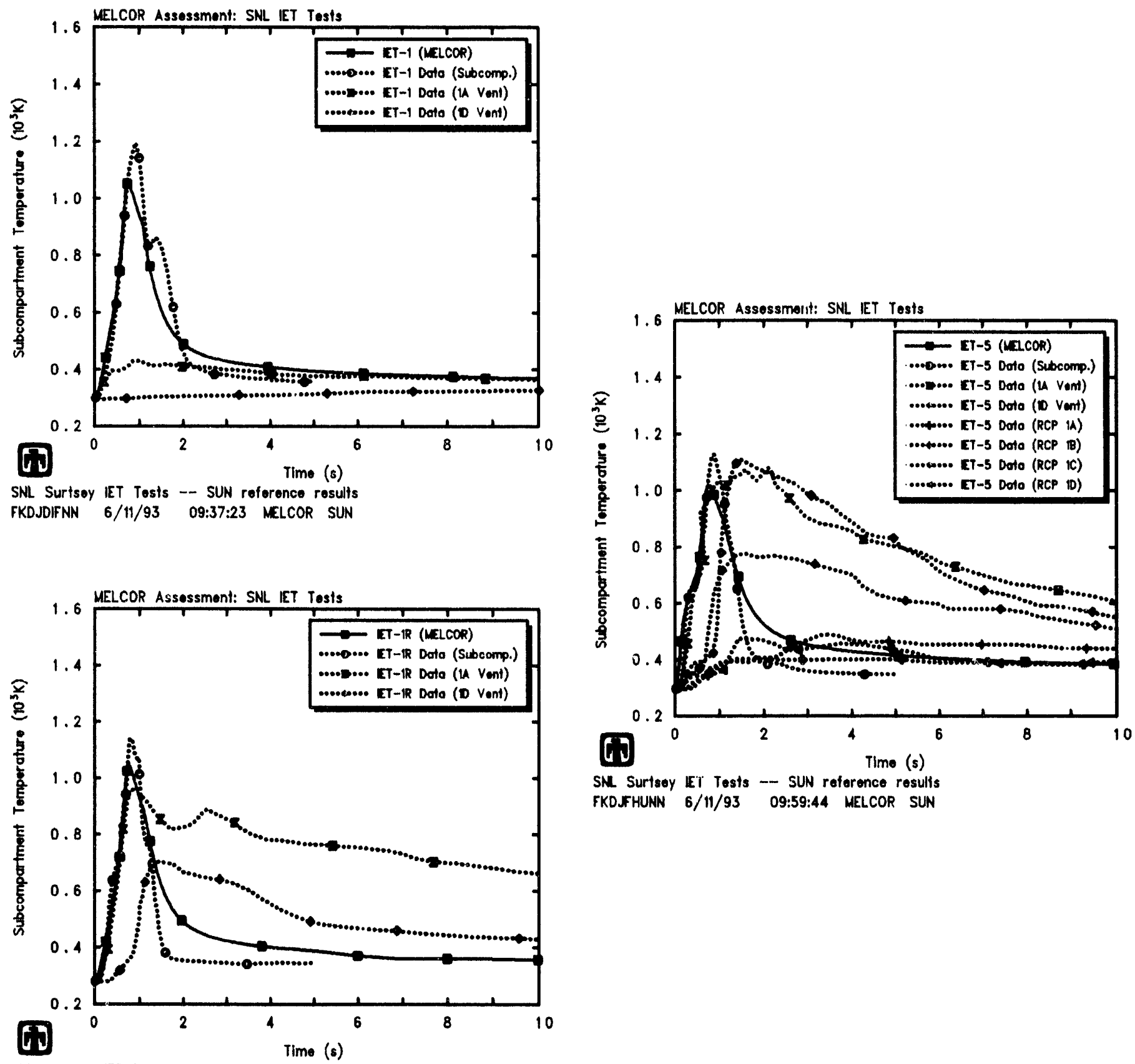

SNL. Surtsoy IET Tosis -- SUN roforence results

FKD JDVINN $6 / 11 / 93$ 09:43:04 MELCOR SUN

Figure 4.7. Subcompartment Temporatures for Experiments SNI/IE'T-1 (upper left), SNL/IET-IR (lower loft) and SNL/IET-5 (middle right) Reference ('alculation 

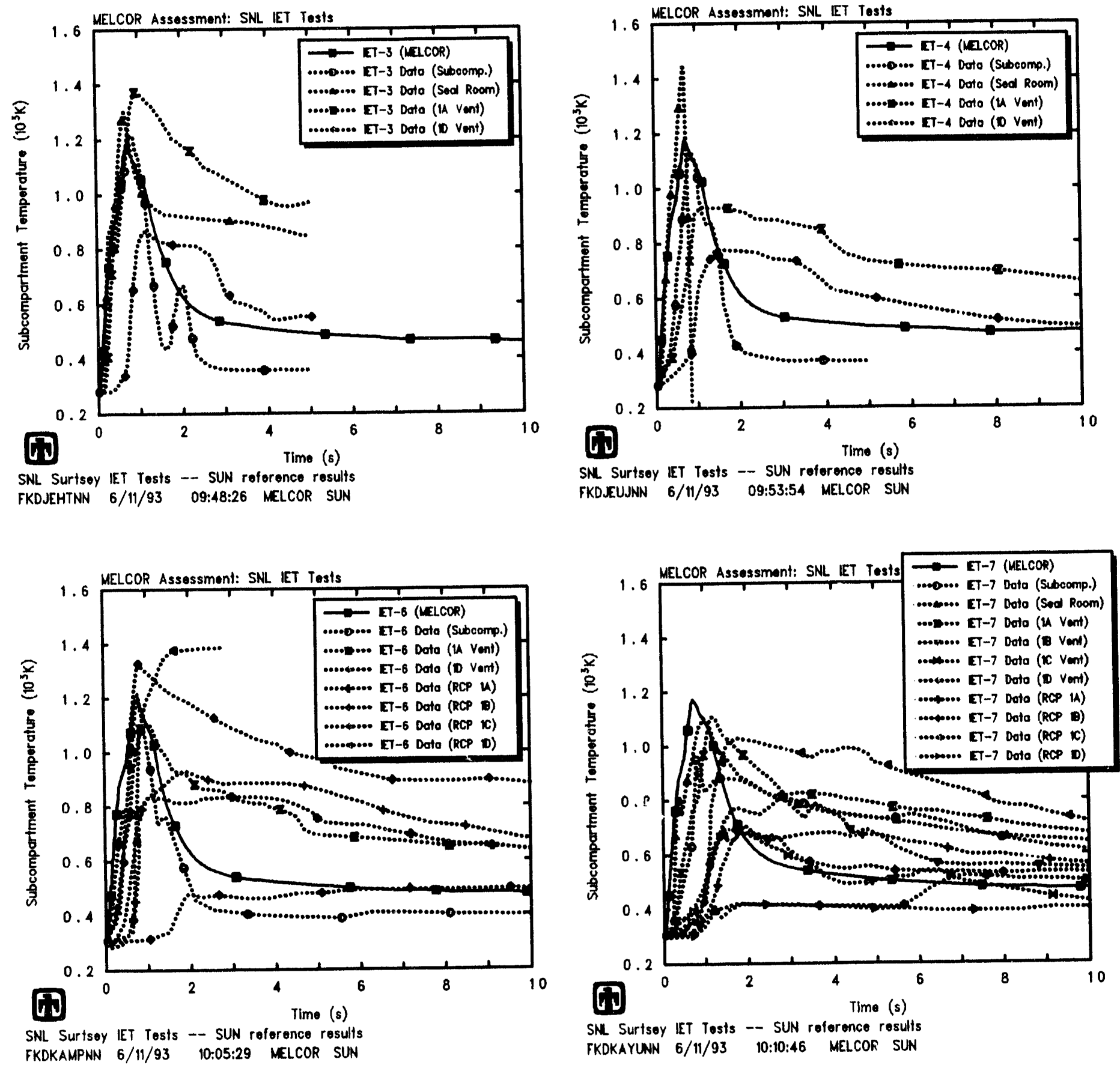

Figure 4.8. Subcompartment Temperatures for Experiments S'NL/H:T-3 (upper left), SNL/IE:T'-4 (upper righte, SNL/IE:T'-6 (lower left) and SNL/IET- (lower right) Reference (alculation 

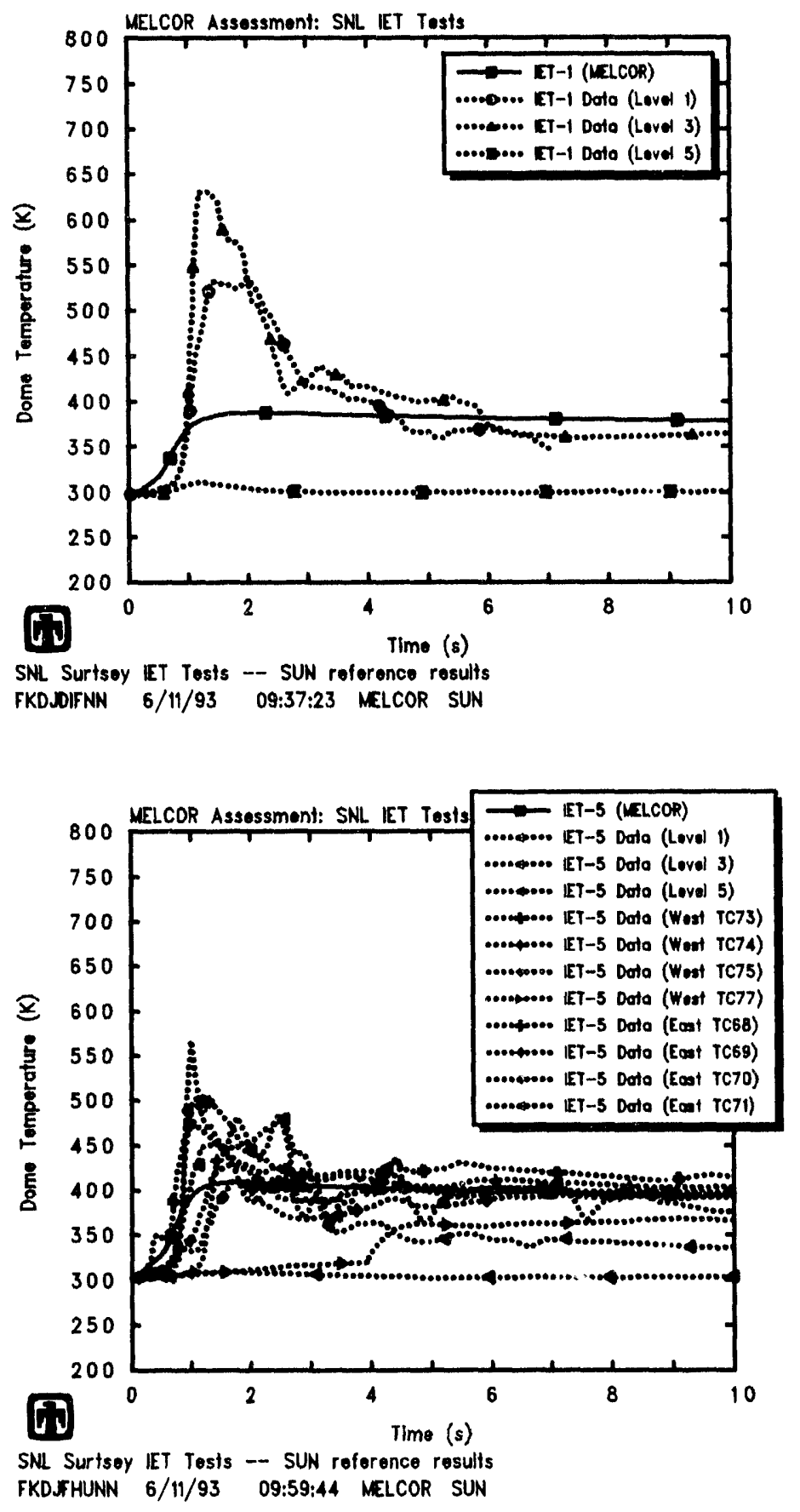

Figure 4.9. Dome Temperatures for Experiments SNL/IET-1 (top) and SNL/IET-5) (bottom) - Reference (alculation 

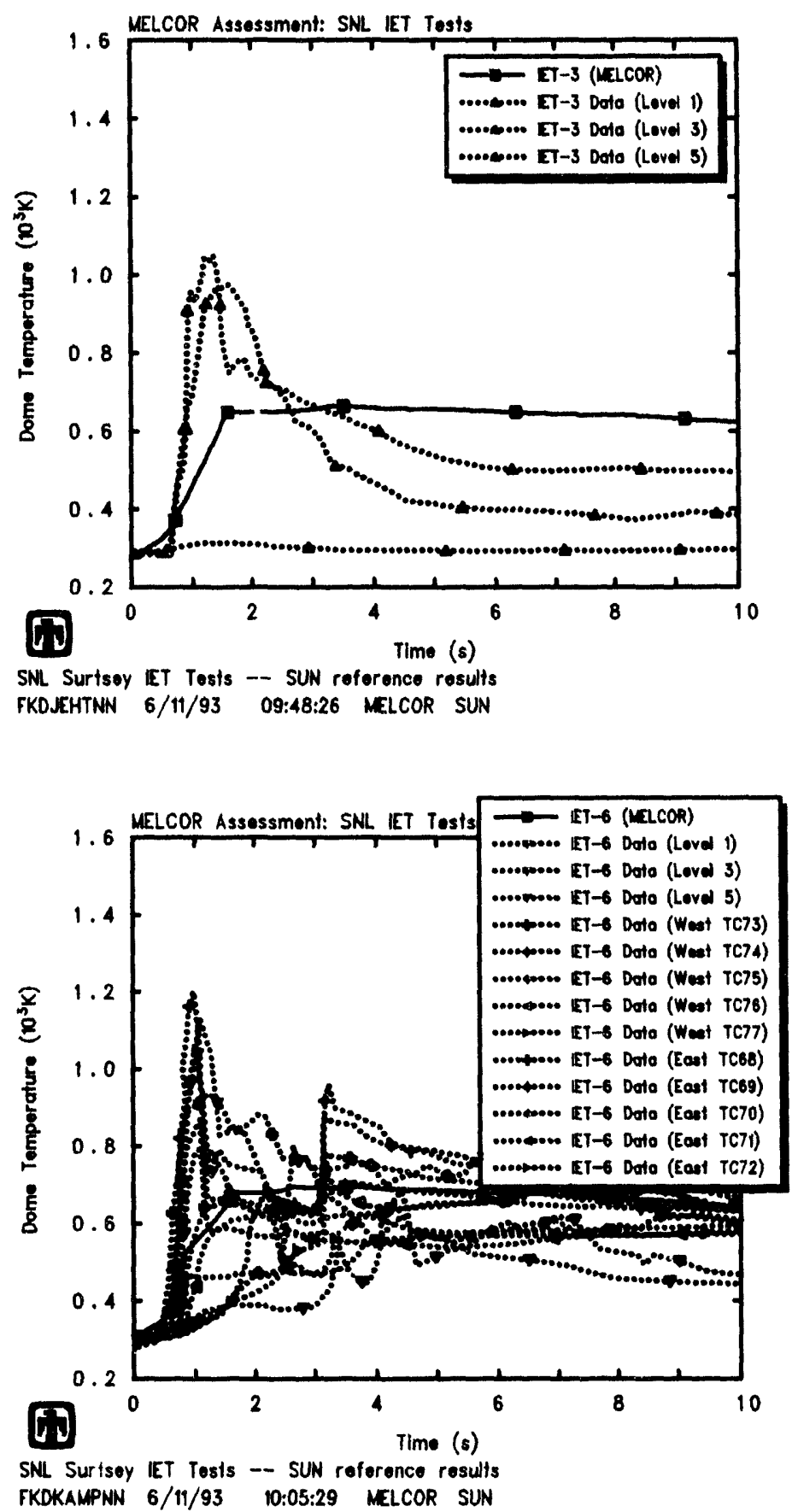
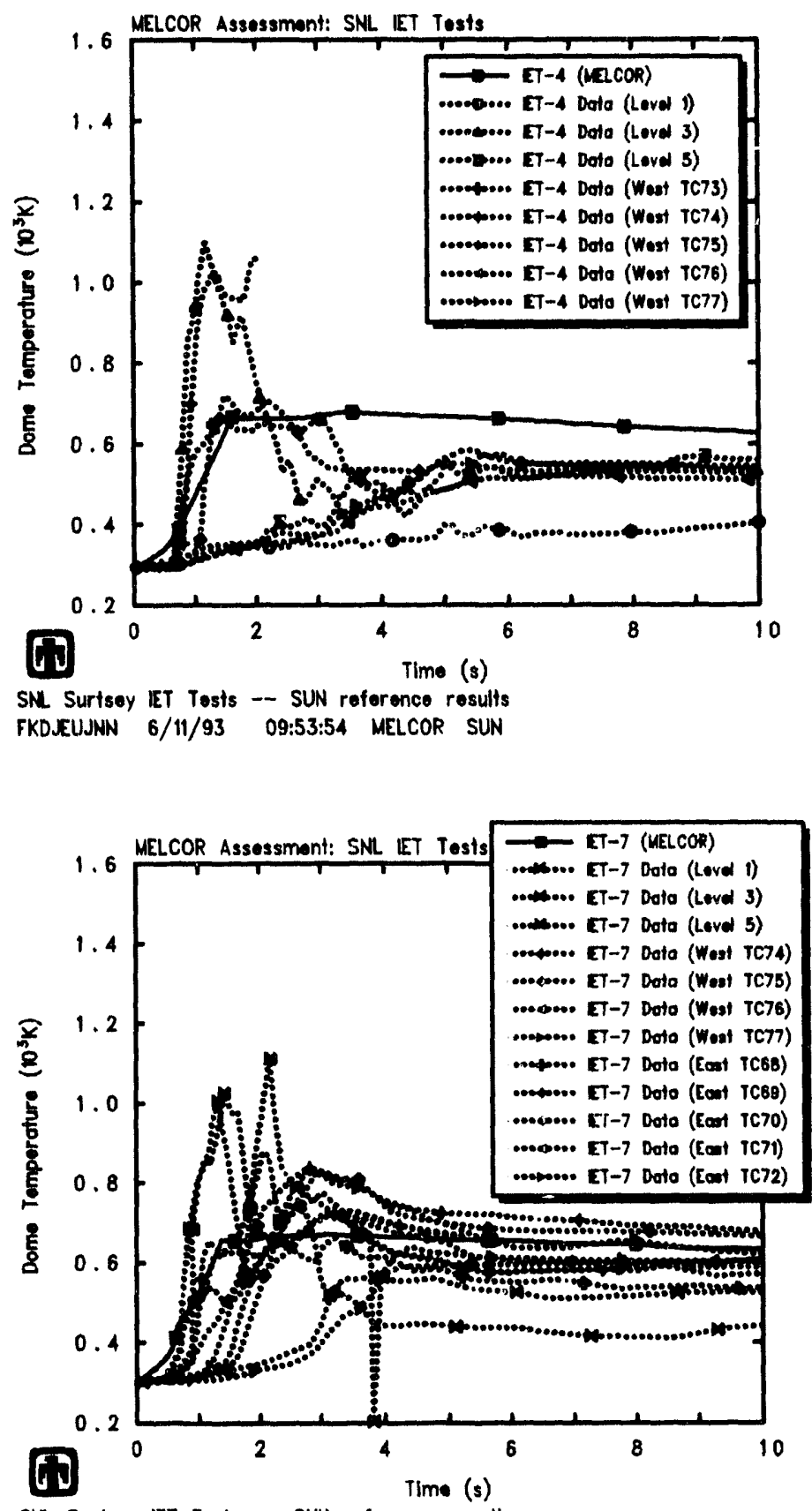

SN Surtsoy IET Tests -- SUN reforence results FKDKAYUNN 6/11/93 10:10:46 MELCOR SUN

Figure 4.10. Dome 'Temperatures for Experiments SSL/IE'T'-3 (uppor left), SNI/IET-4 (upper right), SNL/IET'-6 (lower left) and SNI/IET-7

(lower right, - Reference Calculation 


\section{$5 \quad$ Experiment Uncertainty Studies}

There are experimental uncertainties in both the exact values to be used for some MELCOR input values and in the modelling approach taken to represent other test conditions. As described in this section, a set of sensitivity studies has been done varying those parameters to determine how the results could be affected by such experiment uncertainties.

\subsection{Steam Blowdown}

As described in Section 3.1, a valve with a time-dependent area was used in the flow path from the steam accumulator to the cavity to control the rate of steam injection, with the opening rate adjusted to match the observed steam accumulator depressurization rates reasonably well. Although different final hole diameters were identified in the test. reports for the opening from the melt generator to the cavity (as given in l'able 2.1.2), the input was kept the same for the valve and associated time-dependent area used in the flow path from the steam accumulator to the ravity to control the rate of steam injection. In the experiments the thermite reaction products and the steam were injected through the same opening, with some indication in the data of occasional plugging and flow intermution. In the MLIS(OR model the debris is inserted separately, directly to its ultimate destination; thus MELCOR does not model any debris blockage or obstruction possibly affecting the steam injection rate.

The valve opening rate was selected to match the observed steam accumulator depressurization rates in the various tests reasonably well. ('alculations were done using valve opening times of $0.5 \mathrm{~s}, 1 \mathrm{~s}, 2 \mathrm{~s}$ and $\mathrm{ks}$, with the time-dependent area increasing linearly in all cases. Figure 5.1.1 shows predicted pressures in the steam delivery volume during the blowdown process for all tests analyzed, using the different valve opening times, together with experimental data for comparison. The calculated blowdown is obvionsly too rapid with the valve opening over 0.5 s, and too slow with the valve opening over $4 \mathrm{~s}$. The steam accummlator depressurization predicted with a valve opening time of 2 s appears in slightly better agreement with test data than the results using a valve opening time of Is, and the 2s opening time was used in the rest of our Surtsey IVI' assessment analyses.

The corresponding predicted vessel pressures are presented in ligure 5.1.2, with test data included for reference. The effect of varying the steam blowdown timing is reflected in a small change in the peak vessel pressure, with slightly higher pressures predicted for the more rapid steam blowdown, in the tests with hydrogen burn oceurring; little or no effect is visible for the cases with no hydrogen burn.

The lack of any visible effect of varying the steam blowdown timing for the cases with no hydrogen burn is due to the small contribution made by the steam blowdown to the overall vessel response, as shown in Section 4. The slight rise in vessel pressure sech with the more rapid steam blowdown in the cases with hydrogen burn is due to more steam being available carly in the HPME reaction so that more hydrogen is generated 

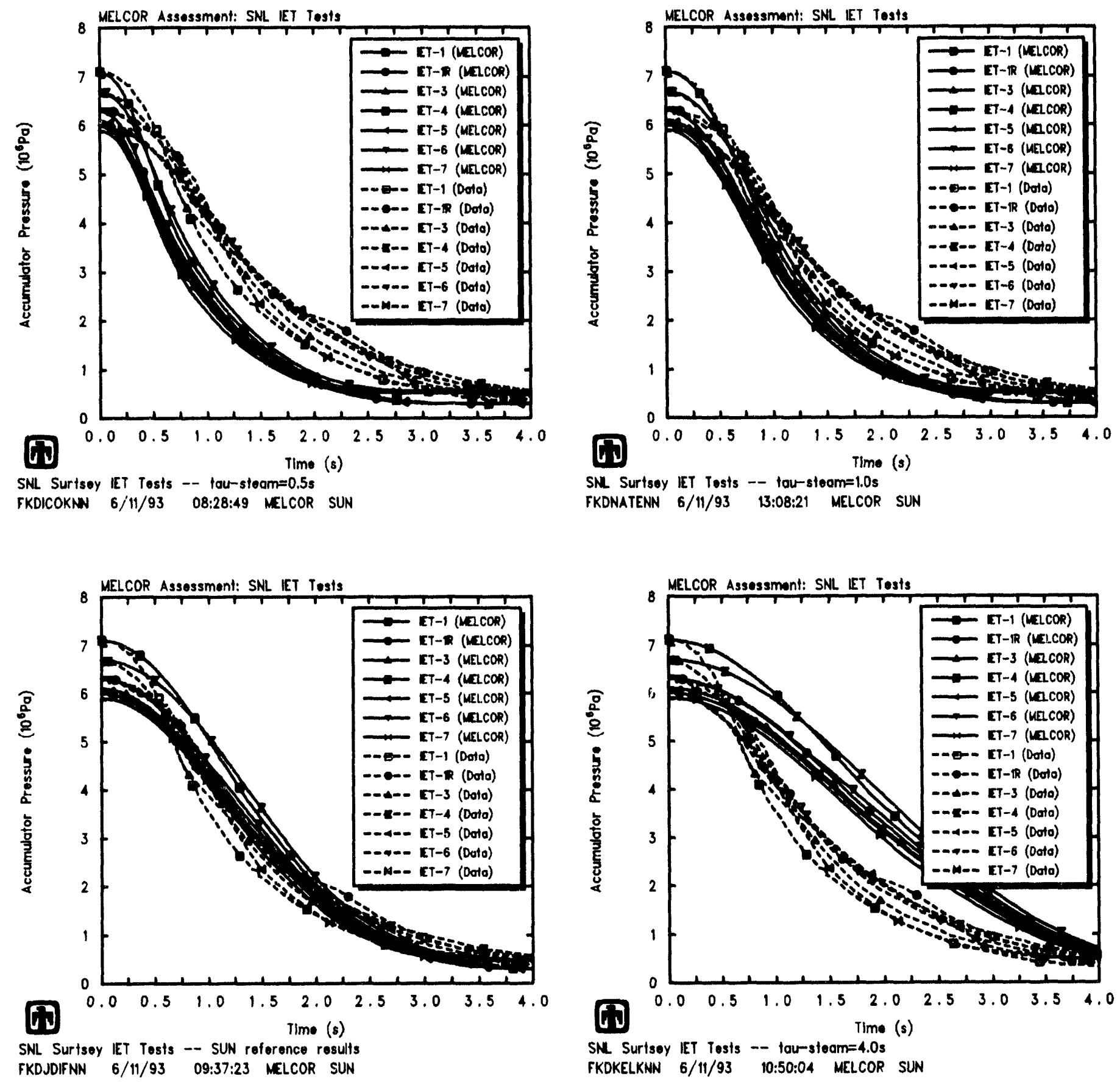

Figure 5.1.1. Stcam Acrumulator Pressures for SNL/IF T Experinents I sing Valve Opening Times of (0.5s (upper left). Is (upper right). Ls (lower left) and Is (lower right) Stcam Blowdown Semsitivity Study 

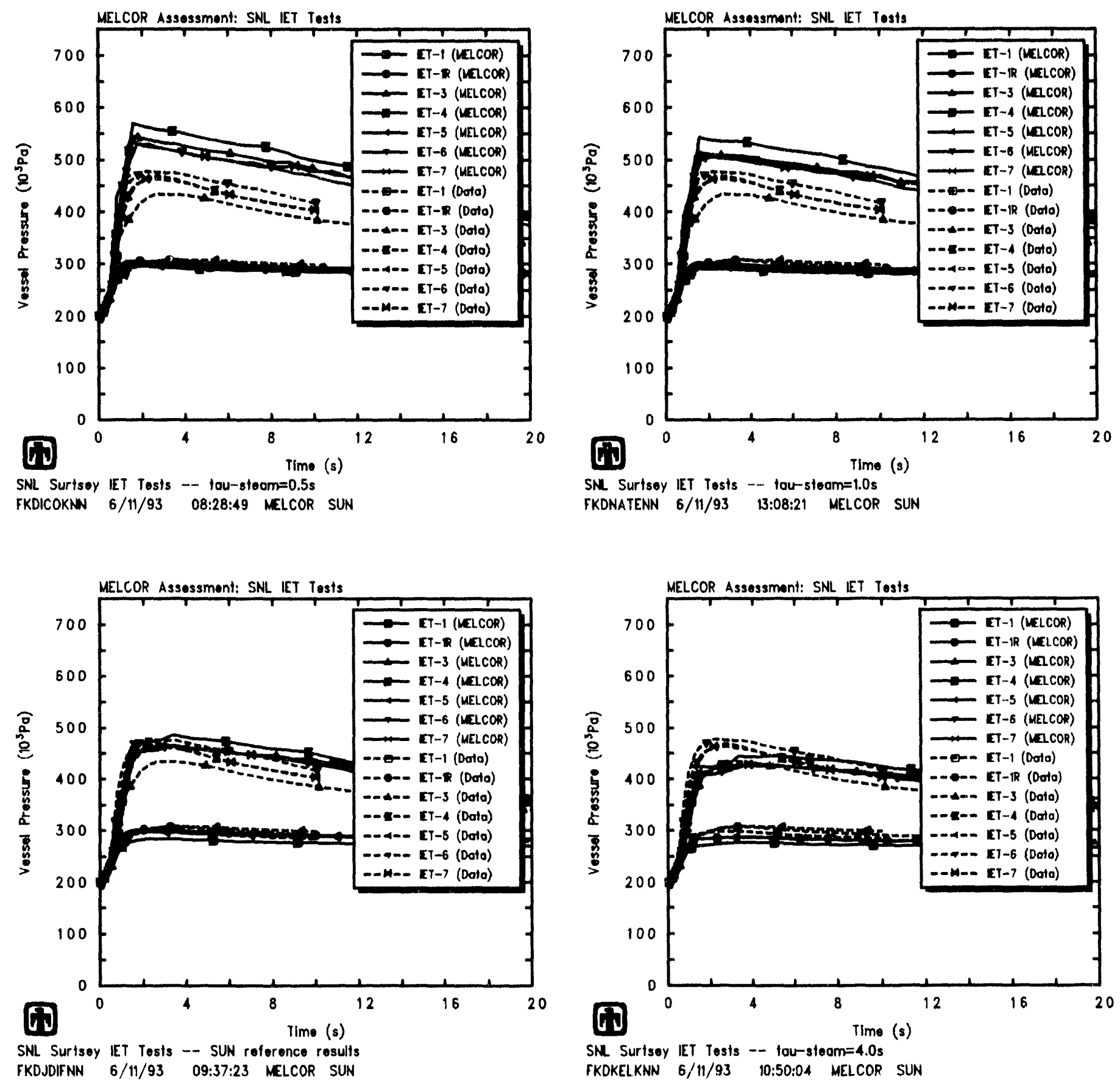

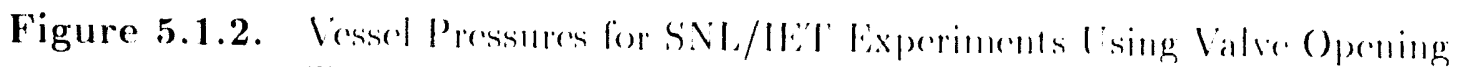

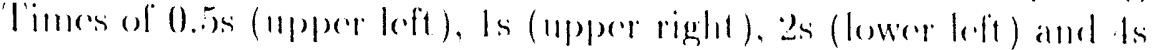
(lower righa) Stram Blowdown Sinnsitivity Stundy 
in steam-debris interactions; the subseguent burning of the greater amount of hydrogen generated then produces the increase in vessel pressure. Tables 5.1.1 and 5.1.2 illustrate this by comparing the amomints of hydrogen generated and burned, respectively, in these various cases. Test data estimates of the amounts of hydrogen produced and burned are included for reference.

\subsection{Melt Injection Timing}

The MELCOOR DC(II model does not model transient transport of debris into and through the system, but instead immediately places the debris at its ultimate destination. MELCOR uses a single function for the time-dependence of the molt injection in all control volumes and heat structures; in reality, the melt reaches the subcompartments later than the cavity, and the dome later than the subcompartments.

Melt injection could begin at $t=0$, since that is defined as the time that the brass plug at the bottom of the crucible failed and was expelled by high-pressure steam into the cavity. Cavity pressure data indicates a pressure spike from fuel-coolant interaction (F(1) as molten brass, steel and thermite enters the cavity between 0 and $~ 0.38$, followed by debris entrainment from the cavity into the subcompartments between about $0.4 \mathrm{~s}$ and 0.8s. High-speed cameras showed debris particles cjected from the subeompartment struetures toward the upper dome of the Surtsey vessel, with acrosols visible at $\sim 0$.ls and hydrogen jet burning visible at about 0.2-0.4s; at about Is, molten particles were secn to fall, implying that debris injection and entraimment was over.

The time-dependence of the melt addition in the Mlil('OR input, was adjusted to match the rate of pressure and temperature increase in the vessel. Melt injection was always assumed to start at time $=0$, but the time period over which melt injection was specified to occur was varied from 0.1 s though 0.5 s and 1 s to 2.5 s in these sensitivity study analyses; in cach case, the injection rate was assumed constant within the time period.

Resulting predicted vessel pressures are shown in Figure 5.2 .1 , together with the test data. 'The effect of lengthening the melt injection timing is reflected in a progressive dolay in the peak vessel pressure and a corresponding increase in the magnitude of the peak pressure. As in the steam blowdown timing study results, the change is more pronounced in the tests with hydrogen burn occurring, with little or no effect visible for the ases with no hydrogen burn. The calculated pressurization is obviously too low and too carly with a melt injection period of $0.1 \mathrm{~s}$, and too high and too late with a melt injection period of $2.5 \mathrm{~s}$. The best agreement for vessel pressure is found using melt injection periods of $0.5-1.0 \mathrm{~s}$.

Tables 5.2.1 and 5.2.2 compare the amounts of hydrogen generated and burned, respectively, in these varions cases. The amount of hydrogen produced is a very strong function of the melt injection period assumed, as is the amount of hydrogen burned. The hydrogen production calculated assuming a melt injection period of $1 \mathrm{~s}$ is in best agreement with data. (The hydrogen combustion predicted appears too low in all cases, 
Table 5.1.1. Hydrogen Generation for the SNL/IET Experiments Steam Blowdown Sensitivity Study

Experiment Hydrogen Produced (gm-moles)
MELCOR $\ddagger$

\begin{tabular}{|c|c|c|c|c|}
\hline \multirow[t]{2}{*}{ Datat } & \multicolumn{4}{|c|}{ MELCOR } \\
\hline & $0.5 \mathrm{~s}$ & Is & $2 \mathrm{~s}$ & Is \\
\hline 233 & $438 / 109$ & $369 / 343$ & $286 / 266$ & $2 \cdot 2 \cdot 1 / 207$ \\
\hline 248 & $407 / 101$ & $341 / 338$ & $266 / 267$ & $210 / 212$ \\
\hline 227 & $335 / \cdot 143$ & $298 / 409$ & $232 / 352$ & $181 / 308$ \\
\hline 30.3 & $350 / 458$ & $314 / 12 x$ & $243 / 361$ & $181 / 319$ \\
\hline 319 & $365 / 125$ & $310 / 374$ & $240 / 313$ & $188 / 267$ \\
\hline 319 & $339 / 415$ & $305 / 411$ & $236 / 354$ & $18: 3 / 309$ \\
\hline 274 & $327 / 138$ & $294 / 405$ & $229 / 351$ & $178 / 305$ \\
\hline
\end{tabular}

from gas grab bottle samples at $30 \mathrm{~min}$ $\ddagger$ (actual values at $20 \mathrm{~s}) /$ (assuming only steam/metal reactions)

Table 5.1.2. Hydrogen Combustion for the SNL/IET Experiments Steam Blowdown Sensitivity Study

Experiment

$$
\begin{aligned}
& \text { Hydrogen Burned (gm-moles) } \\
& \text { Datiat } \\
& \text { MEIC COR } \ddagger \\
& 0.5 \mathrm{~s} \quad \text { is } \tau_{1 \cdot \mu}={ }_{2 \mathrm{~s}} \quad 4 \mathrm{~s}
\end{aligned}
$$

$\begin{array}{lccccc}\text { IET-1 } & 3 & 0 / 4 & 0 / 4 & 0 / 4 & 0 / 4 \\ \text { IET-1R } & 11 & 0 / 28 & 0 / 28 & 0 / 28 & 0 / 28 \\ \text { IET-3 } & 190 & 272 / 387 & 242 / 359 & 188 / 313 & 147 / 278 \\ \text { IET-4 } & 240 & 300 / 414 & 272 / 390 & 209 / 332 & 164 / 296 \\ \text { IET-5 } & 53 & 0 / 88 & 0 / 88 & 0 / 91 & 0 / 94 \\ \text { IET-6 } & 345 & 257 / 373 & 234 / 351 & 182 / 307 & 140 / 272 \\ \text { IET-7 } & 323 & 321 / 437 & 286 / 404 & 223 / 350 & 173 / 304\end{array}$

from gas grab bottle samples at $30 \mathrm{~min}$ $\ddagger$ (actual values at $20 \mathrm{~s}) /$ (assuming only steam/metal reactions) 

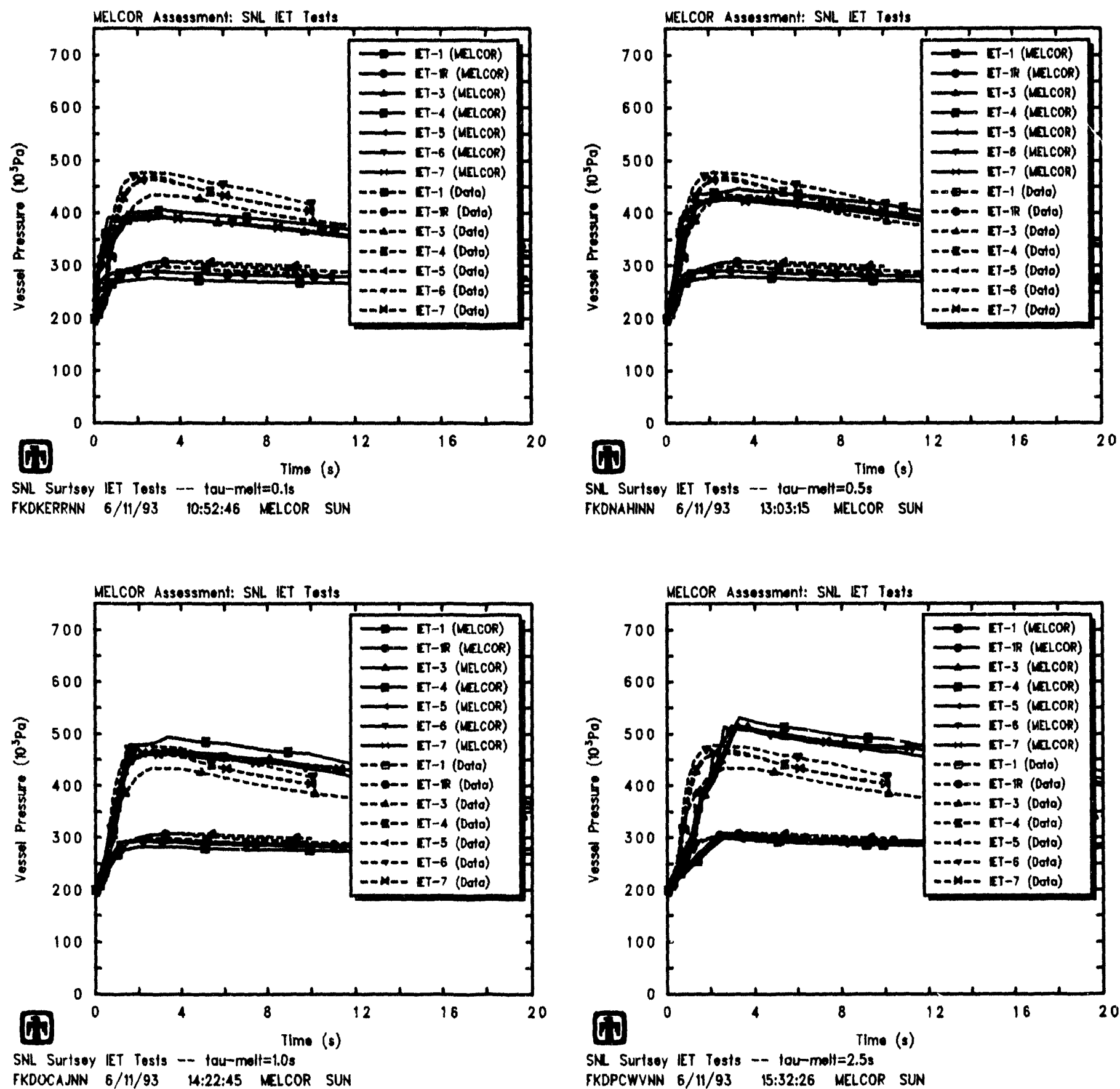

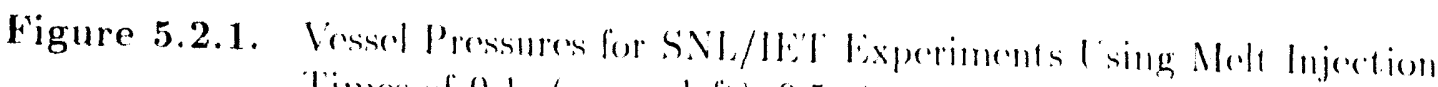

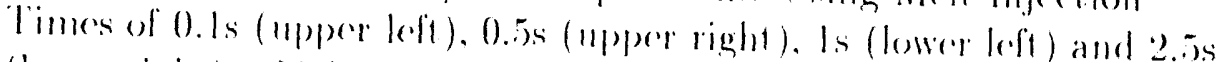
(lower right) Melt Injection Timing Somsitivity Sturly. 
as a fraction of the amount of hydrogen generated, but recall that we are comparing calculater values at 20s with experiment estimates based npon gas grab bottle samples taken at 30min; also recall that the test data indicates some late-time hydrogen burn must have occurred, and the analyses also show a gradual increase in the amomint of hydrogen burmed during the later time periods.)

The timing assumed for the melt injertion also has a very strong effect on the subcompartment tomperatures predicted, as illustrated in Figure 5.2.2. The calculated subcompartment temperatures rise during the assumed injection period, and begin dropping rapidy after molt injection stops, resulting in a strong peak at the end of the injection period. The calculated subcompartment temperature rise is obviously too carly with a melt injertion period of 0.1 s and also with a period of $0.5 s$ and much foo late with a medt injection period of 2.5s. The best agreement is found using a melt injection period of ls. but the different inflections in the test data curves and in the MVI, (O)R results suggest that the melt injection may not have occurred at a constant rate during the injection poriod.

Based upon the results for the vessel pressure, hydrogen generation and subeompartment temperatures. the remainder of our analyses were run with a melt injection period of $1 \mathrm{~s}$, with most of the injection ocenring during the second half of that period. (The actual values used were given in Table 3.1.1.) This $\leq 1 \mathrm{~s}$ melt injertion period is in reason-

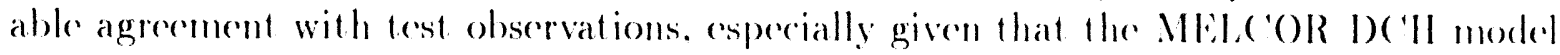
does not account for any localized timing delays due to debris transport to different locations.

\subsection{Melt Injection Amount}

Table 2.1.3 gave a debris recovery summary for the Surtsey Itel experiments. The total debris mass recovered from the vessel was usually greater than the initial themite charge due to melting of the inner wall of the crucible, vaporization of the fusible brass plug, ablation of concrete in the cavity and structures, and oxidation of metallic debris. Despite the careful duplication of the initial $43 \mathrm{~kg}$ thermite charge in the Surtsey IV: experiments, the different amounts of debris collected from the melt generator and from the vessel result in some uncertainty in the actual amount and romposition of melt injected into the vessel, as indicated in Table 5.3.1.

The majority of our MEL(') analyses simply specified the original $43 \mathrm{~kg}$ thermite charge mass, neglecting both the retention of any debris in the melt generator and the addition of any debris due to melting of the inner wall of the crucible, vaporization of the lusible brass plug, ablation of concrete in the cavity and structures, and oxidation of metallic debris. (The same assumption was made in the (ONTAIN analyses [27].) To help determine the effect of the injection mass souree mucertainty, calculations were done in which the total melt mass injected was reduced to $80 \%$ and $90 \%$, and increased to $110 \%$, of the basecase $13 \mathrm{~kg}$ melt souree. The fractional amomts of $\mathrm{Al}, \mathrm{O}_{3}$, Fe and ( $\mathrm{r}$ in the debris, the debris temperature and fractional distribution, and the fraction injerted vis time were unchanged. 
Table 5.2.1. Hydrogen Generation for the SNL/IET Experiments - Melt Injection Timing Sensitivity Study

\begin{tabular}{|c|c|c|c|c|c|}
\hline \multirow[t]{4}{*}{ Experiment } & & \multicolumn{4}{|c|}{ Hydrogen Produced (gm-moles) } \\
\hline & \multirow[t]{3}{*}{ Dataf } & \multicolumn{4}{|c|}{ MELCOR $\ddagger$} \\
\hline & & \multicolumn{4}{|c|}{$\tau_{\text {Debris }}=$} \\
\hline & & $0.1 \mathrm{~s}$ & $0.5 \mathrm{~s}$ & $1 \mathrm{~s}$ & $2.5 \mathrm{~s}$ \\
\hline IET-1 & 233 & $144 / 129$ & $207 / 189$ & $293 / 271$ & $458 / 418$ \\
\hline IET-1R & 2.48 & $134 / 1.12$ & $192 / 197$ & $271 / 270$ & $439 / 418$ \\
\hline IET-3 & 227 & $146 / 269$ & $157 / 310$ & $239 / 374$ & $352 / 47.4$ \\
\hline IET-4 & 303 & $99 / 278$ & $162 / 319$ & $251 / 390$ & $346 / 47.4$ \\
\hline IET -5 & 319 & $108 / 208$ & $167 / 258$ & $241 / 322$ & $390 / 147$ \\
\hline IET-6 & 319 & $97 / 269$ & $160 / 313$ & $239 / 374$ & $351 / 472$ \\
\hline IET-7 & 274 & $96 / 267$ & $154 / 306$ & $231 / 365$ & $350 / 470$ \\
\hline
\end{tabular}

fend-of-calculation values at $20 \mathrm{~s}$

$f($ actual values at $20 \mathrm{~s}) /$ (assuming only steam/metal reactions)

Table 5.2.2. Hydrogen Combustion for the SNL/IE'T Experiments - Melt Injection Timing Sensitivity Study

Experiment

$$
\begin{aligned}
& \text { Data† MELCOR } \ddagger \\
& \begin{array}{llll}
\multicolumn{5}{c}{\tau_{\text {Debris }}=} \\
0.1 \mathrm{~s} & 0.5 \mathrm{~s} & 1 \mathrm{~s} & 2.5 \mathrm{~s}
\end{array}
\end{aligned}
$$

$\begin{array}{lccccc}\text { IET-1 } & 3 & 0 / 4 & 0 / 4 & 0 / 4 & 0 / 4 \\ \text { IET-1R } & 11 & 0 / 26 & 0 / 26 & 0 / 26 & 0 / 26 \\ \text { IET-3 } & 190 & 87 / 262 & 135 / 290 & 191 / 331 & 255 / 391 \\ \text { IET-4 } & 240 & 93 / 273 & 145 / 305 & 214 / 358 & 272 / 413 \\ \text { IET-5 } & 53 & 0 / 109 & 0 / 103 & 0 / 97 & 0 / 95 \\ \text { IET-6 } & 345 & 82 / 257 & 129 / 286 & 184 / 325 & 246 / 385 \\ \text { IET-7 } & 323 & 94 / 267 & 150 / 305 & 225 / 365 & 333 / 466\end{array}$

fend-of-calculation values at $20 \mathrm{~s}$

$\ddagger($ actual values at $20 \mathrm{~s}) /$ (assuming only steam/metal reactions) 


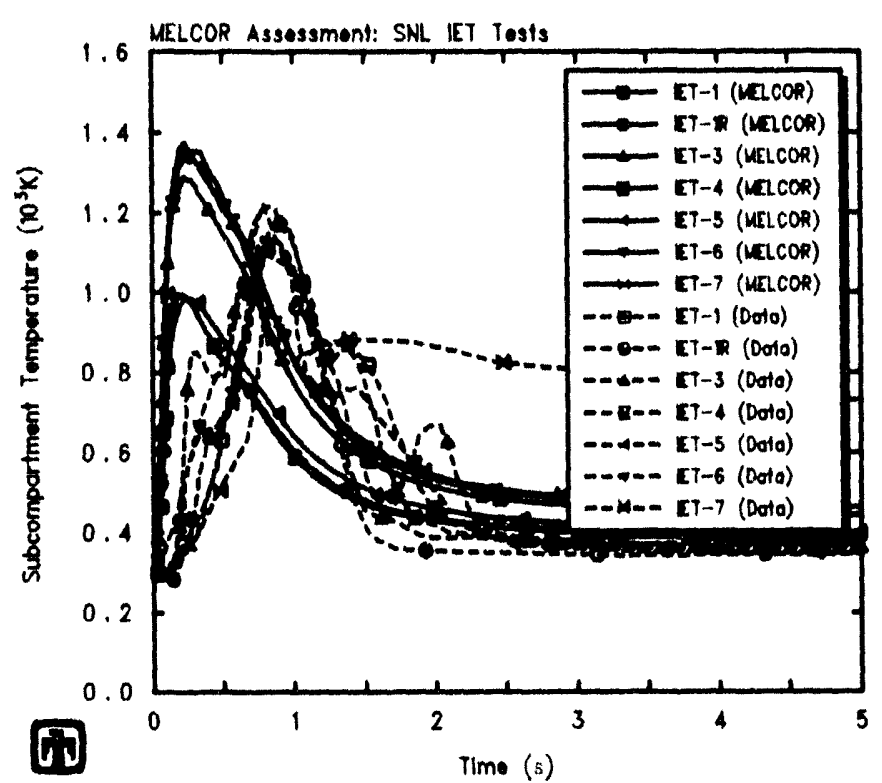

SNL Surtsoy IET Tosts - tau-molt $=0.15$

FKDKERRNN $6 / 11 / 93 \quad 10: 52: 46$ MELCOR SUN

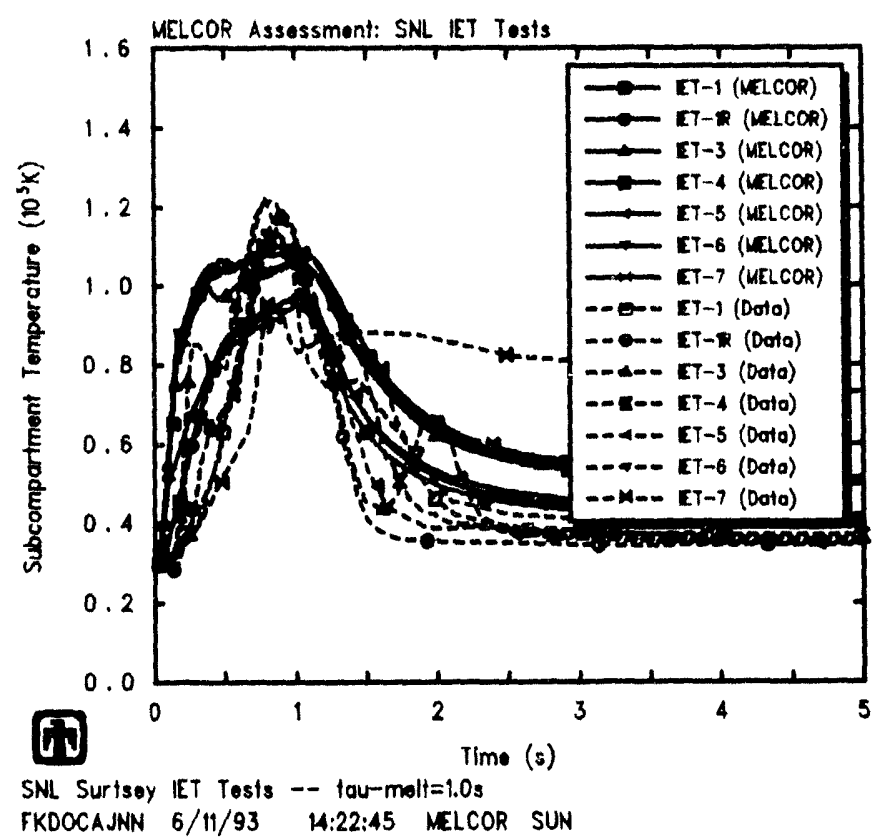

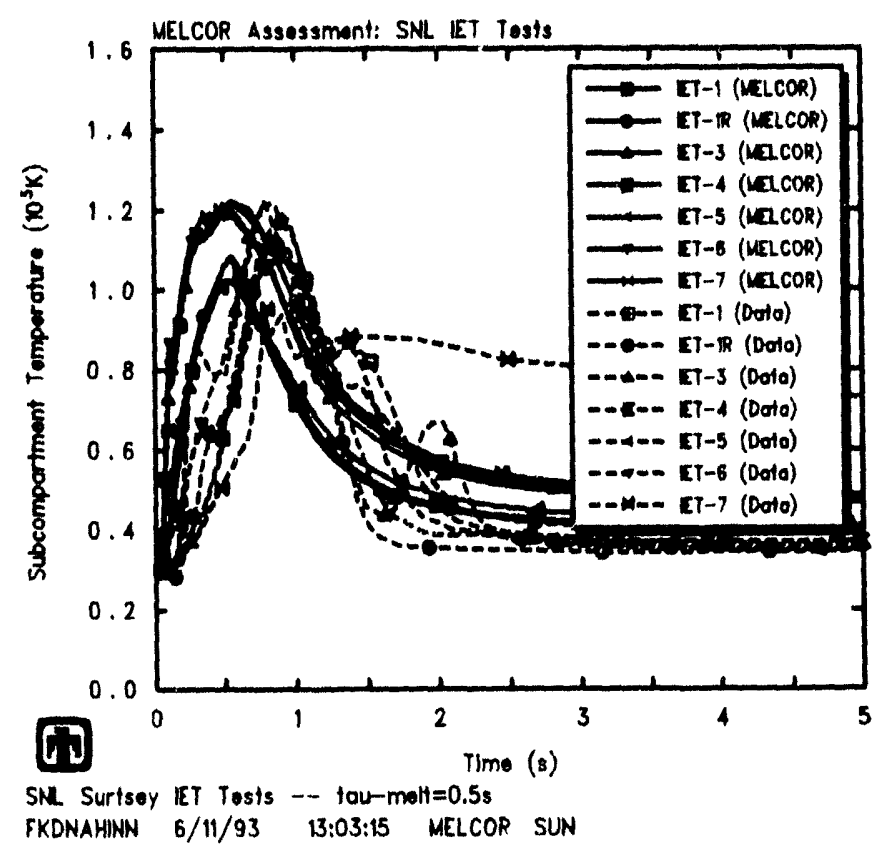

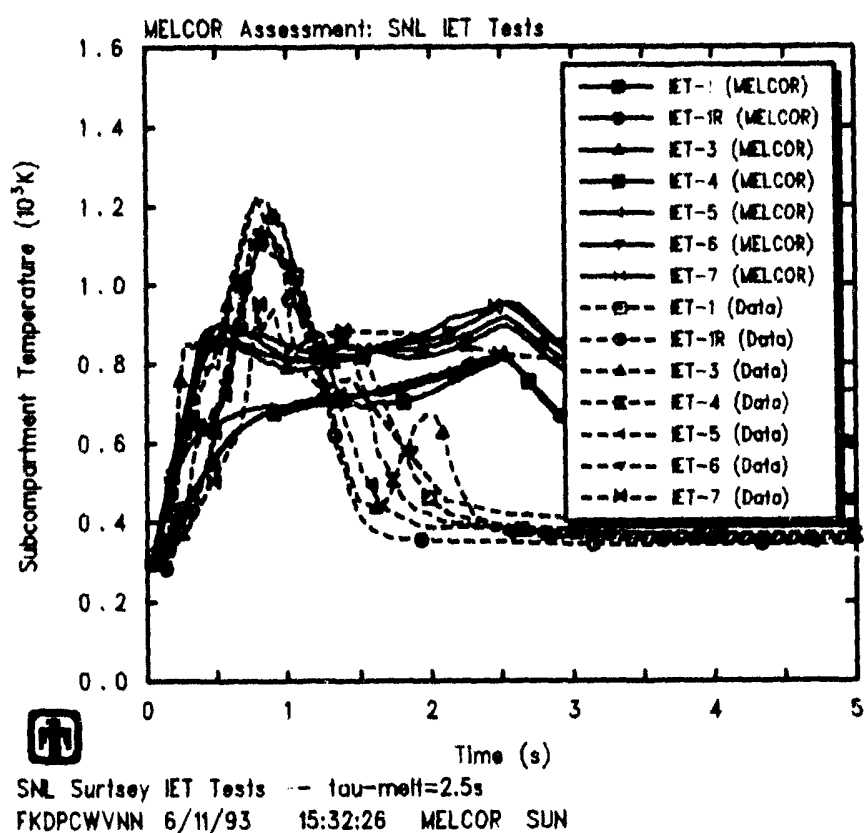

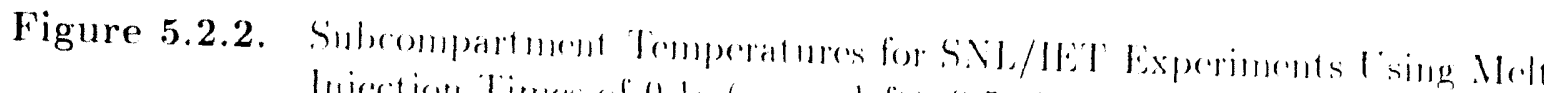

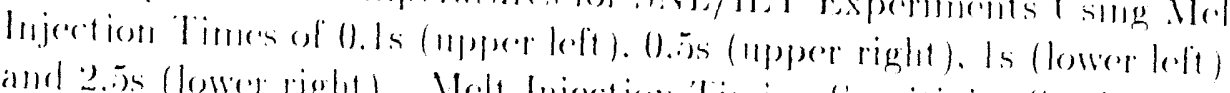

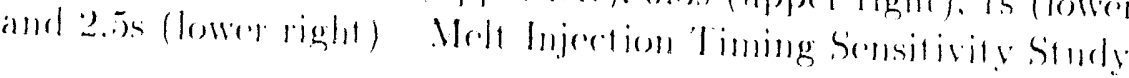


Table 5.3.1. Debris Masses for the SNL/IET Experiments - Melt Injection Amount Sensitivity Study

IET-1 IET-1R IET-3 IET-4 IET-5 IE'T-6 IET'-7

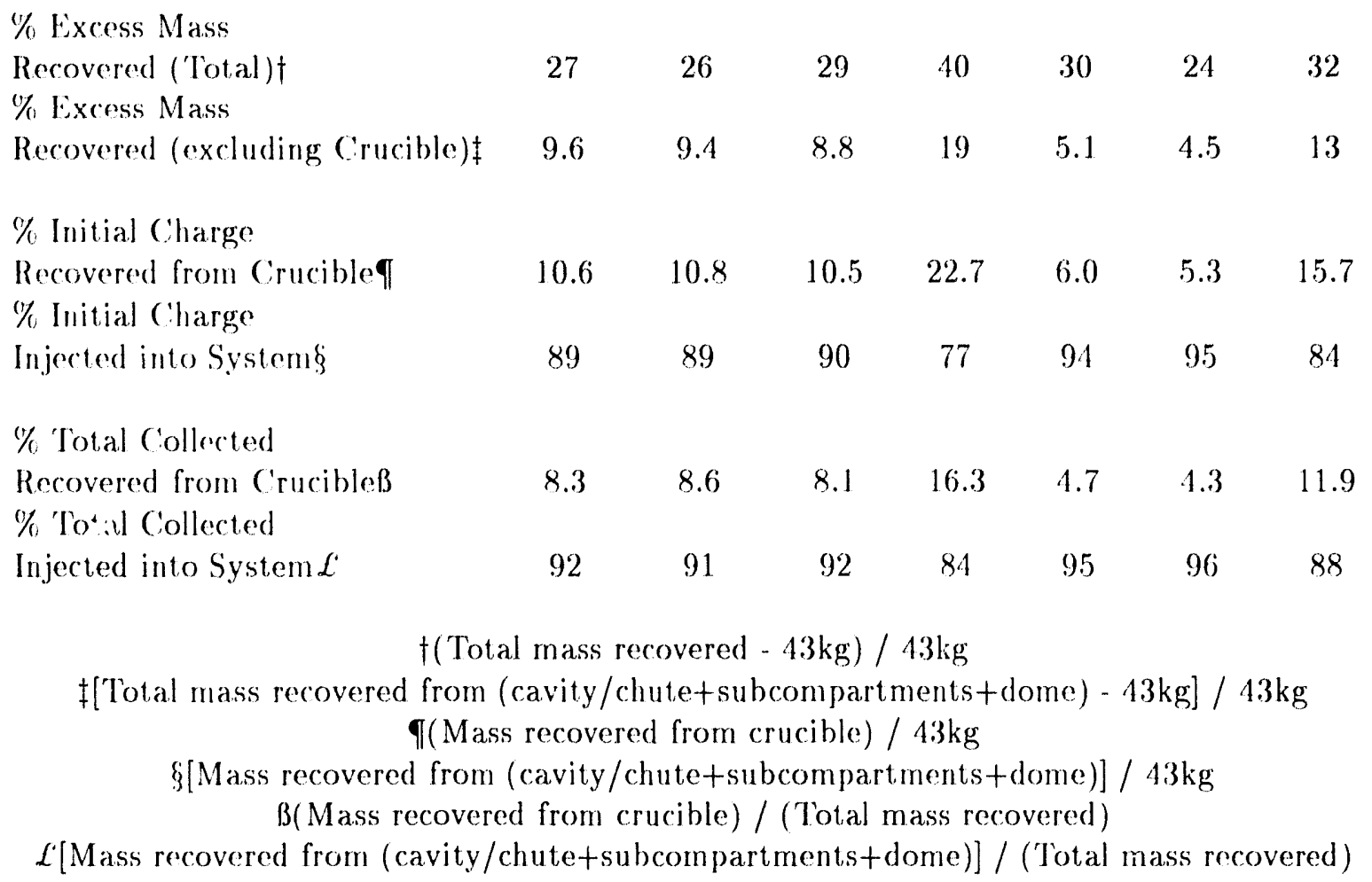


Figure 5.3.1 shows pressures in the vessel predicted using various melt amounts, together with experimental data for comparison. As would be expented, the vessel pressurization increases as more melt mass is injected during the HP'ME. Also, as seen in many of our other sensitivity study analyses, the effect is larger for those tests with hydrogen burn occurring than in the cases with no hydrogen burn.

Tables 5.3.2 and 5.3.3 present the amounts of hydrogen generated and burned, respertively, in these various cases. Test data estimates of the amounts of hydrogen produced

and burned are included for reference. There is a small increase in both hydrogen production and combustion with increasing melt injection amount.

Figure 5.3.2 gives subcompartment temperatures calculated using various melt amounts, together with experimental data. As seen in the hydrogen production and combustion, there is a small increase in subcompartment temperature with increasing melt injection amount.

\subsection{Melt Injection Temperature}

T'est data indicated a debris temperature of $2300 \mathrm{~K}$, which was the value used in our MELCOR reference analyses whose results were given in Section 4 . As a sensitivity study, calculations were run with the debris temperature set to $2000 \mathrm{~K}, 2300 \mathrm{~K}, 2500 \mathrm{~K}$ and $3000 \mathrm{~K}$. Values in the $2300 \mathrm{~K}-2500 \mathrm{~K}$ range were considered most likely in the experiments; $2000 \mathrm{~K}$ and $3000 \mathrm{~K}$ were selected as bounding values based upon zircaloy melting at 2100 )$2200 \mathrm{~K}$ and on $\mathrm{UO}_{2}$ molting at $3113 \mathrm{~K}$.

Vessel pressures predicted varying the rebris temperature are presented in ligure 5.4.1, together with test data. The effect of increasing the melt temperature is to increase the vessel pressures calculated. 'Tahles 5.4 .1 and 5.4 .2 summarize the amounts of hydrogen generated and burned, respectively, with very litte dependence on melt temperature visible.

This debris temperature variation has the strongest effect on the subcompartment temperatures predicted, as indicated in Figure 5.4.2. 'The calculated subcompartment, temperatures increase with increasing debris temperature, with a $1000 \mathrm{~K}$ increase in debris temperature producing a $\sim 500 \mathrm{~K}$ increase in subcompartment peak temperatures.

\subsection{Melt Injection Distribution}

As noted at the start of Section 5.2, the MELCOR D)(II model does not model transient transport of debris into and through the system, but instead immediately places the debris at its ultimate destination. The debris fractions placed in each control volume. and on each heat structure are controlled solely by user input. In these IE'T analyses, the debris injected was all placed in various control volume atmospheres and then allowed to settle out onto floor heat structures; no debris was specified to be deposited directly onto any heat structures. 

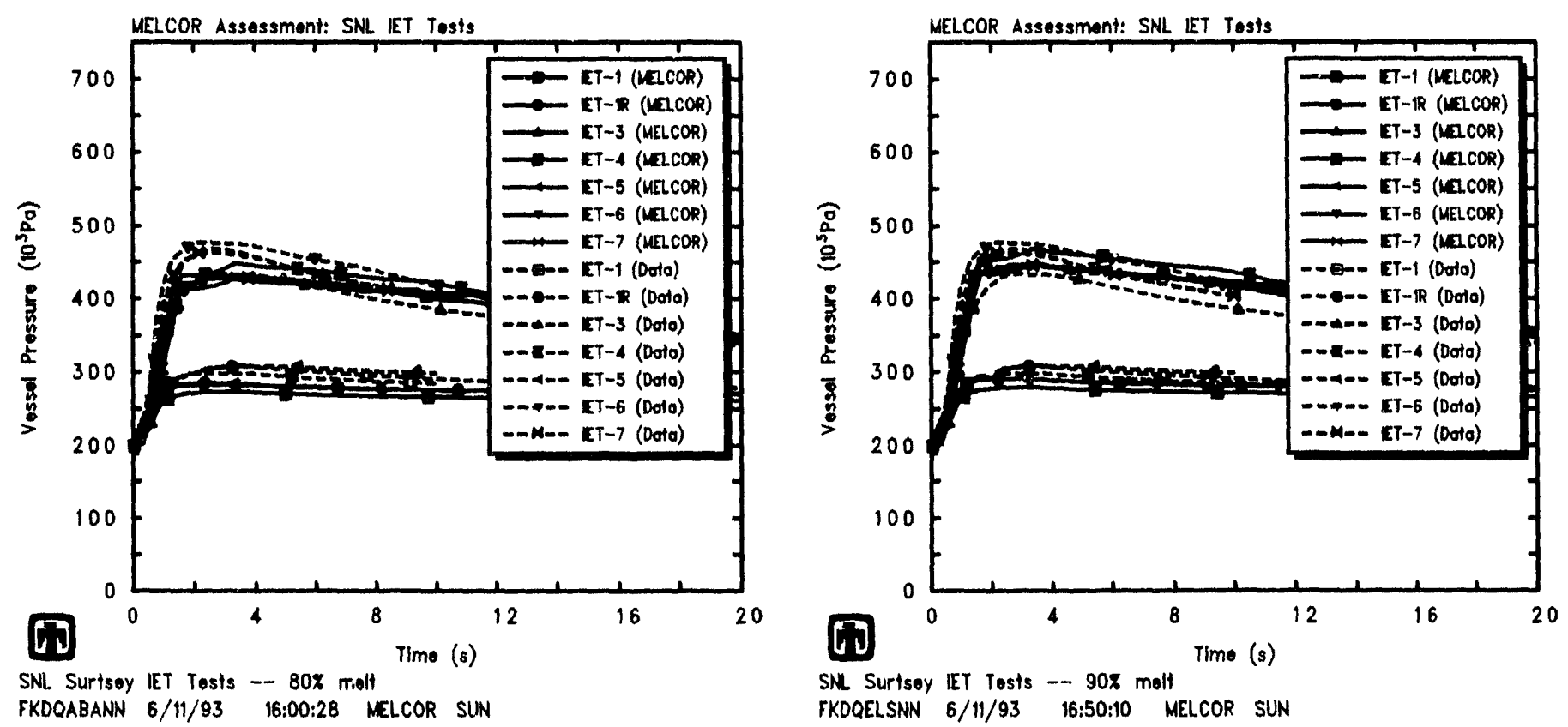

SKL Surtsoy IET Tosts - 902 molt

FKDQELSNN 6/11/93 16:50:10 MELLOR SUN
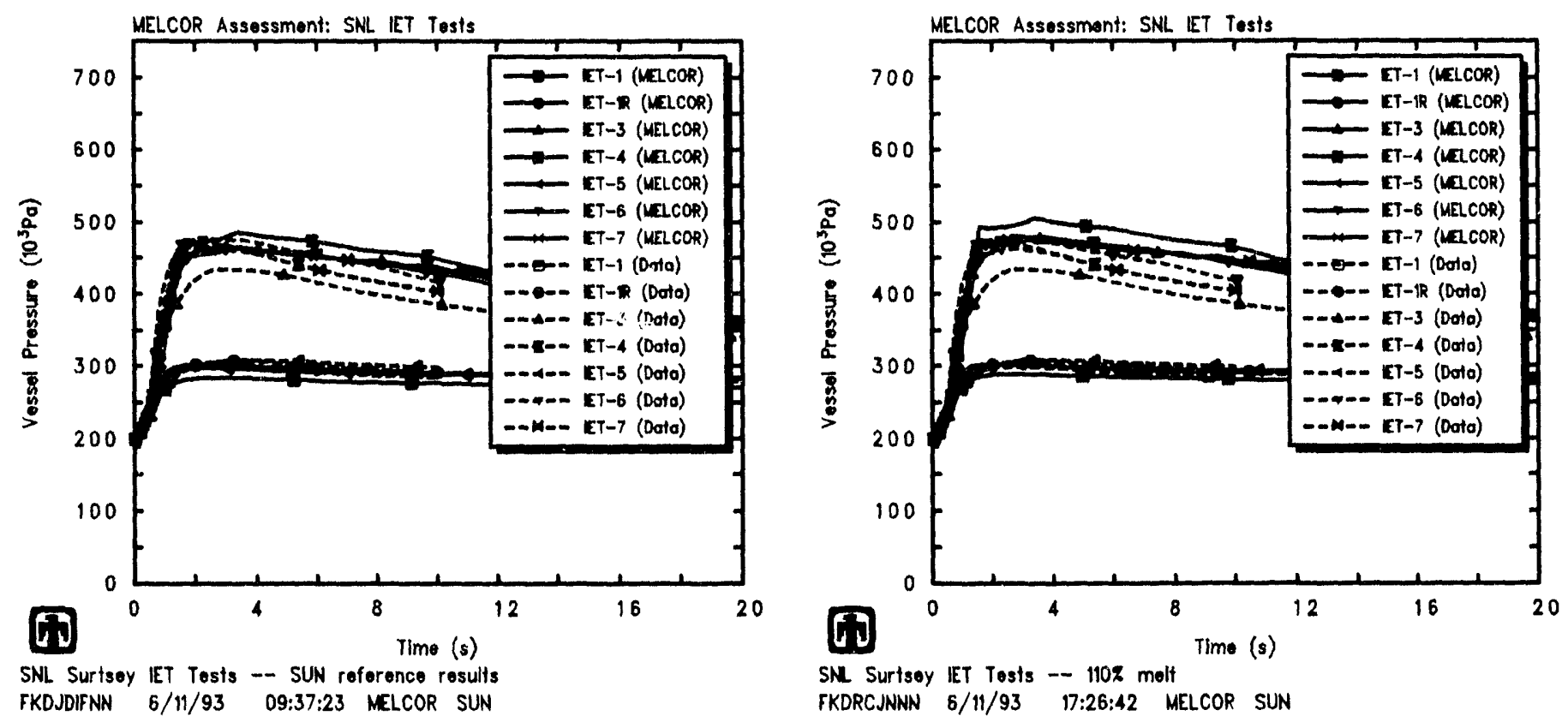

SNL Surtsey IET Tests -- SUN reference results

TKDRCJNNN 6/11/93 17:26:42 MELCOR SUN

Figure 5.3.1. Vessel Pressures for SNL/LET Experiments Using Melt Masses of $80 \%$ (upper loft), 90\% (upper right), 100\% (lower left) and 110\% (lower right) the Initial Charge - Melt Injection Amount Sensitivity Study 
Table 5.3.2. Hydrogen Generation for the SNL/IET Experiments - Melt Injection Amount Sensitivity Study

Experiment

\begin{tabular}{lccccc} 
Experiment & \multicolumn{5}{c}{ Hydrogen Produced (gm-moles) } \\
& Data $\dagger$ & \multicolumn{4}{c}{$\begin{array}{c}\text { MELCOR } \ddagger \\
\text { (nitial Charge) }\end{array}$} \\
& & 80 & 90 & 100 & 110 \\
IET-1 & 233 & $249 / 231$ & $268 / 248$ & $286 / 266$ & $301 / 278$ \\
IET-1R & 248 & $227 / 231$ & $248 / 250$ & $266 / 267$ & $281 / 280$ \\
IET-3 & 227 & $199 / 303$ & $215 / 326$ & $232 / 352$ & $245 / 371$ \\
IET-4 & 303 & $211 / 312$ & $229 / 340$ & $243 / 361$ & $262 / 389$ \\
IET-5 & 319 & $208 / 269$ & $225 / 292$ & $240 / 313$ & $255 / 334$ \\
IET-6 & 319 & $201 / 307$ & $216 / 329$ & $236 / 354$ & $249 / 376$ \\
IET-7 & 274 & $194 / 300$ & $212 / 325$ & $229 / 351$ & $242 / 369$
\end{tabular}

†from gas grab bottle samples at $30 \mathrm{~min}$

$\ddagger$ (actual values at $20 \mathrm{~s}) /$ (assuming only steam/metal reactions)

Table 5.3.3. Hydrogen Combustion for the SNL/IET Experiments - Melt Injection Amount Sensitivity Study

Experiment

$$
\begin{array}{ccc}
\text { Data } \nmid \begin{array}{c}
\text { Hydrogen Burned (gm-moles) } \\
\text { MELCOR } \ddagger \\
\text { (\% Initial Charge) }
\end{array} \\
& \multicolumn{4}{c}{110}
\end{array}
$$

$\begin{array}{lccccc}\text { IET-1 } & 3 & 0 / 4 & 0 / 4 & 0 / 4 & 0 / 4 \\ \text { IET-1R } & 11 & 0 / 28 & 0 / 28 & 0 / 28 & 0 / 28 \\ \text { IET-3 } & 190 & 161 / 268 & 173 / 289 & 188 / 313 & 197 / 328 \\ \text { IET-4 } & 240 & 181 / 286 & 197 / 311 & 209 / 332 & 225 / 357 \\ \text { IET-5 } & 53 & 0 / 77 & 0 / 84 & 0 / 91 & 0 / 99 \\ \text { IET-6 } & 345 & 156 / 267 & 168 / 287 & 182 / 307 & 192 / 326 \\ \text { IET-7 } & 323 & 189 / 300 & 206 / 323 & 223 / 350 & 236 / 368\end{array}$

ffrom gas grab bottle samples at $30 \mathrm{~min}$ $\ddagger$ (actual values at $20 \mathrm{~s}) /$ (assuming only steam/metal reactions) 

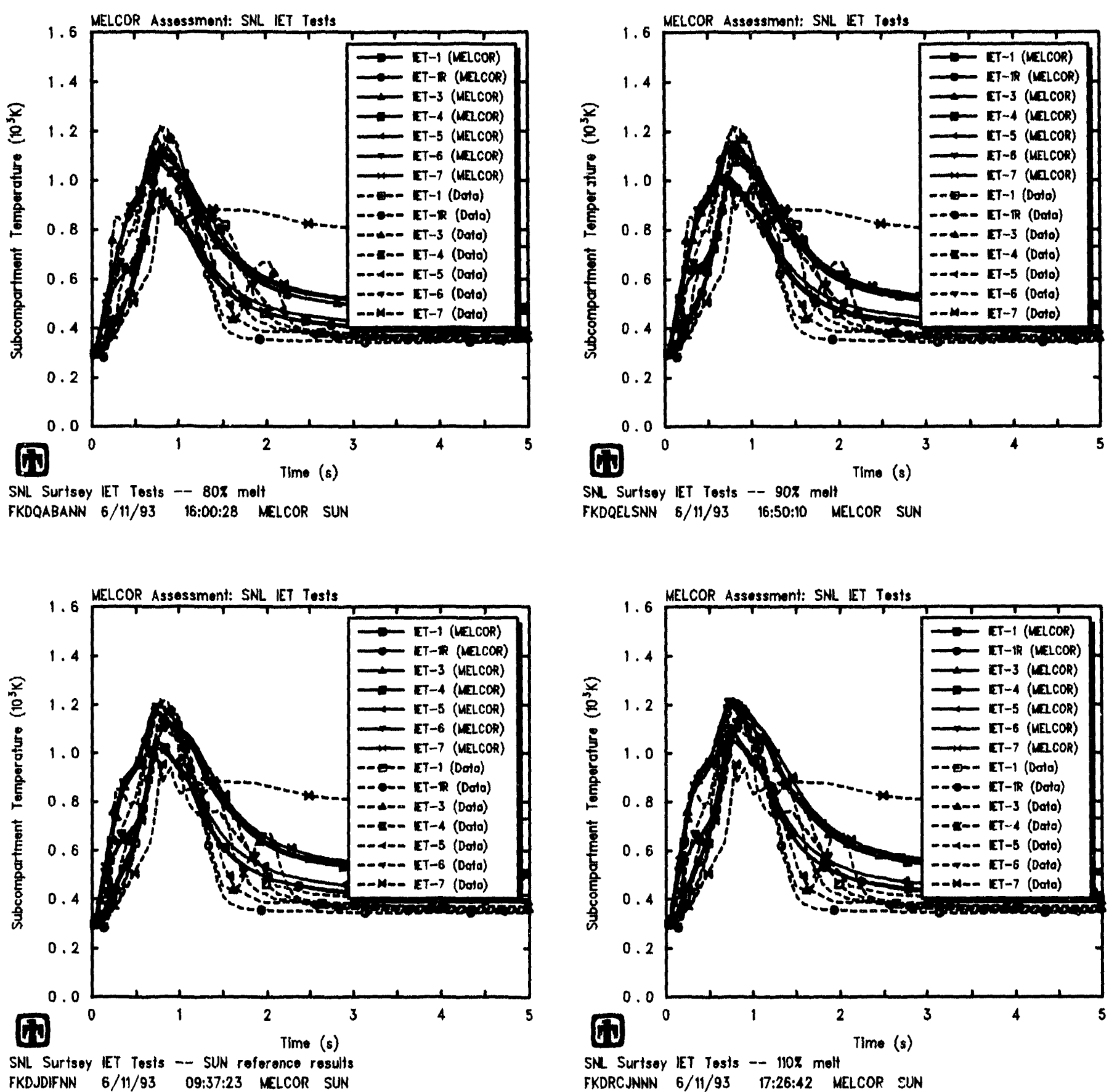

Figure 5.3.2. Subcompartment Temperatures for SNI,IET Experiments Esing Molt Masses of $80 \%$ (upper left), $90 \%$ (upper right), $100 \%$ (lower left) and $110 \%$ (lower right) the Initial ('harge Melt lnjection Amount Sensitivity Sturly 

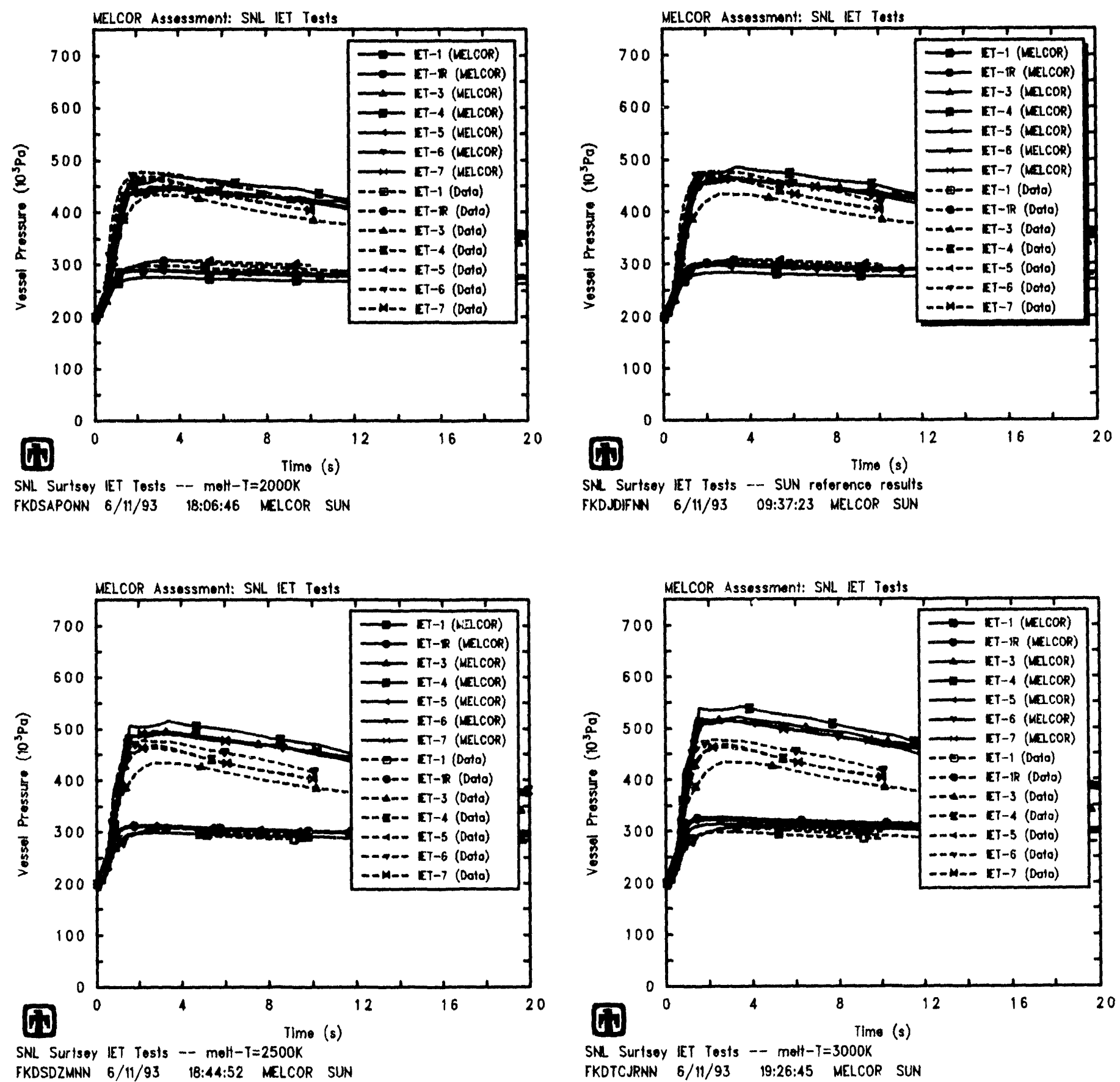

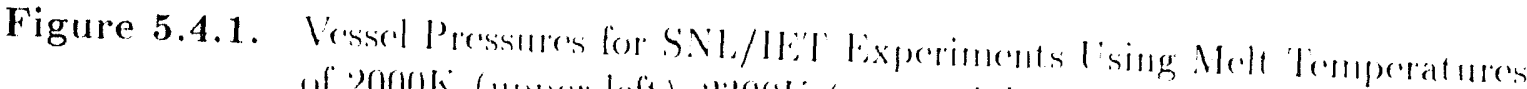

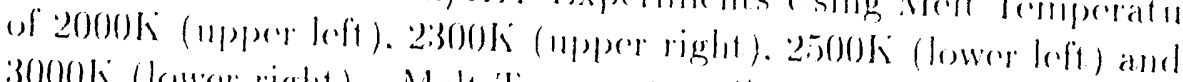

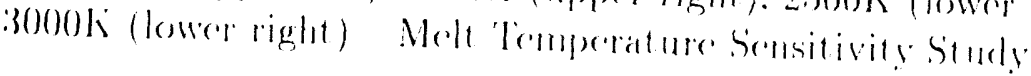


Table 5.4.1. Hydrogen Generation for the SNL/IET Experiments -- Melt Temperature Sensitivity Study

Experiment

\begin{tabular}{|c|c|c|c|c|c|}
\hline \multirow[t]{4}{*}{ Experiment } & \multicolumn{5}{|c|}{ Hydrogen Produced (gm-moles) } \\
\hline & \multirow[t]{3}{*}{ Data† } & \multicolumn{4}{|c|}{ MELCOR $\ddagger$} \\
\hline & & \multicolumn{4}{|c|}{$T_{\text {Debris }}=$} \\
\hline & & $2000 \mathrm{~K}$ & $2300 \mathrm{~K}$ & $2500 \mathrm{~K}$ & $3000 \mathrm{~K}$ \\
\hline IET-1 & 233 & $276 / 255$ & $286 / 266$ & $301 / 281$ & $313 / 293$ \\
\hline IET-1R & 248 & $254 / 253$ & $266 / 267$ & $280 / 286$ & $295 / 298$ \\
\hline IET-3 & 227 & $221 / 341$ & $232 / 352$ & $248 / 364$ & $261 / 374$ \\
\hline IET-4 & 303 & $238 / 355$ & $243 / 361$ & $260 / 374$ & $275 / 387$ \\
\hline IET-5 & 319 & $228 / 301$ & $240 / 313$ & $257 / 330$ & $269 / 343$ \\
\hline IET-6 & 319 & $230 / 348$ & $236 / 354$ & $253 / 367$ & $256 / 370$ \\
\hline IET-7 & 274 & $218 / 338$ & $229 / 351$ & $248 / 363$ & $256 / 370$ \\
\hline
\end{tabular}

ffrom gas grab bottle samples at $30 \mathrm{~min}$ $\ddagger($ actual values at $20 \mathrm{~s}) /$ (assuming only steam/metal reactions)

Table 5.4.2. Hydrogen Combustion for the SNL/IET Experiments - Melt Temperature Sensitivity Study

Experiment

\begin{tabular}{ccc} 
Data $\begin{array}{c}\text { Hydrogen Burned (gm-moles) } \\
\text { MELCOR } \ddagger \\
\end{array}$ & \multicolumn{3}{c}{$T_{\text {Debris }}=$} \\
& $2000 \mathrm{~K} \quad 2300 \mathrm{~K} \quad 2500 \mathrm{~K} \quad 3000 \mathrm{~K}$
\end{tabular}

$\begin{array}{lccccc}\text { IET-1 } & 3 & 0 / 4 & 0 / 4 & 0 / 4 & 0 / 4 \\ \text { IET-1R } & 11 & 0 / 28 & 0 / 28 & 0 / 28 & 0 / 28 \\ \text { IET-3 } & 190 & 176 / 301 & 188 / 313 & 204 / 325 & 218 / 336 \\ \text { IET-4 } & 240 & 201 / 323 & 209 / 332 & 227 / 345 & 243 / 359 \\ \text { IET-5 } & 53 & 0 / 92 & 0 / 91 & 0 / 92 & 0 / 92 \\ \text { IET-6 } & 345 & 174 / 299 & 182 / 307 & 199 / 319 & 207 / 327 \\ \text { IET-7 } & 323 & 212 / 337 & 223 / 350 & 240 / 360 & 248 / 366\end{array}$

tfrom gas grab bottle samples at $30 \mathrm{~min}$ $\ddagger($ actual values at $20 \mathrm{~s}) /$ (assuming only steam/metal reactions) 

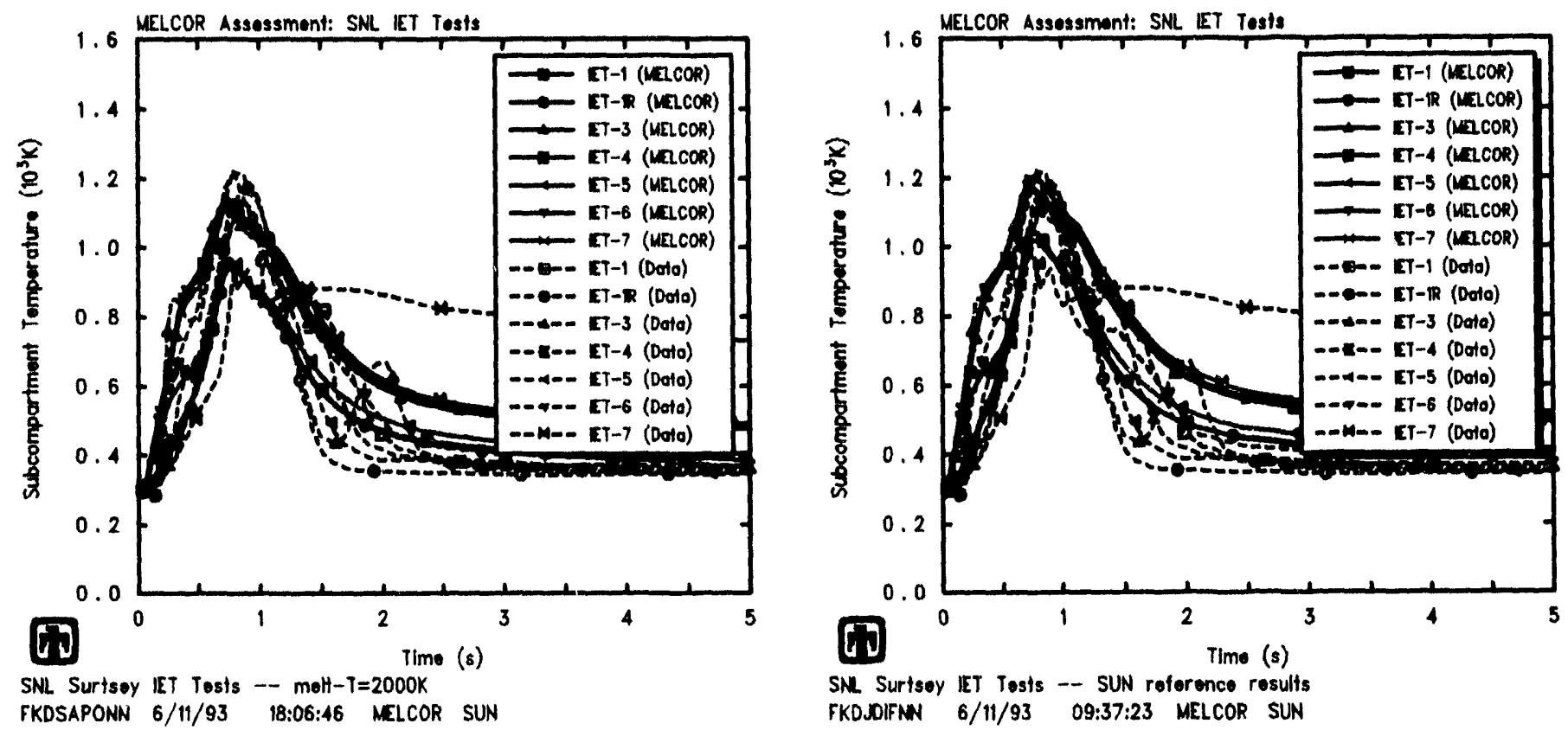

SNe Surtsoy IET Tosts -- SUN roference results FKDJOIFAN 6/11/93 09:37:23 MELCOR SUN
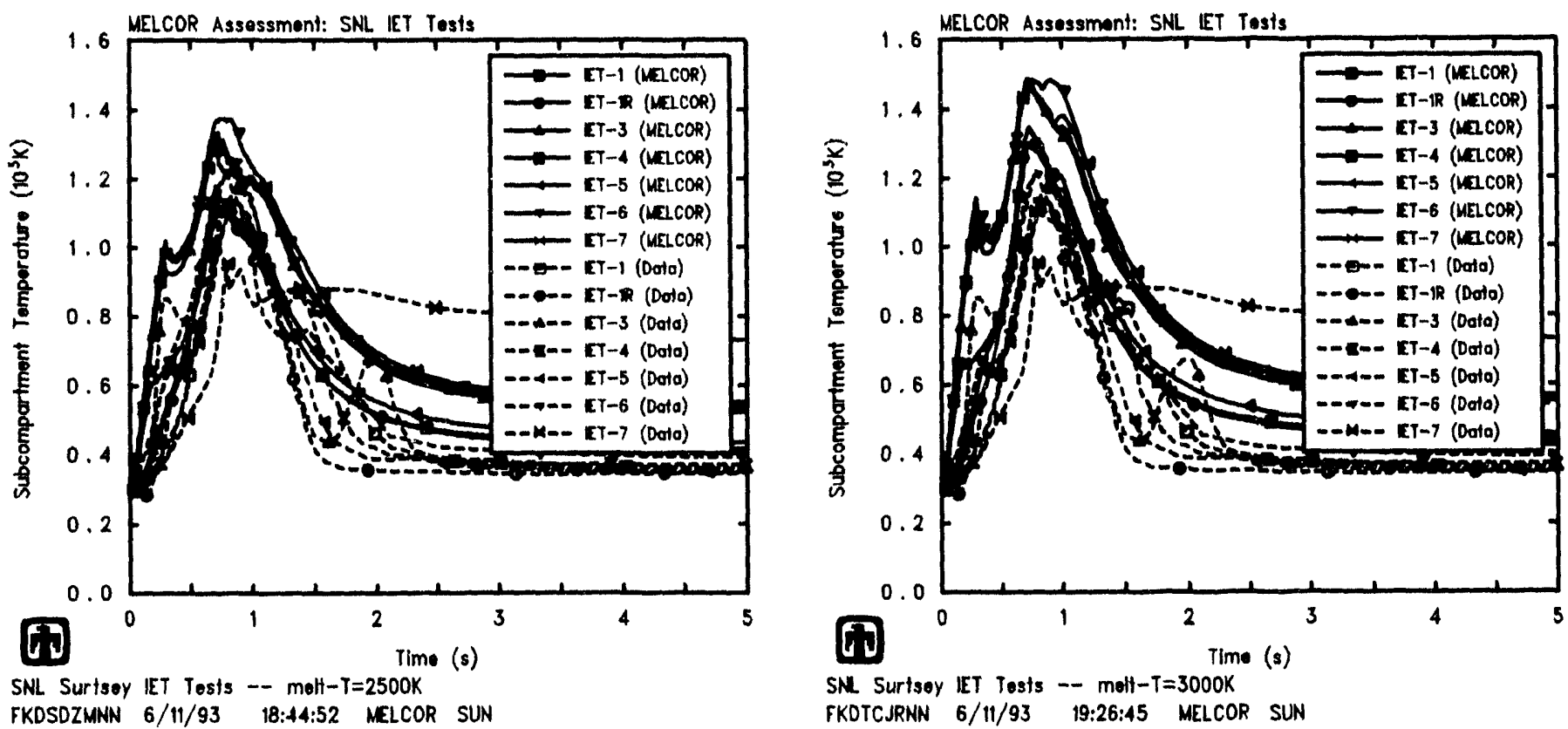

Figure 5.4.2. Subcompartment Temperatures for SNL/IET Experiments Ising Molt

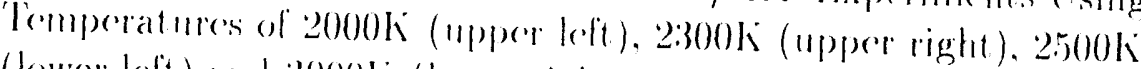
(lower loft) and $30000 \mathrm{k}$ (lowere right) Molt Temperature Sensitivity 
Table 5.5.1. Debris Masses for the SNL/IET Experiments - Debris Distribution Sensitivity Study

\section{IET-1 IET-1R IET-3 IET-4 IET-5 IET-6 IE'T-7}

$\begin{array}{lccccccc}\text { Distribution (\%) } & & & & & & & \\ \text { Cavity/Chute } & 14 & 27 & 33 & 17 & 38 & 17 & 27 \\ \text { Subcompartments } & 76 & 66 & 61 & 59 & 59 & 72 & 68 \\ \text { Dome } & 10 & 7 & 6 & 14 & 0 & 0 & 5\end{array}$

There is no guidance from the experiments on how much debris stuck to walls immediately rather than circulating and falling through the atmosphere before settling. The experimental debris distribution is based upon post-test collection of debris from the vessel and does not distinguish between debris deposited immediately or later. We assumed it was not likely that a large fraction of the debris immediately adhered permanently to a structure surface, given the highly turbulent conditions visible in the video records.

Table 2.1.3 presented a debris recovery summary for the Surtsey IET experiments. Table 5.5.1 gives melt distribution patterns derived from that test data. Although there were small differences in the test data debris distributions, the FDI input debris distribution was kept the same in our MELCOR input for all tests analyzed (with $15 \%$ and $10 \%$ of the debris input to the cavity and chute, respectively, $65 \%$ to the subcompartments and $10 \%$ to the dome).

However, in most plant analyses, there will be no equivalent data set providing guidance on HPME melt distribution. To evaluate the effect of the debris distribution assumed on the overall DCH behavior calculated, calculations were done in which the experimental debris distribution for each test was used, and in which $65 \%$ of the debris was placed either in the cavity and chute (with $25 \%$ in the subcompartments and $10 \%$ in the dome) or in the dome (with $25 \%$ in the cavity and chute and $10 \%$ in the subcompartments).

Figure 5.5.1 shows pressures in the vessel predicted using the various melt distributions, together with experimental data. There is very little difference seen in using a single basecase debris distribution or in using more experiment-specific distributions; this is not surprising because the variations are gerierally quite small. The major difference is seen for the calculation with most $(65 \%)$ of the debris specified to go to the dome (with $25 \%$ in the cavity and chute and $10 \%$ in the subcompartments). The higher pressures calculated in that case are due to the deposition of a majority of the debris into a volume with a longer characteristic settling time (proportional to the volume height) which allows more time for oxidation and especially for heat transfer from airborne debris to the atmosphere; other effects may also be involved to some extent, e.g. a proportionally greater atmospheric heat capacity and less atmosphere-to-structure heat loss. The characteristic 
settling times in the cavity, chute and subcompartments are roughly similar, and there is therefore no big difference found in atmosphere heating and vessel pressurization wher her most of the debris is assumed to go to the cavity/chute or to the subcompartments.

Tables 5.5 .2 and 5.5 .3 present the amounts of hydrogen generated and burmed, resperetively, in these various cases. 'lest data estimates of the amomnts of hydrogen produced and burned are included for reference. Again, there is very little difference seen in using a single basecase debris distribution or in using more experiment-specifie distributions; this is not surprising because the variations are generally guite small. There is somewhat more hydrogen produced when more of the debris is assumed to go to the cavily and chute; these regions are closer to the blowdown steam accummlator sonrece, and oxidation is therefore less likely to be limited by steam avalability in this case. For the same rea. son, less hydrogen is predicted to be produced in IF:T-1 and IF: I - IR when most of the debris is assimmed to go to the dome; the dome is further downst ream from the blowrlown steam accumulator source, and oxidation is therefore more limited by stram availability in this region for these two tests. In the remainder of the experiment simmlations assuming most of the debris going to the dome, much less hydrogen production is calculated berause most of the debris is being oxidized by the relatively large amount of free oxygen available in the dome which, mulike steam oxidation, produces no hydrogen as a reaction product. (Note that, in the MLIC(OR Fl)I IIPML model, a hierarelyy is assumed with debris oxidation consmming free oxygen before steam.)

Figure 5.5.2 gives subcompartment temperatures caleulated using varions melt anomuts, together with experimental data. As found in the pressure and hydrogen production and combustion comparisons, there is very little difference seen in using a single basecase debris distribution or in using more experiment-specifie distributions, beranse the testto-test debris-distribution variations are generally quite small. 'The calculated suldeom. partment temperatures are significantly lower when the majority of the debtris is assmmerl to go to either the dome or to the cavity/chute; as would be expected, the predieted temperatures in the dome and/or in the cavity and chute increase if more debris is assumed to go to the corresponding volume. 

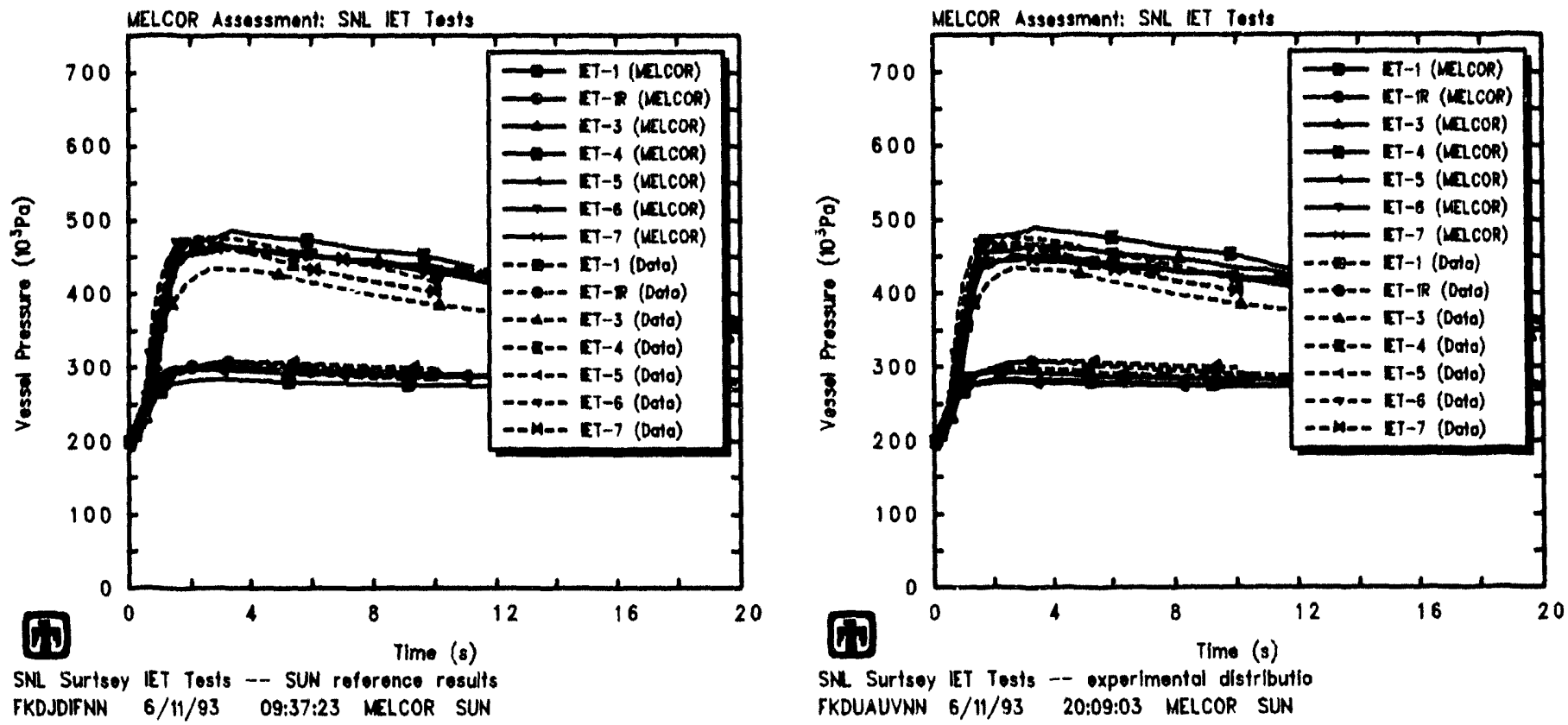

SNe Surtsoy IET Tosts -- oxporimental distributio

FKDUAUVNN 6/11/93 20:09:03 MELCOR SUN
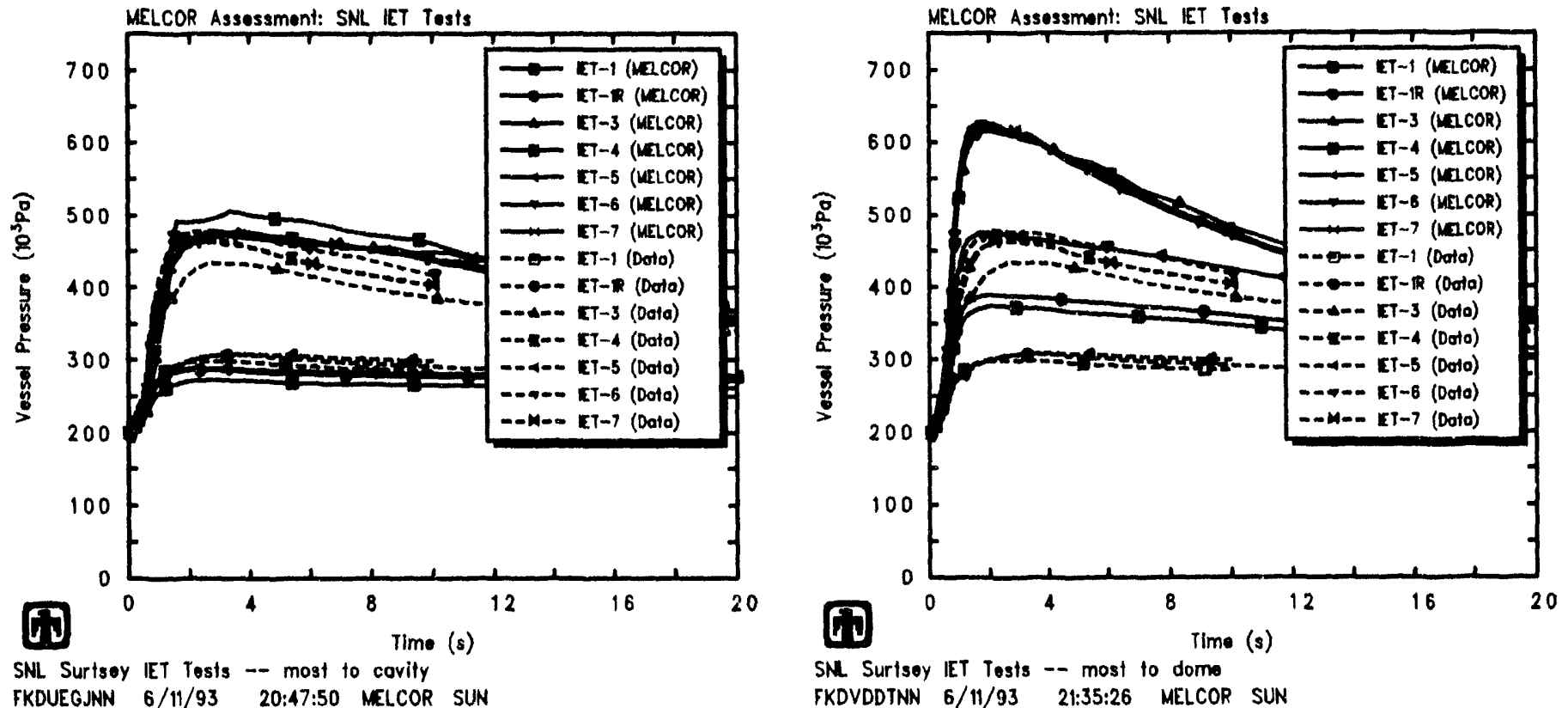

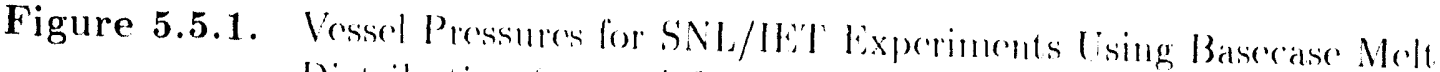
Distribution (upper left). Lxperimental Melt Distribution (upper right), Molt Mostly into (avity (lower left) and Molt Mostly into Dome (lower right) Melt Distribution Sensitivity Study 
Table 5.5.2. Ilydrogen Generation for the SNL/IET Experiments - Melt Distribution Sensitivity Study

\begin{tabular}{lccccc} 
Experiment & Datał & \multicolumn{4}{c}{ Hydrogen Produced (gm-moles) } \\
Basecase & $\begin{array}{c}\text { MELCOR } \ddagger \\
\text { Experimental } \\
\text { Distribution } \\
\text { Distribution }\end{array}$ & $\begin{array}{c}\text { Mostly into } \\
\text { Cavity }\end{array}$ & $\begin{array}{c}\text { Mostly into } \\
\text { Dome }\end{array}$ \\
IET-1 & 233 & $286 / 266$ & $251 / 232$ & $332 / 307$ & $245 / 233$ \\
IET-1R & 248 & $266 / 267$ & $272 / 272$ & $315 / 311$ & $226 / 239$ \\
IET-3 & 227 & $232 / 352$ & $266 / 354$ & $279 / 378$ & $122 / 497$ \\
IET-4 & 303 & $243 / 361$ & $220 / 367$ & $295 / 396$ & $122 / 496$ \\
IET-5 & 319 & $240 / 313$ & $273 / 321$ & $288 / 348$ & $144 / 490$ \\
IET-6 & 319 & $236 / 354$ & $214 / 336$ & $285 / 385$ & $122 / 496$ \\
IET-7 & 274 & $229 / 351$ & $232 / 330$ & $274 / 374$ & $122 / 494$
\end{tabular}

ffrom gas grab bottle samples at $30 \mathrm{~min}$ $\ddagger$ (actual values at $20 \mathrm{~s}) /$ (assuming only steam/metal reactions)

Table 5.5.3. Hydrogen Combustion for the SNL/IET Experiments - Melt Distribution Sensitivity Study

Experiment

Hydrogen Burned (gm-moles)

\begin{tabular}{ccc} 
Datał & \multicolumn{3}{c}{ MELCOR $\ddagger$} \\
Distribution & $\begin{array}{c}\text { Dxperimental Mostly into Mostly into } \\
\text { Distribution }\end{array}$
\end{tabular}

$\begin{array}{lccccc}\text { IET-1 } & 3 & 0 / 4 & 0 / 4 & 0 / 4 & 0 / 4 \\ \text { IET-1R } & 11 & 0 / 28 & 0 / 28 & 0 / 28 & 0 / 28 \\ \text { IET-3 } & 190 & 188 / 313 & 220 / 313 & 220 / 328 & 82 / 460 \\ \text { IET-4 } & 240 & 209 / 332 & 186 / 338 & 251 / 358 & 95 / 471 \\ \text { IET-5 } & 53 & 0 / 91 & 0 / 66 & 0 / 85 & 0 / 357 \\ \text { IET-6 } & 345 & 182 / 307 & 164 / 293 & 216 / 325 & 78 / 456 \\ \text { IET-7 } & 323 & 223 / 350 & 226 / 328 & 265 / 371 & 120 / 494\end{array}$

from gas grab bottle samples at $30 \mathrm{~min}$

$\ddagger$ (actual values at $20 \mathrm{~s}) /$ (assuming only steam/metal reactions) 

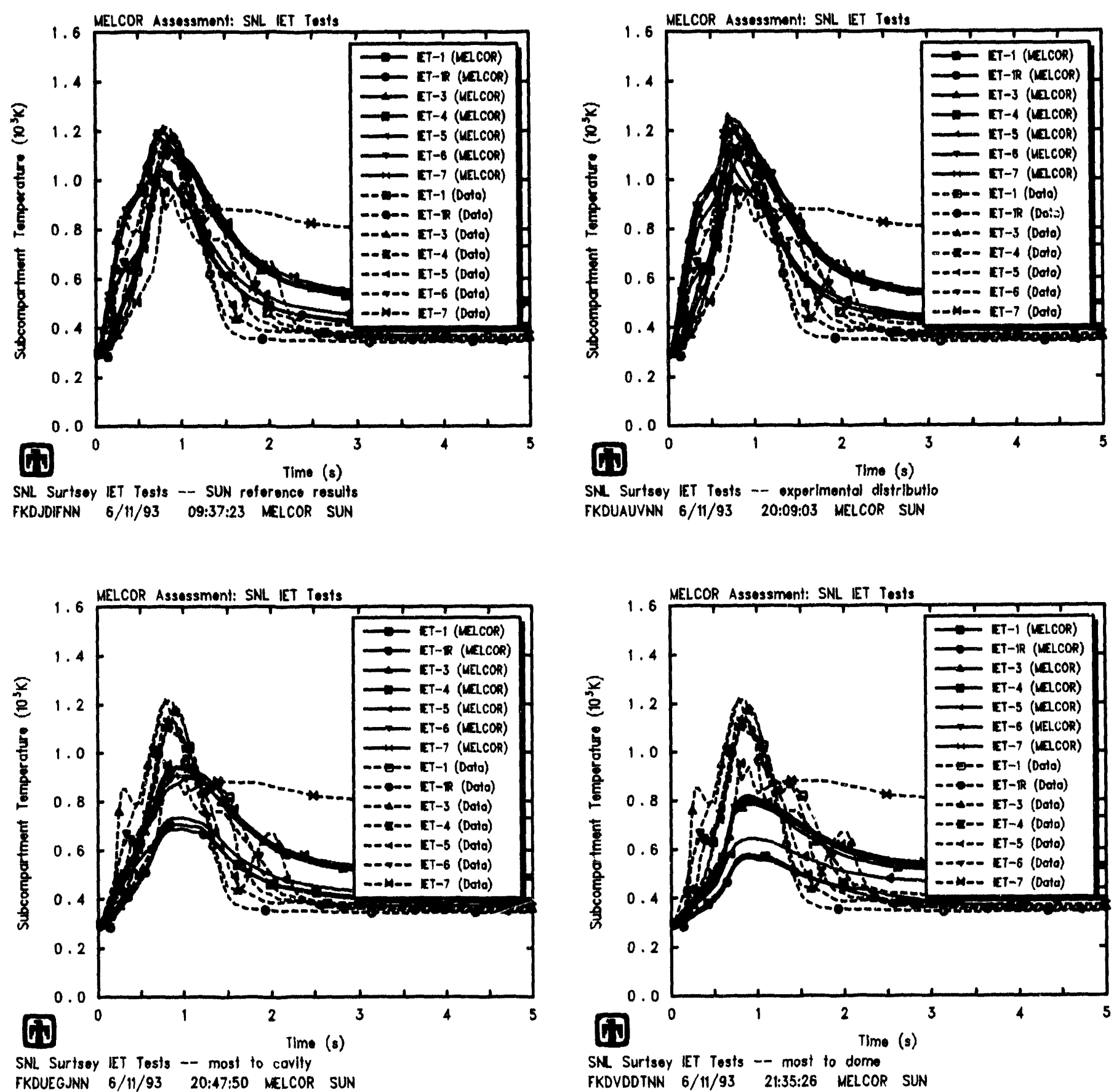

Figure 5.5.2. Subcompartment Temperatures for SNL/ILT Experiments Ising Basecase Melt Distribution (upper left), Experimental Molt Distribution (upper right), Melt Mostly into (avity (lower left) and Melt Mostly into Dome (lower right). Melt Distribution Sensitivity Study 


\section{DCH Modelling Studies}

There are a number of user-input parameters in the high-pressure melt cjection model in MEICOR. These parameters define both the initial debris source and the subsequent debris interaction. The effects of varying the assumed debris source (injection timing, temperature and distribution) were evaluated in the previous section, as part of the experimental-condition uncertainty study. In this section, the effects of varying the characteristic debris interaction times are investigated.

The processes modelled include oxidation of the metallic debris components in both steam and oxygen, surface deposition of the airborne debris by trapping or setting, and heat transfer to the atmosphere and to deposition surfaces; first-order rate equations with user-specified time constants for oxidation, heat transfer and settling are used to determine the rate of each process.

\subsection{Airborne Debris Oxidation Characteristic Time}

The reference analyses discussed in Section 4 used a user-input characteristic time of 0.025 s for oxidation of debris suspended in control volume atmospheres. (O)xidation of settled debris is controlled by a separate characteristic time, as discussed in Section 6.4.) A sensitivity study was done in which this airborne debris characteristic oxidation time was reduced to $0.005 \mathrm{~s}$ and $0.0 \mathrm{Ls}$, and increased to $0.05 \mathrm{~s}, 0.1 \mathrm{~s}$ and $0.5 \mathrm{~s}$; these values were selected to cover a large range of magnitude. All other parameters were left unchanged.

Resulting predicted vessel pressures for four of these six characteristic times are shown in Figure 6.1.1 (together with the test data). Tables 6.1 .1 and 6.1 .2 compare the amounts of hydrogen generated and burned, respectively, in all six cases considered.

The major trend visible in these results is that, with a very long characteristic airborne debris oxidation time, the overall pressurization, and both the hydrogen production and combustion, are all obviously underpredicted; the underprediction is worst in those cases where significant hydrogen combustion occurs, because using a long characteristic oxidation time ( $\geq$ the characteristic settling time) results in substantially less hydrogen produced and consequently less pressurization due to combustion of that hydrogen.

Using shorter characteristic airborne debris oxidation times $(\leq 0.1 \mathrm{~s})$ gives generally similar results because in all these cases the oxidation is generally limited by the availability of oxygen and/or steam. The amount of pre-existing oxygen varies from test to test, as does the amount and timing of the steam injected with the molt debris. 'The occasional small, non-monotonic changes seen in pressurization and hydrogen production and combustion for the shortest oxidation characteristic time values for some of the tests (for example, calculated hydrogen production for I W'I'-4 going up from 243gm-moles with $\tau_{i, r}=0.025 \mathrm{~s}$ to $244 \mathrm{gm}-1$ moles with $\tau_{o x}=0.01 \mathrm{~s}$ but then dropping to $240 \mathrm{gm}$-moles with $\tau_{0, x}=0.005 \mathrm{~s}$ ) are the result of interactions between different initial oxygen inventories, different steam flows and different oxidation rates causing localized steam-starvation and/or oxygen-starvation to occur at slightly different times in the different control volumes. 

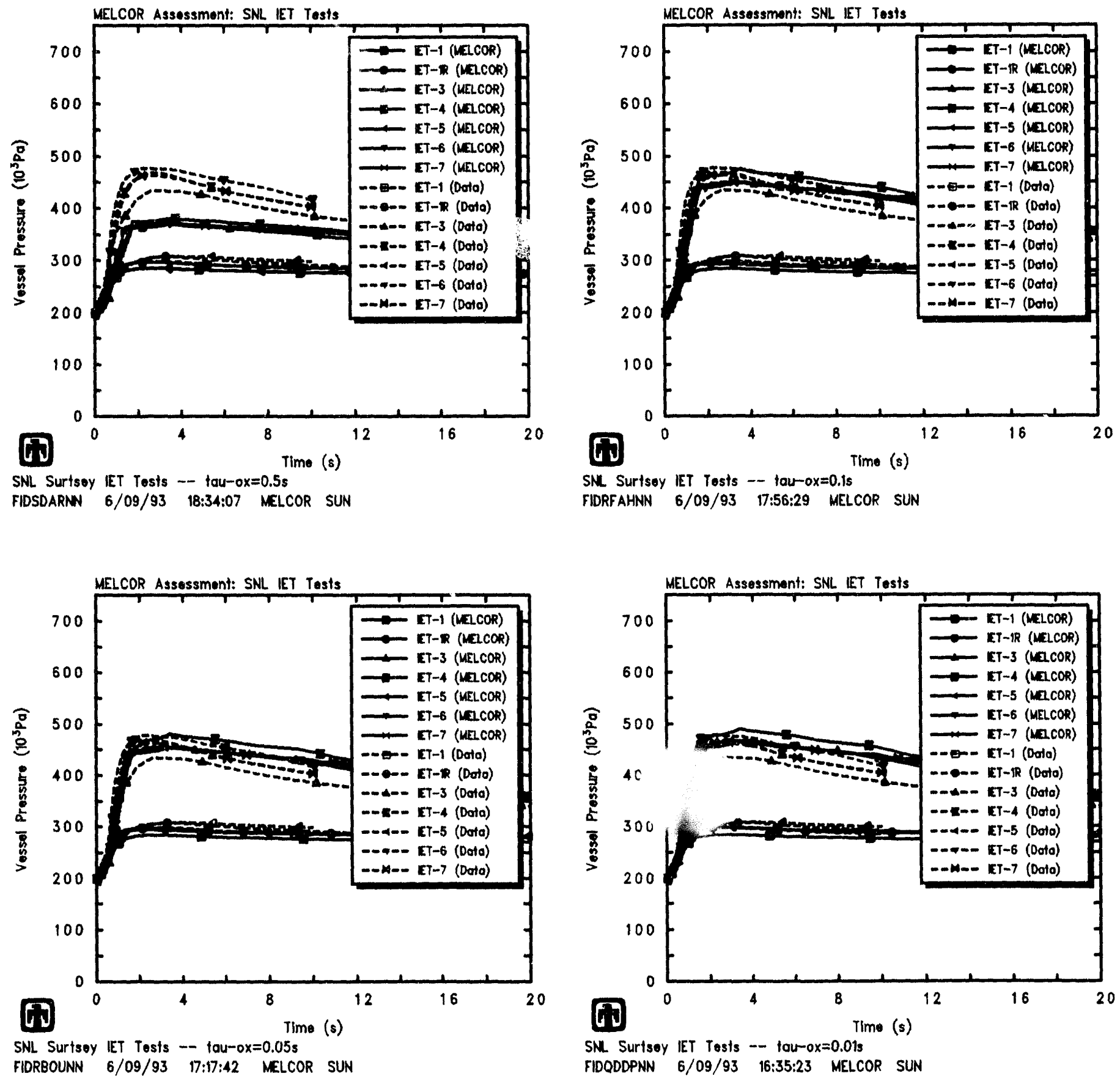

Figure 6.1.1. Vessel Pressures for SNL/IET Experiments / /sing Airborne Debris ('haracteristic Oxidation Times of 0.5s (upper left), 0.1 s (upper right), 0.05 s (lower left) and $0.01 \mathrm{~s}$ (lower right) Airborne Debris Oxidation ('haracteristic 'lime Sensitivity Study 
Table 6.1.1. Hydrogen Generation for the SNL/IET Experiments - Airborne Debris Oxidation Characteristic Time Sensitivity Study

Experiment

Data†

$$
\text { Hydrogen Produced (gm-moles) }
$$

\begin{tabular}{|c|c|c|c|c|c|c|c|}
\hline & \multirow[t]{3}{*}{ Dataf } & \multicolumn{6}{|c|}{ MELCOR $\ddagger$} \\
\hline & & & & & $=$ & & \\
\hline & & $0.005 \mathrm{~s}$ & $0.01 \mathrm{~s}$ & $0.025 \mathrm{~s}$ & $0.05 \mathrm{~s}$ & $0.1 \mathrm{~s}$ & $0.5 \mathrm{~s}$ \\
\hline IET-1 & 233 & $271 / 251$ & $280 / 261$ & $286 / 266$ & $286 / 266$ & $281 / 261$ & $200 / 181$ \\
\hline IET-1R & 248 & $252 / 254$ & $260 / 262$ & $266 / 267$ & $261 / 262$ & $260 / 260$ & $175 / 181$ \\
\hline IET-3 & 227 & $229 / 351$ & $232 / 352$ & $232 / 352$ & $229 / 338$ & $222 / 324$ & $110 / 193$ \\
\hline IET-4 & 303 & $240 / 362$ & $244 / 365$ & $243 / 361$ & $243 / 352$ & $230 / 334$ & $108 / 192$ \\
\hline IET-5 & 319 & $237 / 313$ & $238 / 314$ & $240 / 313$ & $237 / 305$ & $232 / 297$ & $131 / 183$ \\
\hline IET-6 & 319 & $228 / 350$ & $234 / 356$ & $236 / 354$ & $233 / 341$ & $224 / 325$ & $109 / 192$ \\
\hline IET-7 & 274 & $221 / 345$ & $228 / 350$ & $229 / 351$ & $223 / 337$ & $216 / 320$ & $107 / 190$ \\
\hline
\end{tabular}

ffrom gas grab bottle samples at $30 \mathrm{~min}$ $\ddagger$ (actual values at $20 \mathrm{~s}) /$ (assuming only steam/metal reactions)

Table 6.1.2. Hydrogen Combustion for the SNL/IET Experiments - Airborne Debris Oxidation Characteristic Time Sensitivity Study

Experiment

Data†

$$
0.005 \mathrm{~s} \quad 0.01 \mathrm{~s} \quad 0.025 \mathrm{~s} \quad 0.05 \mathrm{~s} \quad 0.1 \mathrm{~s} \quad 0.5 \mathrm{~s}
$$

$\begin{array}{lccccccc}\text { IET-1 } & 3 & 0 / 4 & 0 / 4 & 0 / 4 & 0 / 4 & 0 / 4 & 0 / 4 \\ \text { IET-1R } & 11 & 0 / 28 & 0 / 28 & 0 / 28 & 0 / 28 & 0 / 28 & 0 / 28 \\ \text { IET-3 } & 190 & 185 / 311 & 187 / 312 & 188 / 313 & 183 / 298 & 180 / 286 & 95 / 181 \\ \text { IET-4 } & 240 & 208 / 333 & 211 / 335 & 209 / 332 & 208 / 322 & 199 / 308 & 96 / 183 \\ \text { IET-5 } & 53 & 0 / 95 & 0 / 95 & 0 / 91 & 0 / 87 & 0 / 82 & 0 / 63 \\ \text { IET-6 } & 345 & 177 / 305 & 183 / 311 & 182 / 307 & 178 / 293 & 173 / 280 & 84 / 173 \\ \text { IET-7 } & 323 & 216 / 344 & 222 / 349 & 223 / 350 & 217 / 335 & 209 / 318 & 100 / 189\end{array}$

ffrom gas grab bottle samples at $30 \mathrm{~min}$

$\ddagger($ actual values at $20 \mathrm{~s}) /$ (assuming only steam/metal reactions) 
The characteristic airborne debris oxidation times assumed have very little overall effect on the subcompartment temperatures predicted, as illustrated in Figure 6.1.2, because most of the oxygen initially in the stibcompartments is depleted by the time the calculated subcompartment temperature peaks at $\sim 1$ s and the chemical energy released by metal-steam reaction is relatively small. Note, however, that there is a small increase in subcompartment temperatures visible early in the HPME transient, $(t \leq 0.5 \mathrm{~s})$ with decreasing characteristic airborne debris oxidation times, when metal-oxygen reaction is calculated to occur.

\subsection{Airborne Debris Heat Transfer Characteristic Time}

The reference analyses discussed in Section 4 used a user-input characteristic time of $0.40 \mathrm{~s}$ for heat transfer between airborne debris and the adjacent control volume atmospheres. (The heat transfer between settled debris and the heat structure surface it settles onto is controlled by a separate heat transfer coefficient, controllable through sensitivity coefficient input.) In a sensitivity study, this airborne debris characteristic heat transfer time was reduced to $0.05 \mathrm{~s}, 0.1 \mathrm{~s}$ and $0.25 \mathrm{~s}$, and increased to $0.5 \mathrm{~s}$ and $1 \mathrm{~s}$. All other parameters were left unchanged.

Figure 6.2.1 shows pressures in the vessel predicted using several airborne debris characteristic heat transfer times, together with experimental data for comparison. As would be expected, the vessel pressurization increases as the airborne debris characteristic heat transfer time is shortened.

Tables 6.2.1 and 6.2.2 present the amounts of hydrogen generated and burned, respectively, using the various values of airborne debris characteristic heat transfer times. (Test data estimates of the amounts of hydrogen produced and burned are included for reference.) There appears to be a trend of decreasing hydrogen production and combustion with increasing airborne debris characteristic heat transfer time. Again, the occasional small non-monotonic changes seen in calculated results for some of the tests (for example, calculated hydrogen production for IET-1 increasing with smaller characteristic heat-transfer times to $286 \mathrm{gm}$-moles with $\tau_{h t}=0.4 \mathrm{~s}$ then dropping to $284 \mathrm{gm}$-moles with $\tau_{h t}=0.25 \mathrm{~s}$ but then increasing again to $312 \mathrm{gm}$-moles with $\tau_{h t}=0.1 \mathrm{~s}$ ) are the result of interactions between different initial oxygen inventories, different steam flows and different interaction rates causing localized steam-starvation and/or oxygen-starvation conditions to occur at slightly different times in different control volumes.

Figure 6.2.2 gives subcompartment temperatures calculated using several airborne debris characteristic heat transfer times, together with experimental data. As would be expected, this variable (together with predicted temperatures in the other control volumes) is affected most by varying the airborne debris characteristic heat transfer time; the control volume atmosphere temperatures increase as the airborne debris characteristic heat transfer time is shortened. 

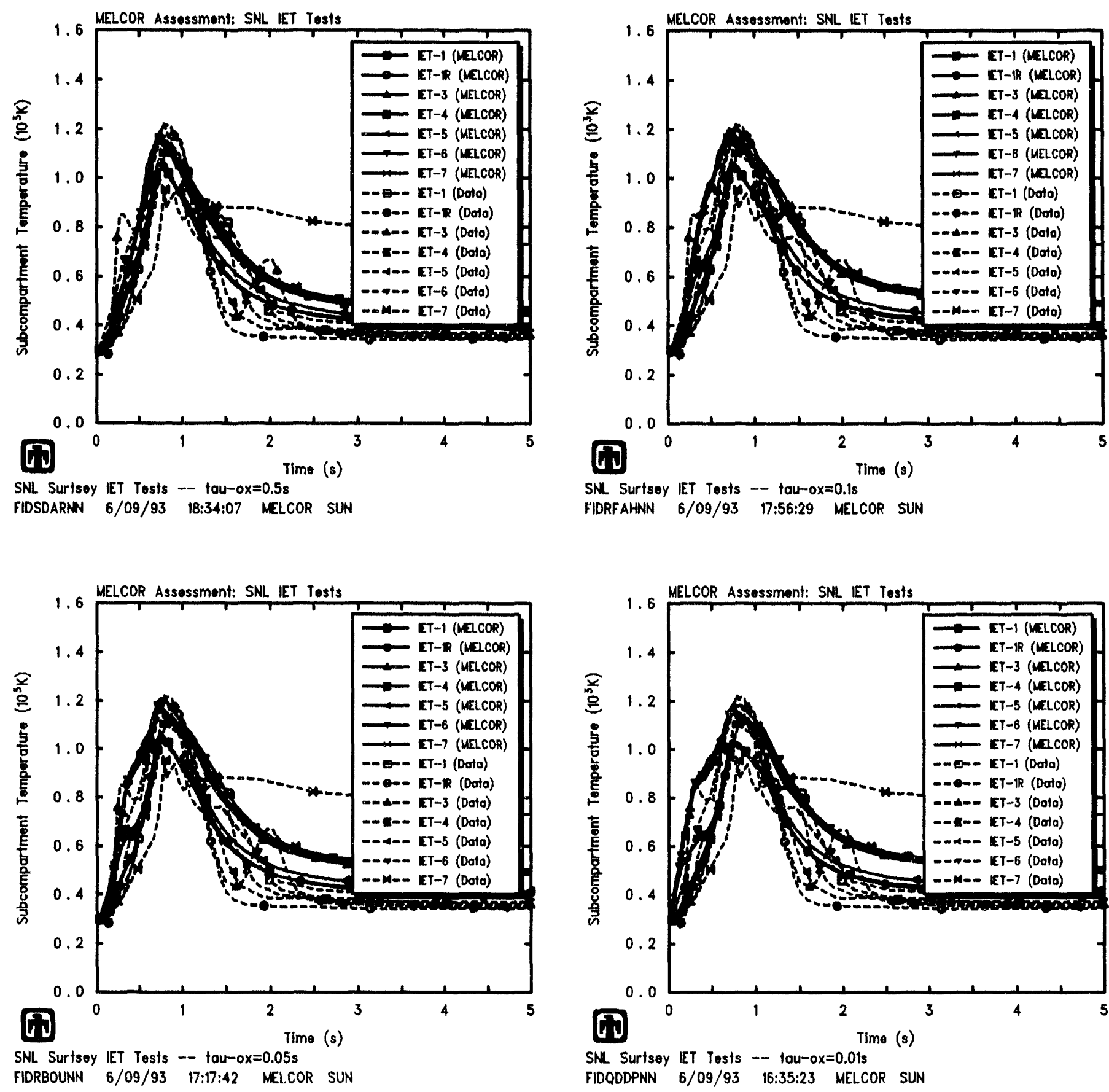

Figure 6.1.2. Subcompartment Temperatures for SNL/IEL Experinents lising Airborne Debris Oxidation (haracteristic limes of $0.5 \mathrm{~s}$ (upper left), 0.1 s (upper right), 0.05s (lower left) and 0.01s (lower right) Airborne Debris Oxidation (haracteristic Time Sensitivity Study 

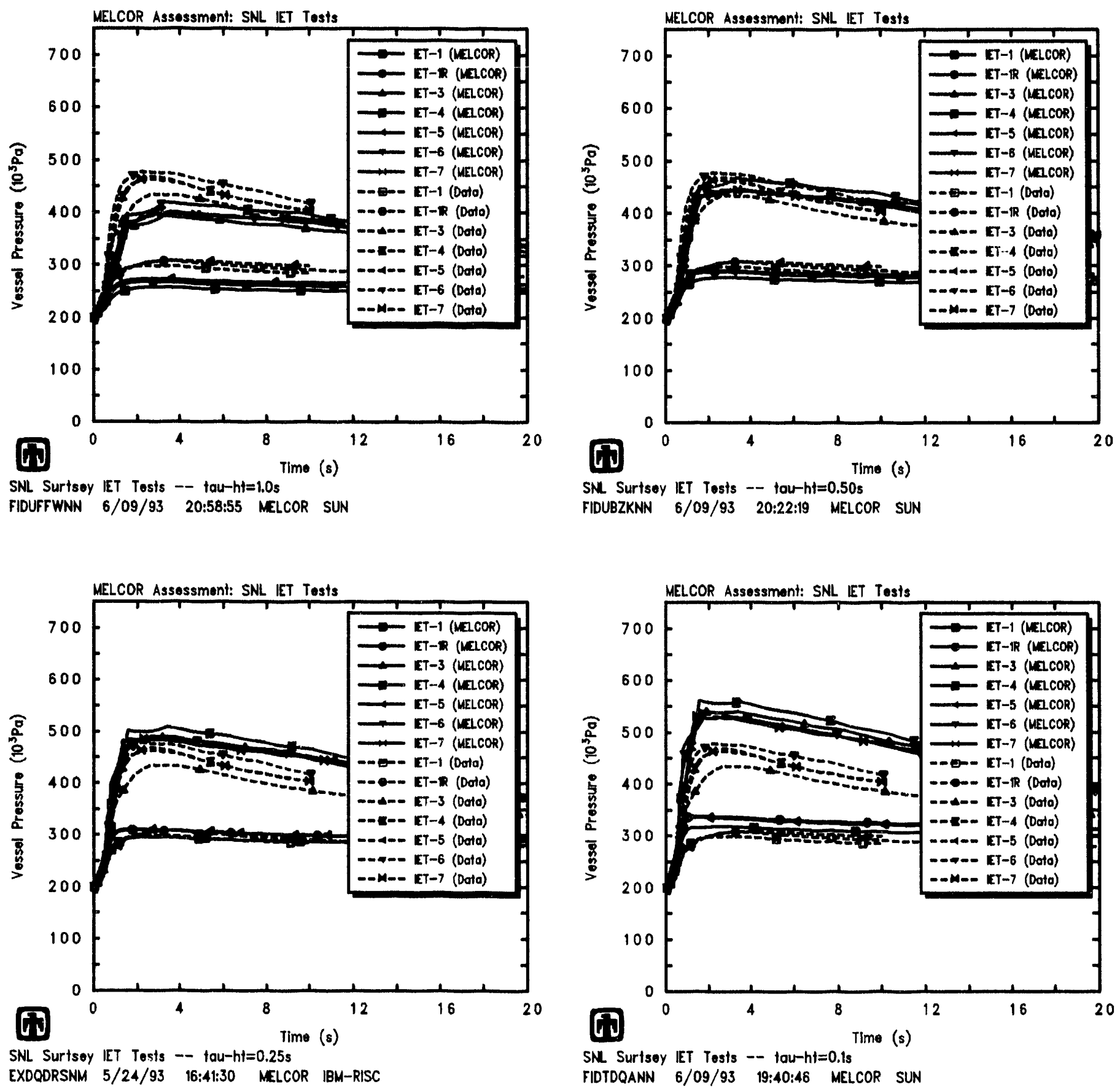

Figure 6.2.1. Vessel Pressures for SNJ/IET Experiments Using Airborne Debris Characteristic Heat Transfer Times of 1 s (upper left), $0.5 \mathrm{~s}$ (upper right), $0.25 \mathrm{~s}$ (lower left) and $0.1 \mathrm{~s}$ (lower right) Airborne Debris Heat Transfer Characteristic Time Sensitivity Study 
Table 6.2.1. Hydrogen Generation for the SNL/IET Experiments - Airborne Debris Heat Transfer Characteristic Time Sensitivity Study

Experiment

Data†

\begin{tabular}{lccccccc} 
& \multicolumn{7}{c}{$\tau_{h t}=$} \\
& & $0.05 \mathrm{~s}$ & $0.1 \mathrm{~s}$ & $0.25 \mathrm{~s}$ & $0.4 \mathrm{~s}$ & $0.5 \mathrm{~s}$ & $1 \mathrm{~s}$ \\
IET-1 & 233 & $316 / 296$ & $312 / 292$ & $284 / 264$ & $286 / 266$ & $273 / 252$ & $234 / 214$ \\
IET-1R & 248 & $302 / 307$ & $299 / 303$ & $275 / 280$ & $266 / 267$ & $252 / 253$ & $214 / 214$ \\
IET-3 & 227 & $254 / 380$ & $262 / 385$ & $241 / 360$ & $232 / 352$ & $217 / 341$ & $182 / 311$ \\
IET-4 & 303 & $265 / 393$ & $279 / 400$ & $248 / 368$ & $243 / 361$ & $234 / 353$ & $195 / 321$ \\
IET-5 & 319 & $274 / 351$ & $279 / 354$ & $252 / 325$ & $240 / 313$ & $226 / 300$ & $189 / 261$ \\
IET-6 & 319 & $256 / 382$ & $268 / 385$ & $249 / 367$ & $236 / 354$ & $220 / 342$ & $186 / 311$ \\
IET-7 & 274 & $250 / 374$ & $258 / 378$ & $232 / 353$ & $229 / 351$ & $216 / 337$ & $179 / 305$
\end{tabular}

†from gas grab bottle samples at $30 \mathrm{~min}$

Table 6.2.2. Hydrogen Combustion for the SNL/IET Experiments - Airborne Debris Heat Transfer Characteristic Time Sensitivity Study

Experiment

Data†

$$
0.05 \mathrm{~s} \quad 0.1 \mathrm{~s} \quad 0.25 \mathrm{~s} \quad 0.4 \mathrm{~s} \quad 0.5 \mathrm{~s} \quad 1 \mathrm{~s}
$$

$\begin{array}{lccccccc}\text { IET-1 } & 3 & 0 / 4 & 0 / 4 & 0 / 4 & 0 / 4 & 0 / 4 & 0 / 4 \\ \text { IET-1R } & 11 & 0 / 28 & 0 / 28 & 0 / 28 & 0 / 28 & 0 / 28 & 0 / 28 \\ \text { IET-3 } & 190 & 220 / 351 & 227 / 354 & 199 / 322 & 188 / 313 & 174 / 303 & 139 / 273 \\ \text { IET-4 } & 240 & 241 / 372 & 251 / 376 & 217 / 340 & 209 / 332 & 198 / 322 & 162 / 292 \\ \text { IET-5 } & 53 & 0 / 95 & 0 / 94 & 0 / 92 & 0 / 91 & 0 / 92 & 0 / 92 \\ \text { IET-6 } & 345 & 216 / 347 & 218 / 342 & 195 / 319 & 182 / 307 & 167 / 295 & 135 / 268 \\ \text { IET-7 } & 323 & 242 / 370 & 250 / 374 & 226 / 351 & 223 / 350 & 211 / 337 & 175 / 307\end{array}$

†from gas grab bottle samples at $30 \mathrm{~min}$

$\ddagger$ (actual values at $20 \mathrm{~s}) /$ (assuming only steam/metal reactions) 

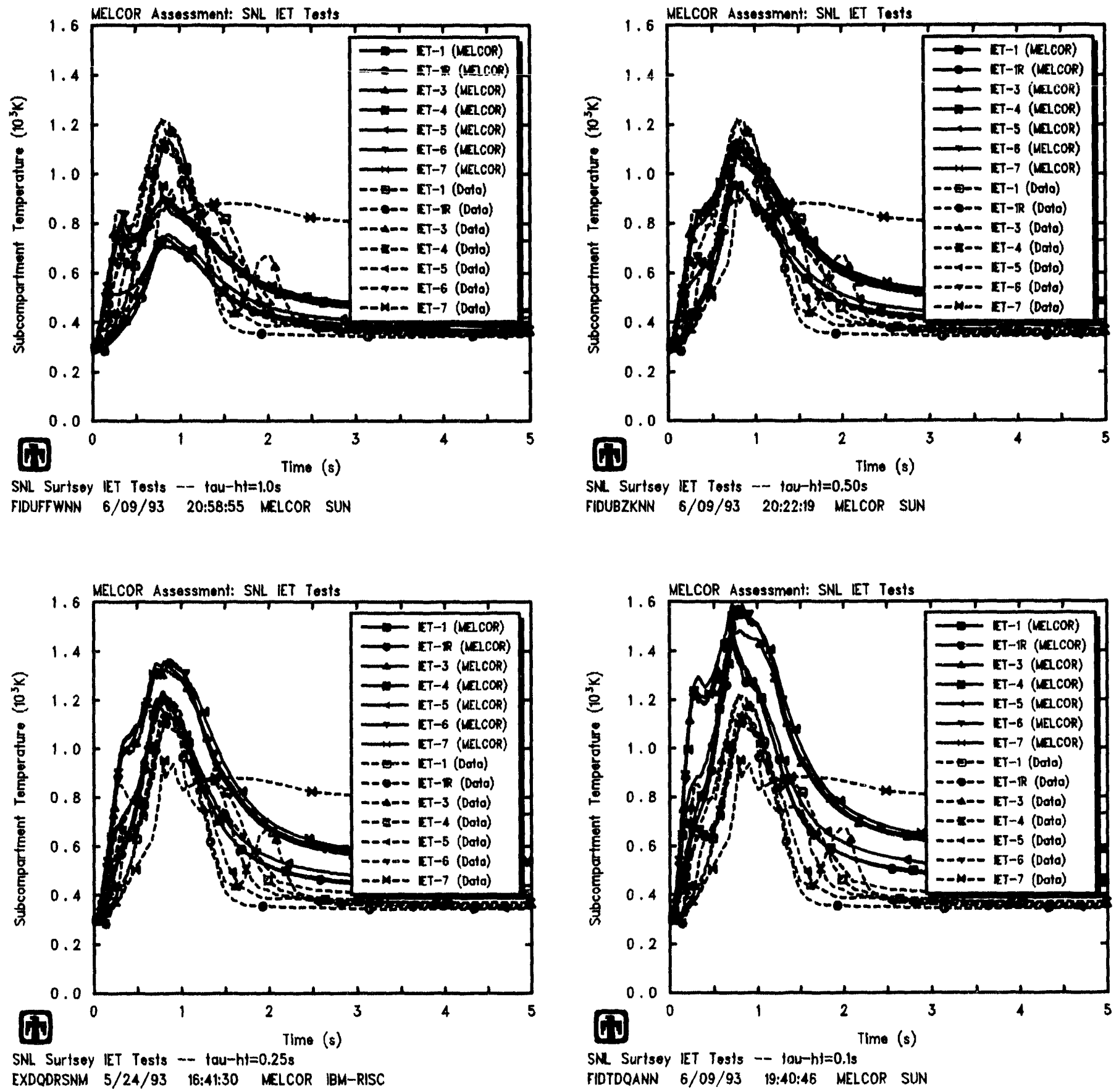

Figure 6.2.2. Subcompartment Temperatures for SNJ/IET Experiments Using Airborne Debris Characteristic Ileat Transfer l'imes of ls (upper left), $0.5 \mathrm{~s}$ (upper right), $0.25 \mathrm{~s}$ (lower left) and $0.1 \mathrm{~s}$ (lower right) - Airborne Debris Heat Transfer Characteristic 'Time Sonsitivity Study 


\subsection{Airborne Debris Settling Characteristic Time}

The reference analyses discussed in Section 4 used a range of user-input characteristic times for settling of airborne debris from control volume atmospheres onto associated "floor" heat structure surfaces, with the characteristic settling times generally proportional to the control volume height $(0.15 \mathrm{~s}$ in the cavity, $0.35 \mathrm{~s}$ in the chute, $0.25 \mathrm{~s}$ in the subcompartments and $0.60 \mathrm{~s}$ in the upper dome). In a sensitivity study, this airborne debris characteristic settling time was set to several fixed values $(0.05 \mathrm{~s}, 0.1 \mathrm{~s}, 0.25 \mathrm{~s}, 0.5 \mathrm{~s}$ and 1s) and set the same in all control volumes. All other parameters were left unchanged.

Vessel pressures predicted using various values of characteristic settling times are presented in Figure 6.3.1, together with test data. The effect of increasing the airborne debris characteristic settling time is to increase the vessel pressures calculated, as would be expected because it increases the available time for both oxidation and heat transfer to occur.

Tables 6.3.1 and 6.3.2 summarize the amounts of hydrogen generated and burned, respectively, with the amount of hydrogen both produced and burned generally increasing with increasing airborne debris characteristic settling times.

Increasing the airborne debris characteristic settling times has the same effect on the subcompartment temperatures predicted as on the overall pressurization and both hydrogen production and combustion, as indicated in Figure 6.3.2. The calculated subcompartment temperatures increase with increasing airborne debris characteristic settling time, due to the longer periods available for heat transfer between airborne debris and atmosphere to occur in the subcompartments. The difference between cases with and without significant hydrogen combustion also increases with increasing airborne debris characteristic settling time, because using a long characteristic set,lling time results in substantially more hydrogen produced, and consequently more overall pressurization and heatup due to combustion of hydrogen produced in or convected into the dome.

\subsection{Deposited Debris Oxidation Characteristic Time}

The reference analyses discussed in Section 4 used a user-input characteristic time of $600 \mathrm{~s}$ for oxidation of debris settled onto structures. (Oxidation of airborne debris is controlled by a separate characteristic time, as discussed in Section 6.1.) $\Lambda$ sensitivity study was done in which this deposited-debris characteristic oxidation time was reduced to $10 \mathrm{~s}$ and $60 \mathrm{~s}$, and increased to $1800 \mathrm{~s}$, to cover a wide range of magnitudes. All other parameters were left unchanged.

Figure 6.4.1 shows pressures in the vessel predicted using these various deposited debris characteristic oxidation times, together with experimental data. There is generally little effect on either the peak or the long-term pressurization as the deposited dobris characteristic oxidation time is varied.

Tables 6.4.1 and 6.4.2 present the amounts of hydrogen generated and burned, respectively, in these various cases. Test data estimates of the amounts of hydrogen produced 

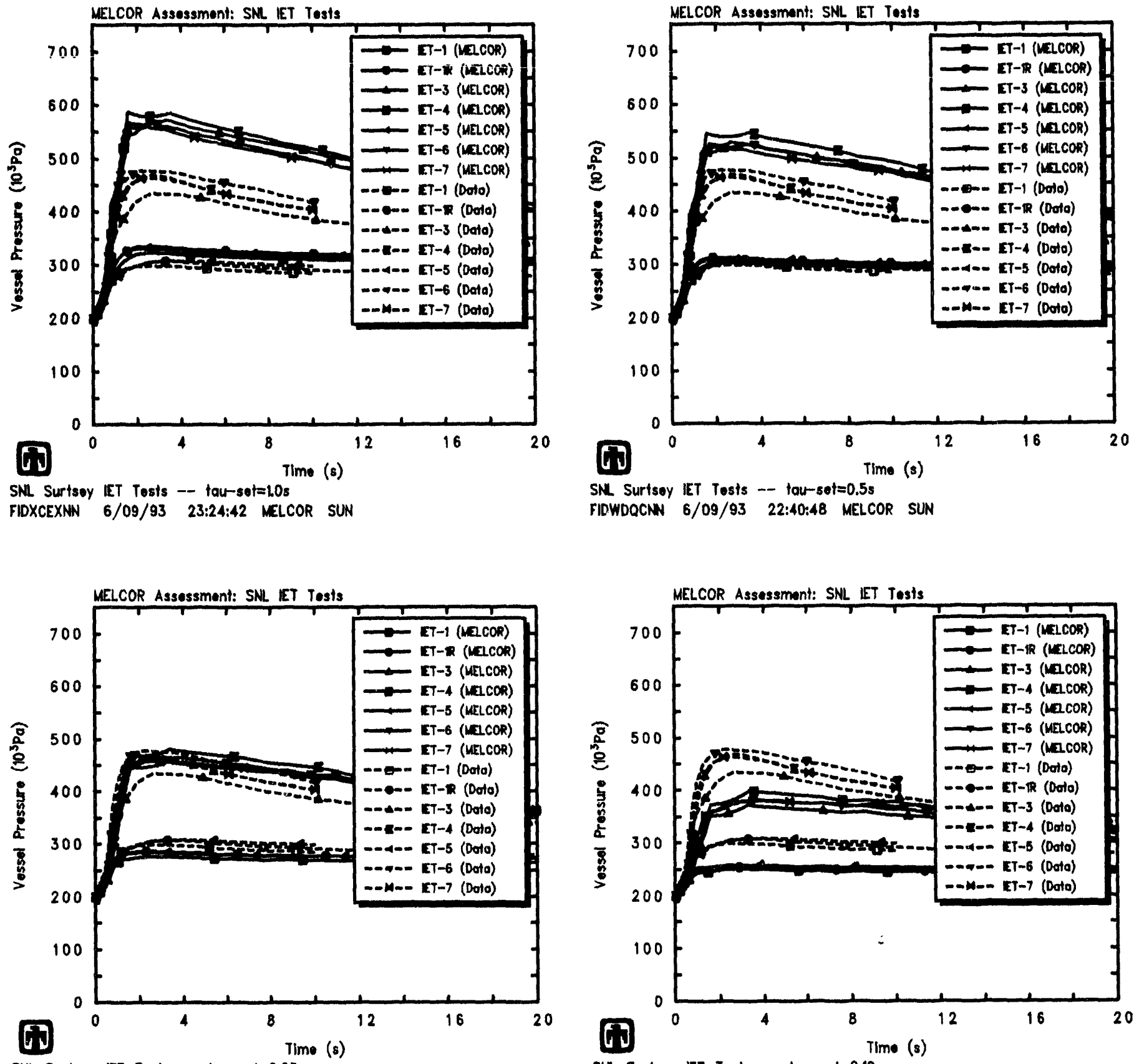

SNL Surtsey IET Tests -- tourset $=0.25 \mathrm{~s}$ EXDVDDWNM 5/24/93 2t:35:31 MELCOR IBM-RISC

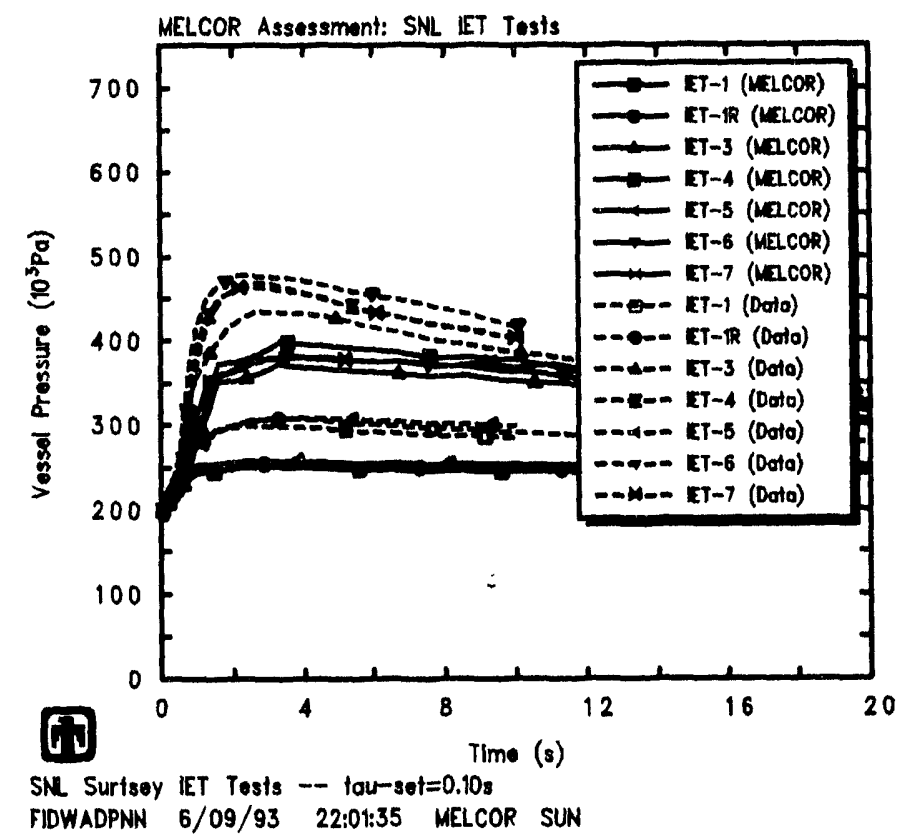

Figure 6.3.1. Vessel Pressures for SNL/IET Experiments Using Airborne Debris Characteristic Settling Times of is (upper left), 0.5s (upper right), $0.25 \mathrm{~s}$ (lower left) and 0.is (lower right) - Airborne Debris Settling Characteristic Timo Sensitivity Study 
Table 6.3.1. Hydrogen Generation for the SNL/IET Experiments - Airborne Debris Settling Characteristic Time Sensitivity Study

Experiment

Data†
Hydrogen Produced (gm-moles)

MELCOR $\ddagger$

$\begin{array}{llll} & \tau_{\text {set }}= & & \\ 0.05 \mathrm{~s} & 0.1 \mathrm{~s} & 0.25 \mathrm{~s} & 0.5 \mathrm{~s} \quad 1 \mathrm{~s}\end{array}$

$\begin{array}{lllllll}\text { IET-1 } & 233 & 177 / 161 & 221 / 203 & 295 / 275 & 346 / 325 & 390 / 368 \\ \text { IET-1R } & 248 & 163 / 171 & 206 / 210 & 294 / 295 & 328 / 331 & 370 / 371 \\ \text { IET-3 } & 227 & 139 / 245 & 183 / 293 & 242 / 357 & 288 / 405 & 316 / 435 \\ \text { IET-4 } & 303 & 151 / 255 & 194 / 306 & 256 / 373 & 305 / 421 & 330 / 449 \\ \text { IET-5 } & 319 & 146 / 206 & 189 / 256 & 257 / 328 & 294 / 369 & 337 / 413 \\ \text { IET-6 } & 319 & 144 / 245 & 187 / 300 & 240 / 374 & 293 / 411 & 319 / 437 \\ \text { IET-7 } & 274 & 138 / 242 & 181 / 293 & 244 / 361 & 281 / 401 & 305 / 429\end{array}$

ffrom gas grab bottle samples at $30 \mathrm{~min}$

$\ddagger$ (actual values at $20 \mathrm{~s}) /$ (assuming only steam/metal reactions)

Table 6.3.2. Hydrogen Combustion for the SNL/IET Experiments - Airborne Debris Settling Characteristic Time Sensitivity Study

Experiment

Data†
Hydrogen Burned (gm-moles) MELCOR $\ddagger$

\begin{tabular}{lllll} 
& \multicolumn{5}{c}{$\tau_{\text {set }}=$} \\
$0.05 \mathrm{~s}$ & $0.1 \mathrm{~s}$ & $0.25 \mathrm{~s}$ & $0.5 \mathrm{~s}$ & $1 \mathrm{~s}$
\end{tabular}

$\begin{array}{lcccccc}\text { IET-1 } & 3 & 0 / 4 & 0 / 4 & 0 / 4 & 0 / 4 & 0 / 4 \\ \text { IET-1R } & 11 & 0 / 28 & 0 / 28 & 0 / 28 & 0 / 28 & 0 / 28 \\ \text { IET-3 } & 190 & 104 / 216 & 138 / 254 & 199 / 320 & 248 / 370 & 279 / 403 \\ \text { IET-4 } & 240 & 118 / 228 & 162 / 278 & 223 / 343 & 274 / 393 & 303 / 425 \\ \text { IET-5 } & 53 & 0 / 74 & 0 / 82 & 0 / 88 & 0 / 94 & 0 / 97 \\ \text { IET-6 } & 345 & 100 / 208 & 139 / 258 & 205 / 323 & 246 / 370 & 267 / 391 \\ \text { IET-7 } & 323 & 136 / 245 & 176 / 294 & 237 / 360 & 274 / 398 & 298 / 427\end{array}$

ffrom gas grab bottle samples at $30 \mathrm{~min}$ $\ddagger$ (actual values at $20 \mathrm{~s})$ / (assuming only steam/metal reactions) 

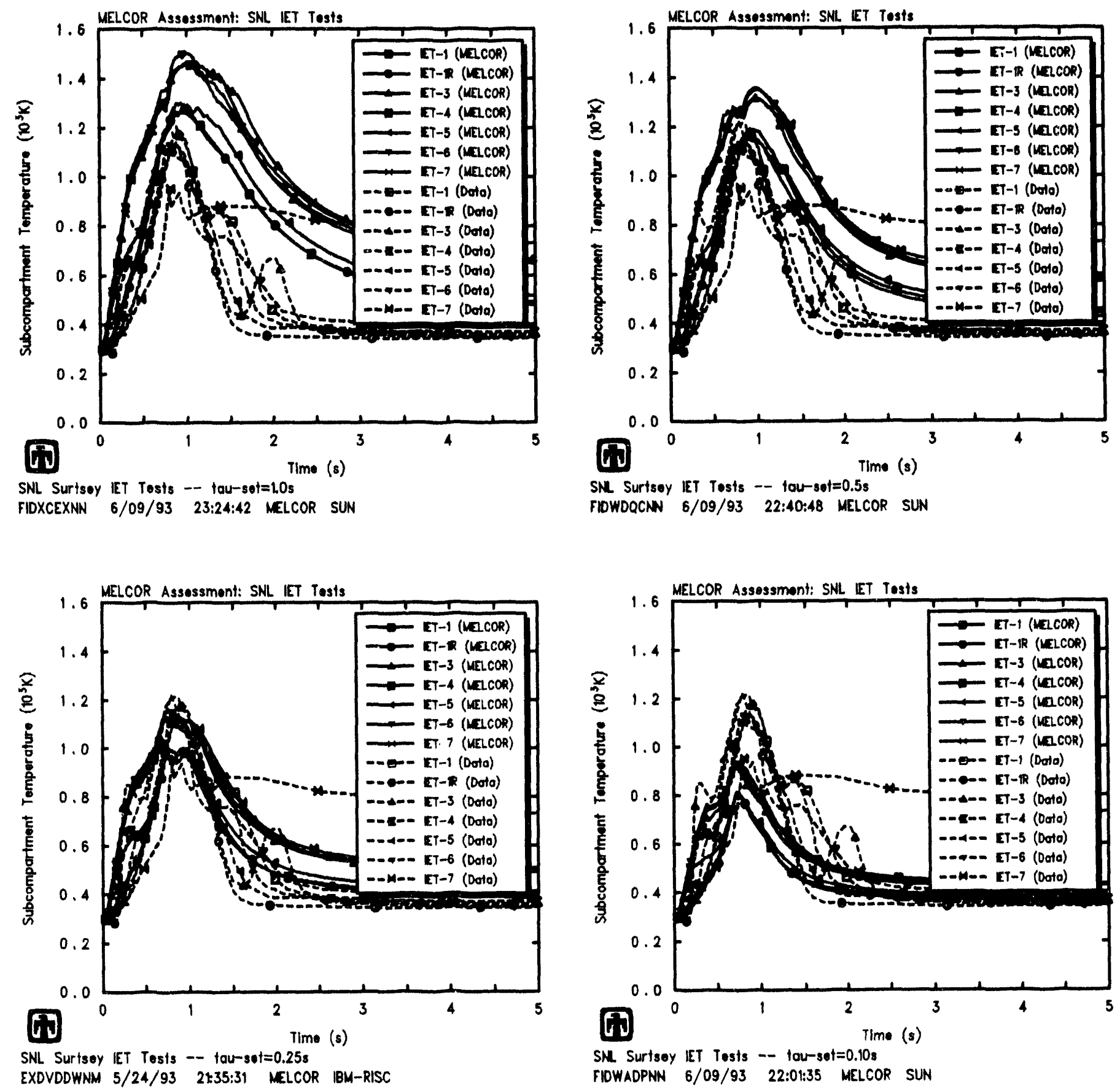

Figure 6.3.2. Subcompartment Temperatures for SNL/IET Experiments (sing Airborne Detoris (Characteristic Settling Times of Is (upper left). 0.5s (upper right). 0.25s (lower left) and 0.1s (lower right) Airborne Debris Settling Heat Transfer Characteristic 'Time Sensitivity Study 

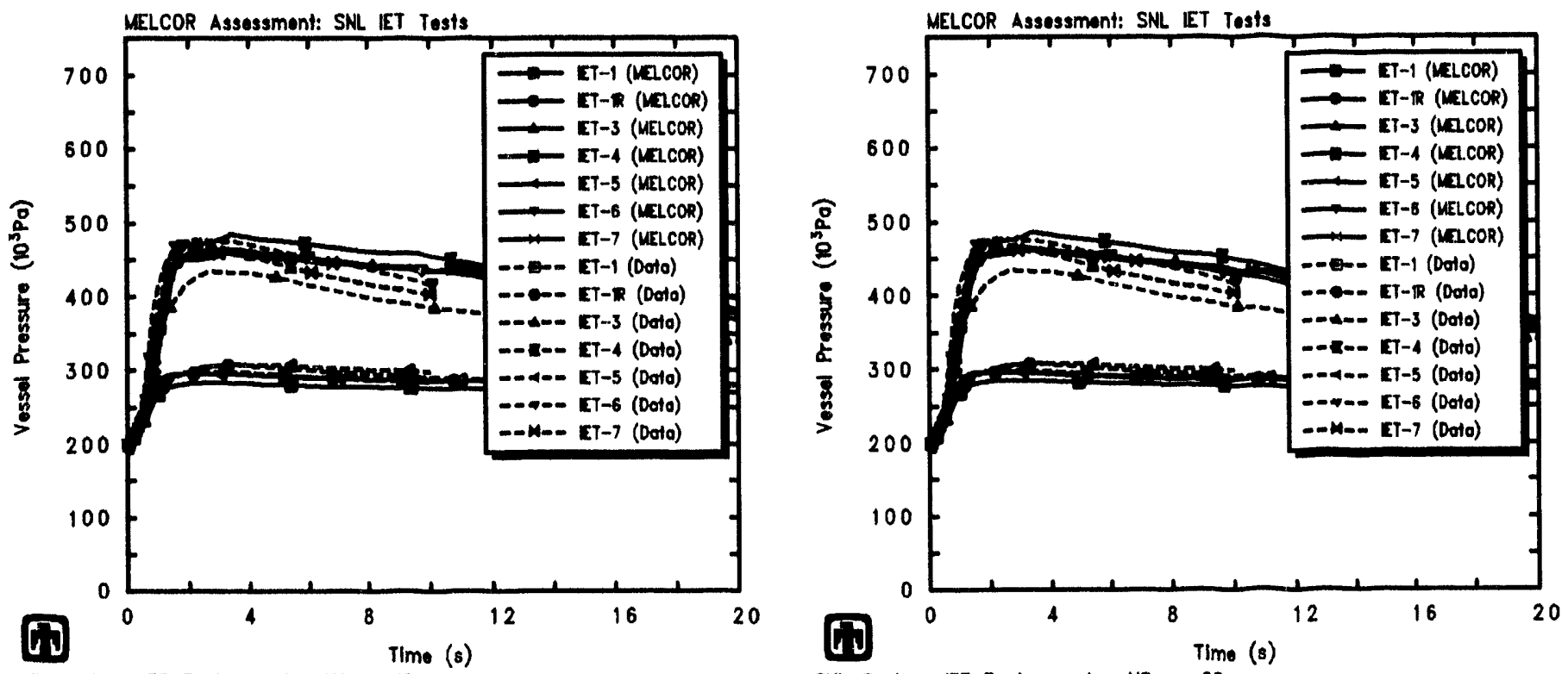

SNL. Surtsoy IET Tosts -- tou-HS-ox=10s

FJDAAVDNN 6/10/93 00:09:11 MELCOR SUN

SNL Surtsoy IET Tosts - - tou-HS-0X $=60$ s

FJDAEFDNN 6/10/93 00:47:20 MELCOR SUN
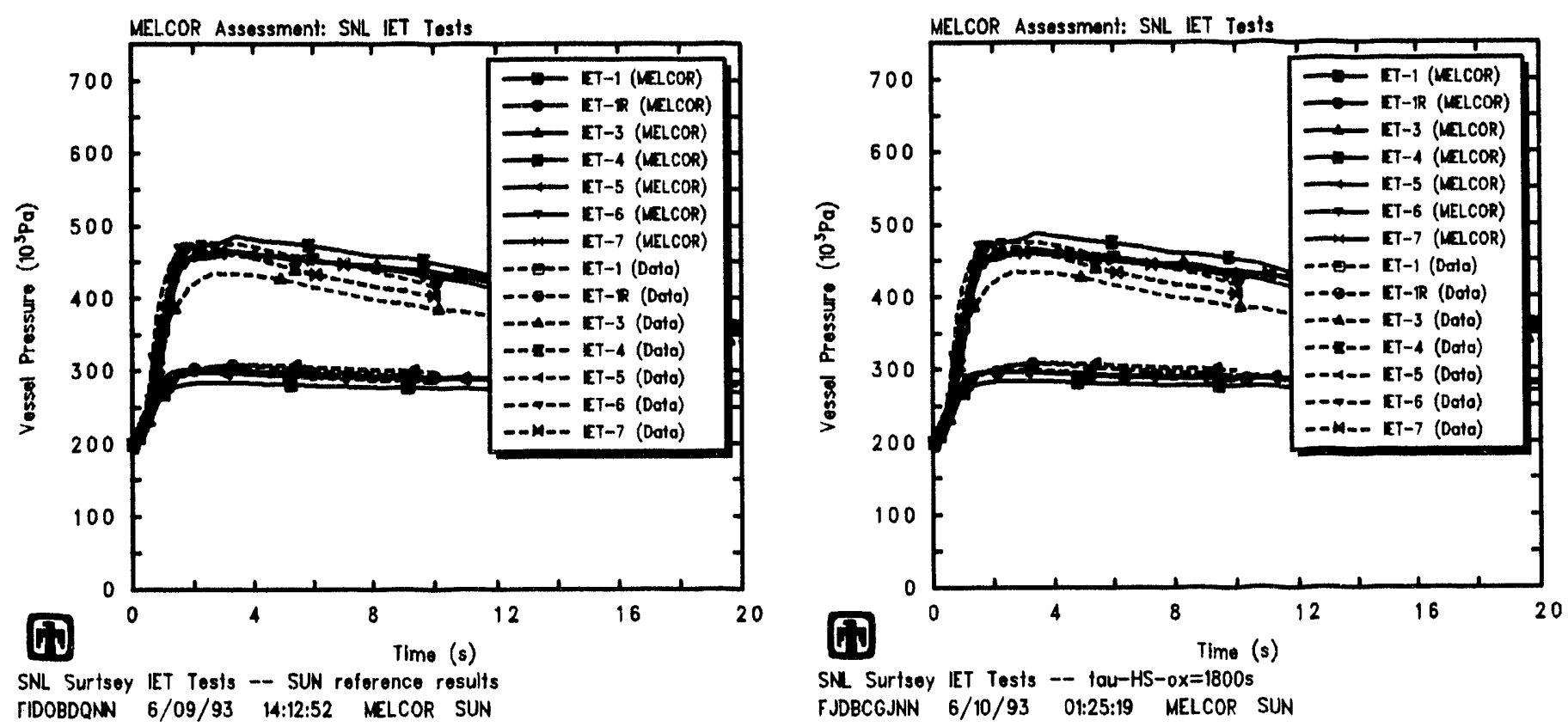

SNL Surtsey IET Tosts -- tau-HS-0x $=1800 \mathrm{~s}$ FJDBCGJNN 6/10/93 01:25:19 MELCOR SUN

Figure 6.4.1. Vessel Pressures for SNL/IET Experiments Vsing I)oposited Dobris ('haracteristic Oxirlation Times of 10 s (upper left). (it)s (upper right), 600s (lower ledt) and 1800s (lower right) Deposited Dohris (Oxidation ('haracteristic 'T'ime Sensitivity Study 
and burned are included for reference. The total amount of hydrogen generated increases as the characteristic oxidation time for deposited debris is decreased, as would be expected, because more hydrogen accumulates late in the transient as the debris settled and/or deposited onto structures continues to oxidize. There is little effect seen on the amount of hydrogen burned, however, because the hydrogen combustion primarily occurs early in the transient, on a time scale of a few seconds or less.

Figure 6.4.2 gives subcompartment temperatures calculated using various deposited debris characteristic oxidation times, together with experimental data. As with the vessel pressure shown in Figure 6.4.1, there is generally little effect on either the peak or the long-term temperature response as the deposited debris characteristic oxidation time is varied.

\subsection{Deposited Debris Heat Transfer Coefficient}

As noted in Section 3.1, the basecase MELCOR IET experiment analyses were run with the coefficient for heat transfer from deposited debris to structure surface reduced to $1 \mathrm{w} / \mathrm{m}^{2}-\mathrm{K}$. This was originally done to avoid temperature iteration convergence problems, and was not changed when the temperature solution algorithm was improved and made more robust (as discussed in Section 11). To see what effect this had on our analyses, a set of calculations were run with that heat transfer coefficient progressively increased to $10 \mathrm{w} / \mathrm{m}^{2}-\mathrm{K}, 100 \mathrm{w} / \mathrm{m}^{2}-\mathrm{K}$, and $1000 \mathrm{w} / \mathrm{m}^{2}-\mathrm{K}$ (the default value).

Figure 6.5.1 shows pressures in the vessel predicted using the different debris-tostructure heat transfer coefficients, together with experimental data. There is little difference visible, especially in the carly-time peak pressures, with the major difference being slightly higher late-time pressures for larger debris-to-structure heat transfer coefficients.

Tables 6.5.1 and 6.5.2 present the amounts of hydrogen generated and burned, respectively, in these various cases. Test data estimates of the amounts of hydrogen produced and burned are included for reference. Again, there is very little difference apparent, especially for heat transfer coefficient values in the $1-100 \mathrm{w} / \mathrm{m}^{2}-\mathrm{K}$ range, with a slight, increase seen in both hydrogen production and (as a consequence) hydrogen combustion for the default value of $1000 \mathrm{w} / \mathrm{m}^{2}-\mathrm{K}$.

Figure 6.5.2 gives subcompartment temperatures calculated using various debris-tostructure heat transfer coefficients, together with experimental data. As found for the pressure comparison presented in Figure 6.5.1, there is little difference visible, especially in the early-time peak temperatures, with the major difference being slightly higher latetime temperatures for larger debris-to-structure heat transfer coefficients. 
Table 6.4.1. Hydrogen Generation for the SNL/IET Experiments - Deposited Debris Oxidation Characteristic Time Sensitivity Study

\begin{tabular}{|c|c|c|c|c|c|}
\hline \multirow[t]{4}{*}{ Experiment } & & \multicolumn{4}{|c|}{ Hydrogen Produced (gm-moles) } \\
\hline & \multirow[t]{3}{*}{ Dataf } & \multicolumn{4}{|c|}{ MELCOR $\ddagger$} \\
\hline & & \multicolumn{4}{|c|}{$\tau_{H S-o x}=$} \\
\hline & & $10 \mathrm{~s}$ & $60 \mathrm{~s}$ & $600 \mathrm{~s}$ & $1800 \mathrm{~s}$ \\
\hline IET-1 & 233 & $472 / 403$ & $354 / 301$ & $286 / 266$ & $281 / 264$ \\
\hline IET-1R & 248 & $436 / 386$ & $332 / 294$ & $266 / 267$ & $261 / 265$ \\
\hline IET-3 & 227 & $288 / 479$ & $235 / 388$ & $232 / 352$ & $235 / 351$ \\
\hline IET-4 & 303 & $288 / 481$ & $249 / 396$ & $243 / 361$ & $246 / 361$ \\
\hline IET-5 & 319 & $365 / 423$ & $250 / 334$ & $240 / 313$ & $240 / 310$ \\
\hline IE'T-6 & 319 & $284 / 479$ & $241 / 389$ & $236 / 354$ & $235 / 350$ \\
\hline IET-7 & 274 & $283 / 474$ & $233 / 385$ & $229 / 351$ & $225 / 344$ \\
\hline
\end{tabular}

from gas grab bottle samples at $30 \mathrm{~min}$ $\ddagger$ (actual values at $20 \mathrm{~s}) /$ (assuming only steam/metal reactions)

Table 6.4.2. Hydrogen Combustion for the SNL/IET Experiments - Deposited Debris Oxidation Characteristic Time Sensitivity Study

Experiment

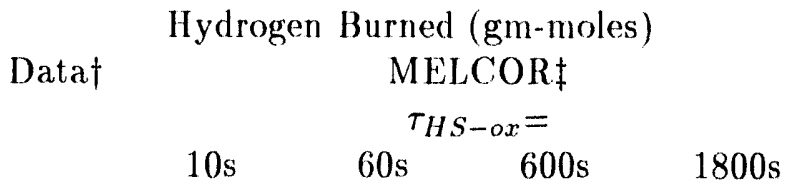

$\begin{array}{lccccc}\text { IET-1 } & 3 & 0 / 4 & 0 / 4 & 0 / 4 & 0 / 4 \\ \text { IET-1R } & 11 & 0 / 28 & 0 / 28 & 0 / 28 & 0 / 28 \\ \text { IET-3 } & 190 & 199 / 411 & 188 / 348 & 188 / 313 & 190 / 311 \\ \text { IET-4 } & 240 & 223 / 434 & 210 / 366 & 209 / 332 & 211 / 330 \\ \text { IET-5 } & 53 & 0 / 130 & 0 / 112 & 0 / 91 & 0 / 89 \\ \text { IET-6 } & 345 & 191 / 407 & 182 / 341 & 182 / 307 & 180 / 301 \\ \text { IET-7 } & 323 & 263 / 476 & 225 / 385 & 223 / 350 & 220 / 343\end{array}$

†from gas grab bottle samples at $30 \mathrm{~min}$ $\ddagger$ (actual values at $20 \mathrm{~s}) /$ (assuming only steam/metal reactions) 


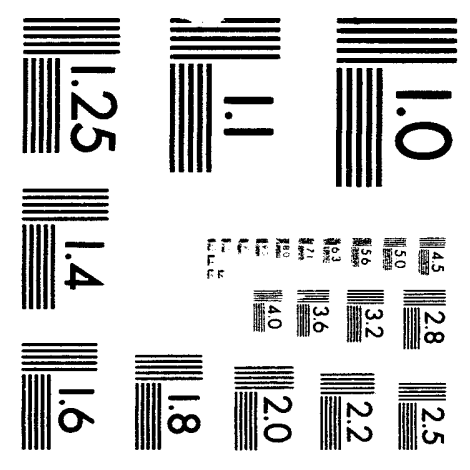



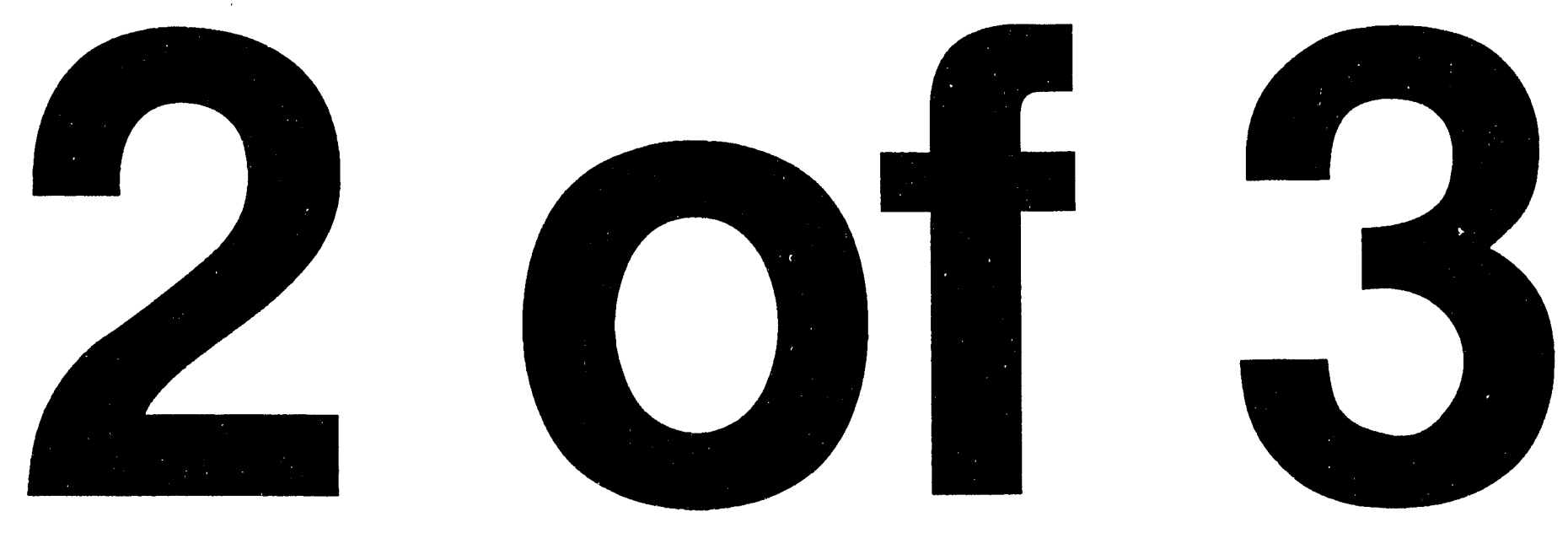

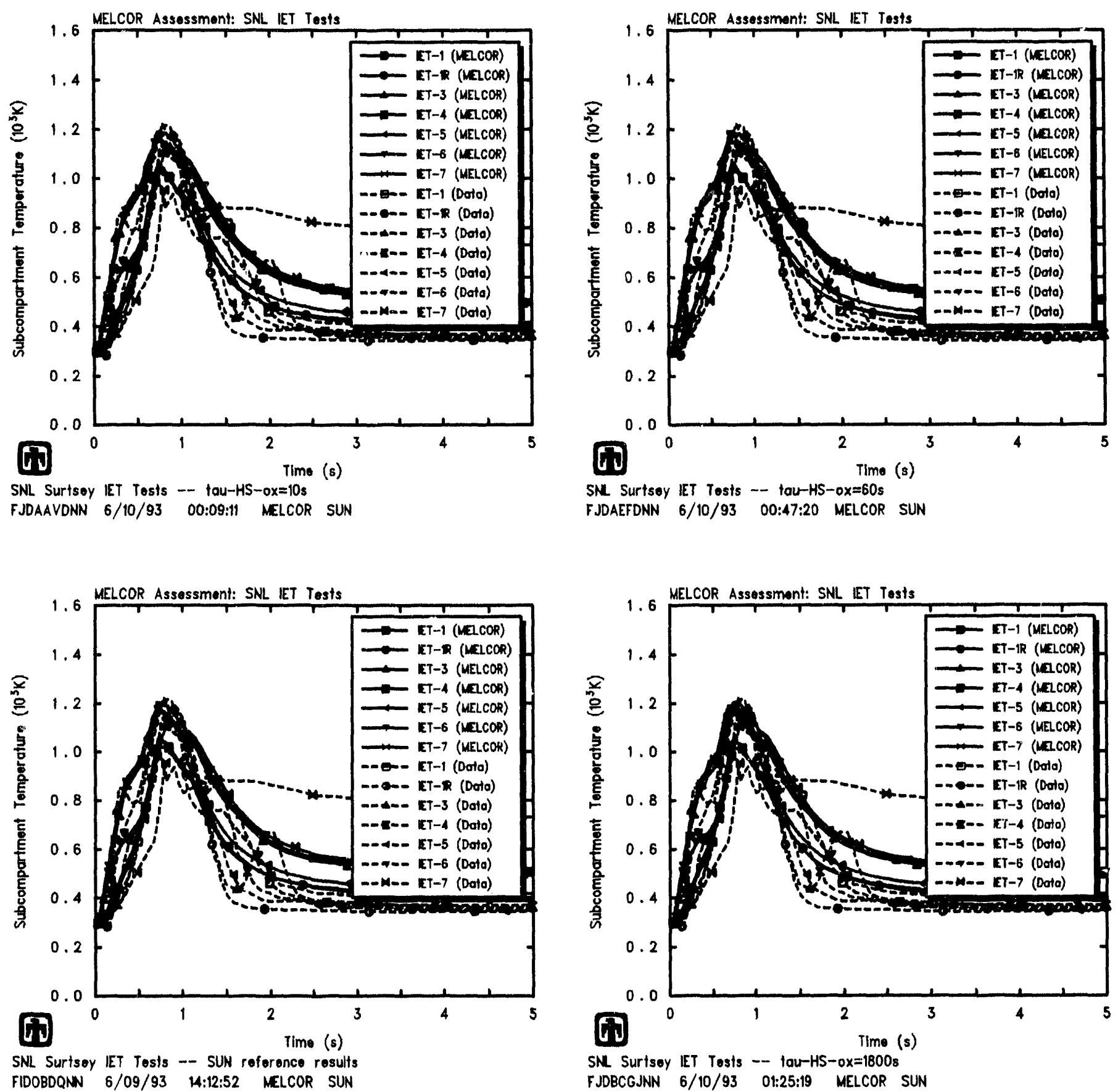

Figure 6.4.2. Subcompartment 'Temperatures for SNL/IET Experiments Ising Deposited Debris Characteristic Oxidation Times of 10s (upper left), 60s (upper right), 600s (lower left) and 1800s (lower right) Deposited Debris Oxidation (haracteristic 'Time Sensitivity Study' 

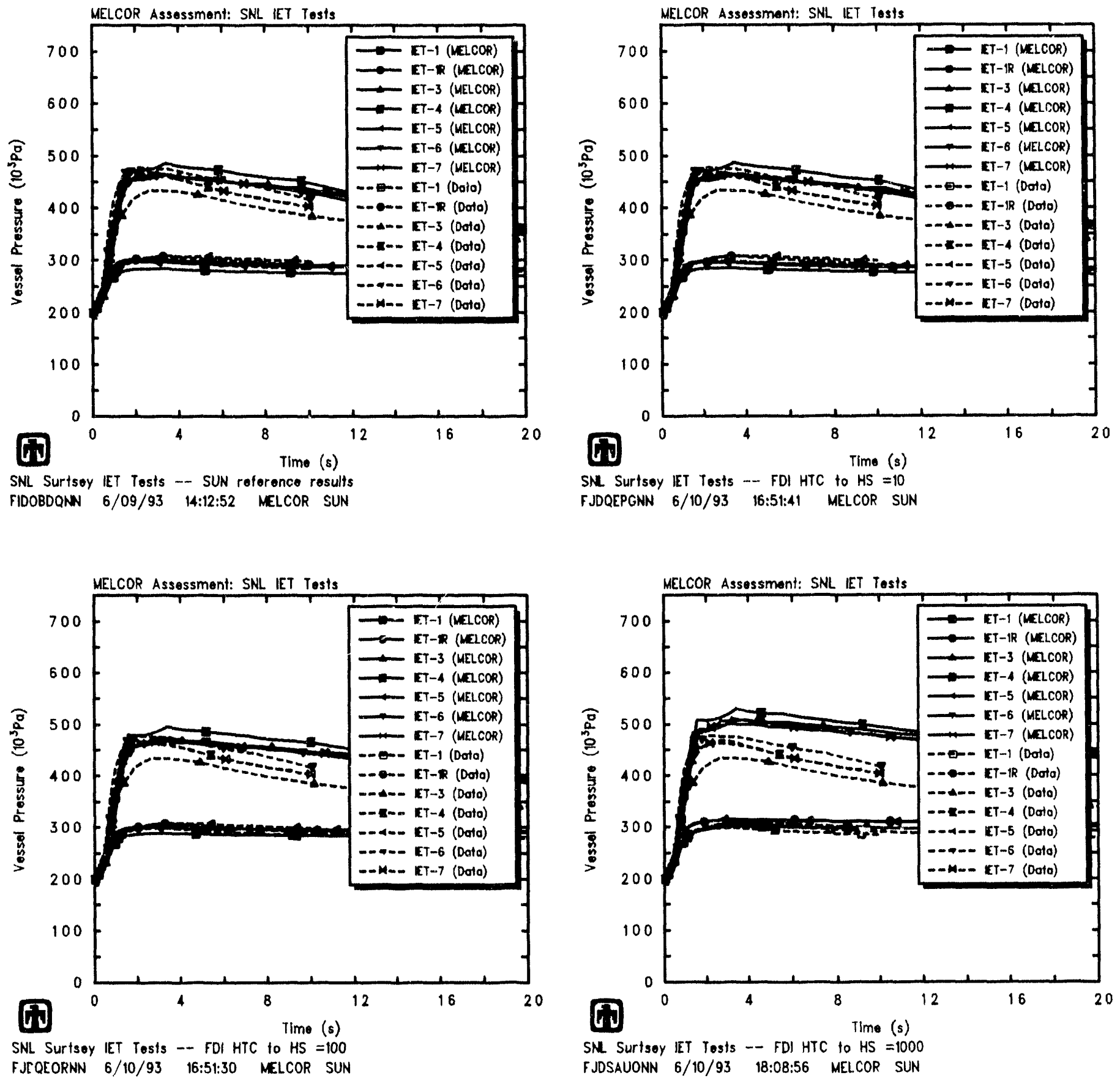

SN Surtsoy IET Tosts -- FDI HTC to HS $=1000$

FJDSAUONN 6/10/93 18:08:56 MELCOR SUN

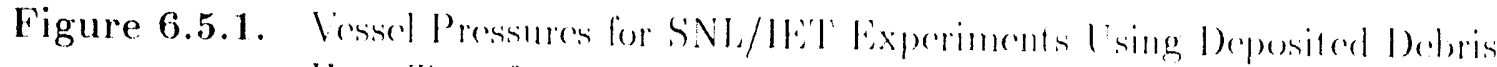

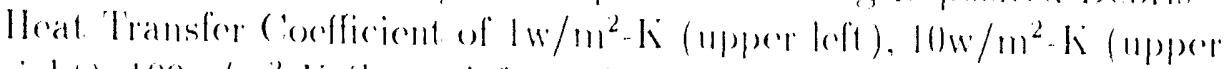
right). $100 \mathrm{w} / \mathrm{m}^{2}-\mathrm{k}$ (lower left) and $1000 \mathrm{w} / \mathrm{m}^{2}$ - $\mathrm{k}$ (lower right)

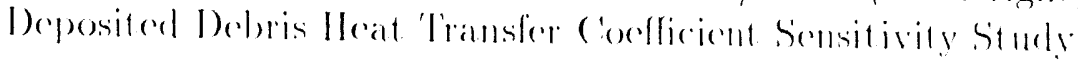


Table 6.5.1. Hydrogen Generation for the SNL/IET Lxperiments. Deposited Debris Heat Transfer Coefficient Sensitivity Study

\begin{tabular}{|c|c|c|c|c|c|}
\hline \multirow[t]{4}{*}{ Experiment } & \multicolumn{5}{|c|}{ Hydrogen Produced (gm-moles) } \\
\hline & \multirow[t]{3}{*}{ Data† } & \multicolumn{4}{|c|}{ MELCOR $\ddagger$} \\
\hline & & \multicolumn{4}{|c|}{ HTC $C_{F D I-H S=}$} \\
\hline & & $1 \mathrm{w} / \mathrm{m}^{2}-\mathrm{K}$ & $10 \mathrm{w} / \mathrm{m}^{2}-\mathrm{K}$ & $100 \mathrm{w} / \mathrm{m}^{2}-\mathrm{K}$ & $1000 \mathrm{w} / \mathrm{m}^{2}$ \\
\hline [ET- 1 & 233 & $286 / 266$ & $284 / 264$ & $287 / 273$ & $307 / 294$ \\
\hline IET-1R & 248 & $266 / 267$ & $266 / 266$ & $266 / 270$ & $286 / 296$ \\
\hline IET -3 & 227 & $232 / 352$ & $231 / 350$ & $234 / 351$ & $252 / 347$ \\
\hline IET -4 & 303 & $243 / 361$ & $247 / 364$ & $248 / 361$ & $264 / 353$ \\
\hline IET-5 & 319 & $240 / 313$ & $242 / 313$ & $243 / 319$ & $260 / 3.37$ \\
\hline IET -6 & 319 & $236 / 354$ & $237 / 355$ & $239 / 35.3$ & $256 / 348$ \\
\hline IET-7 & 274 & $229 / 351$ & $2.30 / 350$ & $230 / 347$ & $246 / 342$ \\
\hline
\end{tabular}

Table 6.5.2. Hydrogen Combustion for the SNL/IET Experiments Deposited Debris Heat Transfer Coefficient Sensitivity Study

\begin{tabular}{lccccc} 
Experiment & Datat & \multicolumn{5}{c}{$\begin{array}{c}\text { Hydrogen Burned (gm-moles) } \\
\text { MELCOR } \\
\text { HTC }\end{array}$} \\
& & $1 \mathrm{w} / \mathrm{m}^{2}-\mathrm{K}$ & $10 \mathrm{w} / \mathrm{m}^{2}-\mathrm{K}$ & $100 \mathrm{w} / \mathrm{m}^{2}-\mathrm{K}$ & $1000 \mathrm{w} / \mathrm{m}^{2}-\mathrm{K}$ \\
IET-1 & 3 & $0 / 4$ & $0 / 4$ & $0 / 4$ & $0 / 4$ \\
IET-1R & 11 & $0 / 28$ & $0 / 28$ & $0 / 28$ & $0 / 28$ \\
IET-3 & 190 & $188 / 313$ & $186 / 310$ & $193 / 315$ & $220 / 327$ \\
IET-4 & 240 & $209 / 332$ & $211 / 333$ & $215 / 333$ & $235 / 339$ \\
IET-5 & 53 & $0 / 91$ & $0 / 90$ & $0 / 89$ & $0 / 88$ \\
IET-6 & 345 & $182 / 307$ & $182 / 307$ & $187 / 307$ & $211 / 317$ \\
IET-7 & 323 & $223 / 350$ & $224 / 349$ & $222 / 344$ & $231 / 339$
\end{tabular}

tfrom gas grab bottle samples at $30 \mathrm{~min}$ $\ddagger($ actual values at $20 \mathrm{~s}) /$ (assuming only steam/metal reactions) 

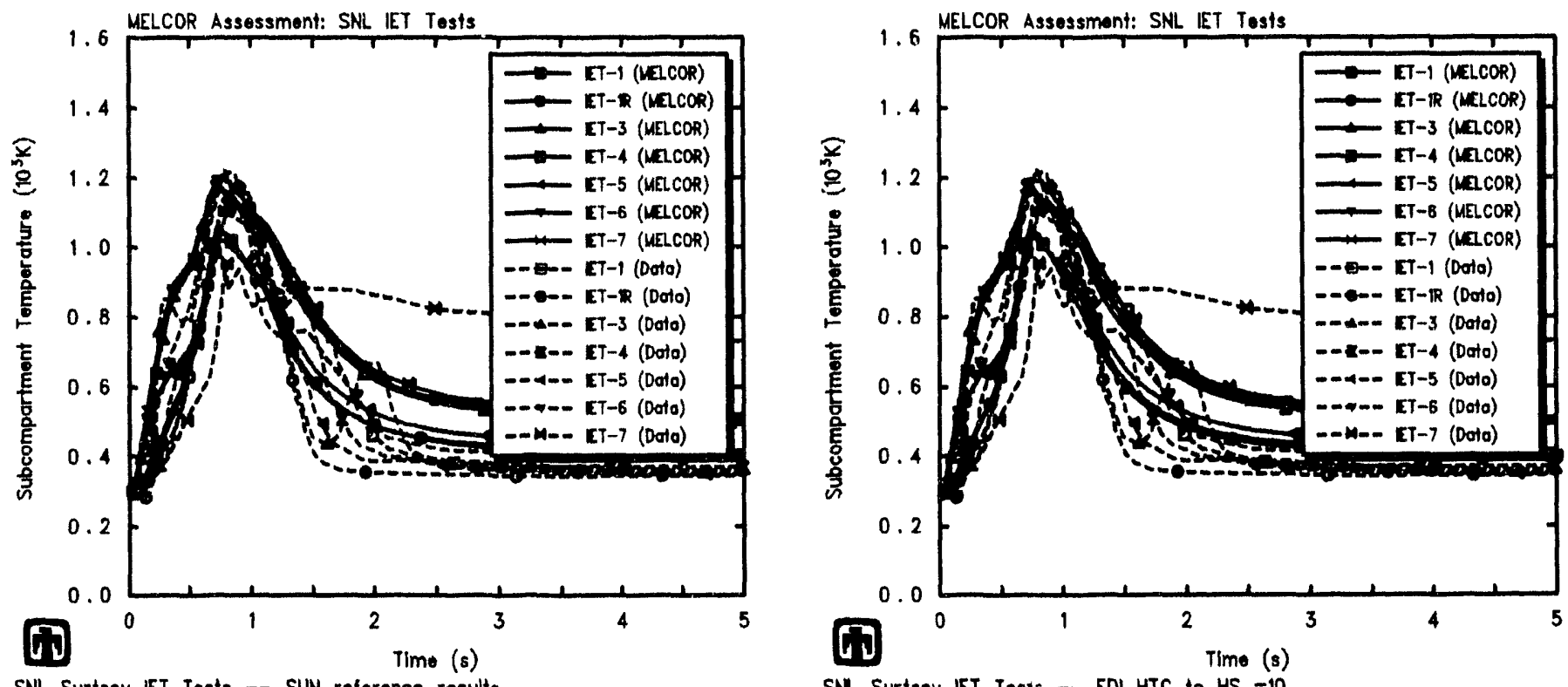

SNL Surtsoy IET Tosts -- SUN reforence results FIDOBDQNN 6/09/93 14:12:52 MELCOR SUN

SN Surtsoy IET Tosis -- FDI HTC to HS $=10$ FJDQEPGNN 6/10/93 16:51:41 MELCOR SUN
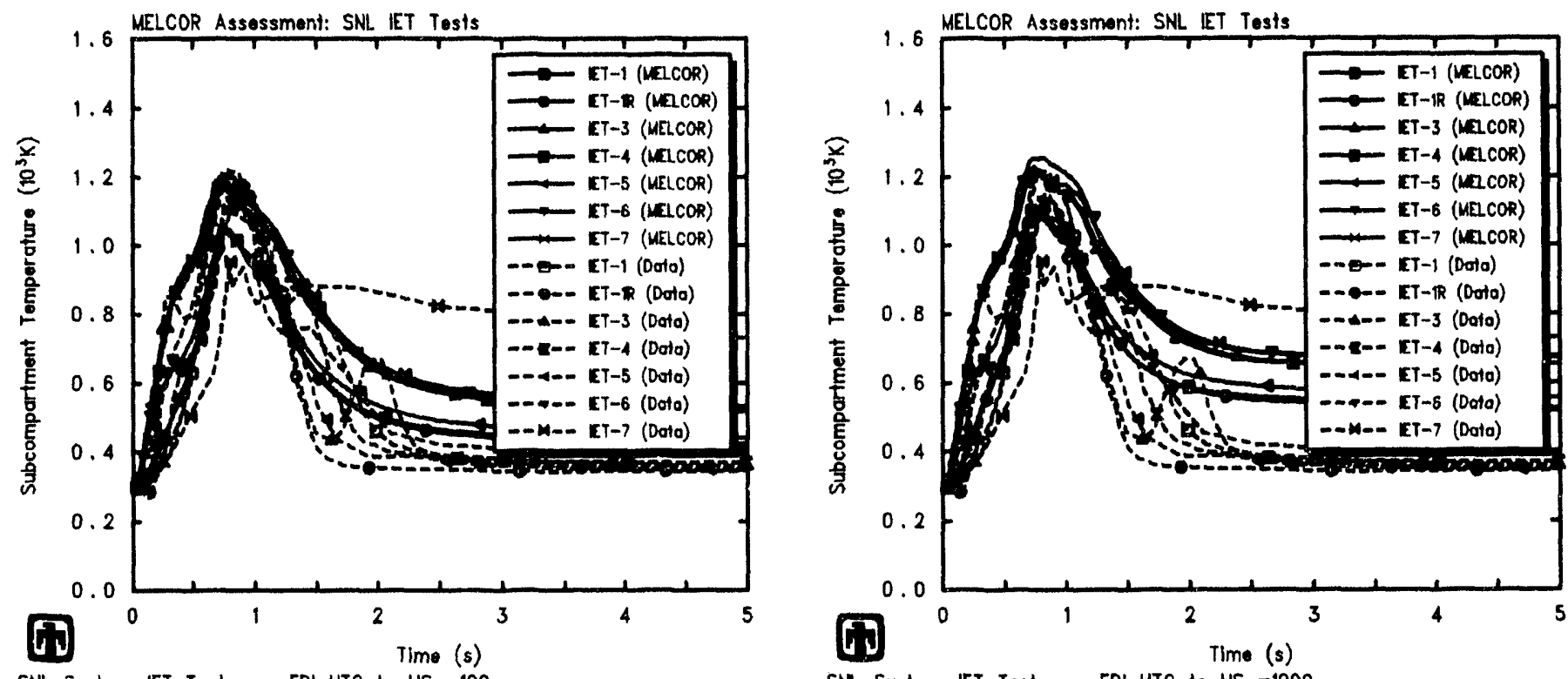

SNL Surtsey IET Tests -- FDI HTC to HS $=100$ FJDQEORNN 6/10/93 16:51:30 MELCOR SUN

Figure 6.5.2. Subempantment Jemperatures for SNL/LWT Experiments Ising Deposited Debris Ileat Transfor ('oefliciont of $1 \mathrm{w} / \mathrm{m}^{2}-K$ (upper left).

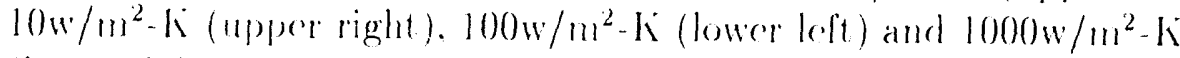
(lower right) Deposited Dobris Heat Transfer Coefficient Sensitivity Study 


\section{Other Modelling Studies}

In addition to the sensitivity studies on user-input parameters controlling the initial debris source and the subsequent debris interaction, respectively, in the new MELCOR high-pressure melt cjection model in MELCOR, presented in Sections 5 and 6 , several other non-default input modelling changes involving other MEL(COR code packages were recuired in our IET assessment analyses, as already discussed in Section 3.1. This section presents the studies whose results demonstrate the need for those non-default input modelling changes.

\subsection{Hydrogen Combustion}

As described in Section 3.1, in the majority of our IET analysis calculations, the burn package was activated. However, burns were suppressed in all control volumes except the vessel dome; this was based upon the experimental observation that a jet of hydrogen produced by steam blowdown and debris oxidation burned as it vented from the subcompartments to the upper dome. The default ignition criterion in the absence of igniters was set to a hydrogen mole fraction of 0.0 , but the combustion completeness was also set to 0.0; this prevents the burning of any pre-existing hydrogen, lint allows burning of any additional hydrogen generated during the IIPME. This was based upon the experimental observation that the pre-existing hydrogen that burned did not burn on a time scale that had a significant impact on the peak pressure [15, 16]. This particular combination of input was found to produce reasonable agrement with test data in all cascs.

To evaluate this input selection, sensitivity studies using other possible input settings were done. Sets of calculations were done with the burn parkage inactivated; with the burn package active but all default input used; with the default hydrogen-mole-fraction ignition criterion in the absence of igniters and the combustion completeness both set to 0.0 , but burn allowed in all control volumes; and with the defanlt hydrogen-mole-fraction ignition criterion in the absence of igniters set to 0.0 but the combustion completeness either calculated from the default correlation or set to 1.0 (with burn suppressed in all control volumes except the vessel dome).

The predicted vessel pressures are presented in Figure 7.1 .1 for some of the hydrogen combustion studies. Tables 7.1 .1 and 7.1 .2 compare the amounts of hydrogen generated and burned, respectively, in all these various cases. Subcompartment temperatures corresponding to the pressures shown in Figure 7.1.1 are given in Figure 7.1.2. (Experimental data are included for reference.)

The calculations done with the burn package inactivated and with the burn package active but all default input used produced identical results; no hydrogen combustion occurred even with the burn package activated because the hydrogen and oxygen mole fraction concentrations precluded ignition. 

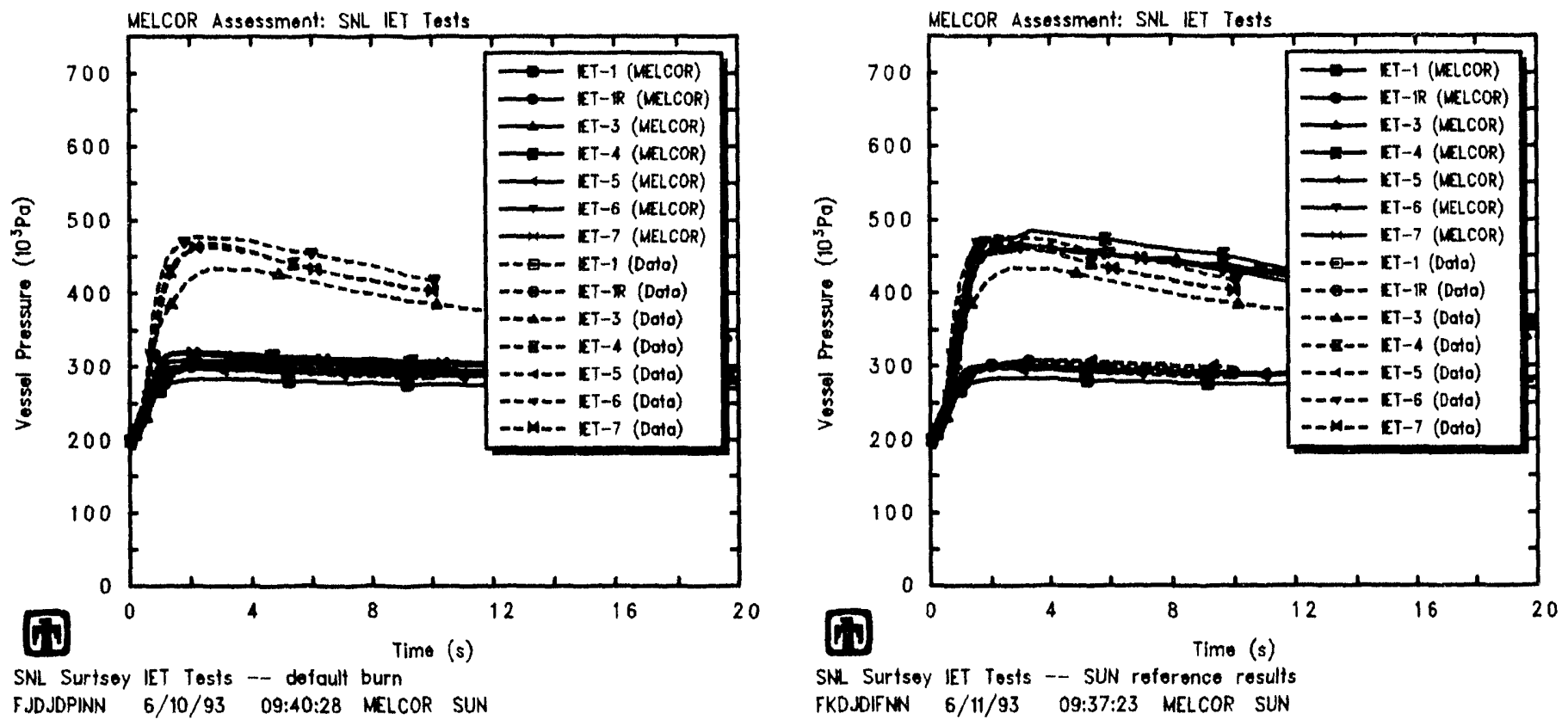

SNL Surtsey IET Tosis - - SUN reforence results

FKD JOIFNN 6/11/93 09:37:23 MELCOR SUN
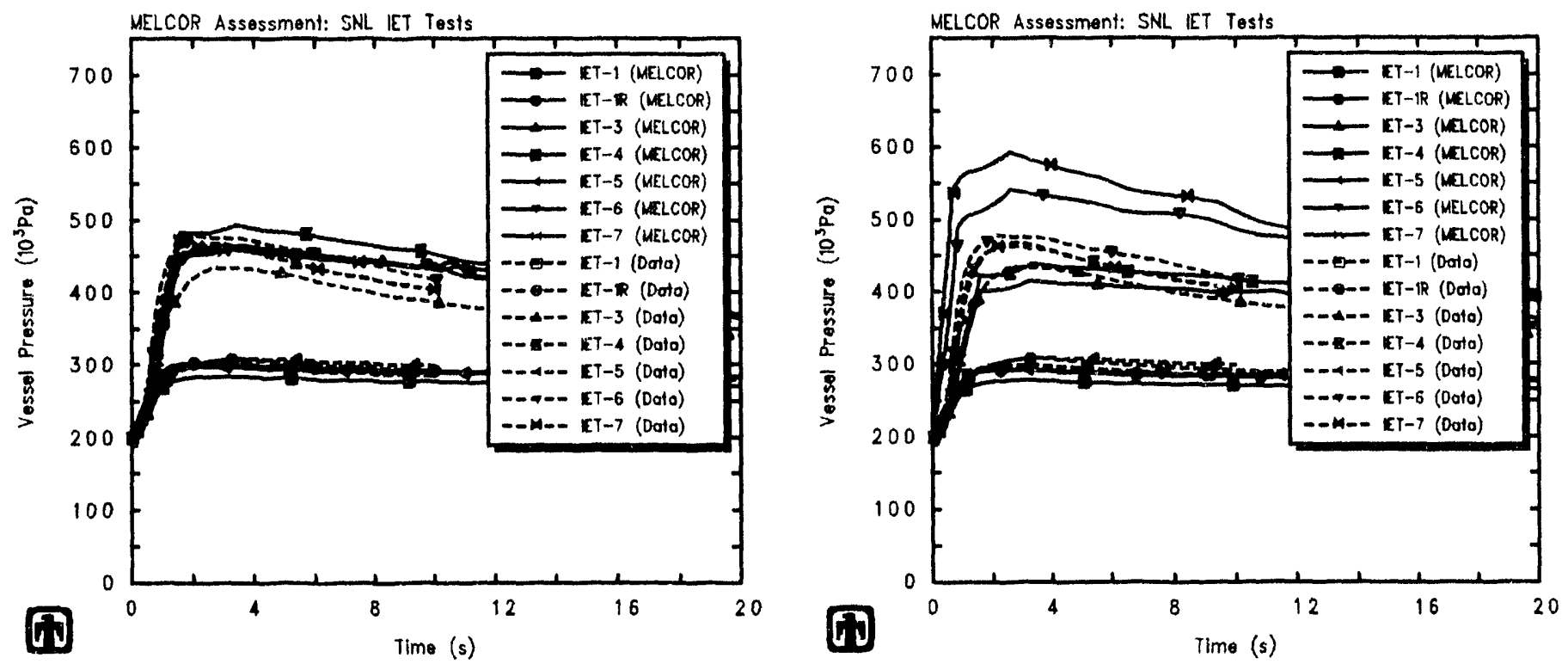

SNL Surtsoy IET Tests -- burn in all volumos FJDLCFQNN $6 / 10 / 93 \quad 11: 25: 00$ MELCOR SUN

SNL Surtsey IET Tesis -- combustion completeness HSDMCPFNW $8 / 19 / 93 \quad$ 12:29:09 MELCOR SUN

Figure 7.1.1. Vesser Pressures for SNL/IET Experiments with Deflault Burn Parameters (uppere left.), Basecase with Burn in the Dome Only with Karo Ignition lianit and (ombustion ('ompleteness of () (upper right), with Burn in all Volumes with Kero lgnition limit and ('ombustion ('ompleteness of 0 (bower left) and with Bum in the Dome Only with Zero Ignition Limit but ('ombustion ('ompleteness of I (lower right) Hydrogen ('ombustion Sensitivity Study 
Table 7.1.1. Hydrogen Generation for the SNL/IET Experiments - Hydrogen Combustion Sensitivity Study

\begin{tabular}{|c|c|c|c|c|c|c|c|}
\hline \multirow[t]{3}{*}{ Experiment } & \multirow{3}{*}{ Datà̀ } & \multicolumn{6}{|c|}{ Hydrogen Produced (gm-moles) } \\
\hline & & & & & MELCOR & & \\
\hline & & no-burn & def-burn & $\begin{array}{l}\text { burn in dome only } \\
\text { with } C C=0\end{array}$ & $\begin{array}{l}\text { burn in dome only } \\
\text { with default } C C\end{array}$ & $\begin{array}{c}\text { burn in all vol } \\
\text { with } C C=0\end{array}$ & $\begin{array}{l}\text { burn in dome o } \\
\text { with } C C=1\end{array}$ \\
\hline IET- 1 & 233 & $286 / 266$ & $286 / 266$ & $286 / 266$ & $286 / 266$ & $286 / 266$ & $218 / 199$ \\
\hline IET-1R & 248 & $266 / 267$ & $266 / 267$ & $266 / 267$ & $266 / 267$ & $266 / 267$ & $200 / 203$ \\
\hline IET-3 & $22 i$ & $233 / 342$ & $233 / 342$ & $232 / 352$ & $232 / 352$ & $242 / 350$ & $162 / 291$ \\
\hline IET-4 & 303 & $24 \bar{i} / 351$ & $24 \overline{7} / 351$ & $243 / 361$ & $243 / 361$ & $256 / 370$ & $17 \tau / 307$ \\
\hline IET -5 & 319 & $240 / 313$ & $240 / 313$ & $240 / 313$ & $240 / 313$ & $240 / 313$ & $172 / 249$ \\
\hline IET-6 & 319 & $238 / 344$ & $238 / 344$ & $236 / 354$ & $236 / 354$ & $240 / 3.51$ & $170 / 300$ \\
\hline IET-T & 274 & $230 / 336$ & $230 / 336$ & $229 / 3.51$ & $229 / 3.51$ & $230 / 348$ & $167 / 295$ \\
\hline
\end{tabular}

ifrom gas grab bottle samples at $30 \mathrm{~min}$

$\ddagger$ (actual values at $20 \mathrm{~s}) /$ (assuming only steam/metal reactions

Table 7.1.2. Hydrogen Combustion for the SNL/IET Experiments - Hydrogen

Combustion Sensitivity Study

Experiment

Datał

no-burn
Hỵdrogen Burned (gm-moles) MELCOR

burn in dome only burn in all vol burn in dome only with $C C^{\prime}=0 \quad$ with default $C C^{\circ}$ with $C C=0$ with $C C=1$

$\begin{array}{lccccccc}\text { IET-1 } & 3 & 0 / 4 & 0 / 4 & 0 / 4 & 0 / 4 & 0 / 4 & 0 / 4 \\ \text { IET-1R } & 11 & 0 / 28 & 0 / 28 & 0 / 28 & 0 / 28 & 0 / 28 & 0 / 28 \\ \text { IET-3 } & 190 & 0 / 126 & 0 / 126 & 188 / 313 & 188 / 313 & 208 / 321 & 158 / 291 \\ \text { IET-4 } & 240 & 0 / 123 & 0 / 123 & 209 / 332 & 209 / 332 & 232 / 350 & 174 / 307 \\ \text { IET-5 } & 53 & 0 / 91 & 0 / 91 & 0 / 91 & 0 / 91 & 0 / 91 & 0 / 92 \\ \text { IET-6 } & 345 & 0 / 126 & 0 / 126 & 182 / 307 & 182 / 30 i & 215 / 328 & 350 / 471 \\ \text { IET-7 } & 323 & 0 / 125 & 0 / 125 & 223 / 350 & 229 / 350 & 239 / 357 & 452 / 567\end{array}$



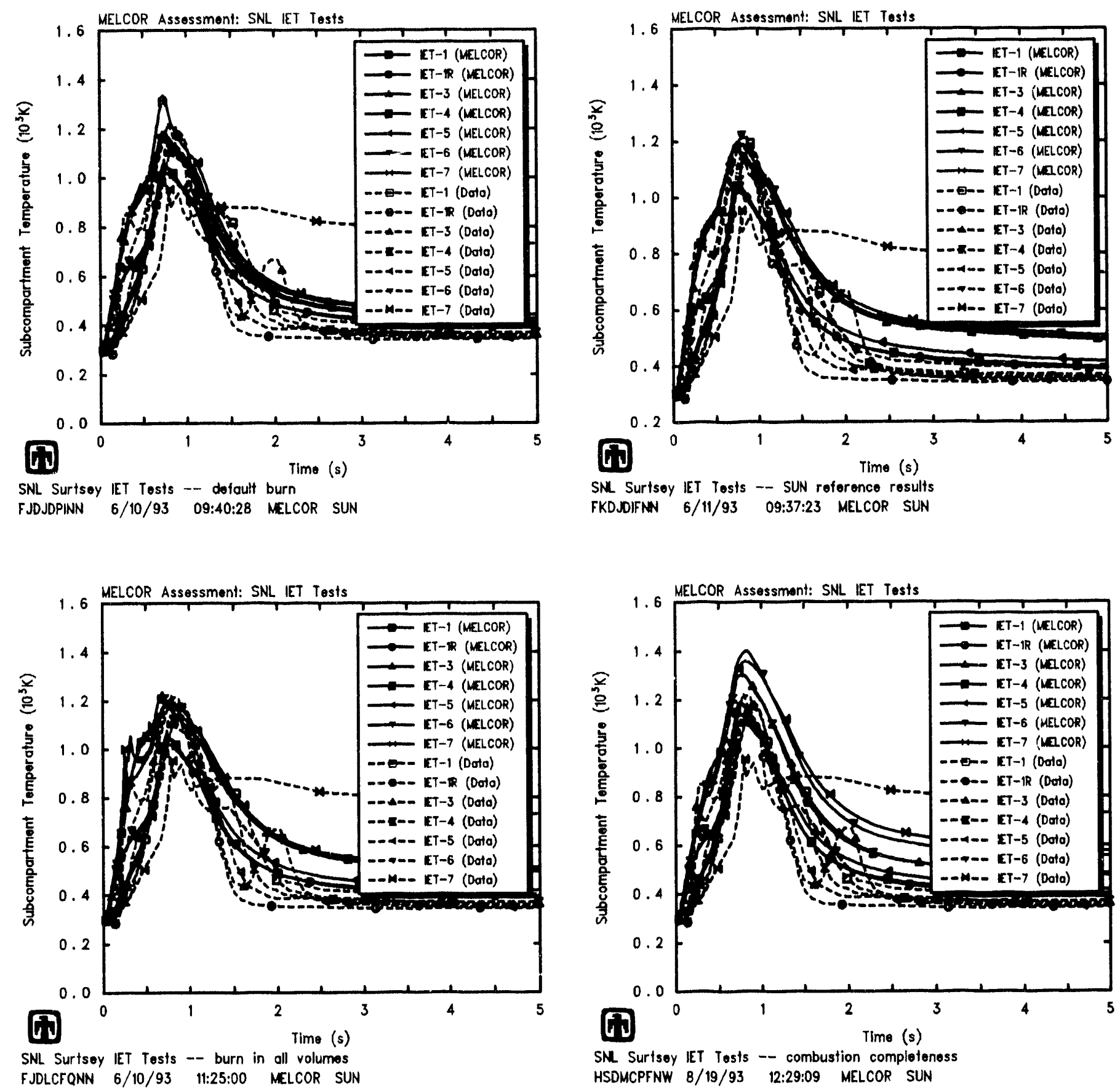

SN Surtsey IET Tests -- combustion completeness HSDMCPFNW B/19/93 12:29:09 MELCOR SUN

Figure 7.1.2. Subcomparment Tomperalures for SN/L/LI lixperiments with Delault Burn Parameters (upper left), Basecase with Burn in the Dome Only with Kero Ignition Limit and Combustion Completeness of 0 (upper right), with Burn in all Volumes with Zero Ignition limit and Combustion (ompleteness of 0 (lower left) and with Burn in the Dome Only with Zaro Ignition Limit but Combustion Completeness of 1 (lower right) Iydrogen (ombustion Sensitivity Study 
The hydrogen combustion behavior predicted using default burn package input is clearly qualitatively different than observed in these experiments. It was obvious from the test results that the hydrogen mole fraction ignition criterion had to be reset to $\sim 0$, at least during the DCH period. It appeared from the SNL/IET-5 test results that the steam and $\mathrm{CO}_{2}$ mole fraction limits for inerting volumes did not need to be changed, and there was no clear indication from the test data whether the oxygen mole fraction ignition criterion had to be altered (so it wasn't).

The results obtained with the combustion completeness set to 0 and with the default combustion completeness correlation used were identical. This is because in these problems the LeChatelier formula is simply the hydrogen mole fraction (because $x_{C O}=0.0$ ) and, with the hydrogen mole fraction ignition limit reset to 0.0 , the LeChatelier formula at the beginning of the burn $\left(Y_{M A X}\right)$ is also 0.0 , and the default correlation used in MELCOR gives combustion completeness $C C=0.0$ for $Y_{M A X} \leq 0.03746$. Note that a combustion completeness equal to 0.0 does not mean no combustion; instead, it tries to maintain the mole fractions after the burn to be equal to the mole fractions before, so that new hydrogen introduced during a time step, either by oxidation or by advection, will be burned but pre-existing hydrogen will remain present and generally unreacted. This agrees much better with experimental data than the results obtained using a combustion completeness of 1.0 , which produces much higher vessel pressurization and hydrogen combustion in the tests with pre-existing hydrogen than observed in the experiments.

\subsection{Heat Transfer to Structures}

As discussed in Section 3.1, most of our calculations were run with control volume flow areas reduced by factors of $\geq 10$ from their default values, to enhance convective heat transfer from the control volume atmospheres to the heat structure surfaces. (Recall that the control volume flow area is used only to calculate the velocities used in convective heat transfer correlations, and thus decreasing the volume flow area is a simple and direct, way of multiplying volume flow velocities; these studies did not change fow path areas or velocities.) This was done for two reasons:

First, the flow through the system in these calculations was primarily that associated with the steam blowdown only, flowing from the steam accumulator through the cavity and chute volumes to the subcompartments and then to the dome. The MELCOR FDI/HPME/DCII model does not model transport of debris between and through volumes but instead deposits the debris directly at its ultimate destination, using the same time-dependent deposition in all volumes regardless of their distance from the debris source. In reality, the melt reaches the subcompartments later than the cavity, and the dome later than the subcompartments. Thus, instead of debris being transported into an "upstream" volume (e.g., the cavity or the subcompartments) with the blowdown steam and the resultant additional heating adding to the driving force pushing flow further "downstream" ( $e g$., from the cavity to the chute or the subcompartments to the dome), the MELCOR logic does not represent this additional fow driving force and in contrast has debris appearing "upstream" and heating the atmosphere in upstream volumes, if 
anything contributing a retarding force to the expected flow. Thus the only flows generated in these MELCOR analyses were those associated with the steam accumulator blowdown, a relatively benign event compared to high-pressure melt ejection with hot debris mixed with the blowdown steam (as can be seen from the relative contributions to vessel pressurization given in 'Table 4.4).

Decreasing volume flow areas results in increased volume velocities more characteristic of the turbulent conditions that might be expected during HPME, and the associated turbulent forced convection heat transfer to structures. For the subcompartment control volume, in particular, it also reflects the fact that there is not a single, large, open subcompartment volume in the Surtsey facility but instead a collection of subcompartments, each with smaller volume and internal flow area and with smaller-area openings connecting the subcompartments to each other and to the dome. Thus, a (default) volume flow area of $\geq 4.5 \mathrm{~m}^{2}$ obtained using the subcompartment volume of $4.65 \mathrm{~m}^{3}$ and a height of $\geq 1 \mathrm{~m}$ may not be indicative of the actual velocities in the subcompartments.

In addition, the MELCOR FIDI/HPME/DCH model does not account for any radiation directly from airborne debris to surrounding structures for from deposited debris directly to atmosphere). There is little or no calculated atmosphere-structure radiation heat transfer early in these transients (except in IET-5), because MEI('OR only considers radiation heat transfer for steam and/or ( $\mathrm{O}_{2}$ in atmospheres. In [E]'-5), some atmosphere-structure radiation heat transfer is calculated because of the large amount of $\mathrm{C}_{2}$ used to inert the system; however, in most of the experiment simulations there is very little steam present early in the transient, because any blowdown steam is consumed in debris oxidation soon after arrival, and very little $(?)_{2}$ present at all. The lack of steam and/or $\mathrm{CO}_{2}$ in the atmosphere would if anything enhance radiation heat, transfer from airborne debris to structures because there would be lit te absorption in the intervening atmosphere. Because there is no way in MELCOR to model this effect, too much energy may be deposited in the atmosphere by the airborne debris; because there is no convenient, way to enhance atmosphere-structure radiation heat transfer in general, we relied on increasing convective heat transfer instead to help remove that cuergy.

Figure 7.2 .1 presents the heat transfer coefficients calculated for the subcompartment wall structure inner surface by MELCOR, with no adjustment to volume flow areas or to overall heat transfer; this heat transfer coefficient sums both the convective and radiative terms. During the first second, the heat transfer coefficient is in the $\sim 5-25 \mathrm{w} / \mathrm{m}^{2}-\mathrm{K}$ range (except for IET-5) and (except for IE'T-5) is due primarily to convective heat transfer. The larger heat transfer coefficients in IET-5 and after $\sim 1$ s for the other test simulations (when steam is no longer being consumed in debris oxidation and a significant steam mole fraction appears) are due to the addition of a radiation term cquivalent to $\leq 50 \mathrm{~W} / \mathrm{m}^{2}-\mathrm{K}$, which then drops in magnitude as the atmosphere temperature drops.

The radiation heat transfer coefficient for an emissivity of 0.8 and a wall iemperature of $300 \mathrm{~K}$ was estimated [34] to be $\sim 65 \mathrm{w} / \mathrm{m}^{2}-\mathrm{K}$ for an atmosphere temperature of $1000 \mathrm{~K}$ and $\sim 425 \mathrm{w} / \mathrm{m}^{2}-\mathrm{K}$ for an atmosphere at $2000 \mathrm{~K}$, in reasonable agreement with the MELCOR value given the effect of gas components other than steam and $\mathrm{CO}_{2}$ present. However, spread sheet calculations [34] suggest that forced convection heat transfer co- 


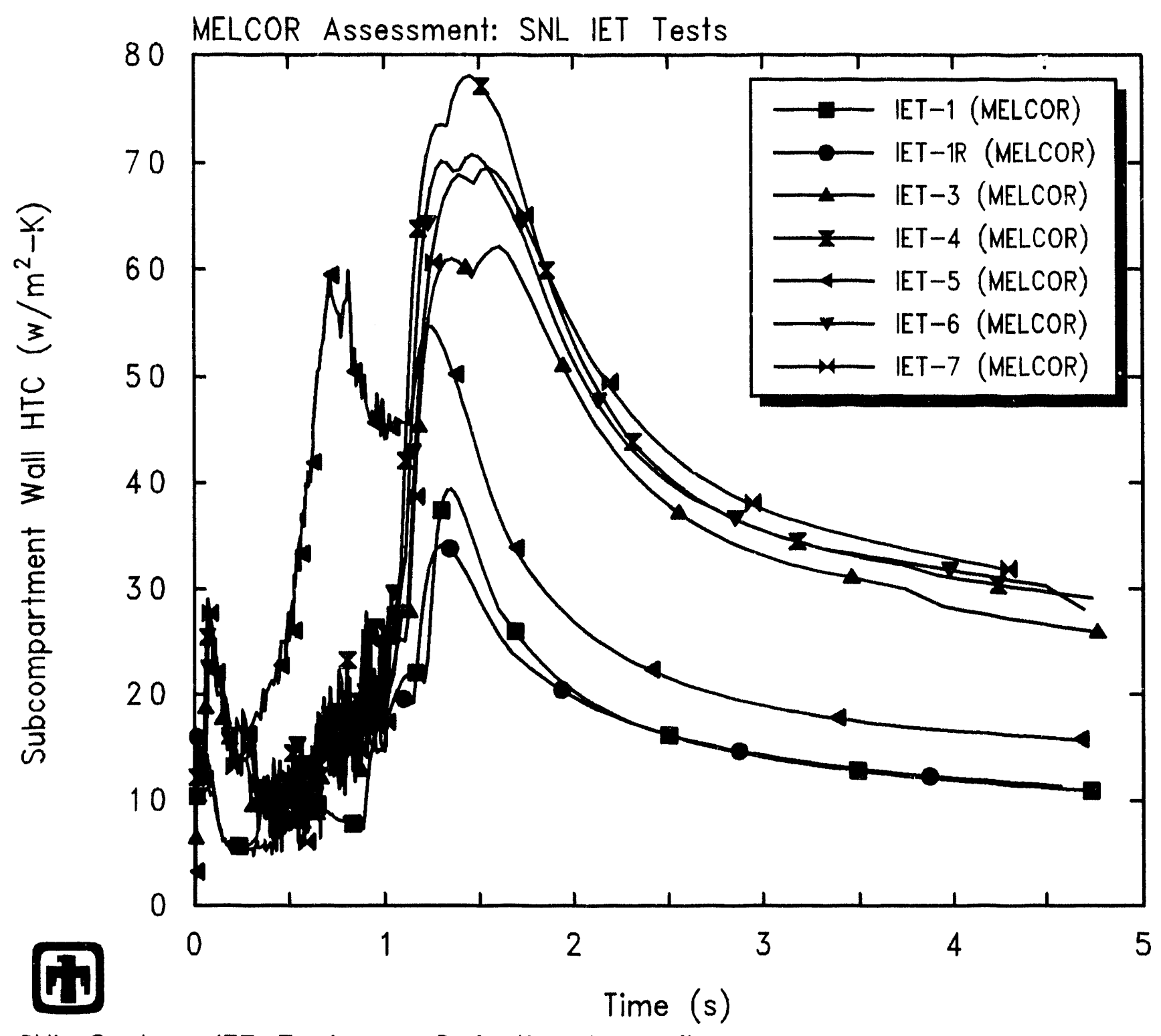

SNL Surtsey IET Tests -- Default volume flow area HODNEZJNW 8/27/93 13:56:06 MELCOR SUN

Figure 7.2.1. Subcompartment Atmosphere-to-Structure Heat Transfer Coefficients for SNI/IET Fxperiments Using Default Volume Flow Areas/Velocities --. Convective Heat Transfer Sensitivity Study 
efficients should be in the $\sim 50-125 \mathrm{w} / \mathrm{m}^{2}-\mathrm{K}$ range for conditions characteristic of the subcompartments in the SNL/IET experiments near the time of peak temperature and pressure. This is significantly higher than the convective heat transfer coefficients calculated in MELCOR with no volume flow area or characteristic velocity adjustment. (Similarly, the convective heat transfer coefficient given by MELCOR for the cavity and chute is in the $20-250 \mathrm{w} / \mathrm{m}^{2}-\mathrm{K}$ range, while spread sheet calculations [34] suggest that forced convection heat transfer coefficients should be in the $\sim 6000-1500 \mathrm{w} / \mathrm{m}^{2}-\mathrm{K}$ range for conditions characteristic of the cavity in the SNL/IET experiments near the time of peak temperature and pressure.)

Other hand calculations [35] showed that the effective heat transfer coefficient for direct radiation from airborne debris in the subcompartments to the structure walls (an effect not modelled by MELCOR) could be of the order $0.2 / R_{d}$, where $R_{d}$ is the debris particle radius. This assumes a debris temperature of $2300 \mathrm{~K}$, a wall temperature of $300 \mathrm{~K}$, and an emissivity of 1 , and also assumes that the airborne debris particles occupy negligible volume so that the radiation view factor from the airborne debris to the walls is $\sim 1$. Posttest sieve analysis of debris recovered from outside the subcompartment structures in SNL/IET-6 [15] shows diameters ranging from $0.05 \mathrm{~mm}$ to $10 \mathrm{~mm}$; for $10 \mathrm{~mm}$-diameter debris particles, the effective heat transfer coefficient for radiation to structures would be $\sim 20 \mathrm{w} / \mathrm{m}^{2}-\mathrm{K}$, while for $0.1 \mathrm{~mm}$-diameter debris particles, the effective heat transfer coefficient for radiation to structures would be $\sim 2,000 \mathrm{w} / \mathrm{m}^{2}-\mathrm{K}$. This could therefore be a significant heat transfer mechanism, early in the transient. Because there is no way in MELCOR to model this effect, too much energy may be deposited in the atmosphere by the airborne debris; because there is no convenient way to enhance atmosphere-structure radiation heat transfer in general, we relied on increasing convective heat transfer instead to help remove that energy.

'o evaluate the effect of heat transfer to the structures, a set of sensitivity calculations were done with the default volume flow areas and with the volume flow areas progressively reduced by factors of 10,100 and 1000 . Figure 7.2 .2 presents the resulting atmosphere-to-structure heat transfer coefficients for the subcompartments. Note that, while decreasing the volume flow area by a given factor increases the volume velocity by that same factor, the heat transfer coefficient does not change by the same factor, both because changing the velocity can change the heat transfer mode and hence the correlation used and because most of the correlations depend on the velocity to a power $\left(v^{0.8}\right.$ for turbulent forced convection, $v^{0.5}$ for laminar forced convection and $v^{0.33}$ or $v^{0.25}$ for natural convection). Thus, increasing defarlt volume areas by 10 increased subcompartment atmosphere-to-structure convective heat transfer coefficients by $\leq 10$ but increasing default volume areas by 100 only increased convective heat transfer coefficients by $\sim 50$ and increasing increasing default volume areas by 1000 only increased convective heat, transfor coefficients by $\sim 250$.

Resulting predicted vessel pressures with the default volume flow areas and with the volume flow areas progressively reduced by factors of 10,100 and 1000 are shown in Figure 7.2.3, together with the test data. The effect of increasing volume velocities and therefore increasing overall heat transfer to structures is to reduce the overall vessel 

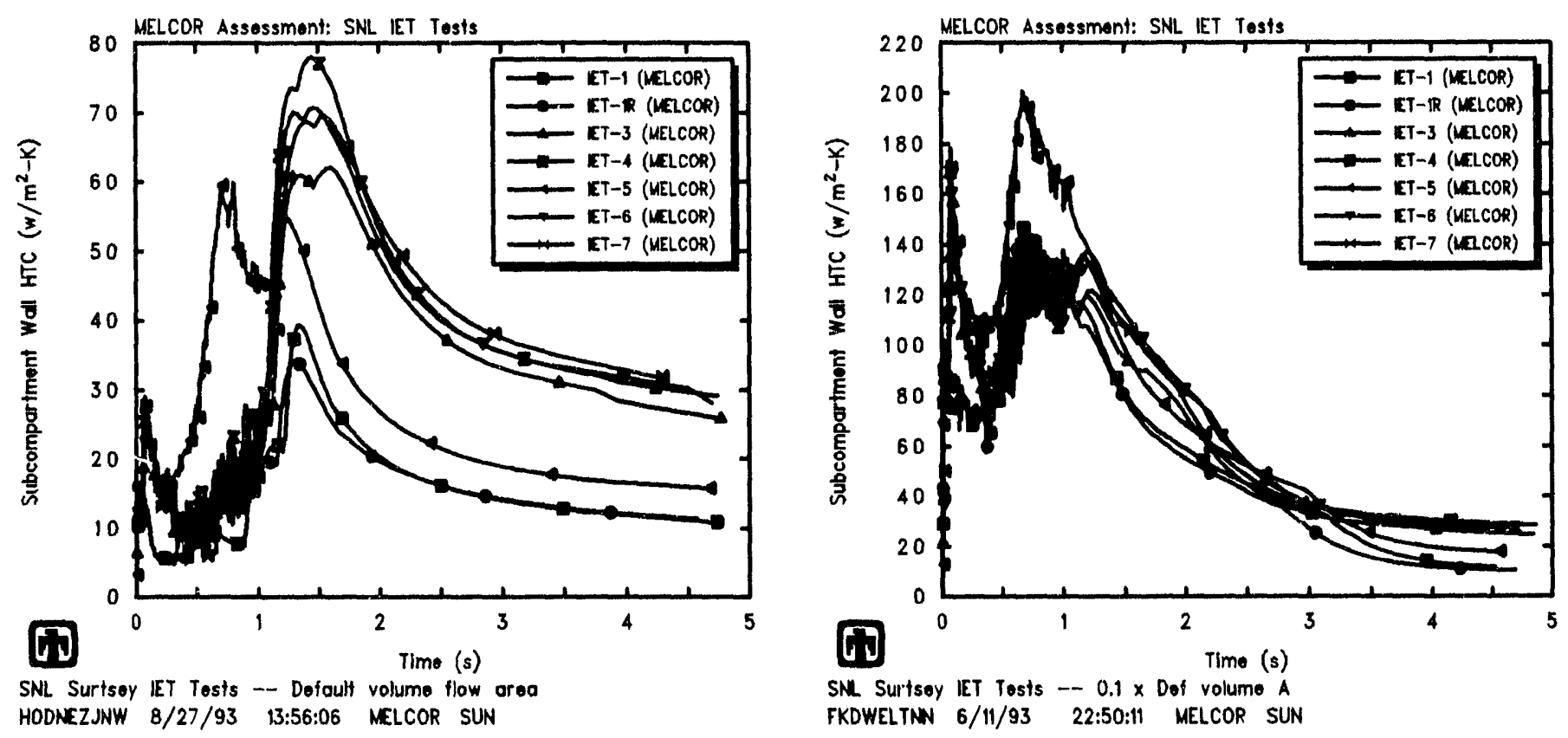

SNL Surtsey IET Tosts -- $0.1 \times$ Dof volume A

FKDWELTNN 6/11/93 22:50:11 MELCOR SUN
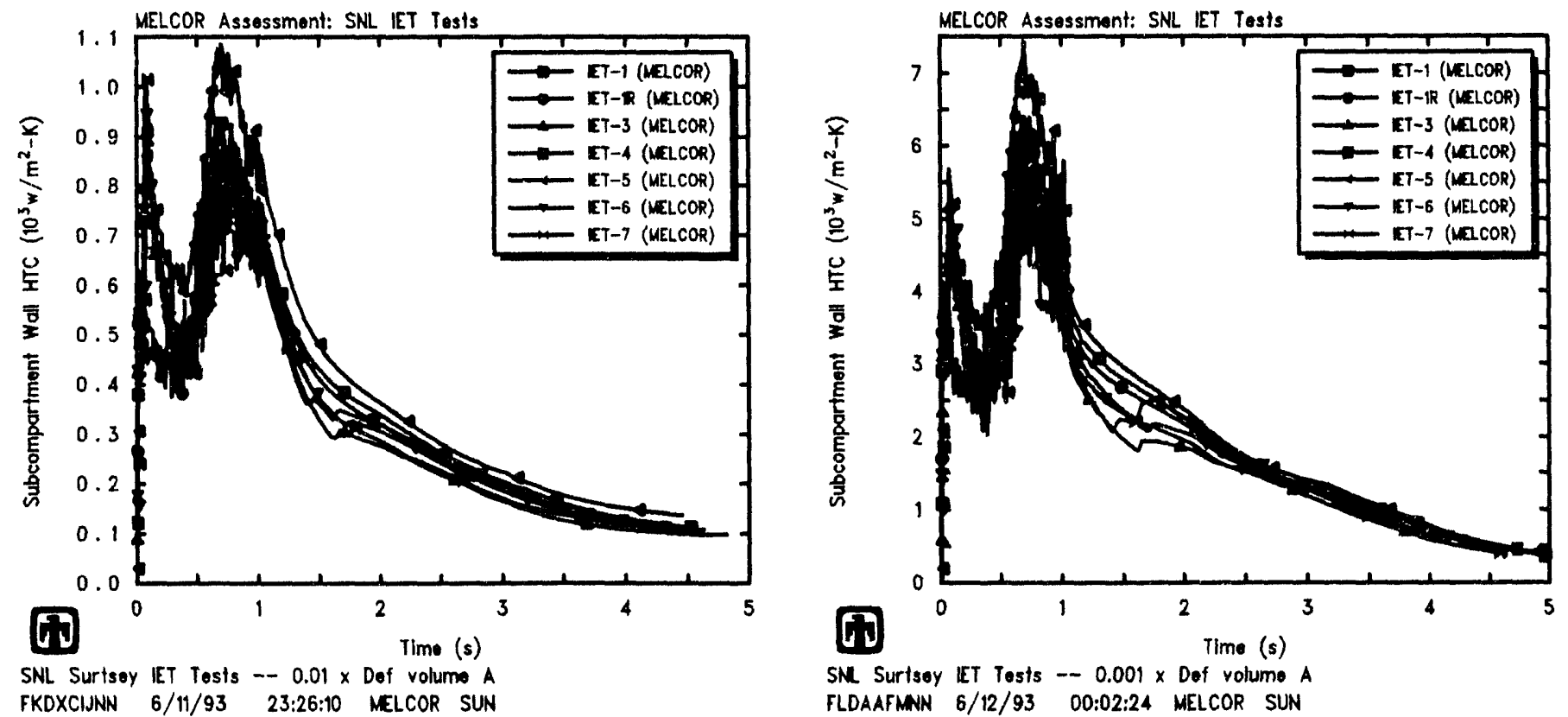

Figure 7.2.2. Subcompartment Atmosphere-to-Structure lleat Transfer Coeffecients for SNL/IET Experiments Using Default Volume flow

Arcas/Velocities (upper left), $0.1 \times$ Volume Flow Areas (upper right). $0.01 \times$ Volume Flow Areas (lower left) and $0.001 \times$ Volume Flow Areas (lower right) Convective Heat Transfer Sensitivity Study 
pressurization calculated.

Tables 7.2.1 and 7.2.2 compare the amounts of hydrogen generated and burned, respectively, in these various cases. While the trend is not as strong as that seen in the vessel pressure responses, slightly more hydrogen generation is calculated as the heat transfer to structures is increased in most cases; the hydrogen combustion varies as the hydrogen production, so increasing production tends to increase combustion also.

The volume areas and velocities have a very strong effect on the temperatures predicted, as illustrated in Figure 7.2.4 for the subcompartments. The calculated temperatures are much higher than measured using the default volume flow areas and velocities or using volume flow areas and velocities decreased and increased by an order of magnitude, respectively; increasing the volume velocities (reducing the defanlt volume flow areas) by 1000 produces significantly lower temperatures than measured in the subcompartments. These changes in atmosphere temperatures are a direct result of changing heat transfer from atmosphere to structures, as would be expected.

\subsection{Recirculation Flow}

'The input model in our MELCOR analyses provided flow pathe for straight-through flow from the steam accumulator to the cavity and chute through the (lumper-together) subcompartments to the vessel dome, and also for recirculation from the upper dome to the subcompartments. That "recirculation" flow path was provided to allow for the fact. that in the actual facility a number of openings exist between the various subcompartments and the vessel dome, with the potential of inflow in some openings and ont flow in others. 'The are*a of that recirculation flow path was set to $10 \%$ of the area of the straight-through flow path from the subcompartments to the dome. Sensitivity studies were done with that recirculation flow path area increased and decreased by a factor of 10 (i.e., set egual to the area of the straight-through flow path from the subcompartments to the dome, and set to $1 \%$ of the area of the straight-through flow path from the subcompartments to the dome), and also simply set to zero.

Figure 7.3.1 shows pressures in the vessel predicted using various recirculation flow path areas (including a zero-area case), together with test data. 'There are visible qualitative and quantitative differences in predicted vessel pressurization both for less and for more ecirculation flow than assumed in our basecase, reference analyses.

The vessel pressurization calculated is slightly lower as the recirculation flow is redued to zero. The direct containment heating in these experiments is primarily driven by debris oxidation in the subcompartments. Because the oxidation rate in the subcompartments is steam-and oxygen-limited, varying the recirculation flow varies the amonnt. of oxygen swept inte the subcompartments from the large rescrvoir in the dome, and thus affects the oxidation rate. In addition, varying the recirculation flow affects the rates at which the rapidly-heated subcompartment atmosphere is mixed with the much rooler, much larger atmosphere in the dome. 

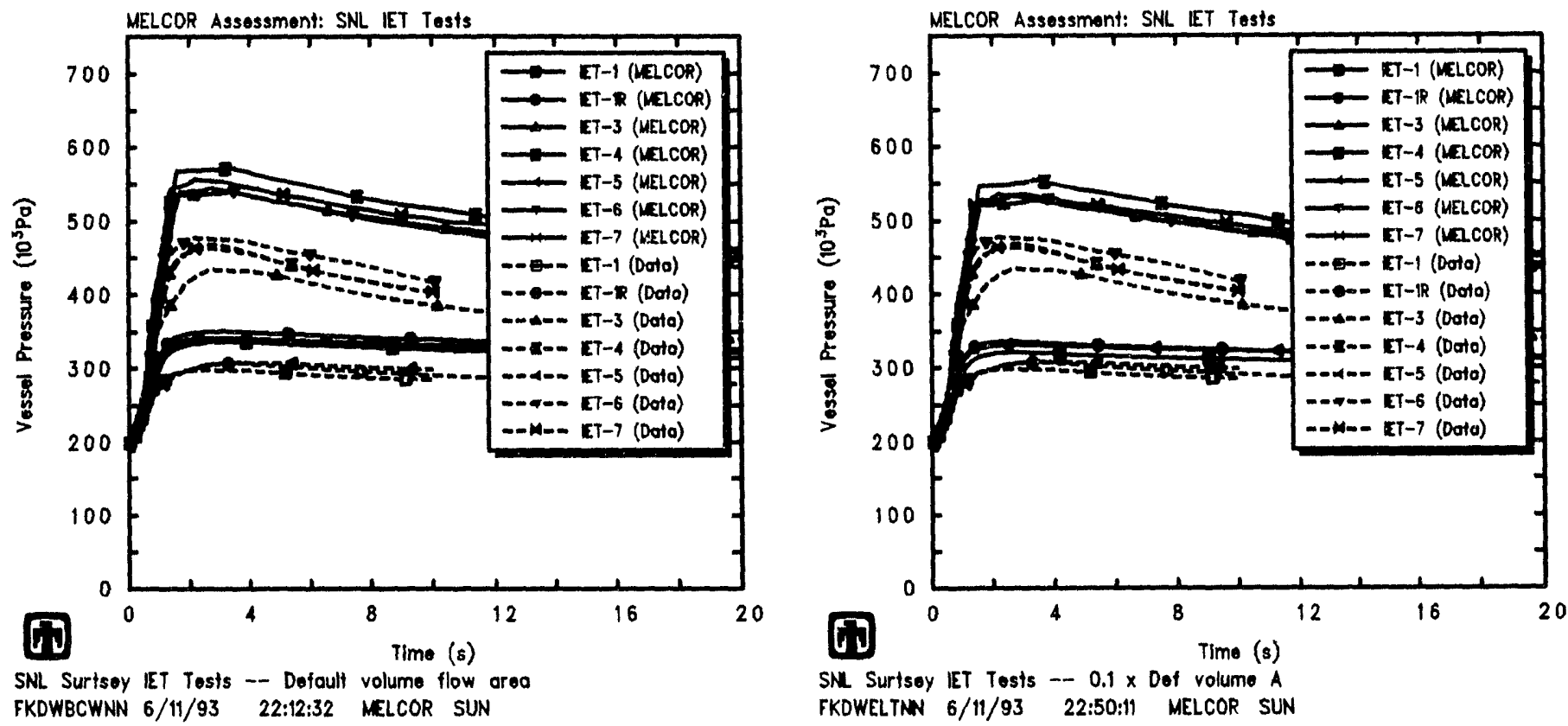

SNL Surtsey IET Tosts - $0.1 \times$ Dof volume $A$

FKDWELTNN 6/11/93 22:50:11 MELCOR SUN
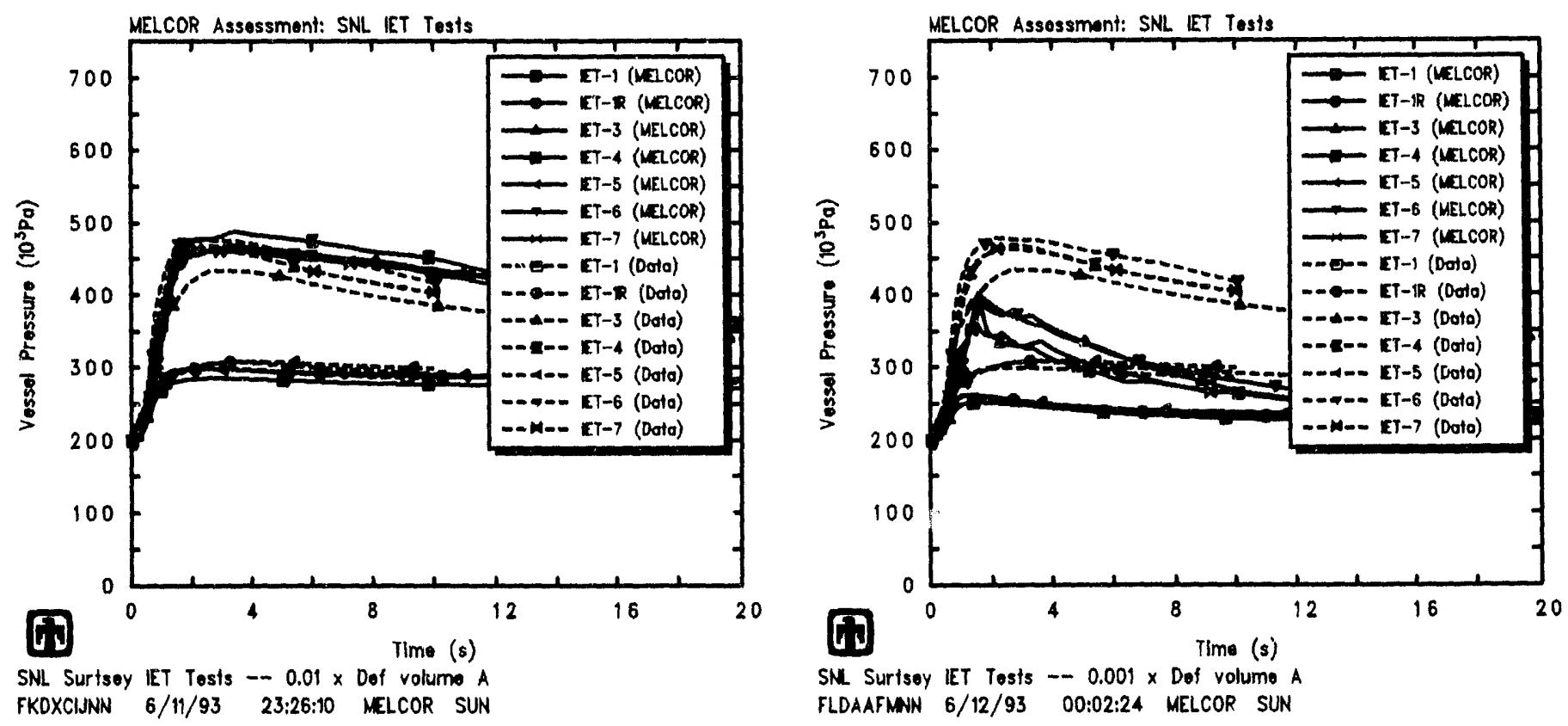

SNL Surisoy IET Tests - $0.001 \times$ Dof volumo A FLDAAFMNN 6/12/93 00:02:24 MELCOR SUN

Figure 7.2.3. Vessel Pressures for SNL/IET Experiments Ising Jefault Volume Flow Areas/Volocities (upper left), $0.1 \times$ Volume Flow Areas (upper right), $0.01 \times$ Volume Flow Areas (lower left) and $0.001 \times$ Volume Flow Areas (lower right) Converdive lleat Transfer Sonsitivity Sindy 
Table 7.2.1. Hydrogen Generation for the SNL/IEI Experiments Convective Ileat 'Transfor Sensitivity Study

\begin{tabular}{|c|c|c|c|c|c|}
\hline \multirow[t]{4}{*}{ Experiment } & \multicolumn{5}{|c|}{ Hydrogen Produced (gm-moles) } \\
\hline & \multirow[t]{3}{*}{ Datat } & \multicolumn{4}{|c|}{ MLLCOR } \\
\hline & & \multicolumn{4}{|c|}{$A_{V O L}=$} \\
\hline & & Def & $0.1 \times D)(f$ & $0.01 \times 1) \mathrm{e}$ & $0.001 \times 1) \mathrm{ef}$ \\
\hline IE' $\left[\mathrm{C}^{\prime}-1\right.$ & 233 & $285 / 269$ & $281 / 268$ & $285 / 2633$ & $287 / 273$ \\
\hline IE:T-1R & 248 & $2633 / 271$ & $265 / 273$ & $264 / 26 !$ & $268 / 278$ \\
\hline IE'T'-3 & 227 & $229 / 3440$ & $231 / 344$ & $229 / 349$ & $2333 / 331$ \\
\hline IE' & $30: 3$ & $241 / 354$ & $217 / 359$ & $242 / 361$ & $247 / 347$ \\
\hline IE' $\mathrm{I}^{\prime}-5$ & 319 & $236 / 313$ & $2: 39 / 313$ & $240 / 314$ & $241 / 321$ \\
\hline IE' & 319 & $232 / 3566$ & $2: 32 / 344$ & $234 / 352$ & $235 / 3333$ \\
\hline は:'-7 & 274 & $224 / 312$ & $225 / 3337$ & $225 / 343$ & $231 / 336$ \\
\hline
\end{tabular}

from gas grab bottle samples at $30 \mathrm{~min}$

$\ddagger$ (actual values at 20 s)/ (assuming only steam/metal reactions)

Table 7.2.2. IIydrogen Combustion for the SNL/IEI Experiments Convective Heat Transfer Sensitivity Study

Pxperiment

$$
\begin{gathered}
\text { Hydrogen Burned (gm-moles) } \\
\text { Maticiolit } \\
A_{V O L}=
\end{gathered}
$$

Dof $(0.1 \times$ Dof $0.01 \times$ Def $0.001 \times 1)$ ef

$\begin{array}{lccccc}\text { IET-1 } & 3 & 0 / 4 & 0 / 4 & 0 / 4 & 0 / 4 \\ \text { IET-1R } & 11 & 0 / 28 & 0 / 28 & 0 / 28 & 0 / 28 \\ \text { IE'-3 } & 190 & 205 / 320 & 2033 / 321 & 189 / 314 & 203 / 309 \\ \text { IET-4 } & 240 & 223 / 3339 & 225 / 341 & 210 / 3333 & 227 / 332 \\ \text { IET-5 } & 53 & 0 / 93 & 0 / 92 & 0 / 92 & 0 / 91 \\ \text { IET-6 } & 345 & 199 / 318 & 197 / 314 & 181 / 305 & 191 / 296 \\ \text { IE'T-7 } & 323 & 227 / 349 & 226 / 344 & 219 / 343 & 226 / 335\end{array}$

from gas grab bottle samples at 30 min

$\ddagger($ actual values at $20 \mathrm{~s}) /$ (assuming only steam/metal reactions) 

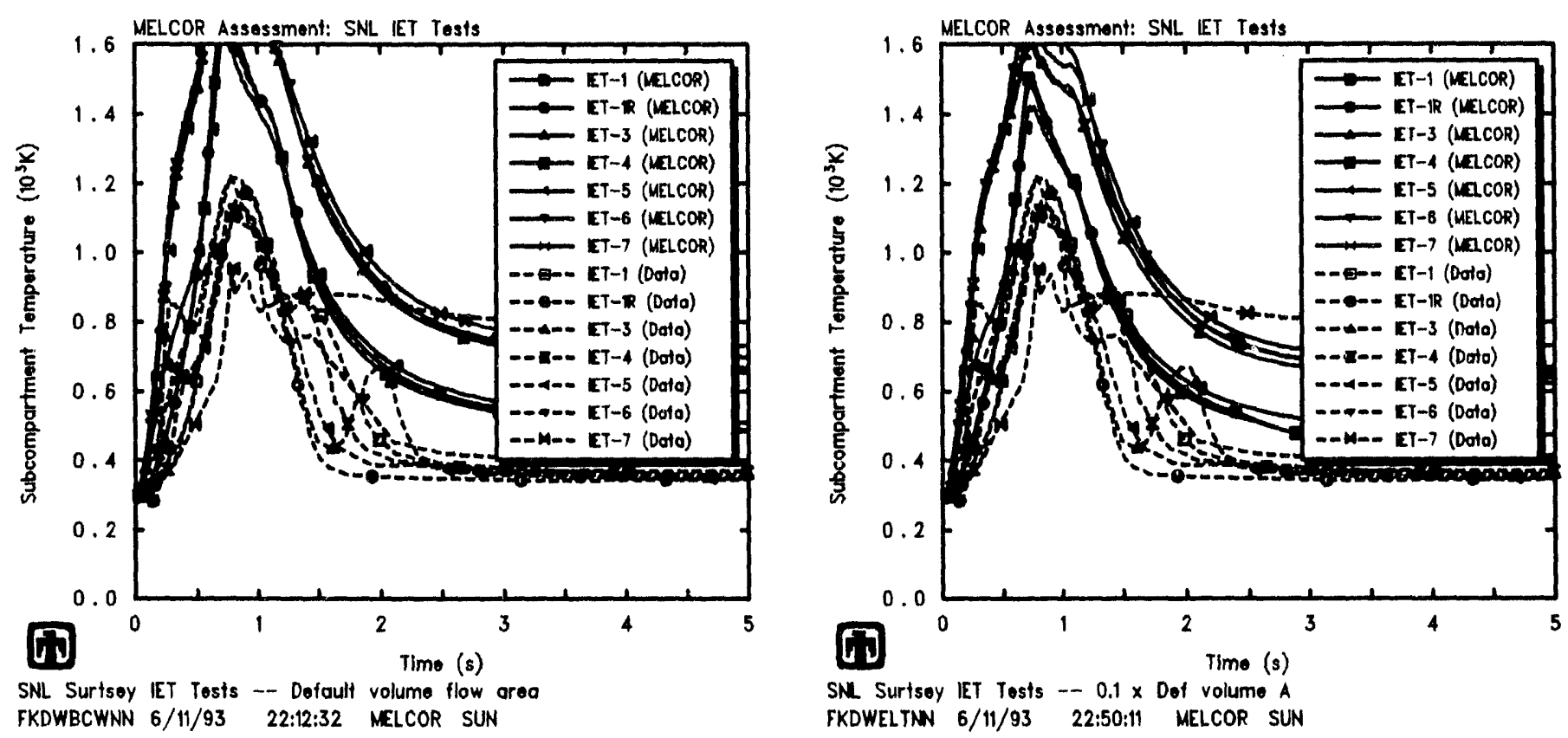

FKDWBCWNN 6/11/93 22:12:32 NELCOR SUN
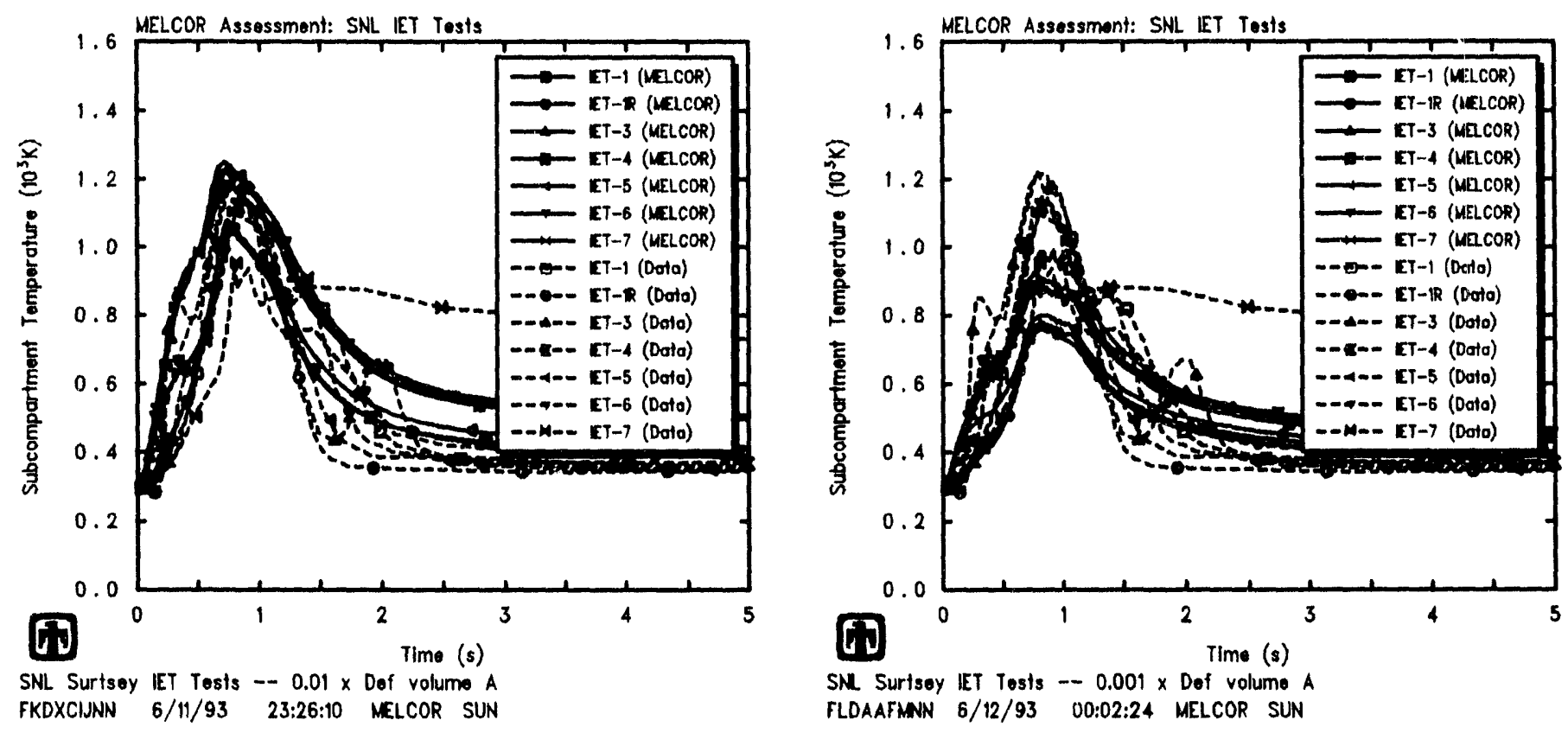

SNL Surisey IET Tests - $0.001 \times$ Dof volume $A$ FLDAAFMNN 6/12/93 00:02:24 MELCOR SUN

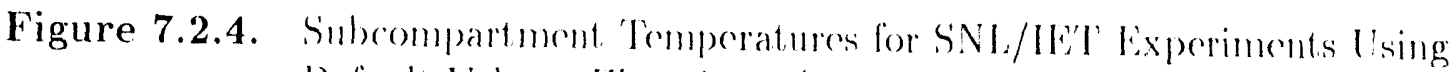
Dedant Volume filow Areas/Volocitices (upper left), $0.1 \times$ Volume lilow Areas (upper right), $0.01 \times$ Volume Flow Areas (lower left) and 0.001 $\times$ Volume Flow Areas (lower right) convertive lleat 'Transfor Somsitivity Study 

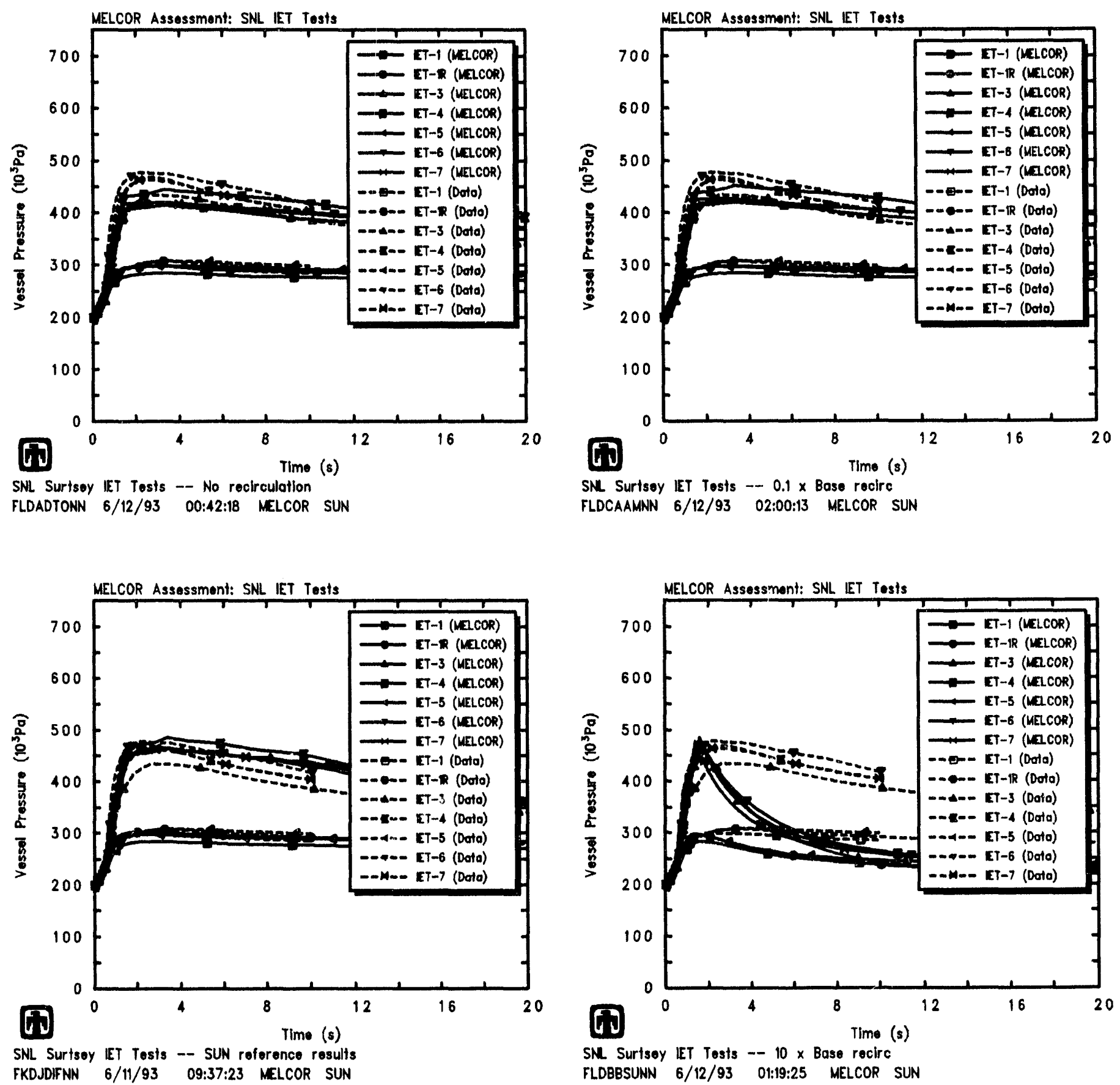

Figure 7.3.1. Vessel Pressures for SNL/ILT Experiments for No Recirculation (upper left), $0.1 \times$ Basecase (upper right), Basecase (lower left) and 10 $\times$ Basecase (lower right) - Recirculation Flow Sconsitivity Study 
Increasing the recirculation flow does not appear to affect the peak vessel pressure very much, but there is a much more rapid depressurization after $\leq 2$ s for the large recirculation flow, qualitatively unlike both the test data and the reference analysis results. The rapid depressurization occurs because varying the recirculation flow affects the volume velocities used to calculate heat transfer coefficients. Figure 7.3 .2 compares the flows rates into ("straight-through") and out of ("recirculation") the dome and the dome inside surface heat transfer coefficients calculated for the reference analyses and for the sensitivity study increasing the recirculation flow area. The flows are nearly stagnant in the reference analyses after about 2 s, while significant flows persist in the sensitivity study increasing the recirculation flow area throughout most of the transient period considered; the heat transfer coefficients in the reference analyses drop by about an order of magnitude after about $2 \mathrm{~s}$, to $\leq 25 \mathrm{w} / \mathrm{m}^{2}-\mathrm{K}$, while the dome inside surface heat transfer coefficients calculated for the sensitivity study increasing the recirculation flow area remain $\geq 100 \mathrm{w} / \mathrm{m}^{2}-\mathrm{K}$ throughout most of the transient period considered. Thus the vessel atmosphere loses substantially more energy to the walls more quickly after the first few seconds of the HPME transient in the sensitivity study calculation increasing the recirculation flow area.

Tables 7.3.1 and 7.3.2 present the amounts of hydrogen generated and burned, respectively, in these various cases. Test data estimates of the amounts of hydrogen produced and burned are included for reference. While there is no systematic variation in hydrogen production as the recirculation flow area is increased, there is a significant difference in the amount of hydrogen combustion calculated for the two sets of calculations with little or no recirculation, compared to the hydrogen combustion calculated in the two sets of calculations with basecase or more recirculation; this is because increased recirculation flow draws more hydrogen from the subcompartments where it was generated to the dome where oxygen is available for reaction and where combustion is permitted to occur.

Figure 7.3.3 gives subcompartment temperatures calculated using various recirculation flow areas and flow rates, together with experimental data. While there is not much change in the magnitude of the peak subcompartment temperatures being calculated, there is a much broader temperature peak in the cases with little or no recirculation flow assumed, probably due to reduced mixing of the hotter subcompartment atmosphere with the cooler dome atmosphere. 

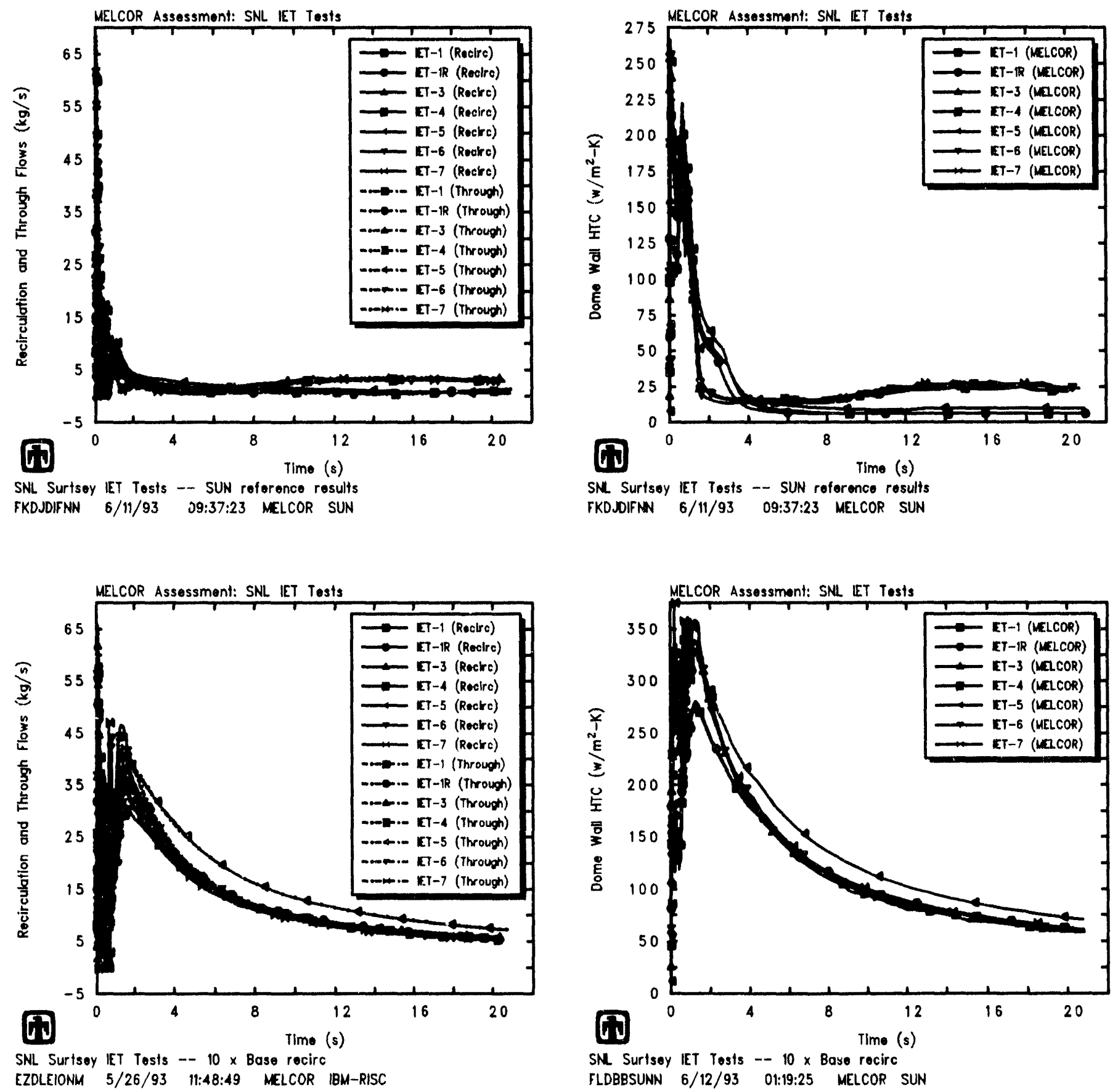

SN Surtsey IET Tests -- $10 \times$ Base recirc

FLDBBSUNN $6 / 12 / 93 \quad 01: 19: 25$ MELCOR SUN

Figure 7.3.2. Flows into and out of the Vessel Dome (left) and Dome Inside Surface

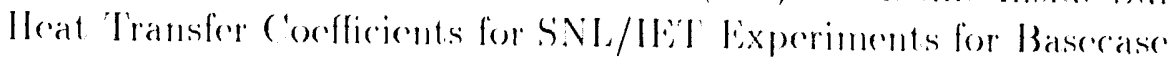
(1op) and $10 \times$ Bäscrase (bottom) Recirculation lilow Sensitivity Studly 
Table 7.3.1. Hydrogen Generation for the SNL/IFT Experiments - Recirculation Flow Sensitivity Study

Experiment

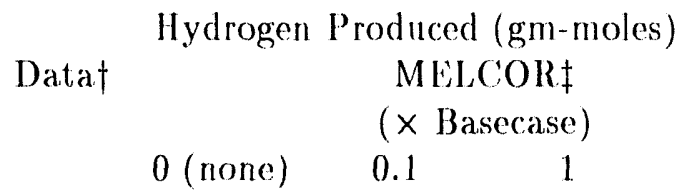

10

$\begin{array}{llllll}\text { IET-1 } & 233 & 282 / 200 & 282 / 208 & 286 / 266 & 288 / 277 \\ \text { IET-1R } & 248 & 263 / 189 & 262 / 197 & 266 / 267 & 267 / 281 \\ \text { IET-3 } & 227 & 242 / 170 & 240 / 182 & 232 / 352 & 210 / 386 \\ \text { IET-4 } & 303 & 253 / 180 & 254 / 195 & 243 / 361 & 220 / 396 \\ \text { IET-5 } & 319 & 246 / 210 & 244 / 226 & 240 / 313 & 235 / 344 \\ \text { IET-6 } & 319 & 244 / 166 & 243 / 179 & 236 / 354 & 208 / 395 \\ \text { IET-7 } & 274 & 236 / 156 & 237 / 223 & 229 / 351 & 207 / 395\end{array}$

tfrom gas grab bottle samples at $30 \mathrm{~min}$

$\ddagger$ (actual values at $20 \mathrm{~s}) /$ (assuming only steam/metal reactions)

Table 7.3.2. Hydrogen Combustion for the SNL/IE'T Experiments - Recirculation Flow Sensitivity Study

Experiment

\begin{tabular}{ccc} 
Datat & \multicolumn{2}{c}{ Hydrogen Burned (gm-moles) } \\
& & MELCOR $\ddagger$ \\
& $(\times$ Basecase) \\
o (none) & 0.1 & 1
\end{tabular}

10

\begin{tabular}{lccccc} 
IET-1 & 3 & $0 / 4$ & $0 / 4$ & $0 / 4$ & $0 / 4$ \\
IET-1R & 11 & $0 / 28$ & $0 / 28$ & $0 / 28$ & $0 / 28$ \\
IET-3 & 190 & $113 / 170$ & $119 / 182$ & $188 / 313$ & $208 / 384$ \\
IET-4 & 240 & $129 / 179$ & $137 / 194$ & $209 / 332$ & $218 / 394$ \\
IET-5 & 53 & $0 / 56$ & $0 / 61$ & $0 / 91$ & $0 / 122$ \\
IET-6 & 345 & $110 / 159$ & $117 / 171$ & $218 / 307$ & $202 / 388$ \\
IET-7 & 323 & $111 / 164$ & $118 / 175$ & $223 / 350$ & $209 / 396$ \\
\multicolumn{5}{c}{} \\
†from gas grab bottle samples at 30min \\
†(actual values at 20s)/ (assuming only steam/metal reactions)
\end{tabular}



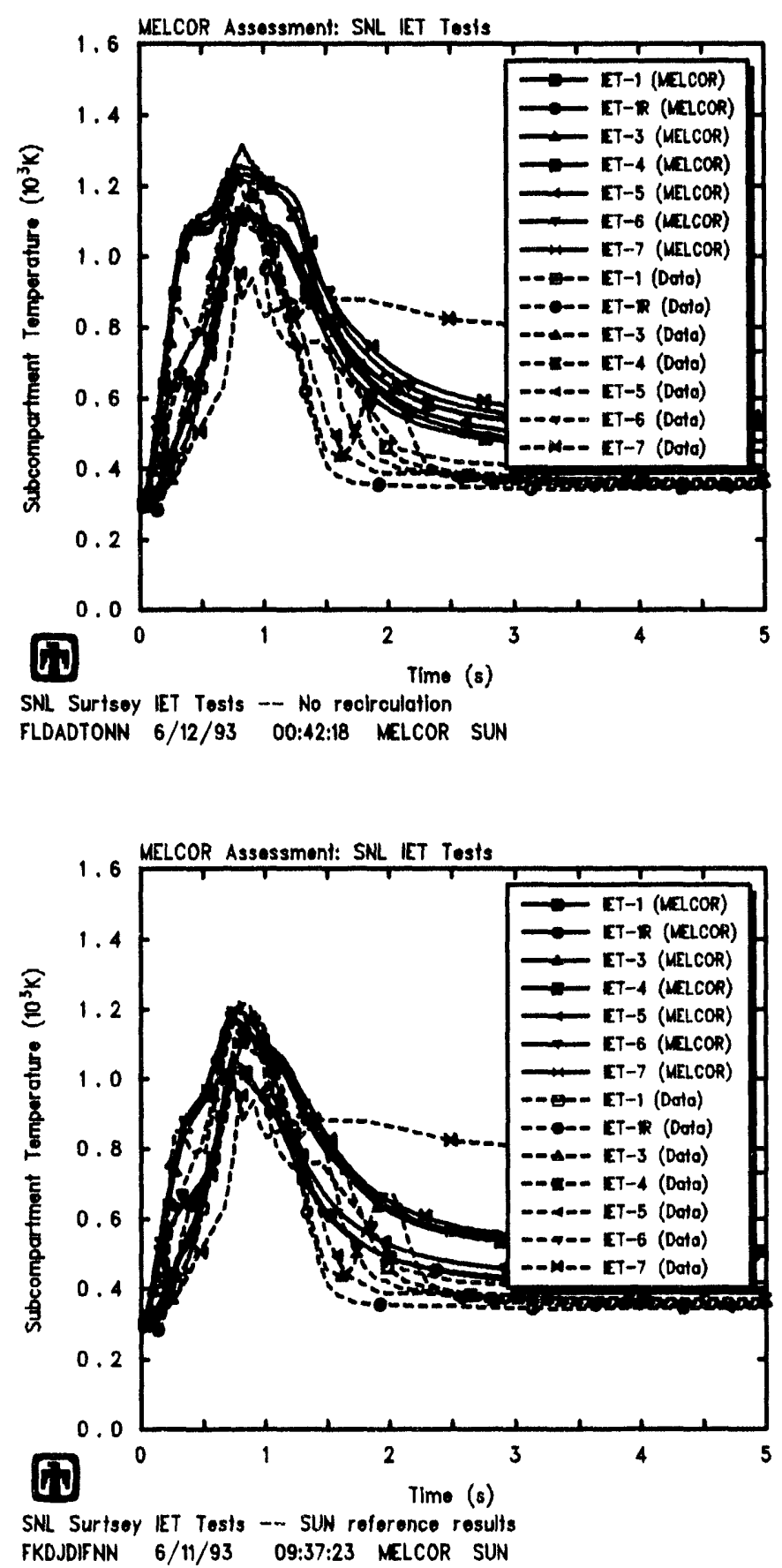

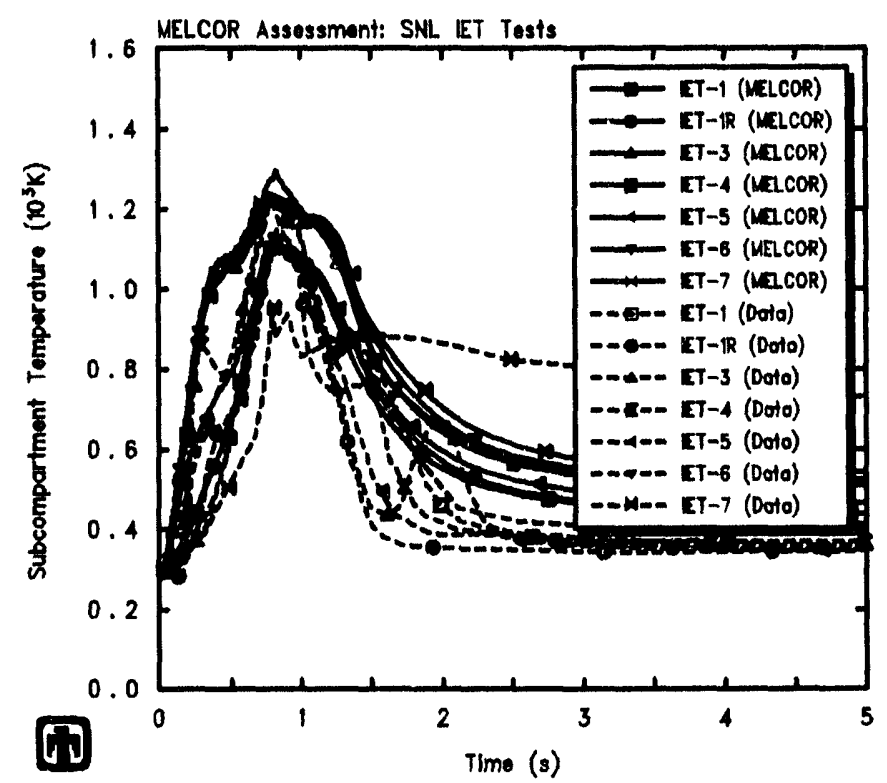

SNL Surtsey IET Tosts -- $0.1 \times$ Base recirc FLDCAAMNN 6/12/93 02:00:13 MEL,COR SUN

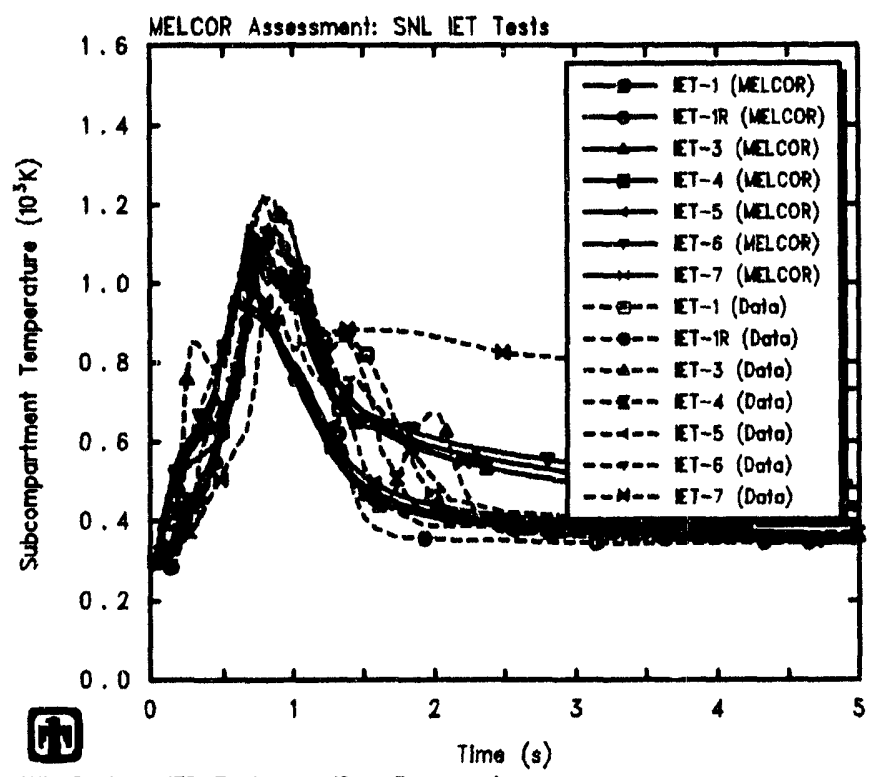

SNL Surtsey IET Tests -- $10 \times$ Base recirc FLDBBSUNN $6 / 12 / 93$ 01:19:25 MELCOR SUN

Figure 7.3.3. Subcompartment 'Temperatures for SNL/IET Experiments for No Recirculation (upper left), $0.1 \times$ Basecase (upper right), Basecase (lower left) and $10 \times$ Basecase (lower right) Recirculation flow Somsitivity Study 


\section{Scaling Sensitivity Study}

Several counterpart tests to the SNL/IET direct containment heating experiments done at Sandia in the 1:10 linear scale Surtsey facility were porformed at $\mathrm{ANI}$ in the 1:40 linear scale COREXIT facility, in an experimental program to investigate the effects of scale on DCH phenomena. The $\Lambda$ NJ facility and test program is described in Section 2.2. Tests ANL/IET-1RR, ANI/IET-3 aid ANI,/IET-6 were counterpart tests to the SNL/IET-1, SNL/IET-1R, SNL/IEI'-3 and SNL/IE'-6 Surtsey experiments. (We did not consider the early counterpart tests. ANL/IET-1 and ANL/IET-IR, because of problems in the experimental procedure affecting steam/debris blowdown timing.)

Our analysis of the ANL/IET experiments was complicated by severat factors. As discussed bricily in Section 3.2, there was not enough facility information and drawings available in the ANL letter reports [18-24] to develop a MELCOR input model for the (OREXI'T facility IET configuration; we often had to simply assume the Surtsey input. model numbers scaled directly to the ANL test facility. Also, some of the copies we had of the letter reports describing the tests and results [18-24] were incomplete, with both figures and pages of text occasionally missing, and those letter reports generally contained very little analysis of the test results. For example, while there was some discussion about the overscaled melt mass being used in ANL/IET-1RR and ANL/IET-3 to compensate. for expected melt retention in the melt generator/crucible, wo found no discussion on why the smaller melt mass was used for ANL/IEI'-6 and on what effect this change would have on comparison of results. Further, we have found little or no documented analysis comparing the counterpart test behavior at the two different facilities and scales, identifying and discussing similarities and differences, although we would have expected this to be an important and high-priority result of the test program.

We did find a limited discussion of the scaling and reproducibility of the SNL/IET-I and SNL/IET-IR test set done in the Surtsey vessel and the ANL/IE/T'IR and ANL/IE'T'IRR test set done at Argonne [36]. However, that scaling analysis seemed overly complicated, with different time and pressure scale factors used for each individual experiment (rather than for each experiment set), and did not address the issue of hydrogencombustion scaling in the other counterpart tests (IET-3 and IET-6) at all. We therefore performed our own, limited review of the facility data scalability in order to complete this required part of this MELCOR assessment task.

\subsection{Facility and Data Scaling Background Discussion}

'Jable 8.1 .1 compares some of the facility parameters and the degree to which scaling was preserved. 'The numbers in the SNL and ANI, facility columms come either from the published data reports [10-24] or in a few cases from [36]. The scaling comparison done in this table is only between the two facilities; the degree to which either facility correctly scaled actual plant conditions is not considered here. Only large discrepancies in scaling are noted; we considered differences $\leq 5-10 \%$ negligible. (Note that the 1:10-scale and 
1:40-scale descriptors usually used for these facilities are approximate. An exact scaling factor of 3.922 was used in the comparisons in this table.)

This comparison identifies several scaling concerns:

1. The melt mass in the earlier ANI, tests (ANL/IET-1RR and ANL/IET'-3) was significantly overscaled.

2. The blowdown steam source was significantly overscaled in volume and, for similar steam pressures and temperatures, therefore significantly overscaled in mass and energy.

3. Although the downstream volumes into which the steam was blowing down were correctly scaled, the ANL vessel aspect ratio $(\sim 5)$ was significantly greater than the Surtsey vessel aspect, ratio $(\sim 3)$.

Figure 8.1 .1 shows the steam accumulator blowdown moasured for four of the SNL test,s (SNL/IET'-1, SNL/IET-1R, SNL/IE'T-3 and SNI/IE'T-6), together with the steam accumulator blowdown measured for three of the $A N L$ counterpart tests (ANI/IF' $-1 \mathrm{RR}$, $\Lambda N L / L E T-3$ and $A N L / I E L-6)$; we did not consider either the $\Lambda$ NL/IET-1 or $\Lambda$ NL/IET$1 \mathrm{R}$ experiments as successful counterpart tests. In this figure, the times for the 1:10-scale Surtsey tests have been multiplied by $1 / 4$ to correspond to the 1:40-scale ANL tests, a factor equivalent to assuming that velocities were kept constant in the two facilities. 'The crossplot results indicate that this simple scaling works quite well (at least as well as the more complicated scaling used in [36]), with test-to-test variations in each facility at least as large as facility-to-facility variations.

The corresponding measured vessel pressures (with the times in the SNL test results scaled by the same $1 / 4$ multiplien) are presented in Figure 8.1 .2. While the results qualitatively scale, with greater pressurization in cases with hydrogen combustion, there are a number of quantitative discrepancies. 'The first thing to note in both Figure 8.1 .2 and in comparing peak vessel pressures given in Tables 2.1 .4 and 2.2 .4 is that the maximum pressure rise due to DCH in the smallor-scale $\Lambda \mathrm{NI}$, facility is significantly $(\sim 50 \%)$ greater than the maximum pressurization due to D)(II observed in the tests done in Surtsey. This is probably partially due to the relatively larger steam blowdown source and melt mass in ANL/IET-1RR compared to SNL/IET-I and SNL/IET-1R, but the difference is so large that it also indicates that DC:H energy-transfer efficiency was greater at the smaller scale. The second thing to note is that the pressurization due to hydrogen combustion is significantly less in the smaller-scale $A N 1$, facility than observed in the tests done in Surtsey, especially given the greater pressurization due to l)(HI. The third thing to note is that there is a much greater difference between the early-time peak vessel pressurization in the ANL 1:40-scale tests with and without pre-existing hydrogen than in the counterpart SNL 1:10-scale tests, especially given the $\sim 15 \%$ decrease in melt mass from $\Lambda \mathrm{NI} /$ IE'T-3 to ANI/IET'-6.

Tables 8.1 .2 and 8.1 .3 summarize the hydrogen production and combustion data from these counterpart tests (with the SNL test results scaled by a $1 / 4^{3}$ multiplier). Again, 
Table 8.1.1. Facility Scaling for the SNL and ANL IET Experiments

\begin{tabular}{|c|c|c|c|}
\hline $\begin{array}{l}\text { Parameter } \\
\text { Parameter }\end{array}$ & $\begin{array}{c}\text { SNI } \\
(1: 10 \text { scale })\end{array}$ & $\begin{array}{c}\text { ANI } \\
(1: 40 \text { scale })\end{array}$ & $\begin{array}{l}\text { Discrepanc } \\
\text { in Scaling }\end{array}$ \\
\hline Thermite (kg) & 43.0 & $0.820 \dagger$ & $+15 \%$ \\
\hline Thermite (kg) & 43.0 & $0.713 \ddagger$ & \\
\hline Steam Accumulator Volume $\left(\mathrm{m}^{3}\right)$ & 0.30 & 0.006 & $+20 \%$ \\
\hline Cavity/Chute Volume $\left(\mathrm{m}^{3}\right)$ & 0.245 & 0.004 & \\
\hline Cavity/Chute Length (m) & 2.4 & 0.61 & \\
\hline Cavity Water (kg) & 3.48 & 0.055 & \\
\hline Subcompartment Volume $\left(\mathrm{m}^{3}\right)$ & 4.6 .5 & 0.077 & - \\
\hline Subcompartment Height (m) & 1.52 & 0.39 & - \\
\hline Dome Volume $\left(\mathrm{m}^{3}\right)$ & 85.15 & 1.43 & \\
\hline Vessel Total Volume $\left(\mathrm{m}^{3}\right)$ & 89.8 & 1.51 & \\
\hline Vessel Height (m) & 9.9 & 3.4 & $+3.5 \%$ \\
\hline Vessel Diameter (m) & 3.38 & 0.76 & $-12 \%$ \\
\hline Vessel Area $\left(\mathrm{m}^{2}\right)$ & 9.0 & 0.454 & $-23 \%$ \\
\hline
\end{tabular}




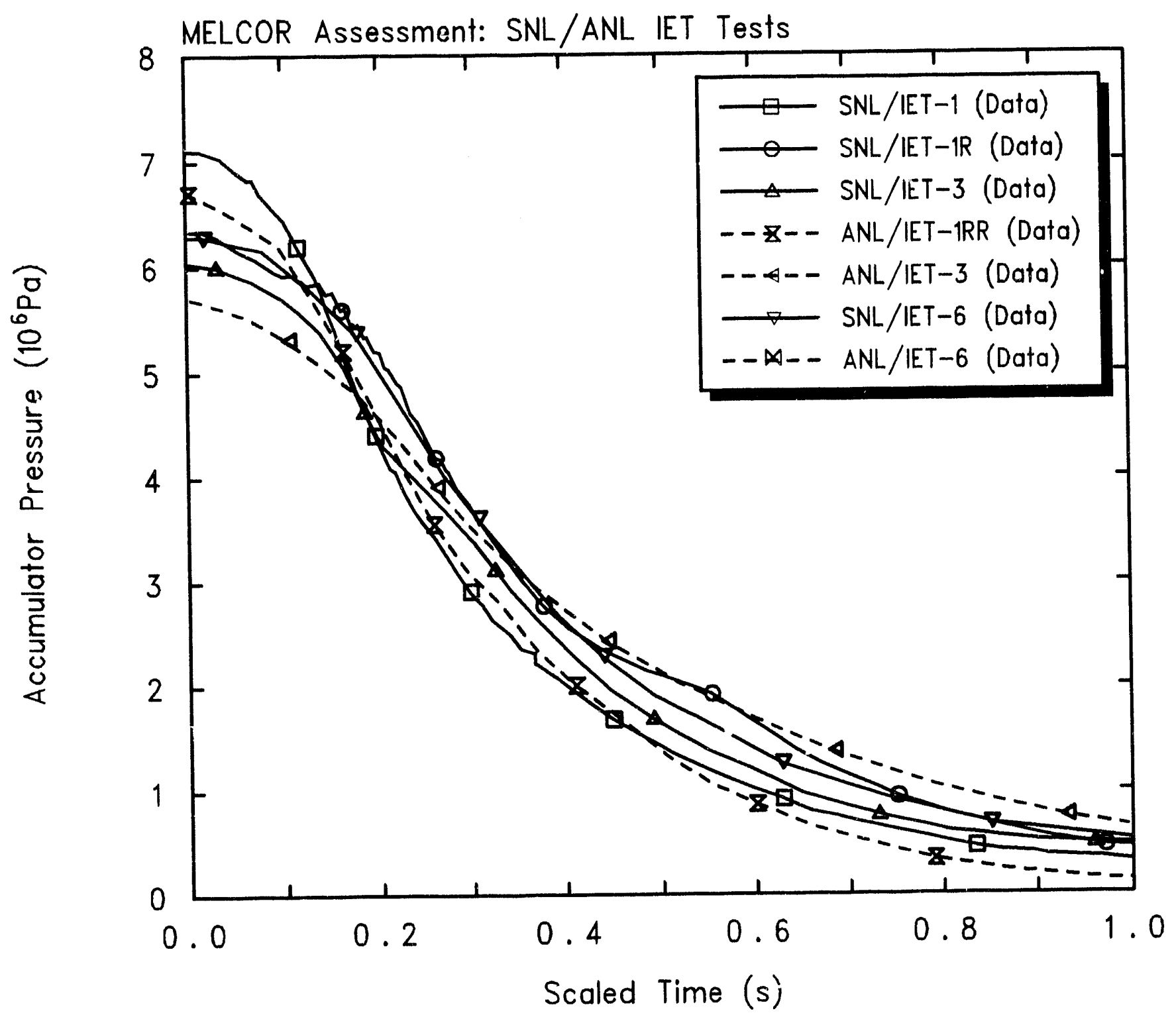

Figure 8.1.1. Scaled, Measured Steam Accumulator Pressures for SNL and ANL Counterpart IET Experiments - Scaling Study 


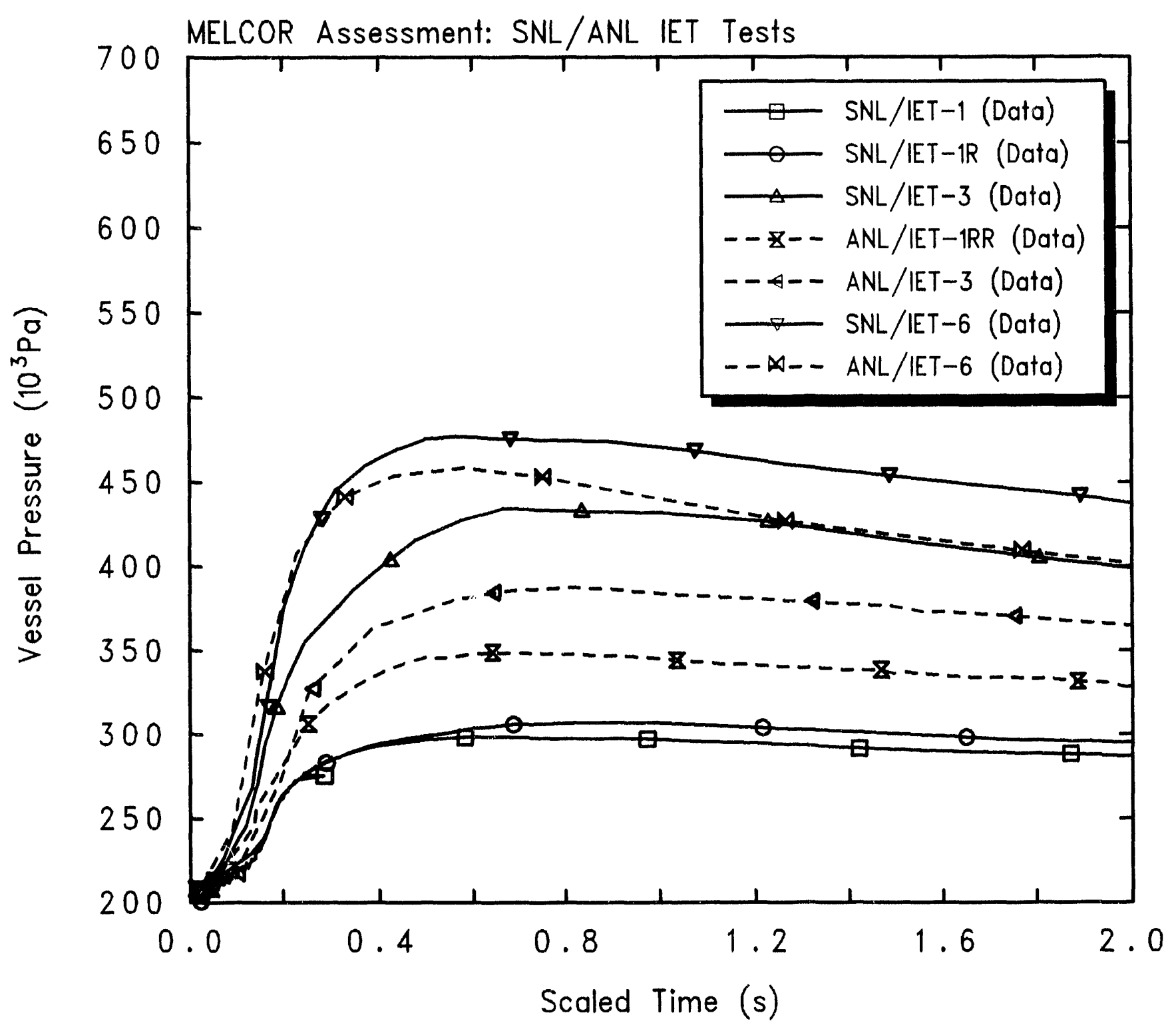

Figure 8.1.2. Scaled, Measured Vessel Pressures for SNL and ANL Counterpart IET Experiments - Scaling Study 
while the results qualitatively scale, with more hydrogen production and combustion in the case with pre-existing hydrogen, there are a number of quantitative discrepancies. In particular, the hydrogen production in both ANL/IET-1RR and in ANL/IET-6 is $5 \%$ less than the corresponding scaled SNL/IET hydrogen production, but the hydrogen production in ANL/LET'-3 is $\sim 25 \%$ more than the corresponding scaled SNL/IET'-3 hydrogen production. The small number of data points and the lack of a clear trend make it impossible to decide how much of the difference is due to scaling effects and how much simply to experimental uncertainties and test-to-test variations. Qualitatively, the data from the smaller-scale ANL facility shows slightly less variation in the amount of hydrogen produced in the various tests, and always has less hydrogen burned than produced (although there are very few data points), while the $\mathrm{SNL}$ data shows some pre-existing hydrogen must have burned in IET-6.

The hydrogen data somewhat contradict the vessel pressurization data given in Figure 8.1.2, because there was relatively more difference in pressurization between $\mathrm{ANL} / \mathrm{IE} \mathrm{T}$ 3 and ANL/IET'-6 than between SNL/IET'-3 and SNL/IET-6, but, with significantly less difference in both hydrogen production and combustion; this suggests the existence of differences in time scales for oxidation, combustion and heat transfer at the different size scales.

Our MELCOR assessment analyses for these 1:40-scale ANI/IET experiments were done in several steps, concentrating on the scaling of the phenomena. First, the $\mathrm{ANL}$ facility geometry and test conditions were modelled (and/or scaled) as discussed in Section 3.2, with no change in the characteristic interaction times input to the MELCOR FDI HPME model. Those characteristic interaction times were then scaled also, in another set of calculations. Finally, the other non-standard MELCOR input used for the Surtsey 1:10-scale SNI.IE'T experiment analyses (i.e., hydrogen combustion parameters, volume flow areas and velocities used to determine heat transfer correlations, and recirculation from the dome to the subcompartments) were varied and the impact on (alculated results evaluated.

\subsection{Scaling Facility Geometry and Test Conditions}

In the first set of calculations done, the ANI facility geometry and test conditions were modelled (and/or scaled) as discussed in Section 3.2, with no change in the characteristic interaction times input to the MELCOR FDI HPME model. Volumes and heights, and the blowdown flow area, were taken from the test data reports whenever possible; otherwise, the input values used for the SNL/IET analyses were simply adjusted as appropriate by the difference in scale factor between the two facilities. The debris amount and distribution were taken from the test data reports, as well as the initial steam and atmosphere conditions; the times in the steam blowdown valve opening and the debris injection timing were both scaled by $1 / 4$ from the values used for our SNL/ILIT reference analyses.

Resulting predicted vessel pressures for the smaller-scale $\Lambda$ NL tests are shown in Figure 8.2.1, together with the test data. The corresponding calculated results and 
Table 8.1.2. Scaled, Measured Hydrogen Generation for SNL and ANL Counterpart IE'T Experiments - Scaling Study

$\begin{array}{ccc}\text { Experiment } & \text { Hydrogen Produced (gm-moles) } \\ & \text { SNL Data ANL Data } & \text { SNL Data } \\ & & \text { (Scaled to ANL) }\end{array}$

$\begin{array}{lccc}\text { IET-1 } & 233 & & 3.7 \\ \text { IET-1R } & 248 & & 4.2 \\ \text { IET-IRR } & & 4.0 & \\ \text { IET-3 } & 227 & 4.65 & 3.7 \\ \text { IET-6 } & 319 & 4.89 & 5.1\end{array}$

Table 8.1.3. Scaled, Measured Hydrogen Combustion for SNL and ANL Counterpart, IET Experiments - Scaling Study

Experiment Hydrogen Burned (gm-moles)

SNL Data ANL Data SNL Data

(Sicaled to ANL)

$\begin{array}{lccc}\text { IEI-1,1RR } & 3 & & 0.04 \\ \text { IET-1R } & 11 & & 0.2 \\ \text { IET-1RR } & & & \\ \text { IET-3 } & 190 & 3.50 & 3.1 \\ \text { IET-6 } & 345 & 4.22 & 5.6\end{array}$


test data for the larger-scale counterpart SNL experiments are also included for comparison, both with the time scaled by $1 / 4$. The peak pressurization predicted in this case for $\Lambda$ NL/IET- IRR is very similar ( 100kPa) to that predicted for $S \mathrm{NL} / \mathrm{LE} / \mathrm{l}-1$ and SNI./LET-IR, significantly less than the $\sim 150 \mathrm{kPa}$ measured, and the rise time is rela-

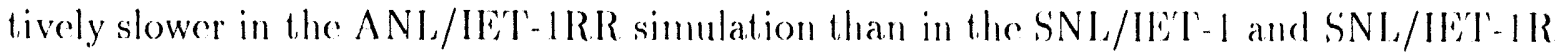
calculations, while the data shows the same time dependence with this time scaling. In contrast, the peak pressurization predicted scaling only geometry for $\mathrm{ANL} / \mathrm{IL} / \mathrm{T}-3$ and $\triangle \mathrm{NL} / \mathrm{EET}-6$ is significantly higher ( $300 \mathrm{kPa})$ both than that measured (200-250kla) and than that predicted and measured for SNI/IE'T-3 and SNL/ILI'-6 ( 250kPa); however, the calculated pressure rise times again are relatively slower in the $\Lambda \mathrm{NI} / \mathrm{IF} / \mathrm{l}-3$

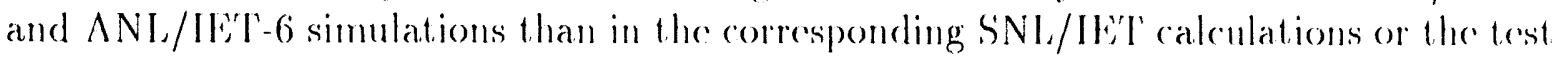
data.

\subsection{Scaling Characteristic Interaction Times}

There is m reason to expect to mateh the $\Lambda$ NL 1:10-scale test results only by sealing the Surtsey facility geometry and using the $\Lambda$ N L test conditions. It secms intuitively. obvious that the characteristic interaction time for airborne debris settling should be scaled as the height of the volume. Therefore, a set of $\Lambda$ NL/IET calculations were done with the characteristic settling times for airborne dobris reduced by $1 / 4 \mathrm{in}$ cach volume. However, it is not intuitively obvious whether the characteristic interaction times for oxidation of airborne or deposited debris, or for heat transfer from airborne debris to atmosphere, should be scaled or not. In more sets of calculations, we scaled the varions characteristic interaction times also by $1 / 1$, both individually and in combination, in adelition to scaling the characteristic settling times.

Figure 8.3.1 gives predicted vessel pressures for the smaller-scale $A N I$ leste, ralculated using set thing characteristic times reduced by the length scale factor, fogether with the test data and the corresponding time-scaled calculated results and test dat a for the largerscale comberpart SNL experiments for comparison. The peak pressurization predicted in this case for all three $A N L /$ IE'T experiment simmlations is signilieantly less than either test data or the SNL/HEI calculated results, and (as in the ase shown in ligure 8.2 .l) the calculated pressure rise times again are relatively slower in all there $\mathrm{ANI} / \mathrm{IE}$ T simmlat joms than in the corresponding SNL/IET calculations or the test data.

These results indicate that the other characteristie interaction times (for exidation of airborne or deposited dobris, and for heat transfer from airborne debris to atmosphere) probably should be scaled also, because these results indicate that more mapd oxidation energy release and transfer to atmosphere is reguired to mateh the ANI test data. Further calculations were done with the airborne-debris oxidation and heat transfer characteristic times individually scaled by $1 / 4$ (with the settling characteristic time also scaled), and with all the characteristic timess scaled.

Vessel pressures for the smaller-scale $A N I$. tests predicted using both oxidation and settling characteristic times reduced by the length scale factor, are depereted in figure 8.3.2. again with the test data and the corresponding time-scaled calculated results 


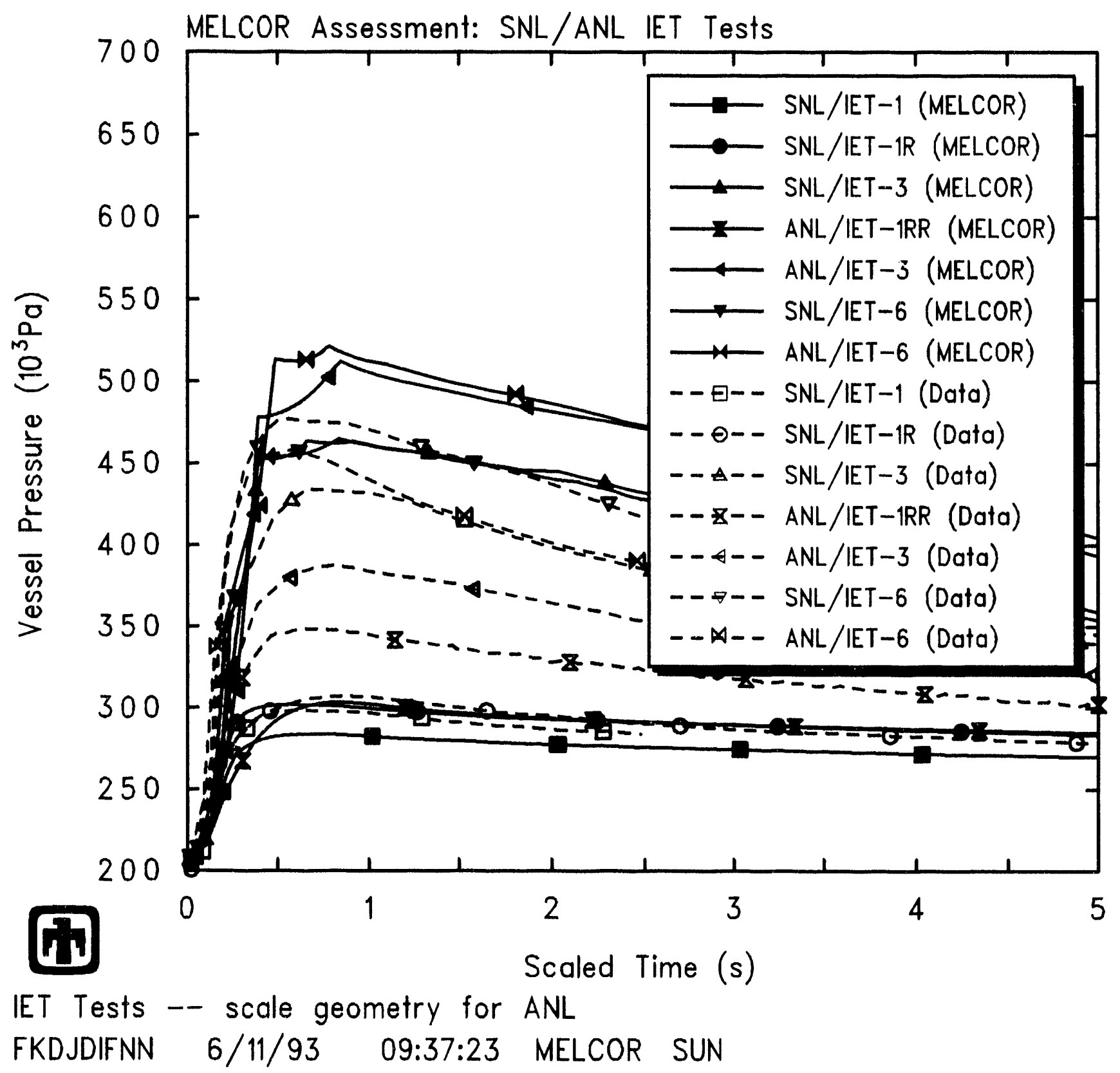

Figure 8.2.1. Scaled Vessel Pressures for SNL and $\Lambda$ NL Counterpart IET Experiments - Scaling Facility Geometry and Test Conditions 


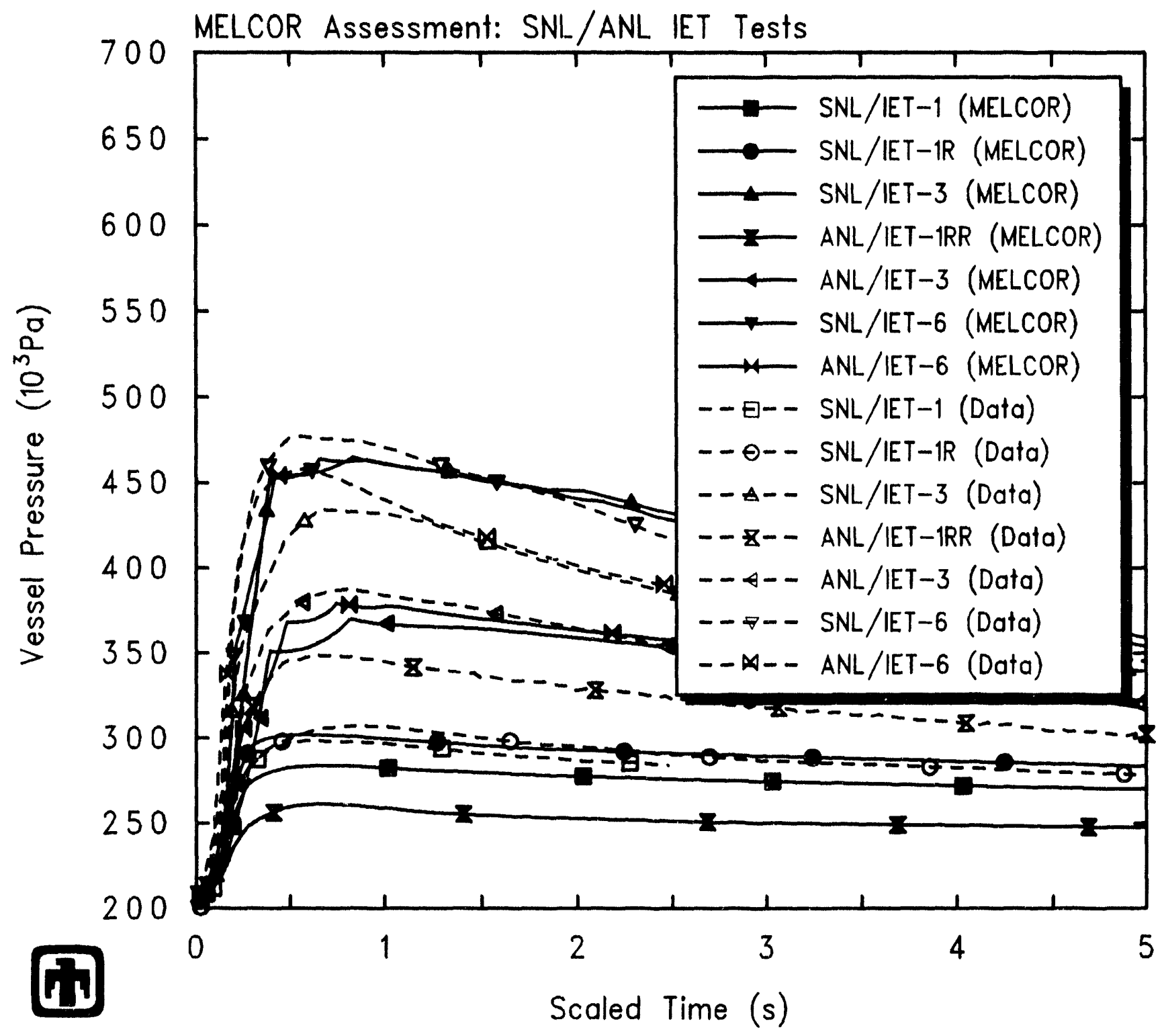

IET Tests -- scale geom and tau-set

FKDJDIFNN 6/11/93 09:37:23 MELCOR SUN

Figure 8.3.1. Scaled Vessel Pressures for SNL and ANL Counterpart IET

Experiments Scaling Airborne-1) brobs Settling (haracteristic Interaction Times 
and test data for the larger-scale counterpart SNI experiments for comparison. There is no change in peak pressurization predicted in this case for ANL/ILE- IRR and only a

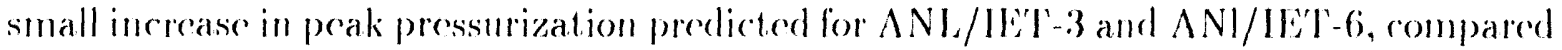
to the results obtained using only a scaled settling characteristic time (Figure 8.3.1).

Figure 8.3.3 gives predicted vessel pressures for the smaller-scale ANI, tests, calculated using both airborne-debris heat transfor and settling characteristic times reduced by the length scale factor, with the test data and the corresponding time , caled calculated results and test data for the larger-scale counterpart SNI experiments included for comparison. The peak pressurization predicted in this case for all three $\mathrm{ANL} / \mathrm{ll} \mathrm{E}$ ' $\mathrm{x}$ periment simulations is significantly higher than for the cases illustrated in Figure 8.3.1, and is in good agrement with the peak pressurization calculated for the comberpart $S N$, tests; the rise time in this case for all thee $\Lambda$ NI./EI experiment simulations also is in very good agreement with corresponding results calculated for the counterpart SNI tests. Because of the differences in the experimental bethavior discussed in Section 8.1 , although the results for the $\mathrm{ANL}$ /IET experiment simulations now agree quite well with the scaled SNIJ/IET results, the predicted peak pressure for ANI/IET-1RR ( 100kPa) is still significantly less than that measured $(\sim 150 \mathrm{kPa})$, while the predicted peak pressure for ANI./EF' -3 ( 250kl'a) is significantly higher than that moasured ( $200 \mathrm{kPa})$.

Vessel pressures for the smaller-scale ANL tests predicted using all characteristic times (for airborne- and deposited-debris oxidation, and airborne-debris settling and heat transfer to atmosphere) reduced by the length scale factor are shown in Figure 8.3.4, again with the test data and the corresponding time-scaled calculated results and test data for the larger-scale counterpart SNL experiments for comparison. There is no change in peak pressurization predicted in this case for ANL/IE'T-IRR and only a small increase in peak pressurization predicted for $A N \mathrm{~N} / \mathrm{IET}-3$ and $\Lambda \mathrm{NI} / \mathrm{IET}-6$, compared to the results obtained using only scaled heat transfer and settling characteristic times (Figure 8.3.3), very similar to the small difference found between results obtained using only scaled settling characteristic times (Figure 8.3.1) and using scaled oxidation and sctuling characteristic times (Figure 8.3.2), verifying that the vessel pressurization results are much more sensitive to the settling and heat transfer characteristic interaction times than to either the airborne- or deposited-debris oxidation characteristic interaction times.

Tables 8.3.1 and 8.3.2 compare the amounts of hydrogen generated and burned, respectively, in the $\Lambda$ NL small-scale test simulations for all the scaling cases considered so far. There are a number of disagreements between calculation and data, both qualitative and quantitative, in all cases. The small number of data points and the uncertainty associated with the methods of estimating hydrogen production and combustion from late-time gas grab bottle samples, however, preclude any definitive judgements on the significance of the differences seen.

The test data shows more hydrogen production in $\Lambda$ NL/IE'T'-3 than in $A N L / I W^{\prime} T$ IRR, and more hydrogen production in ANI./L'L'-6 than in ANI/IEI'-3; the calculations consistently show more hydrogen production in $A$ NL/IE'T'-IRR than in $A$ NI/IET'-3 or ANI,IET-6. The same trend can be found in the MELCOR simulations of the largerscale SNI tests: the test data indicate more hydrogen production in SNJ/IET-4 through 


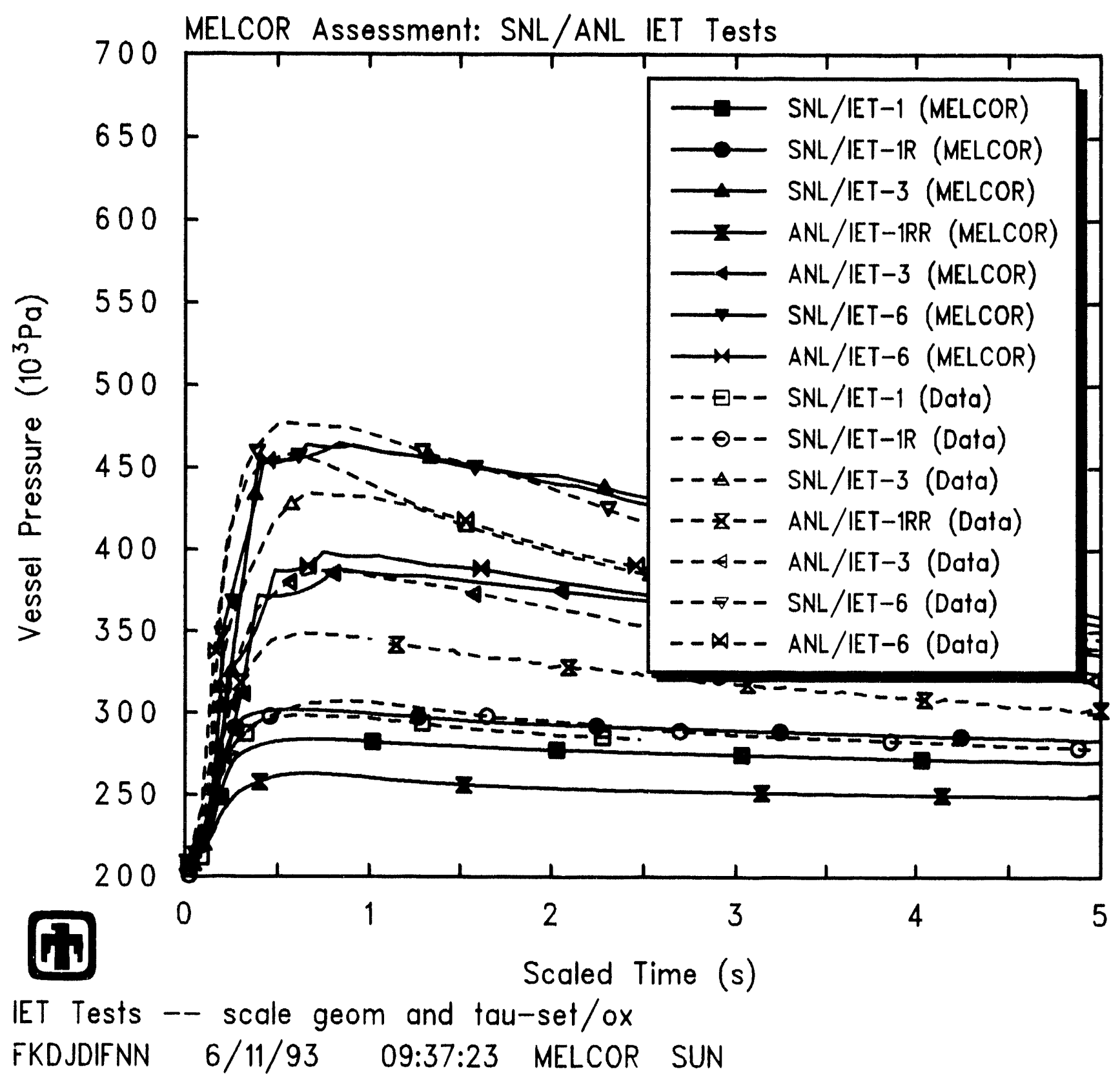

Figure 8.3.2. Sicaled Vessel Pressures for SNI and ANI, ('onnterpart II:T Exporiments - Scaling Airborne-Debris Oxidation and Sottling ('haracteristic Interaction Times 


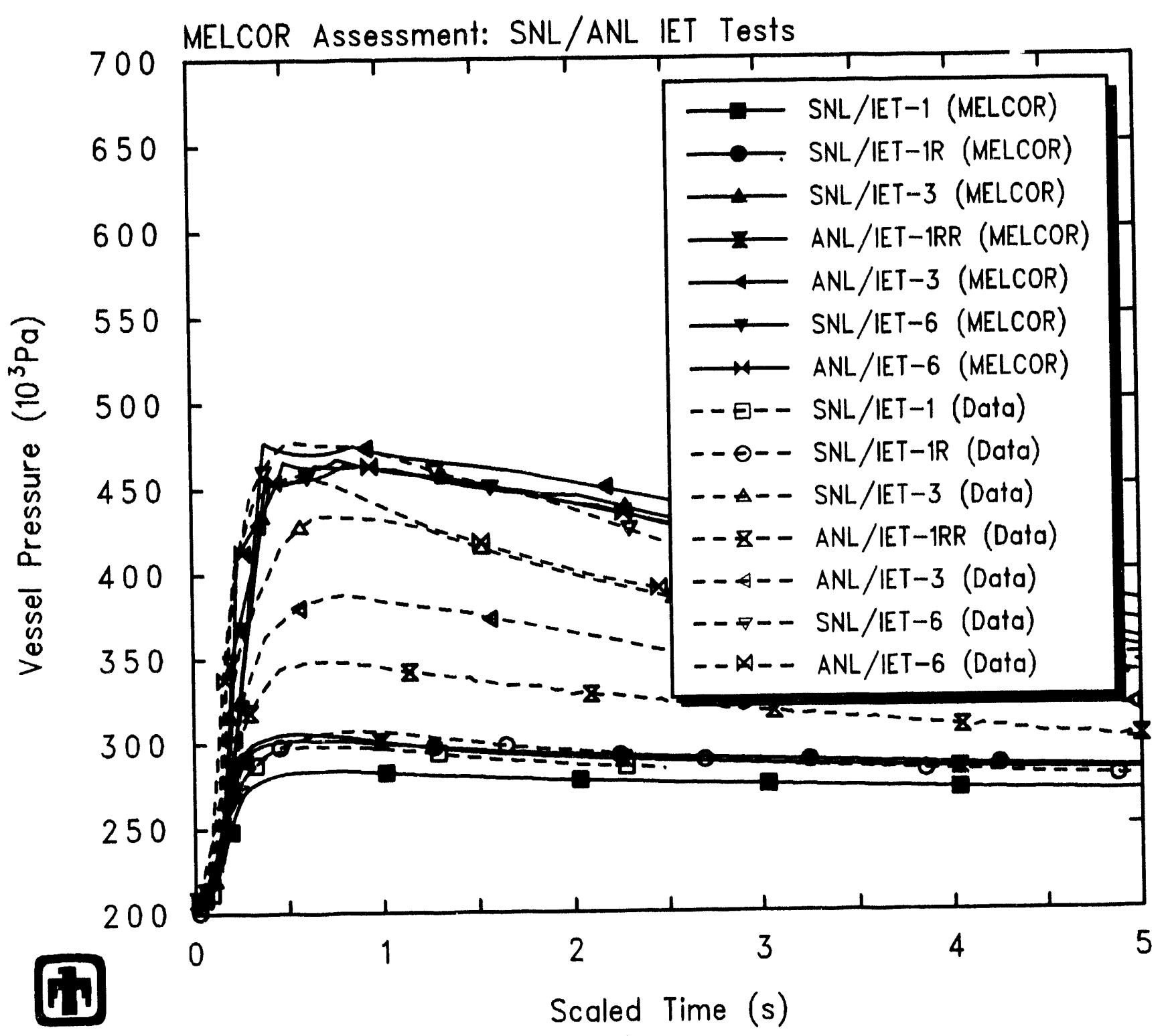

IET Tests -- scale geom and tau-set/ht

FKDJDIFNN 6/11/93 09:37:23 MELCOR SUN

Figure 8.3.3. Scaled Vessel Pressures for SNL and ANL, Counterpart IEI Lxperiments Scaling Airborne-Debris Heat Transfer and Settling (haracteristic Interaction Times 


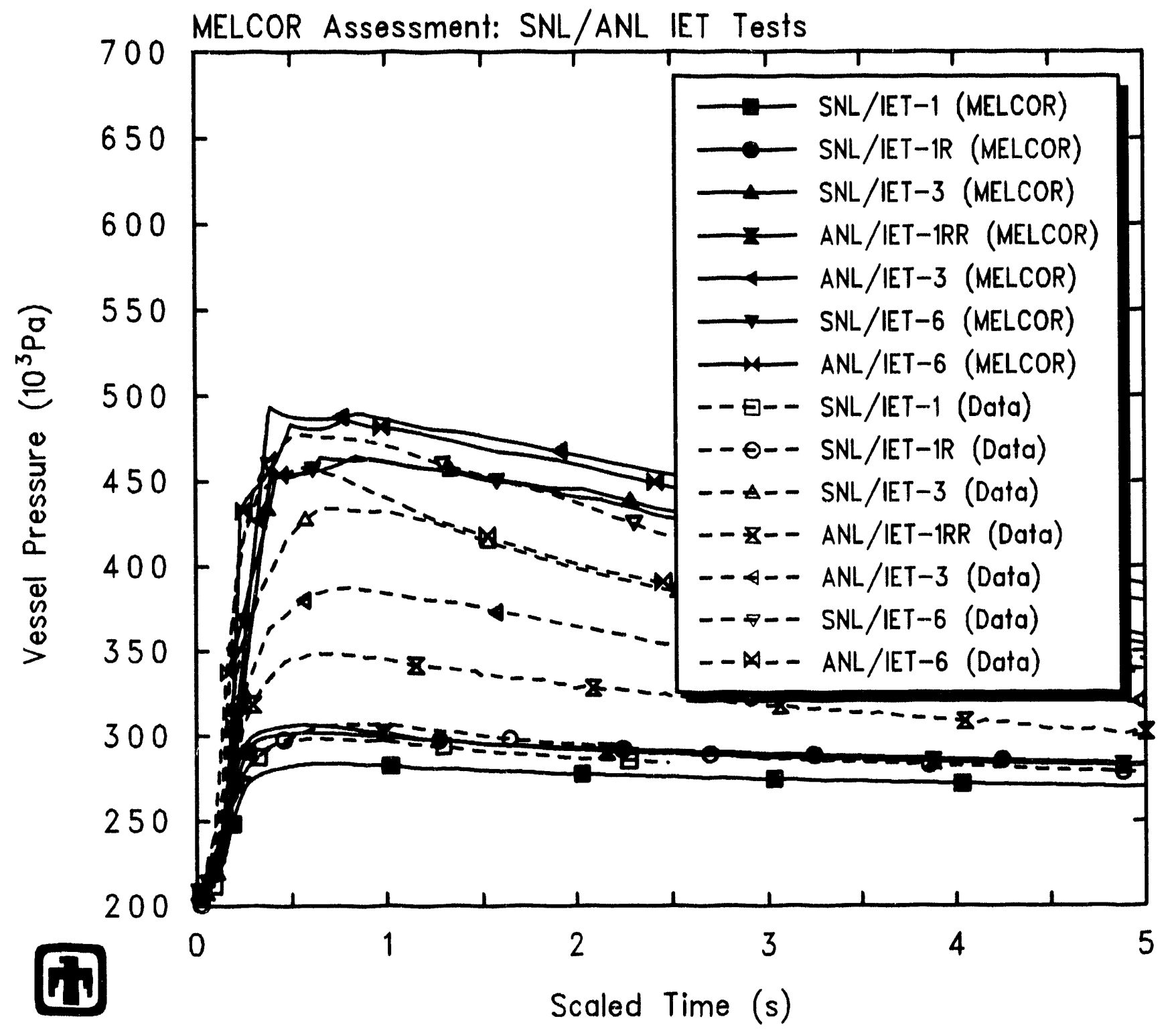

IET Tests - - scale geom and taus

FKDJDIFNN 6/11/93 09:37:23 MELCOR SUN

Figure 8.3.4. Scaled Vessel Pressures for SNL and ANL ('ounterpart IE'T Experiments Scaling $A \mid l$ ('haracteristic Interaction 'Times 
Table 8.3.1. Hydrogen Generation for the $\Lambda$ NL/LET Experiments Scaling Facility Geometry and Test Conditions, and (haracteristic Interaction Times

Experiment

Dataf

$\begin{array}{lcccccc}\text { IET-1RR } & 4.0 & 6.43 / 6.30 & 4.59 / 4.52 & 4.57 / 4.51 & 6.00 / 5.88 & 6.55 / 6.33 \\ \text { IET-3 } & 4.65 & 5.63 / 7.53 & 3.35 / 5.05 & 3.49 / 5.69 & 4.81 / 6.24 & 5.00 / 7.04 \\ \text { IET-6 } & 4.89 & 5.39 / 7.16 & 3.30 / 5.08 & 3.55 / 5.59 & 4.47 / 6.01 & 5.01 / 6.90\end{array}$

ffrom gas grab bottle samples at $30 \mathrm{~min}$ $\ddagger$ (actual values at $20 \mathrm{~s}) /$ (assuming only steam/metal reactions)

Hydrogen Produced (gm-moles) MELCOR scaled geom and

$$
\tau_{S L T} \quad \tau_{S E T} / \tau_{O X} \quad \tau_{S E T} / \tau_{H T} \quad \text { all } \tau \text { S }
$$

Table 8.3.2. Hydrogen ('ombustion for the ANI.IET Experiments Scaling Facility (ieometry and Test Conditions, and Characteristic Interaction Times

Experiment

Datat

IET'-1RR

IE'T-3

IE:T'-6 
SNI/IET-7 than in SNI/IE'T-I and SNL/IET-IR, while the calculations consistently show more hydrogen production in SNL/IE'T-1 and SNI./IET-1R than in the later tests. (The difference is not simply due to hydrogen combustion differences, because the comparisons for $S N L / I E\left[I^{\prime}-3\right.$ and $S N L / I E I^{\prime}-5$ do not fit such a simple trend.) Also, the test data show more hydrogen burned in ANL/IET-6 than in ANL/IET-3, while the calculations consistently show the opposite, althongh the difference is quite small, and could be due to slow, late-time combustion of hydrogen; similar comparisons for the larger-scale. SNL tests and analyses show a similar trend comparing SNI/IET-3 and SNI/IE'T-6, but not when comparing SNL/IEI'-4 and SNI/IEJ'-7 (also a pair without and with preexisting hydrogen, but with the addition of basement condensate water). Scaling cases which predicted peak vessel pressures in reasonable agrement with test data predicted more hydrogen production than measured, especially for $\Lambda$ NL/IET-IRR, while scaling cases that predicted peak vessel pressures significantly lower than observed data predicted about the right amount of hydrogen production.

Note that these results tend to confirm the experimental observation that 1$)(\mathrm{H}$ energy-transfer efficiency is greater at smaller scale (because we include the effects of the relatively larger steam blowdown source and molt mass in $A N L / I E T-1 R R$ compared to SNI./IET-1 and SNL/IETT-IR), and that there is less pressurization due to hydrogen combustion at smaller scale.

\subsection{Varying Hydrogen Combustion Parameters}

As described in Sections 3.1 and 7.1, in the majority of our SNL/HET analysis calculations, the burn package was activated. However, burns were suppressed in all control volumes except the vessel dome; this was based upon the experimental observation that a jet of hydrogen produced by steam howdown and debris oxidation burned as it vented from the subcompartments to the upper dome. 'The defanlt ignition criterion in the absence of igniters was set to a bydrogen mole fraction of 0.0 , but the combustion completeness was also set to 0.0 : this prevents the burning of any pre-existing hydrogen, but allows burning of any additional hydrogen generated during the IIPML. This was based upon the experimental observation that the pre-existing hydrogen that burned did not burn on a time scale that had a significant impact on the peak pressure. This particular combination of input was found to produce reasonable agreement with test data in all the 1:10-scale SNL/IET experiments analyzed, as discussed in Section 7.1 which presented results of sensitivity studies using other possible burn-package input settings.

The results of both our own. limited review of the farility and data scalability (heretion 8.1) and of onr ANL test simulations scaling facility geometry (Section 8.2) and characteristie interaction times (Section 8.3 ) indicate that the pressurization due to hydrogen combustion is significantly less in the smaller-scale $A$ NI facility than in the larger-scale SNI tests (especially given the apparent greater pressurization due to De 'II at smaller scale), and that there appears to be a greater effect of pre-existing hydrogen in the ANI, 1:40-scale tests than in the counterpart S.NL 1:10-scale tests. 
There are several possible contributors to the different hydrogen combustion bethavior at smaller scales. It is harder to keep hydrogen jets burning at smaller scales because the "same" combustion energy release rate noeds to heat up non-burning dilucut gas entrained into the jot more quickly at smaller scales, berause of more rapid mixing and dilution. Also, in this particular case, the different aspeed ratios in the two facilities ( $~ 5)$ for the ANL vessel and 23 for the SNL vessel) may provide relatively less oxygen in the immediate neighborhood of the jet in the taller, thinmer ANL vessel.

There is no input mechanism to model these factors in the burn package in MELC'OR. Sensitivity studies were done in which the hydrogen mole fraction limit for ignition was increased from 0.0 to $0.01,0.02,0.03,0.04$ and 0.05 in the ANL experiment analyses (with the default value in the absence and presence of igniters being 0.10 and 0.07 , respectively).

Vessel pressures for the smaller-scale ANI tests predicted using some of these higher hydrogen-mole-fraction ignition criteria are shown in Figne 8.4.1, again with the test. data and the time-scaled calculated results and lest data for the larger-scale counterpart SNL experiments for comparison. (In these alewlations, the characteristic interaction times also were scaled by the length factor, so these results shombl be compared to those presented in Figure 8.3.1 using a 0.0 hyelegen mole fraction ignition limit to craluate the effects of using different hydrogen ignition limits and therefore different amounts of hydrogen combustion.) The results indicate that, as expecterl, reducing the amount

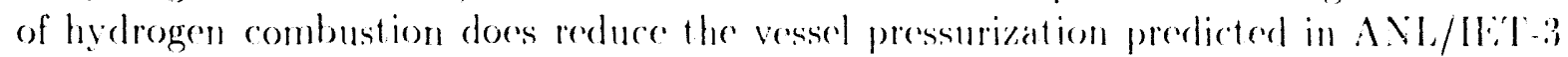
and ANL/IEST-6. Note that different degrees of reduction are reguired to mateh the experimental data for ANL/IET -3 and ANL/IE.T'-6.

Tables 8.4.1 and 8.4 .2 compare the amounts of hydrogen generated and bumed. respectively, in the $A$ NL small-scale test simmations for all the hydrogen-combustion ignition-limit variations considered so far. As experted, changing the hyolrogen mole fraction combustion ignition limit las no effect on hydrogen production thromgh oxidation of debris, but the hydrogen combustion predicted drops off as he hỵdrogen mole fraction combustion ignition limit is increased. Note that values which give good agrerment on peak vessel pressurization seem to give too litte hydegen burn, but this may be due to gradual, late-time hydrogen combustion in the experiment, which is not morlelled in these analyses.

No additional work was done attempting to increase the late-time burn and/or the burn of pre-existing hydrogen.

\subsection{Varying Convective Heat Transfer}

In our first set of calculations done for the smallerescale A VI. tests, the facility geometry (if not explicitly specified in the test data reports) was simply adjusted as appropriate by the difference in scale factor between the two facilities (i.e . . 1/4 for heights or lengths. $1 / 16$ for flow areas or surface areas). The volume flow areds. which had been reduced to obtain volume velocities more characteristic of the turbulent conditions that might 

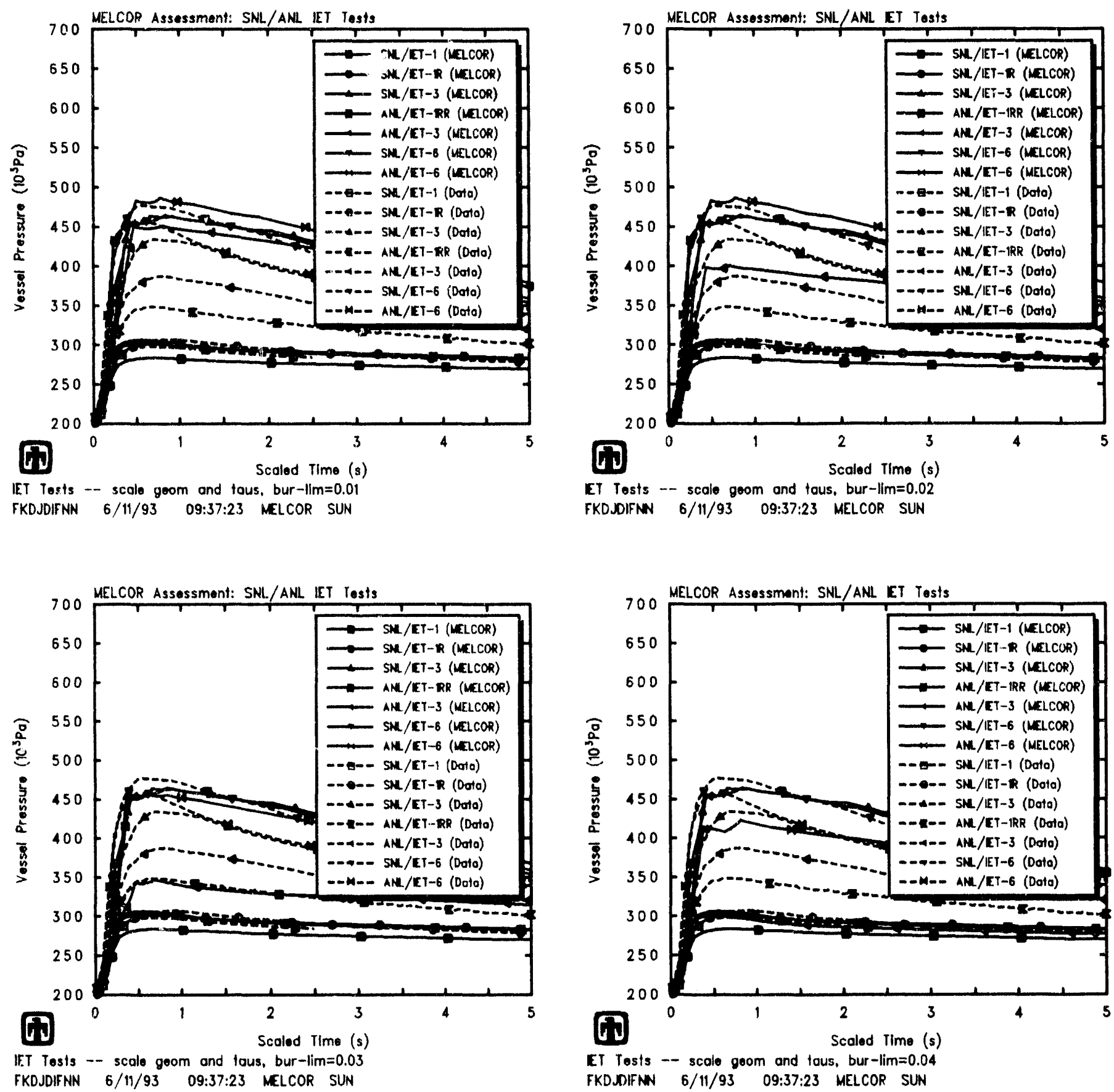

Figure 8.4.1. Scaled Vessed Pressures for SNI and ANI Comberpart IFT Experiments l'sing Ilyelogen Mole Fraction Ignition limits of 0.01 (uppere left). 0.02 (upper right), 0.033 (lower left) and 0.0) (lower right) for the ANL Rxperiment Simmations Varying Hydrogen (ombustion Parameters 
Table 8.4.1. Hydrogen Generation for the $\Lambda$ NL/IET Experiments - Varying Hydrogen Combustion Parameters

\begin{tabular}{|c|c|c|c|c|c|c|c|}
\hline \multirow[t]{4}{*}{ Experiment } & \multicolumn{7}{|c|}{ Hydrogen Produced (gm-moles) } \\
\hline & \multirow[t]{3}{*}{ Data† } & \multirow{2}{*}{\multicolumn{6}{|c|}{$\begin{array}{c}\text { MELCOR } \downarrow \\
\text { ignition } x_{H_{2}}=\end{array}$}} \\
\hline & & & & & & & \\
\hline & & 0.0 & 0.01 & 0.02 & 0.03 & 0.04 & 0.05 \\
\hline IET-IRR & 4.0 & $6.55 / 6.33$ & $6.55 / 6.33$ & $6.55 / 6.33$ & $6.55 / 6.33$ & $6.55 / 6.33$ & $6.55 / 6.33$ \\
\hline IET-3 & 4.65 & $5.00 / 7.09$ & $5.00 / 7.09$ & $5.00 / 7.09$ & $5.00 / 7.09$ & $5.00 / 7.09$ & $5.00 / 7.09$ \\
\hline IET-6 & 4.89 & $5.01 / 6.95$ & $5.01 / 6.95$ & $5.01 / 6.95$ & $5.01 / 6.95$ & $5.01 / 6.95$ & $5.01 / 6.95$ \\
\hline
\end{tabular}

Table 8.4.2. Hydrogen Combustion for the ANL/IET Experiments - Varying Hydrogen Combustion Parameters

Experiment

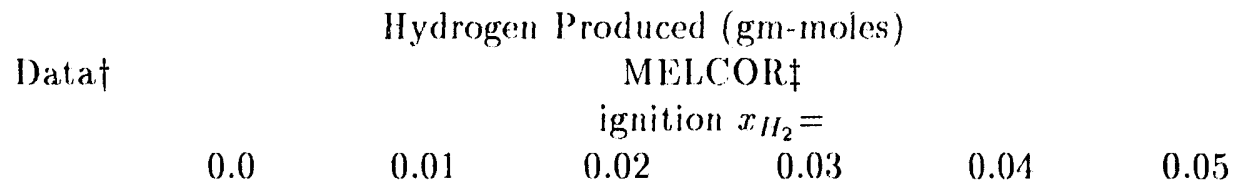

$\begin{array}{lccccccc}\text { IFT-1RR } & & 0 / 0.26 & 0 / 0.26 & 0 / 0.26 & 0 / 0.26 & 0 / 0.26 & 0 / 0.26 \\ \text { IE'-3 } & 3.50 & 3.84 / 6.02 & 2.92 / 5.12 & 1.95 / 4.25 & 0.85 / 3.21 & 0 / 2.39 & 0 / 2.39 \\ \text { IET-6 } & 4.22 & 3.61 / 5.63 & 3.61 / 5.63 & 3.61 / 5.63 & 2.78 / 4.87 & 2.01 / 4.12 & 1.98 / 4.10\end{array}$

from gas grab bottle samples at $30 \mathrm{~min}$

$\ddagger($ actual values at $20 \mathrm{~s}) /$ (assuming only steam/metal reactions) 
be expected during HPME, and the associated turbulent heat transfor to structures (as discussed in Sections 3.1 and 7.2), also were scaled by $1 / 16$ from the input values used for the 1:10-scale SNL test analyses.

The results for the ANL/IET'-1RR test simulations using those arca-scaled volume flow areas (given in Sections 8.2 and 8.4) had too little vessel pressurization calculated due to direct containment heating, one possible contributor to which could be too much heat transfer to structures. A set of calculations was done assuming the convective turbulent heat transfer coefficient scaled with length (i.e., with boundary layer thickness) rather than with area, so that the user-input volume flow arcas for the 1:40-scale ANI, experiment simulations were scaled by $1 / 4$ from the input values used for the 1:10-scale. SNI test analyses.

Figure 8.5.1 gives predicted vessel pressures for the smaller-scale ANI tests, calculated using volume flow areas scaled by the $1 / 4$ length factor rather than by the $1 / 16$ area factor, together with the test data and the corresponding time-scaled calculated results and test data for the larger-scale counterpart SNI experiments for comparison. (In these calculations, the characteristic interaction times also were scaled by the length factor, so these results should be compared to those presented in Figure 8.3.4 to evaluate the effects of using different volume flow areas, velocities and convective heat transfer coefficients.) The peak pressurization predicted in this case for all three $A N L / I E T$ experiment simulations is significantly greater than either test data or the $\$ N L / L E I$ calculated results. These results, which together with those in Figure 8.3.4 bound the $\Lambda$ NL/IET-1RR data, suggest that some of the "missing" extra pressurization due to 1 )(:H at small scale (i.e., in ANI./LET-1RR) may be due to differences in heat transfer to structures at smaller and at larger scale.

\subsection{Varying Recirculation Flow}

The input model in our 1:10-scale SNL/IEI test analyses provided flow paths for straight flowthrough from the steam accumulator to the cavity and chute through the (lumped-together) subcompartments to the vessel dome, and also for recirculation from the upper dome to the subcompartments. The area of the recirculation flow path was set to $10 \%$ of the area of the straight-through flow path from the subcompartments to the dome, based upon the results of sensitivity studies (as discussed in Sections 3.1 and 7.3 ). In our first set of calculations done for the smaller-scale ANL tests, the corresponding recirculation flow path area (as all other flow path areas except the steam blowdown valve area) was simply adjusted by the difference in scale factor between the two facilities, i.e., $1 / 16$ for flow areas. There is no reason to believe that the recirculation pattern is identical in the two facilities, especially given the difference in aspect ratio in the two facilities ( $\sim 5$ for the ANI vessel and $\sim 3$ for the SNI vessel). Therefore, sensitivity studies were done for the $\Lambda N L$ test simulations with that recirculation flow path area increased and decreased by a factor of 10 .

Vessel pressures for the smaller-scale ANL tests predicted assuming both reduced and increased recirculation flows are depicted in Figure 8.6.1, again with the test data 


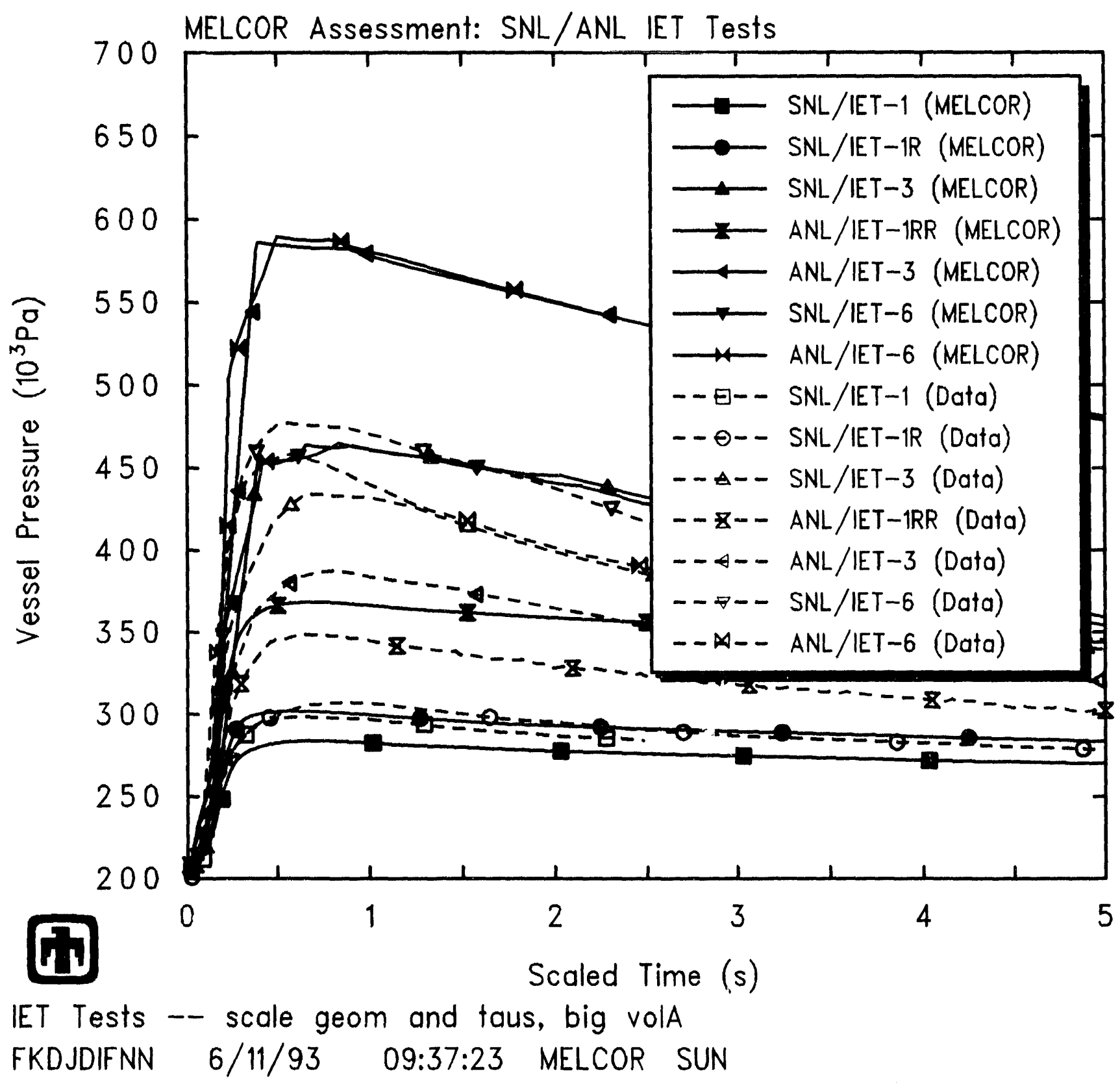

Figure 8.5.1. Scaled Vessel Pressures for SNL and ANL Counterpart IET Experiments - Varying Convective Heat Transfer 
and the corresponding time-scaled calculated results and test data for the larger-scale counterpart SNL experiments for comparison. (In these calculations, the characteristic interaction times also were scaled by the length fartor, so these results should be compared to those presented in Figure 8.3.4 to evaluate the effects of assuming different. recirculation flow areas.) There is little change in peak pressurization predicted in this cese for all three $\Lambda \mathrm{NL} /$ IET experiment simulations, but there is a substantial change in the subsequent dropoff rate, with more rapid depressurization calculated with more recirculation assumed. While a recirculation flow area equal to the original flow area from the subcompartments to the dome is obviously too big, the pressure dropoff rate in the ANL data clearly would be matched better by assuming a recirculation flow area greater than the $10 \%$ assumed in the $\$ \mathrm{NL}$ experiment analyses. 

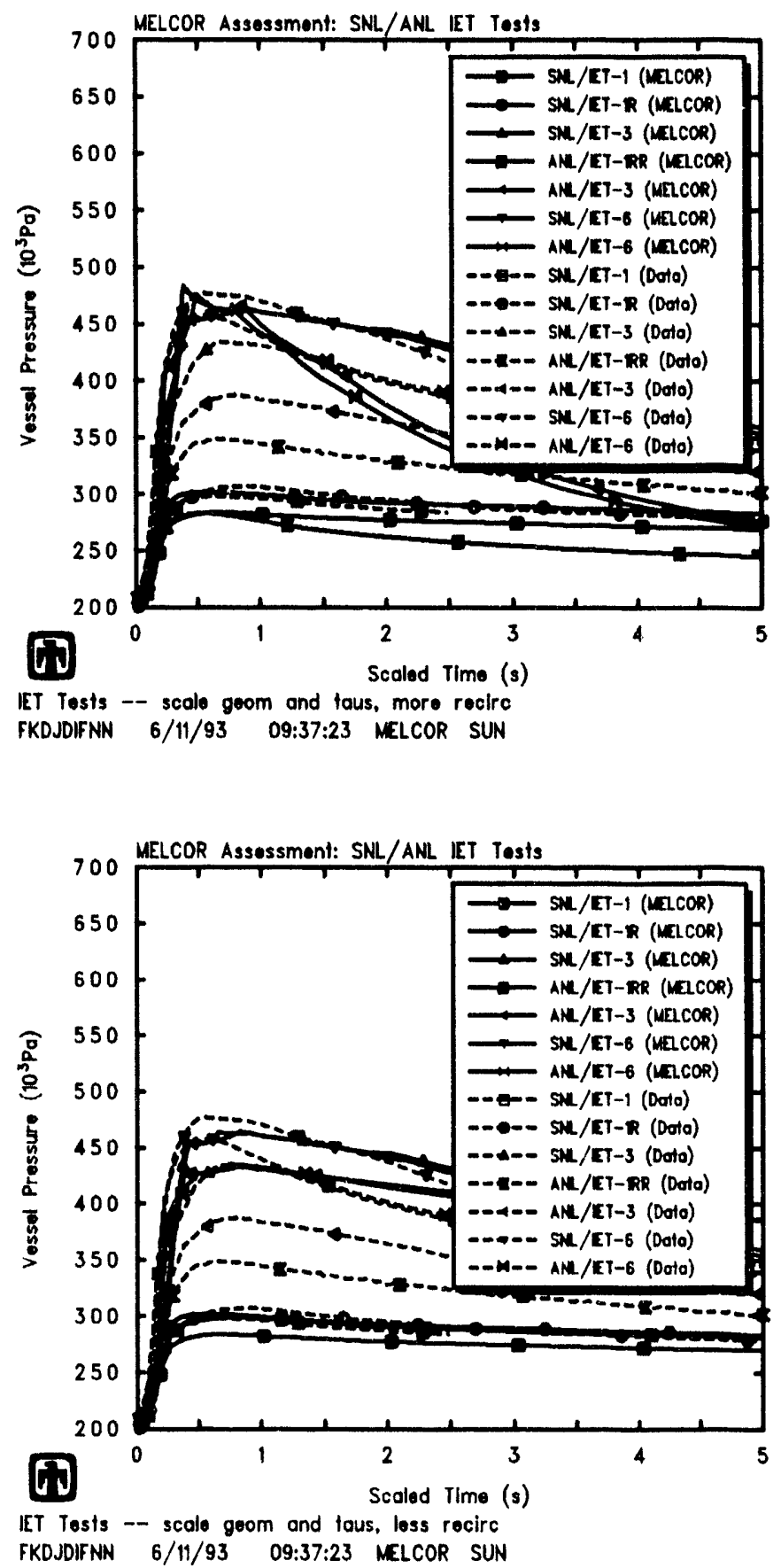

Figure 8.6.1. Scaled Vessel Pressures for SNL and ANL Counterpart IET Expcriments - Increasing (top) and Reducing (bottom) Recirculation Flow 


\section{Time Step Effects and Machine Dependency}

There has been a lot of discussion recently on numeric effects seen in various MELCOR calculations [37], producing either differences in results for the same input on different. machines or differences in results when the time step used is varied. Several calculations have been done to identify whether any such effects existed in our DCH IET assessment analyses.

\subsection{Machine Dependencies}

The calculations discussed in detail in Section 4, and the majority of our sensitivity study analyses, were run on a SUN Sparc2 workstation. The Surtsey SNL/IET reference calculations were rerun, using the same code version $(1.8 \mathrm{NN})$, on an IBM RISC-6000 Model 550 workstation, on an HP 755 workstation, on a CRAY Y-MP8/864, and on a $50 \mathrm{MHz} 486 \mathrm{PC}$.

The predicted vessel pressures for the SUN, IBM and HP workstation, and Cray and PC, calculation sets are presented in Figures 9.1.1 and 9.1.2 for the tests without and with hydrogen combustion, respectively. Tables 9.1 .1 and 9.1 .2 compare the amounts of hydrogen generated and burned, respectively, in these equivalent calculations performed on the various platforms. (Experimental data are included for reference.)

There is generally excellent agreement among results generated on these various hardware platforms. The biggest difference seen is in the vessel pressurization predicted for SNL/IET-1R on the SUN Sparc2 workstation (which will be seen in the noxt subsection to be related to time-step effects); That difference is still relatively small, with io qualitative change in behavior predicted, and there is no corresponding visible difference in amount of hydrogen generated.

Figure 9.1.3 presents run times and time step histories for calculations on the various platforms for the SNL/IET-1 and SNL/LET-6 experiment simulations, as typical results. The three cases with no hydrogen combustion (SNL/IE'I'-1, SNL/IEI'-IR and SNL/LET-5) always show the time step rising relatively smoothly to the user-defined maximum allowed value; the four cases with hydrogen combustion (SNL/IET-3, SNL/IET-4, SNL/IET-6 and SNL/IET'7) always show "sawtooth" time step histories correlated to beginnings and ends of deflagrations. The SUN and P( are always slowest in run time required; the IBM, HP and Cray are all significantly faster with the HP the fastest for these analyses.

\subsection{Time Step Effects}

Otherwise identical MELCOR Surtsey SNL/IET calculations were run on a SUN Sparc2 workstation with the user-input maximum allowed time step progressively set to $1 \mathrm{~s}, 0.5 \mathrm{~s}, 0.1 \mathrm{~s}, 0.05 \mathrm{~s}$ and $0.01 \mathrm{~s}$; simultaneously, the initial time step size for HIPME 

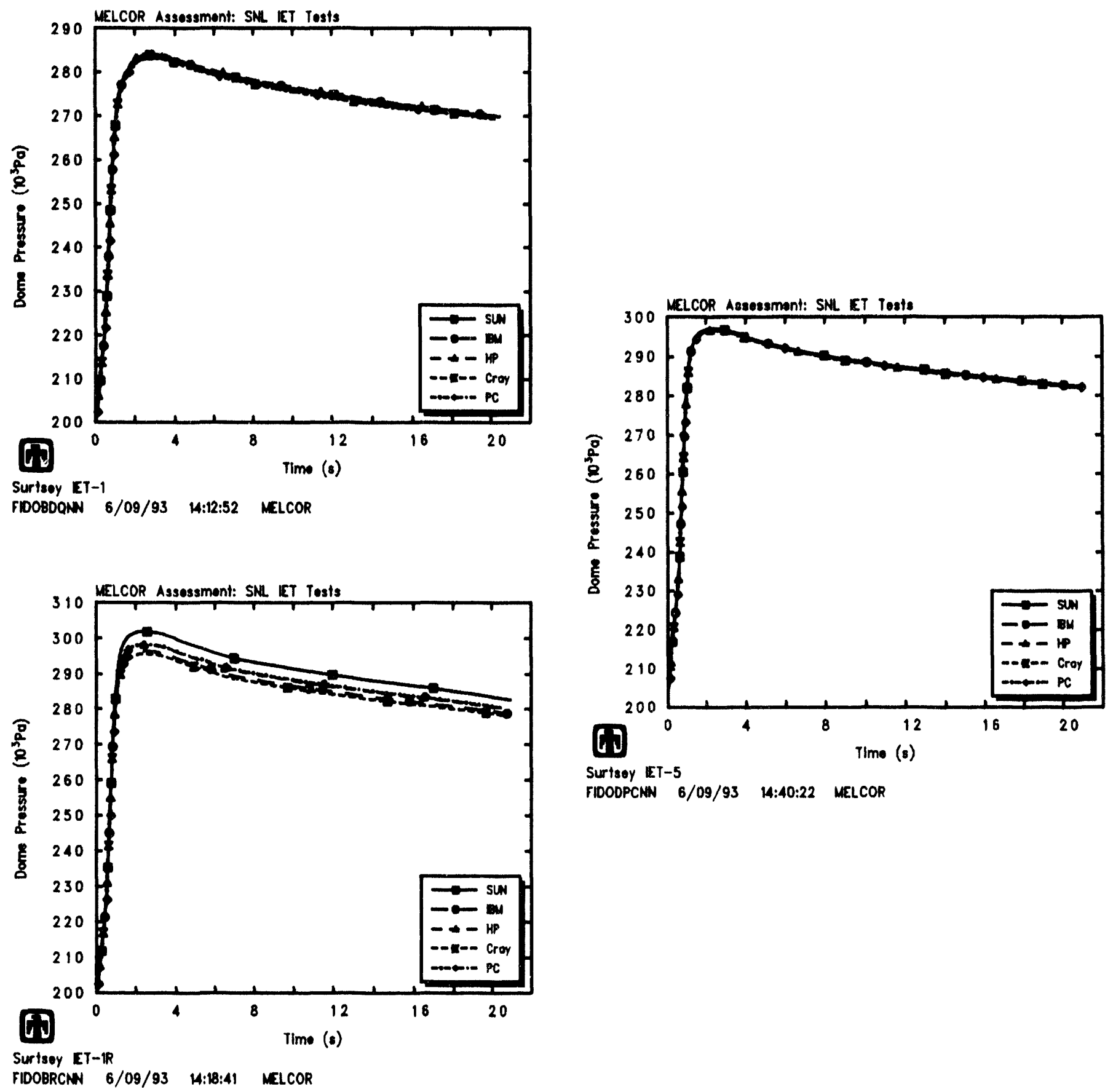

Figure 9.1.1. Vessel Pressures for lixperiments SNL/IET-1 (upper left), $S N L /$ IE:T-IR (lower left) and SSL/IE:T-5) (middle right) Machine Dependency Sensitivity Study 


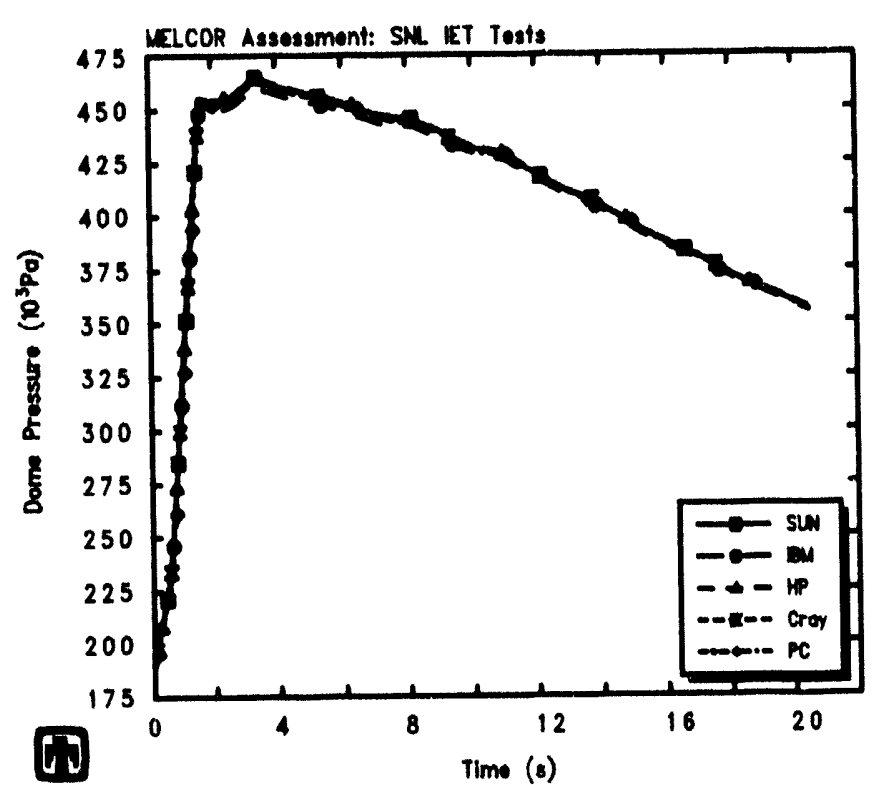

Surtsoy ET-3

FIDOCDINW 6/09/93 44:24:04 NELCOR

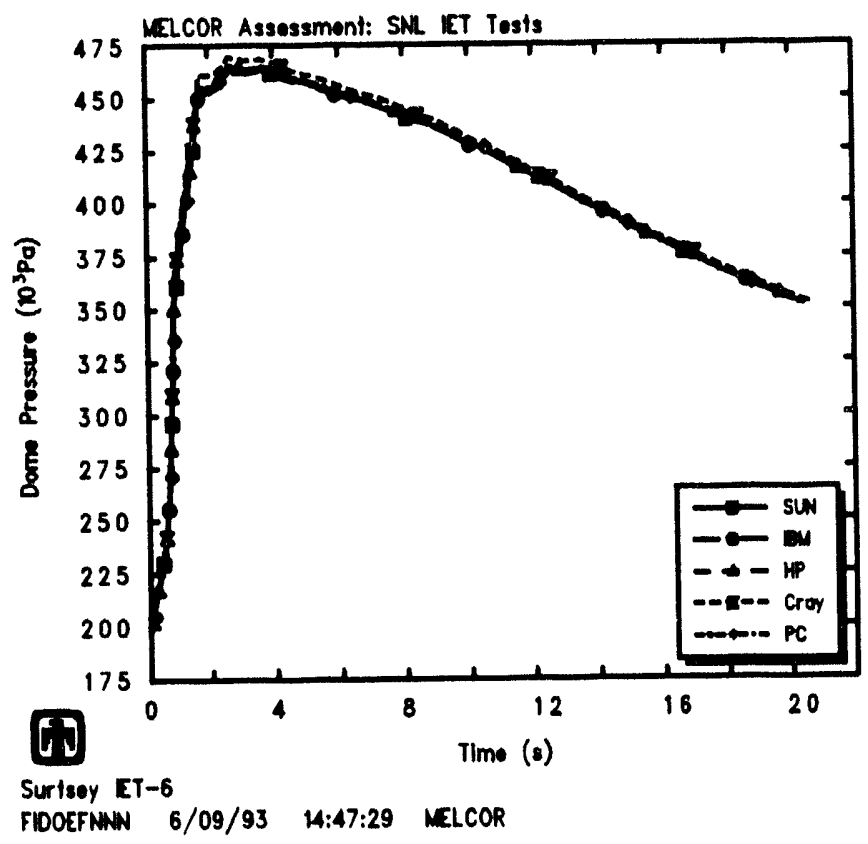

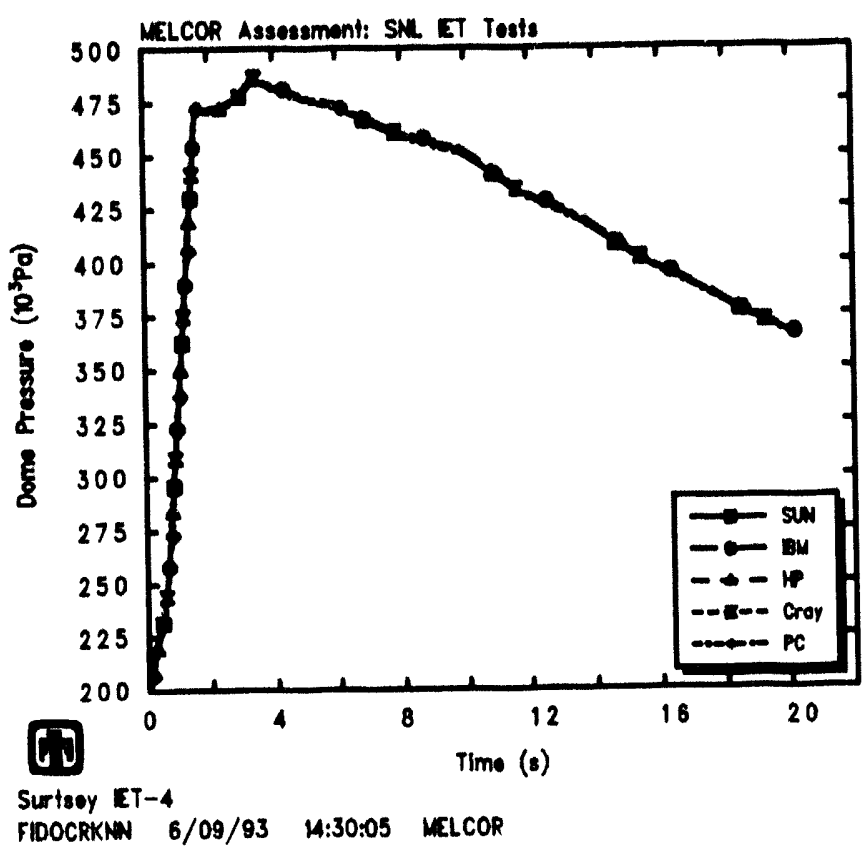

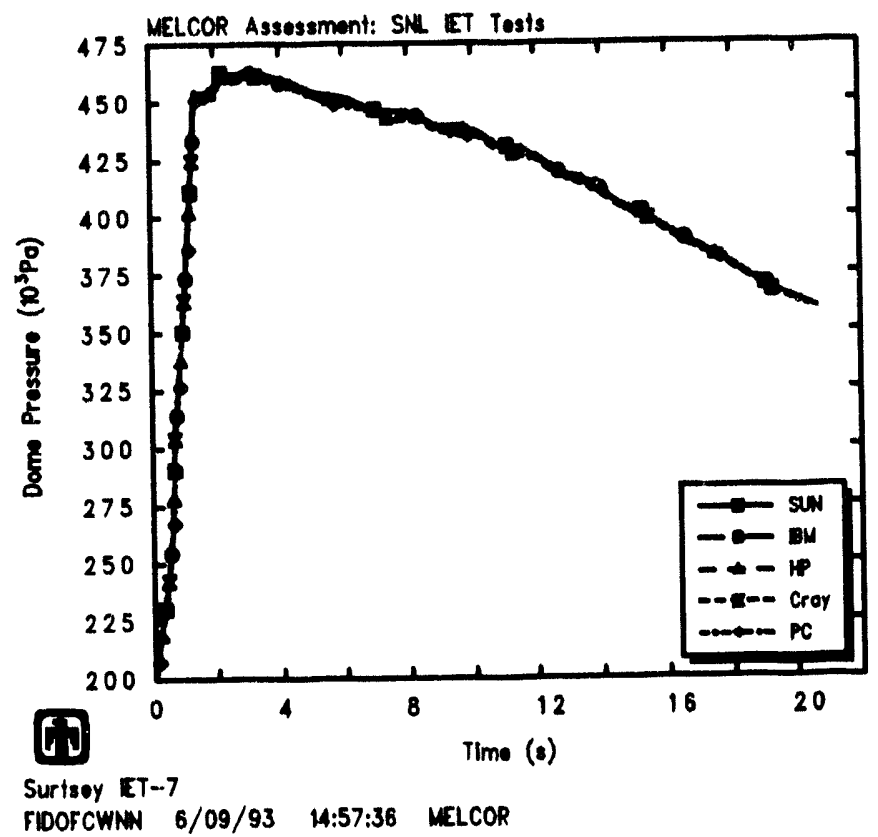

Figure 9.1.2. Vessel Pressures for Experiments SNL/IET-3 (upper left), SNL/IET-4 (upper right), SNL/IET-6 (lower left) and SNL/IE'T-7 (lower right) Machine Dependency Sensitivity Study 
Table 9.1.1. Ilydrogen (ieneration for the SNL/IET Lxperiments Machine Dependency Sensitivity Study

\begin{tabular}{|c|c|c|c|c|c|c|}
\hline \multirow[t]{3}{*}{ lixperiment } & \multicolumn{6}{|c|}{ Ilydrogen Produced (gm-moles) } \\
\hline & \multirow{2}{*}{ Dataf } & \multicolumn{5}{|c|}{ MEICOR } \\
\hline & & $S U N$ & IIBM & $11 P^{\prime}$ & ('ray & PC! \\
\hline II'I'-1 & 233 & $286 / 266$ & $286 / 266$ & $286 ; / 267$ & $286 / 266 j$ & $286 j / 266$ \\
\hline IIET- IR & 248 & $266 / 267$ & $266 / 267$ & $265 / 266$ & $2655 / 266$ & $266 j / 2677$ \\
\hline IE'-3 & 227 & $232 / 352$ & $2: 32 / 350$ & $234 / 35.3$ & $233: 3 / 351$ & $234 / 35.3$ \\
\hline IE'T-4 & 303 & $243 / 361$ & $249 / 366$ & $246 / 364$ & $246 / 365$ & $244 / 363$ \\
\hline IE'T-5 & 319 & $240 / 313$ & $242 / 314$ & $240 / 312$ & $240 / 313$ & $210 / 312$ \\
\hline IE'T-6 & 319 & $236 / 354$ & $236 / 354$ & $235 / 354$ & $233: 3 / 35.5$ & $2: 36 / 356$ \\
\hline IE:T-7 & 274 & $229 / 351$ & $229 / 319$ & $229 / 3550$ & $228 / 319$ & $227 / 348$ \\
\hline
\end{tabular}

from gas grab bottke samples at $30 \mathrm{~min}$ $\ddagger($ actual values at $20 \mathrm{~s}) /$ (assuming only steam/motal reactions)

Table 9.1.2. Machine Dependency for the SNI./IVI Lxperiments Machine Dependency Sensitivity Study

\begin{tabular}{|c|c|c|c|c|c|c|}
\hline \multirow[t]{3}{*}{ Experiment } & \multicolumn{6}{|c|}{ Hydrogen Burned (gm-moles) } \\
\hline & \multirow[t]{2}{*}{ Datat } & \multicolumn{5}{|c|}{ MELCOR } \\
\hline & & SUN & IIBM & IIIP & ('ray & PC' \\
\hline IE'l'-1 & 3 & $0 / 4$ & $0 / 4$ & $0 / 1$ & $0 / 4$ & $0 / 4$ \\
\hline IET- $1 \mathrm{R}$ & 11 & $0 / 28$ & $0 / 28$ & $0 / 2 x$ & $0 / 2 x$ & $0 / 28$ \\
\hline IE:'I'-3 & 190 & $188 / 313$ & $186 / 306$ & $189 / 31.3$ & $187 / 310$ & $18 \times / 312$ \\
\hline IE'T-4 & 240 & $209 / 3332$ & $212 / 3334$ & $210 / 3333$ & $211 / 3334$ & $209 / 3.32$ \\
\hline IE'T'-5 & 5.3 & $0 / 91$ & $0 / 91$ & $0 / 91$ & $0 / 91$ & $0 / 91$ \\
\hline IE' $\left.\right|^{\prime}-6$ & 345 & $182 / 307$ & $181 / 306$ & $18: 3 / 308$ & $18.1 / 311$ & $1 \times 2 / 309$ \\
\hline IE'T'T & $32: 3$ & $223 / 3350$ & $223 / 349$ & $223 / 349$ & $2 \cdot 22 / 349$ & $221 / 348$ \\
\hline
\end{tabular}

trom gas grab bottle samples at 30min

$\ddagger$ (actual values at 20 s)/ (assuming only steam/motal reactions) 

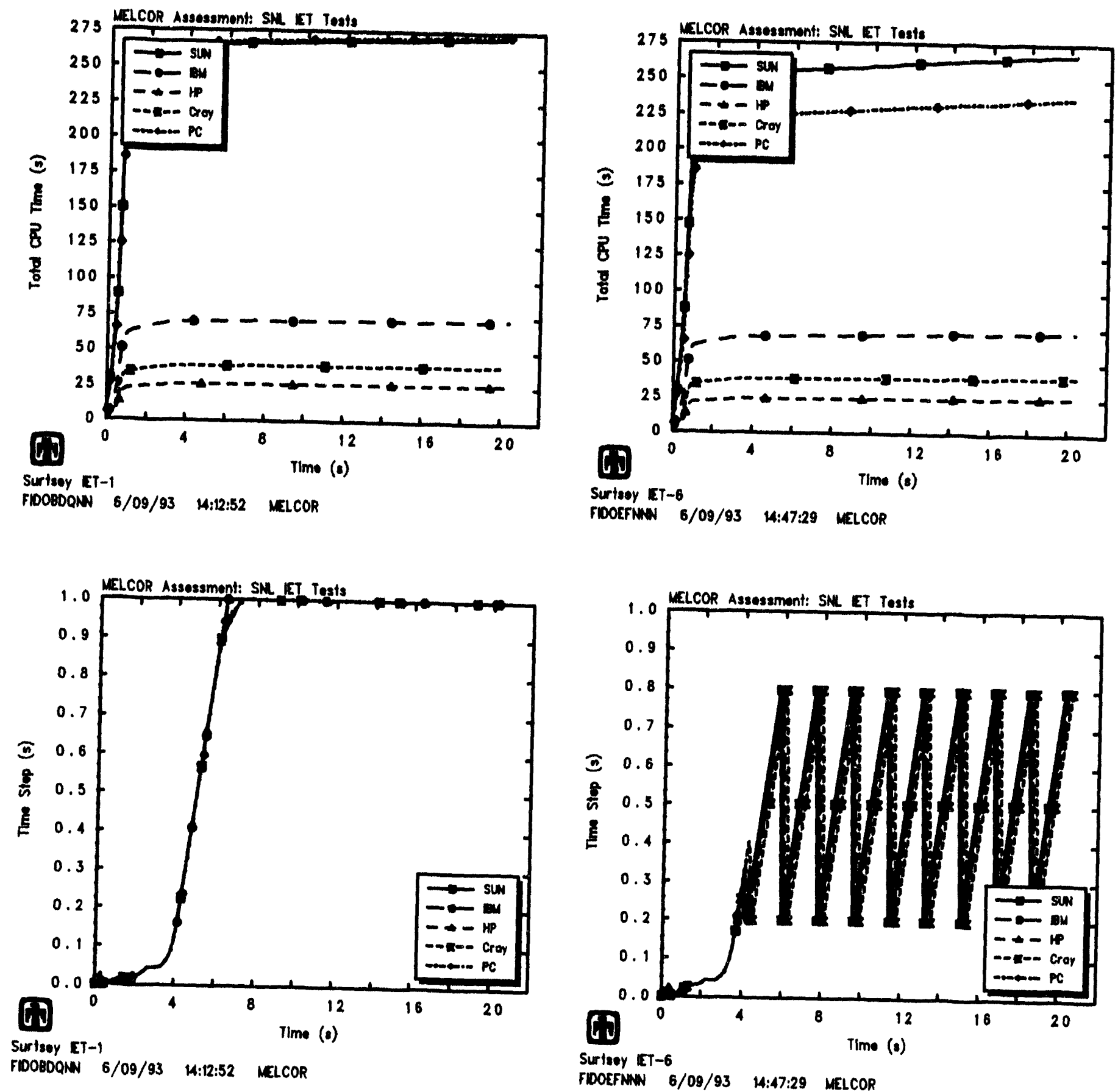

Figure 9.1.3. Total Run Times (top) and Time Step Ilistories (bottom) for SNL/IE'T-I (left) and SNL/IEI'-6 (right) Experiment Analyses Machine Dependency Sensitivity Study 
initiation (S(4607) was progressively set to $1 \times 10^{-4} \mathrm{~s}$ (the default), $5 \times 10^{-5} \mathrm{~s}, 1 \times 10^{-5} \mathrm{~s}$, $5 \times 10^{-6} \mathrm{~s}$, and $1 \times 10^{-6} \mathrm{~s}$. ('The basecase analyses and the other sensitivity study calculations all used a user-input maximum allowed time step of 1 s, and an initial time step size for HPME initiation of $1 \times 10^{-4} \mathrm{~s}$.)

'The predicted vessel pressures for the basecase and reduced-timestep calculation sets are presented in Figure 9.2 .1 and 9.2 .2 for the tests withont and with hydrogen combustion, respectively. ('lest data are included for reference.)

The plot in the lower left of Figure 9.2 .1 shows that the difference seen in vessel pressurization predicted for SNL/IFT'-IR on the SUN Spare2 (Figure 9.1.1) is due to this particular case not having converged fully on the SUN; the reduced time step results on the SUN agree very well with the basecase results calculated on other platforms. Note that most of the other experiment analyses show results converging much better with reduced time steps, especially the no-hurn cases SNL/IE:T-I and SNI./LE'T-5.

There is somewhat more time-step dependence found in the cases with hydrogen burns occurring, as illustrated in Figure 9.2 .2 (which is not surprising). The dependence seen is generally monotonic and converging with reduced time steps. 'Tablo 9.2.1 indicates that there is no significant change in hydrogen production in any case as the time step is varied, while Table 9.2 .2 shows a monotonic increase in amonnt of hydrogen burned as the time step is decreased, except in the SNL/IET'7 rase.

The qualitatively different behavior found in the total amounts of hydrogen calculated to be burned in the SNI/IET-7 andyses is also seen carlier in the HPME/D)(H transiont period. Figure 9.2.3 gives the time-dependent hydrogen combustion in the four cases with hydrogen burn (SNI/IET-3, SNI/IE'T'-4, SNL/IE'T'-6 and SNI/IE'T-7), and shows that the differences found in hydrogen combustion are not generated during the HPNE period (from 0 to $\sim 4 \mathrm{~s}$ ). but are due to a slowly-accumulating divergence later in time. The plots in this figure show that, in general, the runs with the larger time steps $\left(\Delta t_{\text {max }}>0.1 \mathrm{~s}\right)$ may not be converged but the runs with smaller time steps $\left(\Delta t_{\text {M A }} \leq 0.1 \mathrm{~s}\right)$ are converged. The SNL/IET-7 case appears to be converged even at the larger time steps allowed.

Total run times and time step histories for calculations using different time steps for the SNL/IET-1 and SNL/IE'T-IR experiment simulations are presented in Figure 9.2.4. (The corresponding results for SNL/IE'-5) are similar to those shown.) There is no significant, overall difference visible in either run time or time step history to explain the difference in predicted vessel pressurization found in this study for the SNI, IF'T-IR conditions. Figure 9.2.5 gives total run times and time step histories for the SNL/LET'6 and

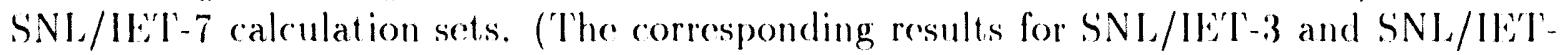
4 are similar to those shown.) While there is no significant, overall difference visible in either run time or time step history to explain the difference in predicted hydrogen combustion found in this study for the SNI/LET-T conditions, these plots suggest that, in three of our four "burn" cases, the time step control causing time step reduction at the start of hydrogen burns may not reduce the time step sufficiently far or long a sufficiently long period; note that the hydrogen masses predicted to be burned in the runs with smaller time step values were generally quite similar, illustrating significant convergence when the time step was reduced. 

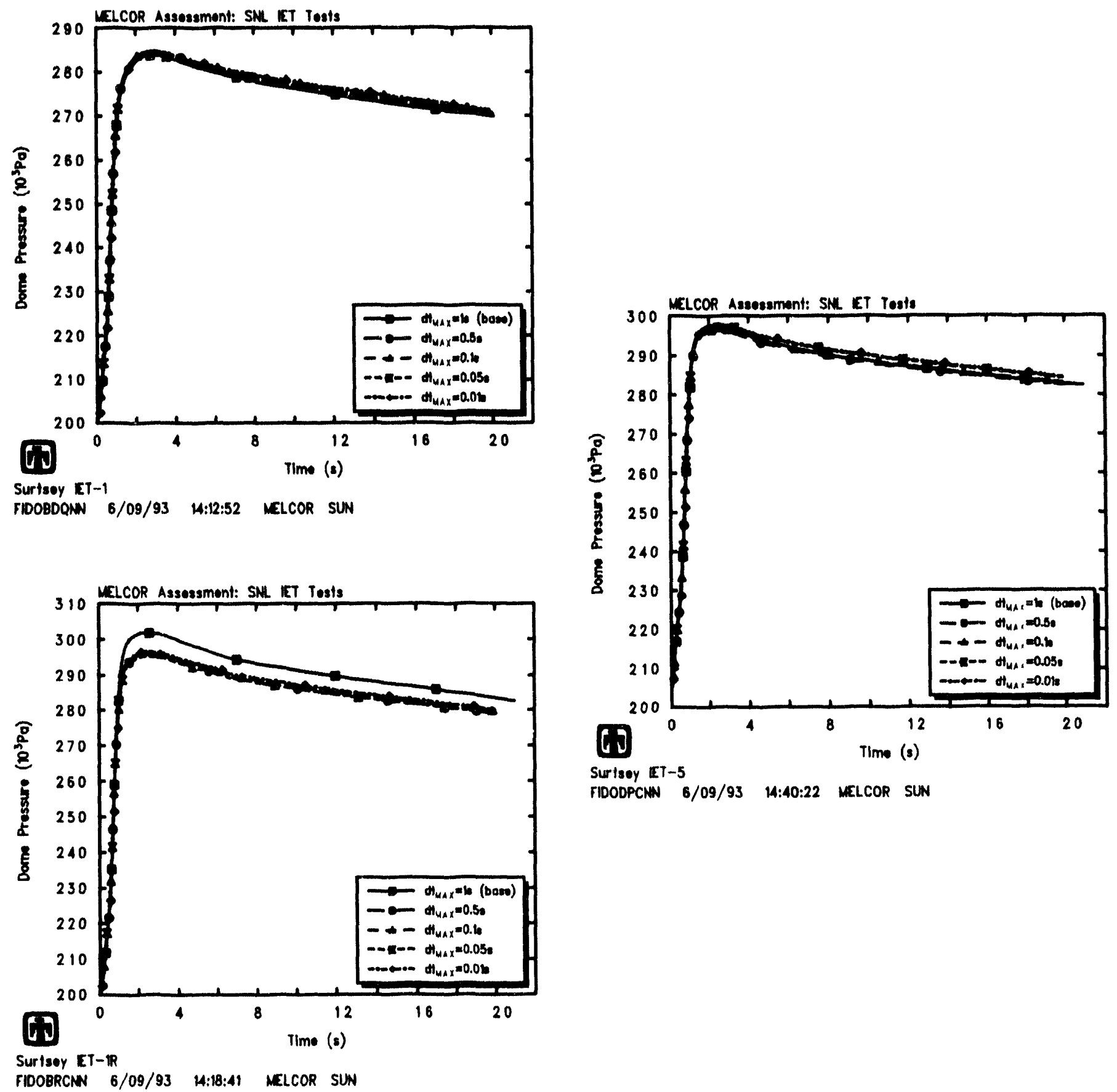

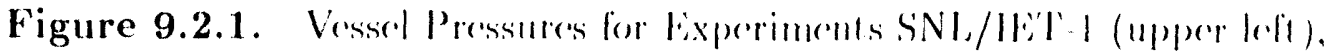

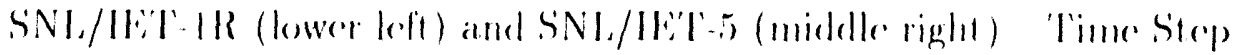
Sonsitivity sturly 

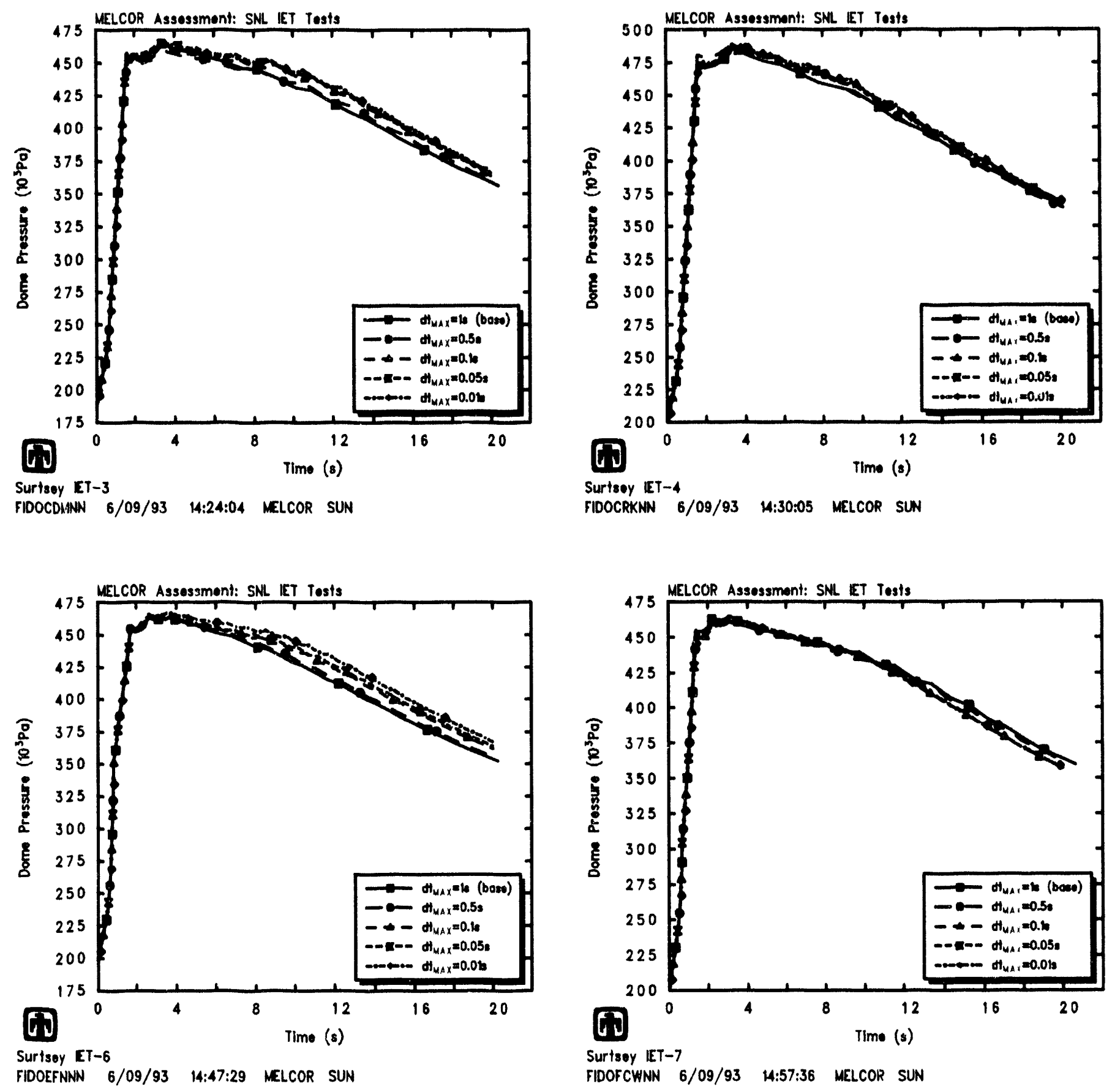

Figure 9.2.2. Vessel Pressures for Experiments SNL/IET-3 (upper left), SNL/IET-4 (upper right), SNL/IET-6 (lower left) and SNL/IET-T (lower right) Time Step Sensitivity Study 
Table 9.2.1. Hydrogen Generation for the SNL/IET Experiments - Time Step Sensitivity Study

\begin{tabular}{|c|c|c|c|c|c|c|}
\hline \multirow[t]{3}{*}{ Experiment } & \multicolumn{6}{|c|}{ Hydrogen Produced (gm-moles) } \\
\hline & \multirow[t]{2}{*}{ Datał } & \multicolumn{5}{|c|}{ MELCOR $\ddagger$} \\
\hline & & 1s & $0.5 \mathrm{~s}$ & $\begin{array}{c}\Delta t_{M A X}= \\
0.1 \mathrm{~s}\end{array}$ & $0.05 \mathrm{~s}$ & $0.01 \mathrm{~s}$ \\
\hline IET-1 & 233 & $286 / 266$ & $286 / 266$ & $286 / 265$ & $286 / 265$ & $287 / 266$ \\
\hline IET-1R & 248 & $266 / 267$ & $265 / 264$ & $267 / 266$ & $267 / 264$ & $267 / 265$ \\
\hline IE'T-3 & 227 & $232 / 352$ & $231 / 351$ & $233 / 353$ & $232 / 356$ & $233 / 354$ \\
\hline IET-4 & 303 & $243 / 361$ & $244 / 368$ & $246 / 364$ & $246 / 365$ & $245 / 366$ \\
\hline IE'T-5 & 319 & $240 / 313$ & $240 / 312$ & $240 / 313$ & $241 / 312$ & $242 / 313$ \\
\hline IET-6 & 319 & $236 / 354$ & $237 / 355$ & $233 / 354$ & $234 / 355$ & $237 / 357$ \\
\hline IET-7 & 274 & $229 / 351$ & $227 / 346$ & $226 / 347$ & $229 / 350$ & $227 / 348$ \\
\hline
\end{tabular}

Table 9.2.2. Hydrogen Combustion for the SNL/IET Experiments - Time Step Sensitivity Study

Experiment

Datat
Hydrogen Burned (gm-moles)

MELCOR+

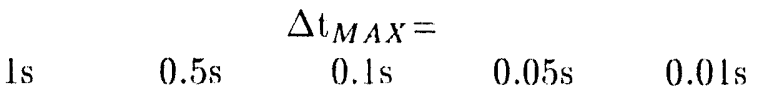

$\begin{array}{lcccccc}\text { IE'T-1 } & 3 & 0 / 4 & 0 / 4 & 0 / 4 & 0 / 4 & 0 / 4 \\ \text { IE'-1R } & 11 & 0 / 28 & 0 / 28 & 0 / 28 & 0 / 28 & 0 / 28 \\ \text { IET-3 } & 190 & 188 / 307 & 201 / 326 & 221 / 345 & 225 / 351 & 229 / 353 \\ \text { IET-4 } & 240 & 209 / 332 & 222 / 349 & 236 / 358 & 238 / 361 & 241 / 365 \\ \text { IET-5 } & 53 & 0 / 91 & 0 / 91 & 0 / 92 & 0 / 89 & 0 / 91 \\ \text { IE'-6 } & 345 & 182 / 307 & 185 / 310 & 210 / 336 & 215 / 341 & 224 / 350 \\ \text { IET-7 } & 323 & 223 / 350 & 221 / 346 & 221 / 346 & 223 / 349 & 222 / 348\end{array}$

ffrom gas grab bottle samples at $30 \mathrm{~min}$ $\ddagger$ (actual values at $20 \mathrm{~s}) /$ (assuming only steam/metal reactions) 

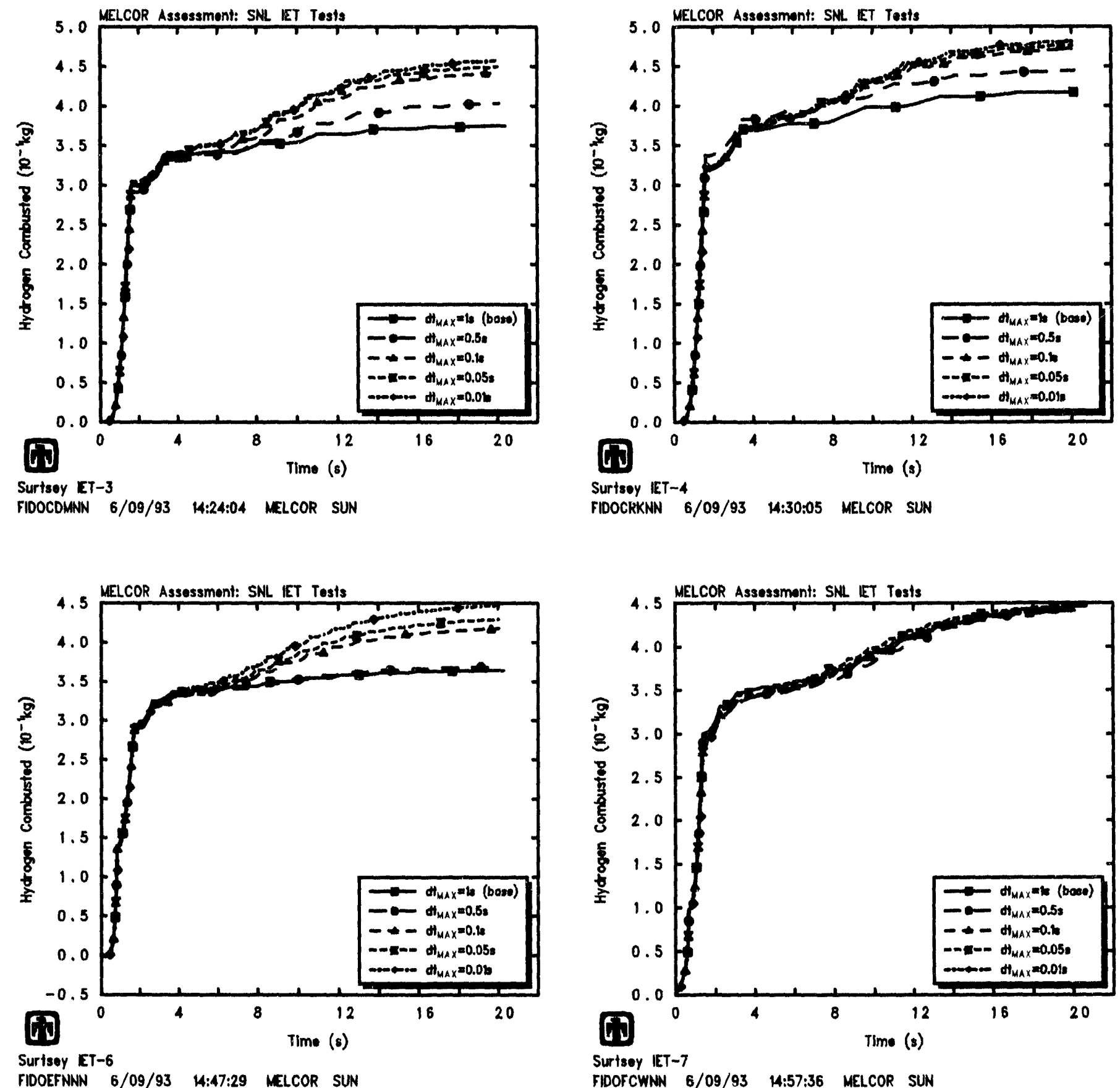

Figure 9.2.3. Hydrogen Combustion for Experiments SNL/IET-3 (upper left), SNL/IET-4 (upper right), SNL/IET-6 (lower left) and SNL/IET-7 (lower right) - Time Step Sensitivity Study 

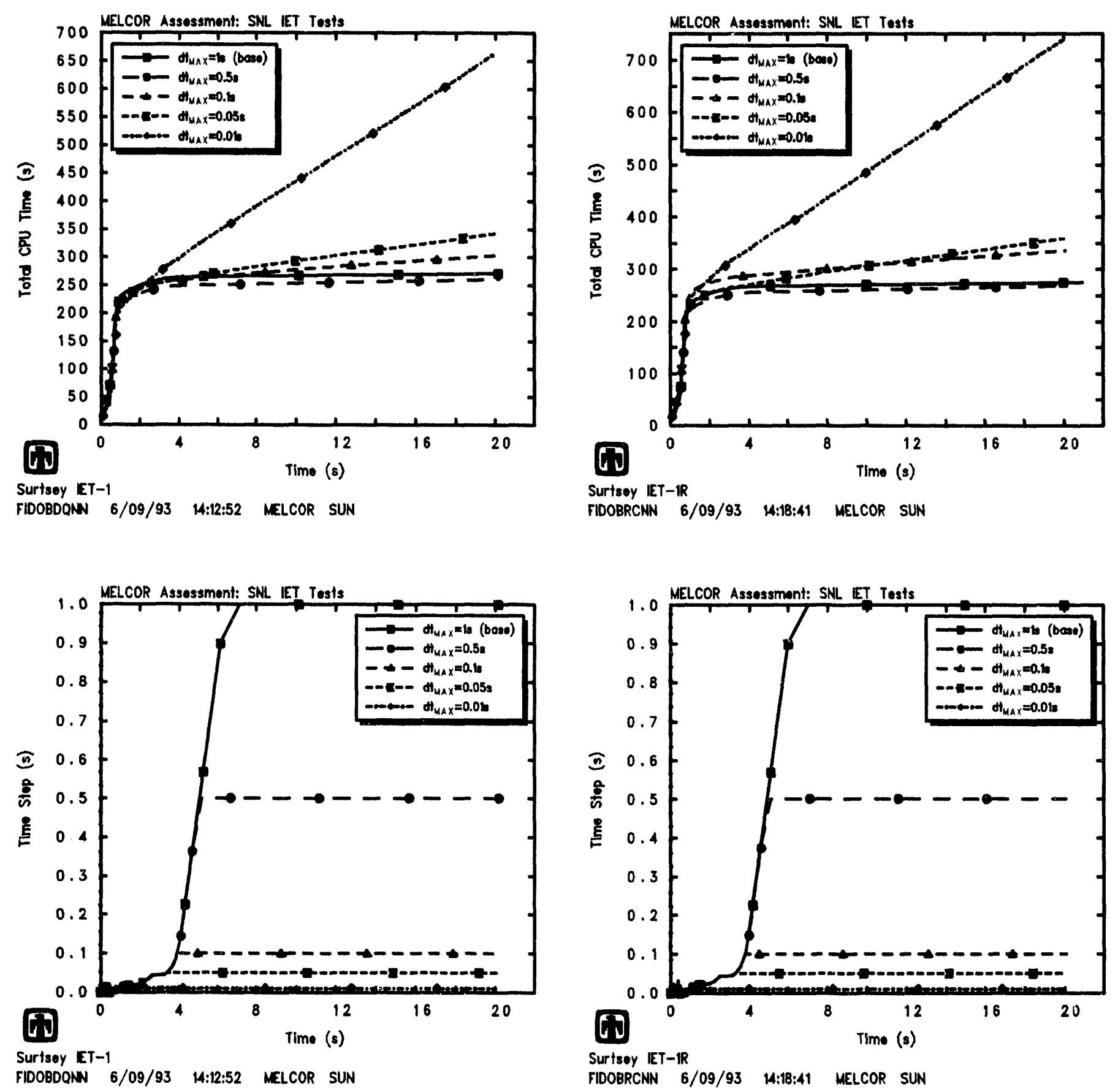

Figure 9.2.4. Total Run Times (top) and Time Step Histories (bottom) for SNL/IET-1 (left) and SNL/IL:T-IR (right) Experiment Analyses Time Step Sensitivity Sturly 

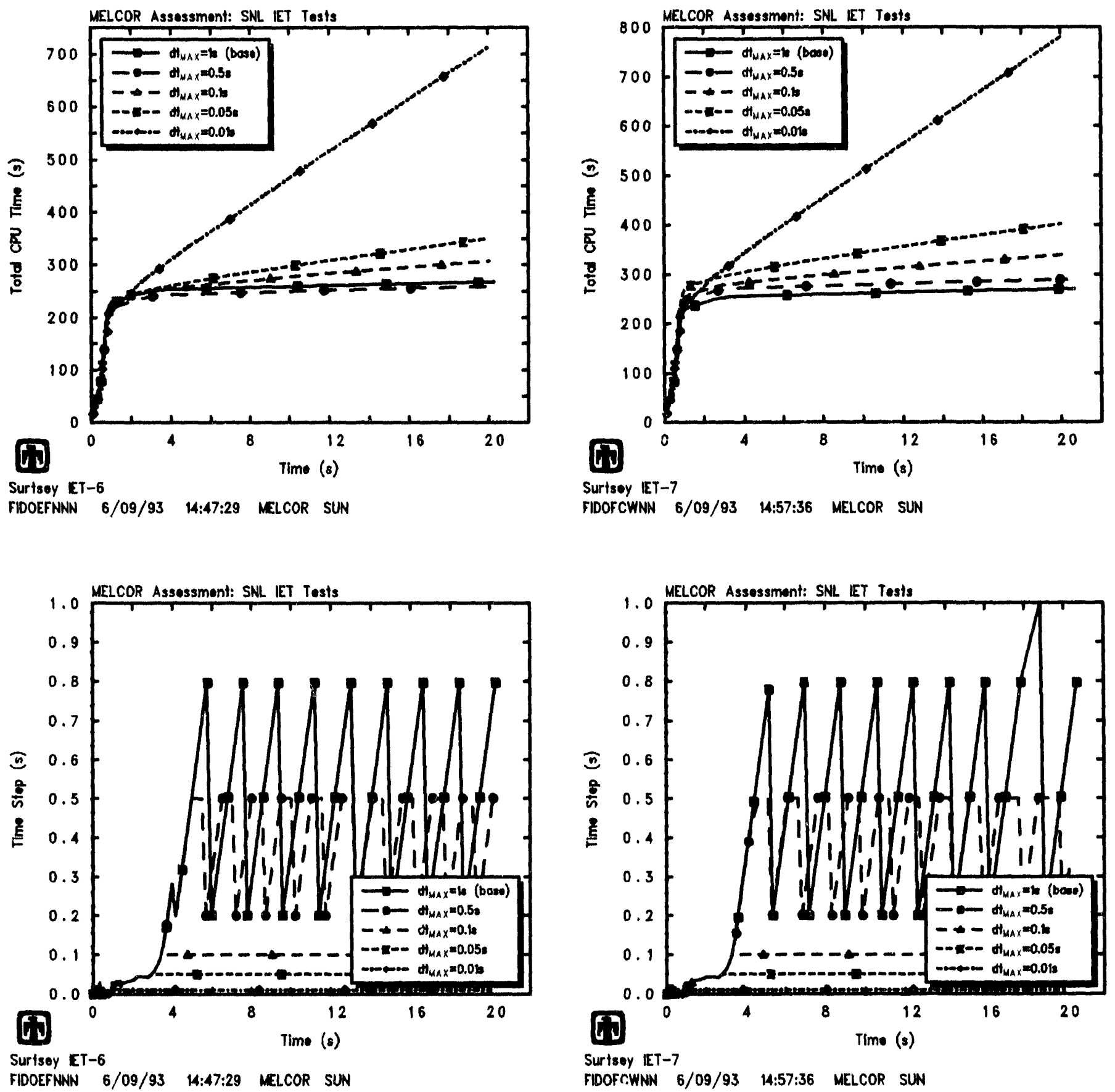

Figure 9.2.5. Total Run Times (top) and Time Step Histories (bottom) for SNL/IET-6 (left) and SNL/IET-7 (right) Experiment Analyses - Time Step Sensitivity Study 


\section{Comparison to CONTAIN}

Several of the 1:10 linear scale SNL/Het' experiments done in the Surtsey vessel have bern analyzed with the (:ON'IAIN code. The ('ON'IAIN D) 'II model is quite different. from the MELCOR FDI/IIPME I)('H model, being a more detailed, more mechanistic treatment rather than a more obviously paramotric approach.

A number of CON'IAIN calculations were done with evolving versions of the code. 'The early SNL/LE'T'- and SNI./LEI'-1R pretest calculations were done with ('ON'AIN 1.12 citecontain-1-pretest,contain-1r-pretest,contain-1-posttest, contain-1-bypass. Pretest calculations were also done for SNL/IE'T-3 [31] and SNI,/IE'T'-5 [32] using ('ONIAIN 1.12 with the unconditional hydrogen burn (U(HB) model added, and SNI/IET -3 postitest calculations [33] were performed using the most recent, diffusion flame burn (I)F B ) and bulk spontancous reaction (BSSR), combustion models. In all cases, a number of sensitivity study calculations were done evaluating the effects of varions paraneters and modelling options.

More recently, several of the $\$ N$ L/IE'T experiment simulations have been rerum, with results presented at the ('ON'AIN Peer Review [38]. Those results wereobtained using a "standard" input prescription based upon prior experience [39]. Many inputs were defined as described in Appendix $B$ of [29]. The new models for vessel failure and blowdown, and models for cavity entrainment and dispersal, weren't being assessed; hence, blowdown rates and debris dispersal fractions were matched to the experimental results, and debris sonre time-dependenee was derived from the cavity pressurization history in order to uncouple uncertainties in these processes from the assessment of phenomena which were being modelled. Particle size was 1 mm MMI) (mass median diameter), assuming a lognormal distribution with $\sigma_{g}=4$. 'The parametric model for nonairborme debris was used in the cavity with an effective particle size of $0.01 \mathrm{~m}$.

A number of sensitivity study results were presented in [38]. The results presented here, on the recommendation of $\mathrm{D}$ ). ( $\therefore$ Williams of the (OONTAIN development gromp) [39], are those obtained using default DFH concent,rations, which correctly predicted $\mathrm{H}_{2}$ combustion for all four Zion SNI./E'T tests analyzed. (However, note that $\mathrm{I}^{2}$ combustion in other tests, especially SNI/IET'-9, was underpredicted by the default model and that further refinement in combustion criteria is still needed. Also note that the "standard" case in [38] involved parameters set to make DFB almost unconditional, which wouldn't work for SNL/IE'T-5; this made little difference on the other Zion SNI/HEL' experiments simulated (i.e., SNI,/IE'T-1, SNL/IE'T'-3 and SNI,/IET-6), but did matter for SNI/IET9.)

Table 10.1 compares measured peak vessel pressures with results calculated by both MEI, YOR and by (OONTAIN. ('The MELCOR results used in this section are those from the reference calculations described in Section 4.) Tables 10.2 and 10.3 compare measured hydrogen production and combustion, respectively, with corresponding calculated results; note that the hydrogen production and combustion for (ONTAIN are estimated from hydrogen and oxygen molar balances, as is the experimental data. 
Table 10.3. Hydrogen Combustion for the SNL/IET Experiments - Code Comparison Study

\begin{tabular}{cccc} 
Experiment & \multicolumn{3}{c}{ Hydrogen Burned (gm-moles) } \\
& Datat & MELCORt & CONTAIN \\
IE'T-1 & 3 & $0 / 4$ & {$[27]$} \\
& & & $\cdots 29]$ \\
& & & {$[38]$}
\end{tabular}

\begin{tabular}{|c|c|c|c|}
\hline IET-1R & 11 & $0 / 28$ & {$[28]$} \\
\hline IE'T-3 & 190 & $209 / 313$ & $\begin{array}{l}37[31]\}_{3} \\
250[31] \rrbracket \\
222[33] \Phi \\
200[33] B \\
150[38] B\end{array}$ \\
\hline
\end{tabular}

$\begin{array}{llll}{\left[F^{\prime} T^{\prime}-5\right)} & 53 & 0 / 91 & {[32]}\end{array}$

$3.5[38]$

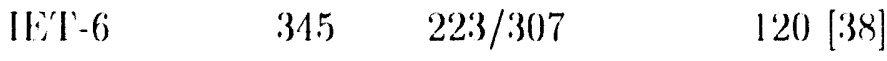

from gas grab bottle samples at 30min

$\ddagger($ actual values)/ (assuming only steam/metal roactions)

qusing DHB (default hydrogen burn) Gusing UC'HB (unconditional hydrogen burn)

Busing DFB and BSRR latest combustion models 
The results obtained with the two code models are generally similar. In particular, a pressure rise of $\leq 100 \mathrm{kPa}$ is calculated for tests with no significant hydrogen combustion, and a larger pressure rise of $\sim 200-250 \mathrm{kPa}$ is obtained for cases with substantial hydrogen burn. Some other observations on the MELCOR-('ON'IAIN comparisons taken from [39] are:

1. The CONTAIN calculations indicated that, with a degree of debris-steam coherence equal to that inferred from the experimental results, CON'TAIN underpredicted $\Delta \mathrm{P}$ and $\mathrm{H}_{2}$ production unless substantial contributions from nonairborne debris and/or co-dispersed cavity water were allowed.

2. CONTAIN sensitivity studies indicated that improved agreement could be obtained for $\triangle \mathrm{P}$ in SNL/IET-3, SNL/IET-5 and SNL/IET-6 (but not necessarily SNL/IE'T1) if increased nonairborne debris interactions (i.e., in the subcompartment) or interaction with co-dispersed water were allowed, relative to the standard input set. This would overpredict $H_{2}$ in SNL/IET-1 and SNL/IET-3, but not in SNL/IET'-5 and SNL/IET-6. There was no tendency of model assumptions giving good $\Delta \mathrm{P}$ results to underpredict $\mathrm{H}_{2}$ results; thus, the CON'TAIN calculations do not support the possibility that much of the hydrogen production inferred from the gas analyses represents "late" effects occurring on time scales of minutes rather than seconds.

3. CONTAIN sensitivity studies indicated that substantial mitigation results from the combined effects of heat transfer and inability of all I)(H-produced hydrogen to burn promptly due to oxygen starvation in the subcompartment; incomplete debrisgas equilibration was also a significant tuitigation effect, but not as important as the heat transfer and hydrogen effects in the calculations.

4. DCH time constants calculated by CON'IAIN tended to be strong functions of location and time during the event. Trapping and heat transfer time constants tended to be shorter but oxidation time constants tended to be greater than those input to MELCOR; however, the significance of longer oxidation time constants was reduced by the fact that CONTAIN still used most of the coherent steam.

5. Differences resulting from different ways of evaluating $\mathrm{H}_{2}$ production and combustion are considerably less for CONTAIN than in MELCOR because unreacted debris in the CONTAIN model doesn't see nearly as much oxygen as in MELCOR's model. 


\section{Code Problems Identified}

A number of code and modelling errors and inarlecuacies were identified and corrected during our DCH IE'T experiment MELC'OR assessment analyses. Many of these have been mentioned throughout the text, hut are summarized in this section for easy reference.

\subsection{Debris Material and Source Input}

The first problem encountered in beginning these I)(H IE'T experiment MELC(O) assessment analyses was that some of the required post-thermite reaction materials (Fe, $\mathrm{Al}$, (r and $\mathrm{Al}_{2} \mathrm{O}_{3}$ ) were not available as materials recognized by the new IIPME model added recently to the FDI package in MELCOR. In the original coding, the FI)I IIPME model only recognized the standard (OOR-package materials $U \mathrm{O}_{2}, \mathrm{hr}, \mathrm{hr} \mathrm{O}_{2}$, stecl, stcel oxide and cont rol rod poison. The ('AV package recognizes all of the standard (O)RCON materials as possible inputs, including the post-thermite reaction materials, but this was of no help in modelling debris dispersal to control volume atmospheres and/or to heat structure surfaces. Therefore, $\mathrm{Al}$ and $\mathrm{Al}_{2} \mathrm{O}_{3}$ were added as allowed input materials in the FIDI HPME model.

While $\mathrm{Al}$ and $\mathrm{Al}_{2} \mathrm{O}_{3}$ were arded as allowed input materials in the Fl) HPME model, Fe and (ir were not added as separate input materials because they could already be input as constitutive components of sted (assumed to consist of a mixture of $\mathrm{Fe}, \mathrm{Ni}$, ( $\mathrm{r}$ and ('). For user convenience and for consistency, the optional user input specification of the composition of steel was moved from the (OR package input to be MP ("material properties") input; for internal self-consistency, the oxidation reaction energy of steel is then calculated within the MP package for the composition specified.

At the same time, a "stand-alone" input capability was added to the FI) HPME model allowing specification of debris input through tabular function input in addition to the previously-available specification of debris input through 'I'P' ("transfer process") package input; the previously-available TP input assumed debris sources coming from the (OR package through translation matrices or from external user-specified data sets defined using the EDF ("external data file") package in MELCOR. The stand-alone tabular-function input capability added to the FI)I HPME model allows a much more user-friendly and convenient format for specification of dobris input, particularly for experiment analyses such as in this study.

Our first IET experiment analyses would frequently abort with tomperature convergence failures. After several patches were tried, the II)I HPME Lemperature convergence coding was changed to be much more robust. No corle aborts due to temperature convergence failures during HPME have been seen since, despite the large number of calculations done and the wide range of conditions encountered. 
These carly problems were reported as DIR1097 and D)lRl098, and the code modifications implemented in version I.8MY. 'These modilieations are therefore inducled in the relase version of MLI, ( ) 1.8 .2 (1.8NM).

\subsection{Debris Interaction with Structures}

After work on these analyses had been in progress for some time, we became concerned about the interaction of debris with heat structures. In the original HIPML model added to MEl('O)R, any debris immediately deposited onto a heat structure or later sedtled onto a heat structure essentially left the problem; there was no subserguent interaction of any kind for that debris, except for decay heating of the structure surface. This was identified as a major potential problem area during onr Mlilo(O) I)('Il analyses,

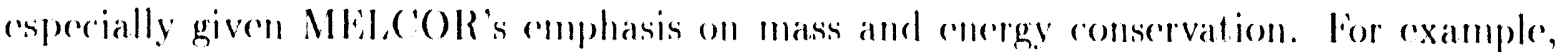
the lack of any lhermal interaction of debris with structures condel adversely affect the ability to correctly prediet late time revaporization of volatile fission products. Also, the lack of any oxidation of deposited debris meant that the total amount of hyelrogen producable during IIPME was very highly dependent on He user-specilied initial debris distribution any debris deposited or settled could not generate any hydrogen, regardless of oxygen and/or steam availability or debris temperature and/or amount. 'Therefore two major effects were later adeled to the original IIPMLi model: the heating of the structure surface by deposited hot debris, and the continued oxidation of the deposited debris. The heating of the structure surface by deposited hot debris is controlled by a heat transfer coeflicient adjustable through sensitivity coeflicient input, and the contimued oxidation of the deposited debris is controlled by a user imput structure oxidation characteristic time (distinct from and usually much longer than the characteristic time input for oxidation of aiborne debris). With these input and coding modifications, IIPML debris deposited on structures now ean comtimue to affect the overall system response through several potential interactions.

These model enhancements needed were reported as D)IR1130, and the code modifications implemented in version $1.8 \mathrm{NN}$. Note that this set of code changes is not included in the relcase version of MELC(')R 1.8.2 (1.8NM).

\subsection{Hydrogen Combustion during DCH}

We found during the course of these analyses that nom-default input for the BUR package was recuided to match the hydrogen combustion behavior observed in these experiments. While this conde be done with the standard BUth package input for these experiment analyses, the same input modification could not be made in plant analyses, because the non-standard input would affect the results calculated both before and alter the IIP'Mliperiod. ('These experiments and associated analyses, in comparison, consisted of only the IIPME period.) This problem was addressed by providing new, optional input. parameters in the Blll parkage, essentially allowing the user to specify one set of input, 
parameters fo be used during periods of IIP'Ml: and anothere set of input paraneters to be used during the remaining times. The hydrogen combustion input during IIPME is defanlt to the non-IIPMlE values if not specified otherwise. The IIPME period in any given control volume is a time period which satisfies const raints on minimum airborne debris amomut and/or density, and temperature, all of which cutofl values are adjustable through semsitivity coefficient input.

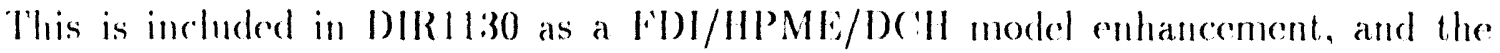
code modifications implemented in version $1.8 \mathrm{NN}$. Note that this set of code changes are not included in the release version of MEL(C)R 1.8 .2 (1.8NM).

\subsection{Additional Output}

While studying results from our varions calculations, we found that there were not enough control functions and plot variables to readily analyze the hydrogen production es combustion in the varions cases. Reactant masses and energies for oxidation on structures were added as control functions and plot variables to the lil) package IIPMF; model, similar to those already provided for oxidation of airborne debris; reactant masses and energies for hydrogen combustion also were added as control functions and plot variables to the BUR package, which had very limited ontput capabilitices prior to these ontput enhancements. This was also included in DIR II30, and the code modifications implemented in version 1.8NN. Note that this set of code changes is therefore not included in the relcase version of Mlic (OR 1.8.2 (1.8NM).

\subsection{Debris Heat Transfer}

As noted in Sections 3.1 and 7.2 , most of our calculations were pun with control volume flow areas reduced by factors of $\geq 10$ from their default alues, to enhance convective heat transfer from the control volume atmospheres to the heat structure surfaces. 'The convertive heat transfer was enhanced to account for some potential missing heat transfer merhanisms and effocts:

First, preliminary calculations showed that the flow predicted through the system was primarily that associated with the steam blowdown only, flowing from the steam accummlator through the cavity and chute volumes to the subempartments and then to the dome. The MELC(OR FDI/HPME/D)(II model does not model transport of debris betwern and throngh volumes but instead deposits the debris directly at its ultimate destination, using the same time-dependent deposition in all volumes regardless of their distance from the debris souree. Thus, instead of debris being transported into an "upstream" volume (c.g., the cavity or the subcompartments) with the blowdown steam and the resultant additional hoating adding to the driving force pushing flow further "downstream" (e.g., from the cavity to the chute or the subcompartments to the dome), the MELCOR logic does not represent this additional flow driving force and in contrast has debris appearing "upstream" and heating the atmosphere in upstream volumes, if 
anything contributing a retarding fore to the expected flow. This results in lower velocities, and is more benign than the transient IIPME blowelown actually ocenrring in the experiments, with transport of hot debris together with the steam blowelown. Decreasing volume flow areas results in increased volume velocities more chatacteristic of the turbulent conditions that might be expected during IIPML, and the associated turbulent forced convection heat transfor to structures.

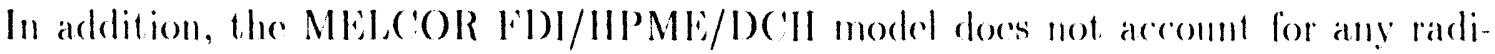
ation directly from airborne debris to surrounding structures for from deposited debris directly to atmosphere). There is little or no calculated atmosphere-structure radiation

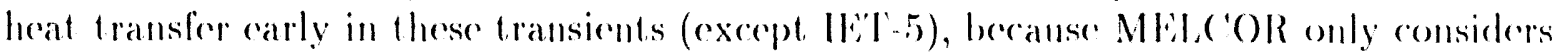
radiation heat transfor for steam and/or ( ()$_{2}$ in atmospheres; in most of the experi ment simulations there is very little steam present carly in the transient, hecanse any blowdown steam is consumed in debris oxidation soon after arrival, and very litlde ( ()$_{2}$ present at all (except in IE'T'-5). The lack of steam and/or (') $)_{2}$ in the atmosphere would if anything enhance radiation heat transfer from airborme debris to structures becanse there would be little absorption in the intervening atmosphere. Hand calculations in dicate that this conld be a significant heat transfor meehanism, carly in the transiont. Berause there is no way in MELC'OR to model this effect, loo much energy may be de. posited in the atmosphere by the airborme debris; because there is mo comenenent way to collance atmosphere-structure radiation heat transfer in general, we relied on increasing comvective heat transfer instead to help remove that energy.

The capability to adjust the volume velocities through the control volume flow areas in order to cohanere convertive heat transfer to structures only during lo('ll was provided through new input, this time to the ('VIl package, adding a sensitivity reseflicient that optionally multiplies the volume velocities during the IIPMli, period only in any given conteol volume. This was included in D)|R II:30, and the code modilications implemented in rersion I.SNN. Note that this set of code changes are not included in the release version of MLI, (O) I.S.2 (1.8NM).

However, the capabilities of the MEI, (O)R Fil)I/HPME/D)('Il molel would he significantly enhanced in general if the following effects were adderl:

1. radiation heat transfer from airborme debris directly to structures,

2. radiation heat transfer from deposited debris directly to at mosplenere.

3. time delays for debris deposition to account for different transit distances from the source point, and

4. fission product release from debris not deposited in or solt led into a cavity (not discussed in this report, but discussed in [10], and included here for completeness. 


\subsection{Cavity Condensate Water}

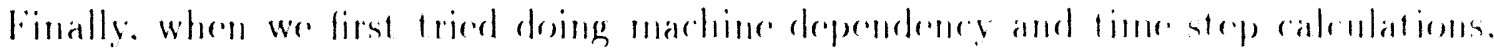

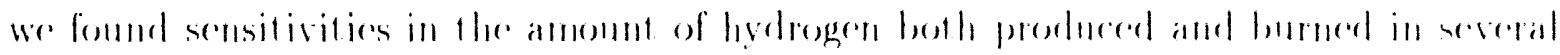

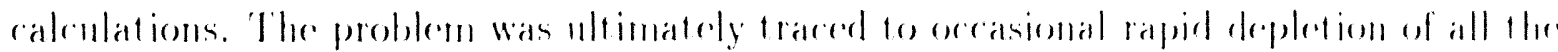

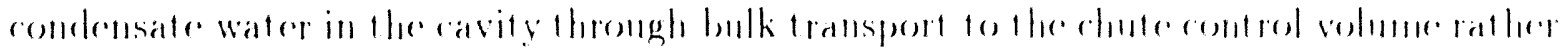

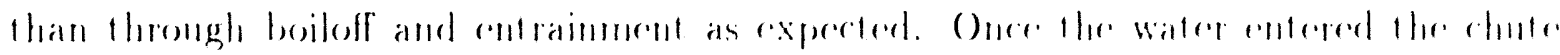

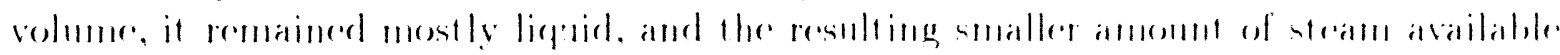

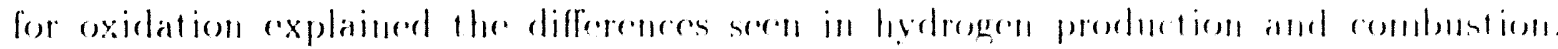

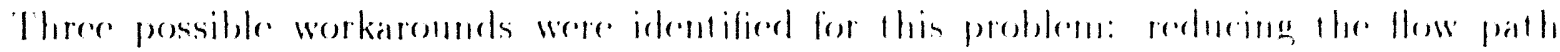
opening height slightly. rhanging the flow path from a horizontal to a vertical flow palth

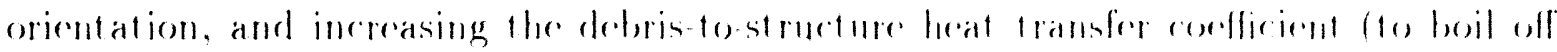

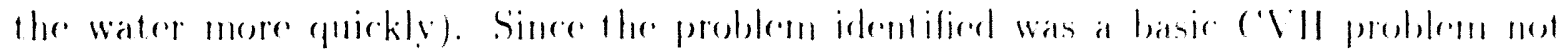

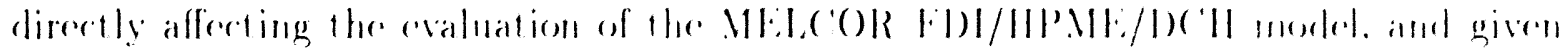

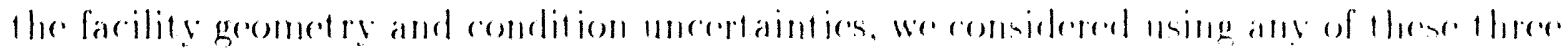

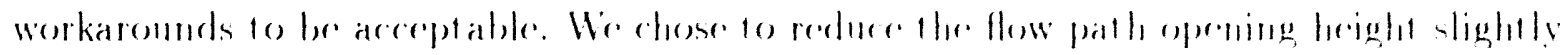

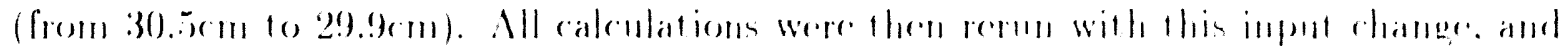

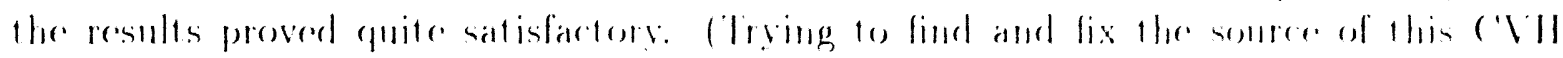

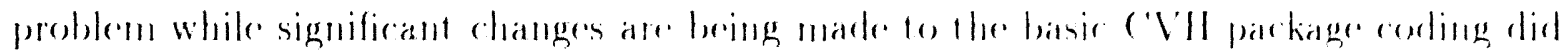
not serm useful in the long term.) 


\section{Summary and Conclusions}

The MELCOR computer code has been used to analyze several of the IET direct containmont heating experiments done at 1:10 linear scale in the Surtsey test facility at Sandia and at 1:40 linear scale in the corium-water thermal interactions (CW'II) (COREXIT test facility at Argonne National Laboratory. This report documents the results of those analyses.

Note that these MELCOR calculations were done as an open post test study, with both the experimental data and CONTAIN results available to guide the selection of cole input. Most individual parameters in our MELCOR input models were not separately adjusted in each of our MELCOR IET experiment analyses to best match data for cach individual experiment. Instead, the basic control-volume/flow-path/heat-structure model was kept the same for all SNL/IET experiments analyzed, and a single set of debris source, distribution and interaction time parameters was used for all the SNL/IET experiments analyzed. The only test-specific changes made were to set the initial pressures, temperatures, gas composition, and liquid pool heights to match individual experiment initial conditions. A similar approach was taken for the ANL/IET analyses.

The processes modelled in the MELCOR FDI/HPME/DCH model include oxidation of the metallic debris components in both steam and oxygen, surface deposition of the airborne debris by trapping or settling, and heat transfer to the atmosphere; first-order rate equations with uscr-specified time constants for oxidation, heat transfer and settling are uscd to determine the rate of each process.

A single set of characteristic interaction times was specified for all the seven of the 1:10-scale tests analyzed (SNL/IET-1 through SNL/IET-7). The characteristic times for settling of debris in the control volume atmospheres onto floor heat structures were based upon free-fall times for the various volume heights, and therefore proportional to volume heights and constant in the various tests; there could be some test-to-test variations in turbulent flow circulation patterns, thermal buoyancy effects, etc., but these were assumed negligible. The characteristic oxidation and heat transfer times were assumed to depend primarily on parameters such as average airborne or deposited particle concentrations, which in a given geometry should be approximately constant for identical molt debris and blowdown steam sources such as used in the tesis analyzed.

'The characteristic times for oxidation and heat transfer of debris in the control volume atmospheres, as well as a characteristic time for oxidation of debris deposited on heat structures, were selected after a number of iterations in sensitivity studies as giving reasonable agrecment with a subset of test data (in particular, vessel pressure, subcompartment temperature and hydrogen production and combustion) in the SNL/IET experiments simulated. Note that there is no reason to assume that the debris source and interaction input parameter set used in our reference analyses is unique (i.e., the only set to provide rasonable agreement, with the selected test data). It is also not guaranteed that the iterative procedure followed results in an input parameter set that yields the best agreement, with data, or agreement with data for the "correct" reasons (i.e., representing 
the actual behavior). For example, freezing some of the parameter values early in this iterative process undoubtedly affected the values assinied for other parancters. Further, experiment ambiguities may have led to incorrect modelling assumptions that would also affect the values chosen for various parameters (such as the characteristic oxidation time, as discussed below).

The results of the MELCOR reference calculations for the Surtsey 1:10-scale tests correctly reproduce the subdivision of the pressure response into two major families, caused by the effect of hydrogen combustion, as seen in the test data, with a peak pressure rise of $\sim 100 \mathrm{kPa}$ due to HPME and an additional pressure rise of $\sim 150 \mathrm{kPa}$ due to hydrogen combustion. The results also correctly reproduce the lack of any significant, effects of presence $v s$ absence of pre-existing hydrogen or presence $v$ s absence of basement condensate water.

The hydrogen production and combustion calculated by MELCOR is generally in reasonable agreement with test data (after careful adjustment of the BUR package input, as described below). However, it is difficult to quantitatively compare the measured and calculated hydrogen production and combustion because of the basic assumption made by the experimenters that all oxygen depletion was due to reaction with hydrogen. 'The experimenters assumed in their data analysis that debris reacted only with steam, not with free oxygen, whereas MELCOR assumes that oxidation of metals with free oxygen occurs preferentially to oxidation with steam. Therefore, throughout this report, pairs of values are given for the hydrogen production and combustion calculated by MEL(COR, presenting both the actual amounts of hydrogen calculated to be produced by HPME steam/metal reactions and burned, and the amounts of hydrogen produced and burned that wonld be calculated using the initial and final oxygen and hydrogen moles from the MELCOR analyses in the same formulae as in the experiment data analysis.

The two sets of MELCOR values differ by twice the number of moles of $\mathrm{O}_{2}$ consumed by direct metal/oxygen reactions. There is little difference found in the hydrogen production evaluated using the experimental procedure and actually calculated by MELCOR in the tests with little or no free oxygen present (i.e., SNL/IEI-I and SNI/ILT-IR); however, note that, for those two tests and for SNL/IET-5, assuming all oxygen depletion was due to combustion reaction with hydrogen does result in a small mass of hydrogen calculated to be burned, similar to the experimental results. The actual moles of hydrogen produced and burned in these MELCOR analyses appear generally less tnan measured values, especially in the experiments with hydrogen combustion, while the hydrogen production and combustion calculated using the experimental procedure on the MELCOR results are generally greater than measured. Also, the actual amount of hydrogen calculated to be produced by MELCOR is lower in the tests with oxygen initially present (SNL/IET-3 through SNL/IET-7) than in the experiments with no significant oxygen initially present, (SNL/IET-1 and SNL/IE'T-IR). However, deriving the amounts of hydrogen produced and burned in the MELCOR calculations by assuming that all oxygen depletion is the result of hydrogen burning yields greater hydrogen production in SNL/IET'-3 through SNL/IET-7 than in SNL/IET-1 and SNL/IET-1R, reproducing the trend seen in the tabulated experimental data. 
Overall, the "correct" answers are likely to lie somewhere between the two limiting assumptions. It is unlikely that there is no oxidation of metal with free oxygen at all (as assumed in the experimental analysis protocol). However, MELCOR would be expected to exaggerate the relative degree to which metal oxidizes with free oxygen vs with steam, because of the hierarchical assumptions in the MELCOR FDI/IIPME/DCH model and because, in the experiment, the debris transport probably lags the steam/hydrogen mixture flow, so that not much of the debris gets to see much oxygen, while in the MELCOR model the debris is immediately transported to its ultimate distribution (within a userspecified time period, in this case 1 s) while the steam blowdown is modelled "normally" as a transient process taking several seconds.

The quantification of hydrogen production and combustion in the SNI/IET experiments assuming that all oxygen depletion was due to reaction with hydrogen had an unforeseen effect on our MELCOR analyses. In particular, the choice of a very short time constant for airborne debris oxidation (0.025s in the reference analyses) was driven by trying to explicitly match the reported hydrogen production and combustion data; sensitivity study results show very little difference in calculated pressures or temperatures for $0.01 \mathrm{~s} \leq \tau_{o x} \leq 0.1 \mathrm{~s}$, because the oxidation rate is essentially limited by availability of steam and/or oxygen at the shorter characteristic interaction times, and the hydrogen production and combustion results later derived from a molar balance assuming only steam/motal reactions (as in the test data analysis) is in better agreement with test rata for calculations using longer characteristic airborne-debris oxidation times $\left(\tau_{o r} \geq 0.1 s\right)$, which serms a more reasonable value based on physical grounds. (This does not affect any of the comparative conclusions drawn from the various other sensitivity studies.)

The hydrogen combustion observed in these tests could not be calculated using the default burn package input, because the default ignition criteria are never satisfied in these experiments. Instead, in the majority of our IET analysis calculations, the hydrogen mole fraction ignition criterion in the alsence of igniters was set to 0.0 , which (in the absence of (O) also gives a combustion completeness correlation value of 0.0 ; in addition, burn was suppressed in all control volumes exeept the vessel dome. This particular combination of input was found to produce reasonable agreement with test data in all ases. The combustion completeness being set to 0 prevents the burning of any preexisting hydrogen, but allows burning of any additional hydrogen generated during the IIPME: Suppressing burn except in the dome minicked the experimental betavior of a jet flame burning at the ontlet from the subcompartments to the dome; because litule or no hydrogen was generated by debris oxidation in the dome in our analyses, only hydrogen advected into the dome from the subcompartments burned, and only on the time scale over which it was advected into the dome.

(While these non-standard combustion criteria cond be specified with the standard BUR parkage input for these experiment analyses, the same input modification could not be made in plant analyses, herause the non-standard input wonld affect the results calculated both before and after the IIPME period. This problem was addressed by providing new, optional input parameters in the BUR parkage, essentially allowing the user to specify one set of input parameters to be used during periods of HIPML and 
another set of input parameters to be used during the remaining times.)

Most of our calculations were run with control volume flow areas reduced by factors of $\geq 10$ from their default values, to enhance convective heat transfer from the control volume atmospheres to the heat structure surfaces. (The control volume flow areas are used only to obtain volume velocities for use in the calculation of convective heat transfer coefficients; changing control volume flow arcas does not affect flow path calculations at, all.) The convective heat transfer was enhanced for two reasons:

First, our preliminary calculations showed that the flow through the system in these calculations was primarily that associated with the steam blowdown only, flowing from the steam accumulator through the cavity and chute volumes to the subcompartments and then to the dome. The MELCOR FI)I/HPME/DCH model does not model transport of debris between and through volumes but instead deposits the debris directly at its ultimate destination, using the same time-dependent deposition in all volumes regardless of their distance from the debris source. Thus, instead of debris being transported into an "upstream" volume with the blowdown steam and the resultant additional heating adding to the driving force pushing flow further "downstream", the MELCOR logic does not represent this additional flow driving force and in contrast has debris appearing "upstream" and heating the atmosphere in upstream volumes, if anything contributing a retarding force to the expected flow. This results in lower velocities, and is more benign than the transient HPME blowdown actually occurring in the experiments, with transport of hot debris together with the steam blowdown. Decreasing volume flow arcas resulted in increased volume velocities more characteristic of the turbulent conditions that might be expected during HPME, and the associated turbulent forced convection heat transfer to structures.

In addition, the MELCOR FII/HPME/DCH model does not account for any radiation directly from airborne debris to surrounding structures (or from deposited debris directly to atmosphere). Although radiation heat transfer was included in the MELCOR input model, there is little or no calculated atmosphere-structure radiation heat transfer early in these transients (except in IET-5), because MELCOR only considers radiation heat transfer for steam and/or $\mathrm{CO}_{2}$ in atmospheres. In $\mathrm{IE} T-5$, some atmosphere-structure radiation heat transfer is calculated because of the large amount of $\mathrm{CO}_{2}$ used to inert the system; however, in most of the experiment simulations there is very little steam present early in the transient, because any blowdown steam is consumed in debris oxidation soon alter arrival, and very litte $\mathrm{CO}_{2}$ present at all. The lack of steam and/or $\mathrm{CO}_{2}$ in the atmosphere would if anything enhance radiation heat transfer from airborne debris to structures because there would be little absorption in the intervening atmosphere. Hand calculations indicate that this could be a significant heat transfer mechanism, early in the transient. Because there is no way in MELCOR to model this effect, too much energy may be deposited in the atmosphere by the airborne debris; because there is no convenient way to enhance atmosphere-structure radiation heat transfer in general, we relied on increasing convective heat transfer instead to help remove that energy.

(Again, while this could be done with the standard C:VH package input for these experiment, analyses, the same input modification could not be made in plant analyses, 
because the non-standard input would affect the results calculated both before and alter the HPML period. 'This problem also was addressed through new input capabilities, adeling a sensitivity coefficient to the ('VIl parkage that optionally multiplies the volume velocities in any given control volume during the HIPML period only.)

The MEL(?OR FI)I/IIPME/D)(II model does not model transient transport of debris into and through the system, hut instead immediately places the debris at its ultimate destination. MELCOR uses a single finction for the time-dependence of the melt injertion in all control volumes and heat structures; in reality, the melt reaches the subcompartments later than the cavity, and the dome later than the subcompartments. The time period over which melt, injection was specified to orent was varied in sensitivity sturly analyses, and the time-dependence of the melt addition in the MES, (O) input, was adjusted to mateh the rate of pressure and temperature increase in the vessed. Based upon results results for vessel pressure, hydrogen generation and subcompartment temperatures, our analyses were run with a melt injection period of $1 \mathrm{~s}$, with most of the injection occurring during the second half of that period. 'This $\leq 1 \mathrm{~s}$ melt injection period is in reasonable agrecment, with test observations indicating molten brass, stoce and thermite contering the cavity between 0 and $\sim 0.3 s$, and debris entrainment from the cavity into the subcompartments between about 0.4 s and $0.8 \mathrm{~s}$.

The total debris mass collected in these experiments was usually greater than the initial thermite eharge due to melting of the inner wall of the crucible, vaporization of the fusible brass plug, ablation of concrete in the cavity and structures, and oxirlation of metallic debris. Thus, despite the careful duplication of the initial thermite charge, the different amounts of debris collected from the melt generator and from the vessel result in some uncertainty in the actual amount and composition of melt injected into the vessel. The majority of our MEJCOR analyses simply specified the original thermite charge mass, neglecting both the retention of any debris in the melt generator and the addition of any dobris due to melting, vaporization, ablation, and/or oxidation. 'lo determine the effect of the injection mass soure uncertainty, calculations were done varying the melt mass. As would be expected, the vessel pressurization increases slightly as more melt mass is injected during the HPME; there is also a small increase in both hydrogen production and combustion with increasing melt injection amount, and a small increase in subcompartment temperature.

Sensitivity studies varying the debris temperature showed, as would be expected, that increasing debris temperature increases the vessel pressures calculated, but has very little effect on either the amounts of hydrogen generated or burned. The debris temperature variation has the strongest effect on the subcompartment temperatures predicted, with a $1000 \mathrm{~K}$ increase in debris temperature producing a $\sim 500 \mathrm{~K}$ increase in subcompartment peak temperatures.

The MELCOR FIDI/IPME/I)(II model does not model transient transport of debris into and through the system, but instead immediately places the debris at its ultimate destination. 'The debris fractions placed in each control volume and on each heat structure are controlled solely by user input. In these IET analyses, the debris injected was all placed in various control volume atmospheres and then allowed to settle out onto floor 
heat structures: no deloris was specified to be deposited directly onto any heat structures. The debris distribution was kept the same in our MEL(C)R input for all tests analyzed, because there were only small differences in the test data debris distributions.

However, in most plant analyses, there will be no equivalent data set providing gnidance on HPME melt distribution. To evaluate the effect of the debris distribution assumed on the overall De(Il behavior calculated, calculations were done in which the experimental debris distribution for each test was used, and in which most of the debris was placed either in the cavity and chute or in the dome. The major difference is seen for the calculation with most of the debris sperified to go into the vessed dome, a volume with a longer characteristic settling time (proportional to the volume leright), which allows more time for oxidation and especially for heat transfer from airborne debris to the atmosphere; assuming most of the debris goes to the dome results in much less hydrogen production calculated for most of the tests because then most of the debris is oxidized by the relatively large amount of free oxygen available in the dome.

The effects of varying the characteristic debris interaction times were also invest igated. With a very long chatacteristic airborne debris oxidation time, the overall pressurization, and both the hydrogen production and combustion, are all underperedicted. Using shorter characteristic airborne debris oxiclation times $(\leq 0.1 s)$ gives generally similar results brcanse in all these ases the oxidation is mostly limited by the availability of oxygen and/or steam. As would be expected, cont rol volume temperatures are afferted most by varying the airborne debris characterist ic heat transfer time; the control volume atmosphere temperatures increase as the airborne debris characteristic heat transfer time is shortence; the vessel pressurization also increases, and there is decreasing hydrogen production and combustion. The effert of increasing the airborne debris chatacteristie settling time is to increase the vessel pressures and temperatures calculated, as well as the amonnt of hydrogen both produced and burned, because this increases the available time for both oxidation and heat transter to ocenr.

After work on these analyses had been in progress for some time, we became concerned about the interaction of debris with heat structures. In the original HIPME model added to MESCOR, any debris immediately deposited onto a heat structure or later settled onto a heat structure essentially left the problem; there was no subsecquent interaction of any kind for that debris, except for decay heating of the structure surface. This was identified as a major potential problem area, especially given MELC'OR's cmphasis on mass and energy conservation. For example, the lack of any thermal interaction of debris with structures conld adversely affect the ability to correctly predict late-time revaporization of volatile fission products. Also, the lack of any oxidation of deposited debris meant that the total amomt of hydrogen producable during HPME was very highly dependent on the user-specified initial debris distribution and on the characteristic settling time constants any debris deposited or settled could not continue to generate hydrogen through further oxidation, regardless of oxygen and/or steam availability or debris temperature and/or amount. Therefore two effects were added to the original IIPME model: heat transfer to the structure surface from deposited hot debris, and the continued oxidation of the deposited debris. The heating of the structure surface by deposited hot debris 
is controlled by a heat transfer coefficient adjustable throngh sensitivity coeflecient input, and the continued oxidation of the deposited debris is comtenled by a user-input. structure oxidation characteristic time (distinct from and nswally much longer than the chatacteristic time input for oxidation of airborne debris). With these input and cod ing modifications, IIPME dobris deposited on structures now can contimue to allect the overall system response through several potential interactions.

In these llid' experiment analyses, there was generally little effect on either the peak or the long term pressurization as the deposited debris characteristic oxidation time was varied. 'The total anomot of hydrogen generated increased as the characteristic oxida tion time for deposited debris decreased, as would be expected, because more hyelrogent arcommatates late in the transient as the debris settled and/or deposited onte structures contimues to oxidize. 'There was little affect seen on the amomut of hydrogen burned, however, because the hydrogen combustion primarily occurs carly in the transient, on a time seale of a few seconds or less, as the airborme debris provides an ignition sonter during the high-pressure melt cioction.

Much of this "lack of effect" of deposited debris oxidation is probably doe to the

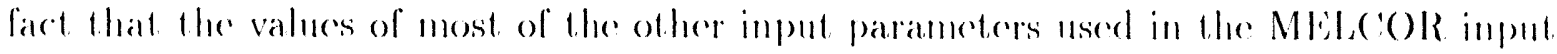
were set in andier sensitivity study calculations, before this effect was included in the

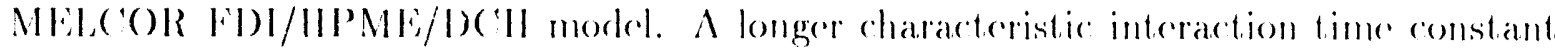
for oxidation of airborme debris (which wonld probably be more reasomable on physical grounds) would have left more debris moxidized during the first few seconds of the transient and thus would allow more oxidation of deposited debris later in the transiont. Oxidizing less airborne debris within the first few seconds and more deposited debris later in the transient conld also potentially allow both high enongh hydrogen gencration and combustion and low chongh vessed pressurization and subeompartment temperatures to mateh the measured test data, without recuiring as large an increase in heat transfer to structures carly in the transiont.

Several counterpart tests to the IES direct containment heating experiments done at Sandia in the 1:10 lincar scale Surtsey facility were performed at $\Lambda N \mathrm{~N}$, in the $1: 40$ linear scale (COREXI'T facility, in an experimental program to investigate the effects

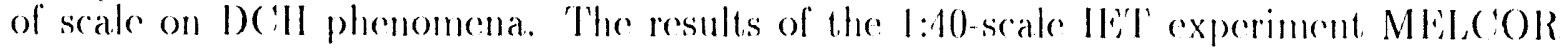
simulations were generally inconclusive. 'The vessel pressures predicted in our S'NI, and ANL comuterpart-test calculations were quite similar when both the geometry and the characteristic interaction times in the Fl)I IIPME input were scaled, but the test data showed a mumber of non-scaled effects. In particular, the results of both ond limited review of the facility and data scalability and of our $\Lambda$ NI, test simulations snggest that, in the experiments, the D(II conergy-transfer efficiency is greater at smaller srale, that there is less pressurization due to hydrogen combustion at smaller scale, and that there appoars to be a greater effect of preexisting hydrogen in the $\Lambda$ NI, 1:10-scale tests than in the comnterpart SSL 1:10-scale tests. These scale-dependent differences are not reproduced in the corresponding MEL( O)R analyses. Other sensitivity studies indicated that some of the greater pressurization due to 1$)($ 'Il at small scale observed in the experiments but "missing" in onr MELC(O)R calculations may be due to differences in heal, transfor to 
structures at smaller compared to larger scale, that the pressure dropoff rate in the $\mathrm{ANI}$. data clearly would be matched better by assuming a recirculation flow area greater than the $10 \%$ value assumed in the SNL experiment analyses, and that the data for those tests in which hydrogen combustion occurred could not be matched by using the same, non-default hydrogen burn package input that gave good agreement with test data for the 1:10-scale test simulations.

The reference MELCOR calculations for the 1:10 linear scale IET experiments done in the Surtsey vessel have been compared to similar calculations done with the (ON'TAIN code, when available. The CON'TAIN DCH model is quite different from the MELCOR FDI/HPME DCH model, being a more detailed, more mechanistic treatment rather than a more parametric approach. Despite these differences, the results obtained with the two code models are generally quite similar: in particular, a pressure rise of $\leq 100 \mathrm{kPa}$ was calculated by both for tests with no significant hydrogen combustion, and a larger pressure rise of $\sim 200-250 \mathrm{kPa}$ for cases with substantiai hydrogen burn.

Several calculations have been done to identify whether any numeric effects exist in our DCH IE'T assessment, analyses, producing either differences in results on different machines or differences in results when the time step used is varied. The SNL/IET reference calculations were run, using the same code version, on an IBM RISC-6000 Model 550 workstation, on an HP 755 workstation, on a SUN Sparc2 workstation, on a CRAY $\mathrm{Y}$-MP8/864, and on a $50 \mathrm{MHz} 486 \mathrm{PC}$. There is generally excellent agreement among results generated on these various hardware platforms. The SUN and PC were always slowest in run time required; the IBM, HP and Cray were all significantly faster with the HP the fastest for these analyses. In addition, otherwise identical MELCOR SNL/IET calculations were run on a SUN Sparc2 workstation with both the user-input maximum allowed time step and the initial time step size for HPME initiation simultaneously reduced by factors of $2,10,20$ and 100 from the basecase values. The results showed about half of the SNL/IET experiment analyses fully converged for all these time steps, with the other half demonstrating convergence with reduced time steps. 


\section{Bibliography}

[1] R. M. Summers et al., "MEL, (OR 1.8.0: A Computer Code for Severe Nucloar Reactor Accident Source 'Term and Risk Assessment Analyses", NIBREC/CR-5531, $S \Lambda N I) 90-(0364$, Sandia National Laboratories, January 1991.

[2] (. D. Leigh, ed., "MEL(COR Validation and Verification 1986 Papers", NUREG/ (R-4830, SANI)86-2689, Sandia National Laboratories, March 1987.

[3] L. N. Kmetyk, "MELCOR 1.8.1 Assessment: LACL Acrosol Experiment LA4", SAND91-1532, Sandia National Laboratories, September 1991.

[4] L. N. Kmetyk, "MELCOR 1.8.1 Assessment: FLECHT SEASET Natural Circulation Lxperiments", SAND91-2218, Sandia National Laboratories, December 1991.

[5] L. N. Kmetyk, "MELCOR 1.8.1 Assessment: ACRR Source Term Experiments S'TI/S'T'-2", SANI)91-2833, Sandia National Laboratories, April 1992.

[6] I. N. Kmetyk, "MELCOR 1.8.1 Assessment: LOF'T Integral Experiment LP-FP-2", SANI)92-1273, Sandia National Laboratories, December 1992.

[7] R. J. Gross, "MELCOR 1.8.1 Assessment: PNL Ice Condenser Experiments", SANI)92-2165, Sandia National Laboratories, June 1993.

[8] L. N. Kmetyk, "MELC(OR 1.8.1 Assessment: Marviken-V Aerosol Transport Tests

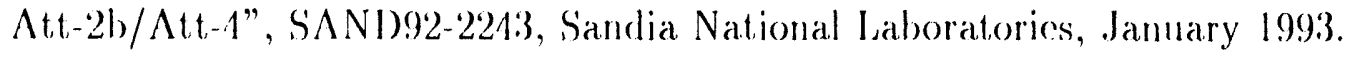

[9] T'. J. Tautges, "MEI, (OR 1.8.2 Assessment: the I)F-A BWR Fud Damage Wxperiment", SAN1)93-1377, Sandia National Laboratories, ()ctober 1993.

[10] M. I). Allen, M. Pilch, R. (). (Érffith, R. T. Nichols, 'T. K. Blanchat, "Lxperiments to Investigate the Effects of 1/10th Scale Zion Structures on Direct (Containment Heating (I)('II) in the Surtsey 'Test Facility: the IE'T'-1 and IE'T'-1R T'ests", SANI)92(2255, Sandia National Laboratories, July 1992.

[11] M. I). Allen, 'T'. K. Blanchat, M. Pilch, R. 'T'. Nichols, "Quick-Look Report on the Second Integral Effects Test (IE'T'-2): 'Thermite 'Temperature Measurements", Sandia National Laboratories, preliminary report, June 1992.

[12] M. 1). Allen, M. Pilch, R. (). Griffith, D. ('. Williams, R. 'T'. Nichols, "I'he 'Third

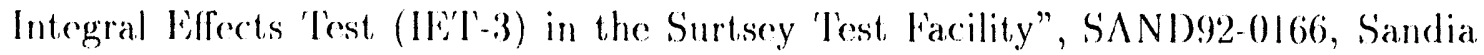
National Laboratories, March 1992.

[13] M. I). Allen, T. K. Blanchat, M. Pilch, R. 'T. Nichols, "Results of an Experiment in a Zion-like Ceometry to Investigate the Effect of Water on the ('ontaimment Basement Floor on Direct ('ontainment Heating (I)(SII) in the Surtsey 'lest Facility: the IE'I'-4 'I'est", SANI)92-1211, Sandia National Laboratories, September 1992. 
[11] M. 1). Allen, T. K. Blanchat, M. Pilch, R. T. Nichols, "Fexperimental Results of an

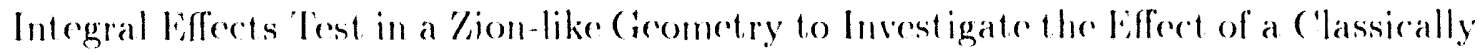
Inert Atmosphere on Direct Containment Heating: the IL"T-5 Thest", SAN1)92-1623, Sandia National laboratories. November 1992.

[15] M. 1). Mllen, T. K. Blanchat, M. Pilch, R. 'T. Nichols, "An Integral Liffects Test in a Zion-like Cometry to Investigate the Effects of Pre-lixisting Hydrogen on Direct ('ontainment Heating in the Surtsey Test Facility: the IF'l-6 Experiment", SAND92-1802, Sandia National Laboratories, Jamnary 1993.

[16] M. D. Allen, T'. K. Blanchat, M. Pilch, R. T. Nichols, "An Integral Fiffects 'Test to Investigate the Effects of ('ondensate levels of Water and Prexisting Hydrogen on Direct Containment Hoating in the Surtsey T'est Facility: the IE T-7 Fxperiment", $S A N 1) 92-2021$. Sandia National laboratories, Jamuary 1993.

[17] M. 1). Allen, T. K. Blanchat, M. Pilch, R. T. Nichols, "lixporiments to Investigate the Effects of Fuel/Coolant Interactions on Direct ('ontainment Heating (The IFT-8A and IET'-8B Fxperiments)". SAN1)92-2849, Sandia National laboratories, liobruary 1993.

[18] J. I. Binder, L. M. McUmber, B. W. Spencer, "Quick Look Data Report on the Integral Effects Test IR in the ('OREXIT Facility at Argonne National Laboratory, LWR-92-2, Argonne National Laboratory, May 1992 (draft).

[19] J. L. Binder, L. M. Mc Umber, B. W. Spencer. "Quick Look Data Report on the Integral Effects lest IRR in the (O)REXT Facility at Argonne National laboratory, IWR-92-3, Argome National Laboratory, May 1992 (draft).

[20] J. L. Binder, L. M. McUmber, B. W. Spencer, "Quick Look Data Report on the Integral Effects 'Test 2 in the (OREXIT Facility at Argonne National Laboratory, IWR-92-1, Argonne National Laboratory, February 1992 (draft).

[21] J. L. Binder, I. M. McUmber, B. W. Spencer, "Quick Look Data Report on the Integral Effects 'Test 3 in the COREXIT Facility at Argonne National Laboratory, ANL/RE/LWR 92-7, Argonne National Laboratory, July 1992 (draft).

[22] J. L. Binder, L. M. Melmber, B. W. Spencer, "Quick Look Data Report on the Integral Effects 'Test 6 in the (OREXIT Facility at Argonne National Laboratory, ANL/RE:/LWR 92-8, Argonne National Laboratory, August 1992 (draft).

[23] J. I. Binder, L. M. McUmber, B. W. Spencer, "Quick Look Data Report on the Integral Effects Test 7 in the (OREXI'T Facility at Argonme National Laboratory, ANL./RL/LWR 92-9, Argonne National Laboratory, September 1992 (draft).

[24] J. L. Binder, L. M. McUmber, B. W. Spencer, "Quick Look Data Report on the Integral Effects 'Test 8 in the COREXIT Facility at Argonne National Laboratory, ANL/RE/LWR 92-10, Argonne National Laboratory, October 1992 (draft). 


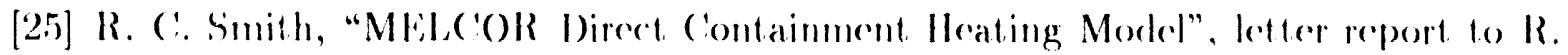
13. Foulds (NIR(:), Sandia National Laboratorio's, Fobruary 10, 1992.

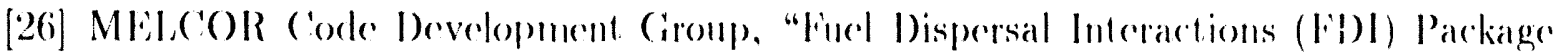
Reference Mamual", Sandia National Laboratories, August 26, 19933.

[27] 1). (: Williams, "Pretest ('alculations for the First Integral Effects Experiment (IE:T'

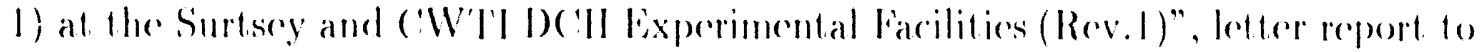
A. Notafrancesco (NIR('), Sandia National Laboratories, August 2.3, 1991.

[28] D). (: Williams, "Pretest (alculation for IleT-13", memo to M. 1). Allen, Sandia National Laboratories, Jannary $30,1992$.

[29] 1). ('. Williams, "Posttest ('alculations for the First Integral liffects lexperiment (IE'l'-1) at the Surtsey De(ll lacility", letter report to $A$. Notafranceseo (NRe), Sandia National Laboratories, Jambary 22, 1992.

[30] 1). (: Williams, letter to A. Notafranceseo (NIR()), Sandia National laboratories, March 3, 1992.

[31] D). ('. Willians, "IF:T'3 Pretest (alculations", memo to M. 1). Allen, Sandia National Laboratories, Decomber $24,1991$.

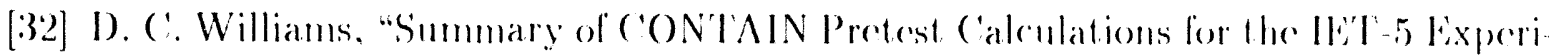
ment in the Surtsey d)(II Experimental lacility", letter to A. Notalranceseo (NRe!), Sandia National laboratories, May 13, 1992.

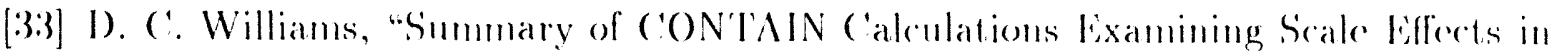
Direct Containment Heating (I)('II) Scenarios", letter to A. Notafranceseo (NR('), Sandia National laboratorie's, May 4, 1992.

[34] J). ('. Williams, "MEl('OR DCII Assessment Report", Sandia National Laboratories memo to 1. N. Kmetyk, August 17, 1993.

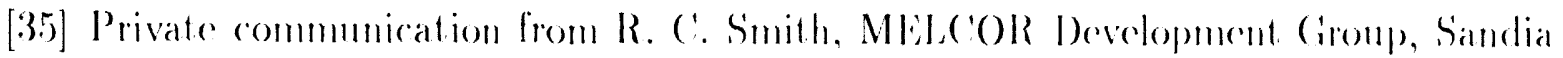
National Laboratories, Angust :31, 199:3.

[36] M. M. Pilch, M. 1). Allen, J. L. Binder, "('onnterpart and Replicate I)(:Il Lx-

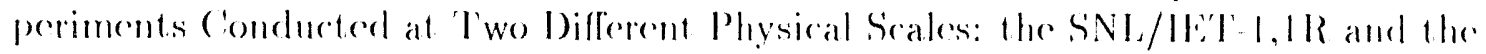
ANI/IET'-IR, IRR lexperiments", Samdia National Laboratories, draft report (dated July 15,1992$)$.

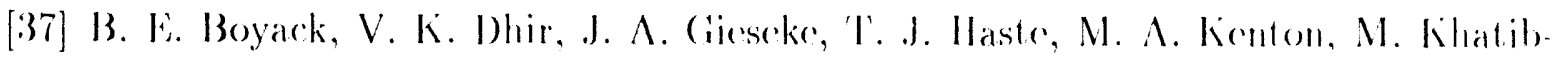

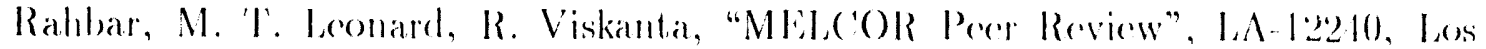
Alamos National Laboratory, March 1992.

[38] 1). (: Williams, "Proposed Assessment Approach for the ('ONTAIN I)('Il Morlats", presented at the ('ONTAIN Peor Review moeting, Albuequer(que, August 2:3-25, 19933. 
[39] D. C. Williams, "MELCOR-CONTAIN Comparisons", Sandia National Laboratories memo to L. N. Kmetyk, September 1, 1993.

[40] L. N. Kinetyk, "MELCOR 1.8.2 Assessment: Surry PWR 'TMLB' (with a DCH Study)", SAND93-1899, Sandia National Laboratories, to be published. 


\section{A MELCOR FDI package HPME/DCH Model (excerpted from [27])}

The Fuel Dispersal Interactions (FI)I) package in MEL(COR calculates the behavior of debris in contaimment from the time it is ejected from a failed reactor pressure vessel until the time it is deposited in a cavity. Both bow pressure melt ciection (LPME) from the reactor vessel and high pressure molt ejection (IIPME) from the reactor vessel (direct. containment heating) are modelled.

The fil) l package becomes artive whenever debris material enters the package via the MELC(OR Transfer Process ('TP) package interface. Debris material typically enters the TP package in one of three ways. In a reactor plant accident calculation debris enters the 'Tl package from the core (() (OR) package after failure of the reactor pressure vessel has bern calculated. In a stand-alone direct contaimment heating (I)('II) calculation debris material is sourced into the 'T'P package from either tabular function user input or a user source file via the external data file (E)

After the introduction of debris material, the flol package classifies the ejection event as either a low or a high pressure melt ejection event on the basis of the ejection velocity passed through the TP parkage or a flag set by the user for stand-alone De 'H calculations.

If the velocity of the molten debris ejected from the reactor vessel exceeds a critical value prescribed by sensitivity coeflicient 4602 (default value oflo $\mathrm{m} / \mathrm{s}$ ), or if the useer has invoked the stand-alone option for high pressure melt ejection modeling, then the fuel dispersal interactions will be treated by the high pressure model instead of the low pressure model. 'The paranetric high pressure model requires user input to control both the distribution of debris throughout the containment and the interaction of the hot debris with the containment atmosphere.

The HPME model does not include a mechanistic debris transport model; rather, the user specifies a set of debris destinations with a corresponding set of transport fractions that preseribe where the ejected debris is assmmed to go. 'The debris destinations may include the atmosphere of any (VII control volume, the surface of any heat structure and cavities defined by the ( $A \mathrm{~V}$ package. The sum of the transport fractions over all the specified control volume atmospheres, heat structure surfaces and cavities must equal one. 'Transport of the cjected debris to its assumed destinations occurs instantaneously with no interactions occuring between the point of ejection and the destination sites. As long as the IIPME model is active (i.e. as long as the ejection velocity exceeds the LPME/HPME transition velocity prescribed by sensitivity coefficient 4602 or if the user has invoked the stand-alone HPMF model) the ejected debris will be partitioned among the destinations as specified by the transport fractions. When the ejection velocity falls below the LPME/HPME transition velocity for non-stand-alone applications, any debris subsequently ejected is passed to the LPME model, which uses LPME model input. instead of the ITPME transport model to determine the debris destination. However, debris that was transported to the IIPME debris destinations before the model transition occured will continue to be treated by the IIPME model. 
The processes modeled include oxidation of the metallie components of the debris in both stean and oxygen. stuface deposition by debris trapping on arborne-debris settling and heat transfer to the atmosphere and heat structure sulfaces. Howerere debris whed:

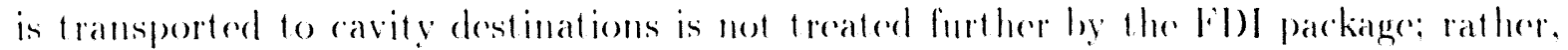
smbsequent treatment is provided by the CAl parkage. As implemented in the IIPME: model. surface deposition of dobris can ocent in two distinct ways. Fijected debris which imparts structures prion to any significant interaction with the atmosphere is sourced directly to the destination surface via the user-specified transport fraction for that surface. This process is refered to as trapping in MELCOR. Alternatively, debris which interacts significantly with the atmosphere should be soured to the appropriate control volume, in which a user-specified settling time constant will determine the rate of depesition to the specified settling destination (either a heat structure surface or a cavity). This process is reforred to as settling in MELC'OR.

First order rate equations with user specified time constants for oxidation, heat transfer and settling are used to determine the rate of each process. ()xidation of airborne and depositer debris is only calculated if the dobris temperature exceeds a value, TOX.MIN, which is adjusted using sensitivity cocflicient 4609 and has a defant value of $600 \mathrm{~K}$. If a pool of water exists in the reactor cavity at the time of debris ejection, then the model ejects the water into the droplet field (fog) of the atmosphere at a rate proportional to the rate of injection of the debris into the pool. The proportionality constant is adjustable through sensitivity coefficient 4605) and has a default value of 10 . When the HPME model first initiates direct containment heating in a control volume, the Fol package requests a fallback of the cycle if the time step exceeds the recommended start-up value prescribed by sensitivity coefficient 4607 (with a defanlt value of $10^{-4}$ s). Fixperience has indicated that for most realistic scenarios the rapid excursions in pressure and temperature caused by direct rontainment heating dictate the use of very small time steps for several cycles following I)('H initiation.

\section{Airborne Debris}

The airborne masses of $\mathrm{U}, \mathrm{O}_{2}$ and other materials that neither oxidize nor are the products of oxidation are described by the following first order linear differential equation:

$$
\frac{d M(i, k, t)}{d t}=-\frac{M(i, k, t)}{T_{S T}(i)}+S(i, k)
$$

where $M(i, k, l)$ is the mass of component $k$ in control volume $i$ at time $t, T S T(i)$ is the time constant for settling or trapping in control volume ind $s(i, k)$ is the constant mass source rate of component $k$ in control volume $i$ associated with the high pressure melt ejection process. The solution of $\mathrm{b}$. $\Lambda .1$ is given by:

$$
M(i, k, t)=\left[M\left(i, k, t_{0}\right)-S^{\prime}(i, k) \times T_{S T}(i)\right] \times c . t p\left(\frac{-d t}{T_{S T}(i)}\right)+S^{\prime}(i, k) \times T_{S T}^{\prime}(i)
$$


where $M\left(i, k, t_{0}\right)$ is the mass at arbitrary initial time $t_{0}$, and $d t$ is the difference between the final time, $t$, and time $t_{0}$. The airborne masses of $\mathrm{Zr}, \mathrm{Fe}$ and other materials that are oxidized in the presence of oxygen or steam are described by the following first order linear differential equation:

$$
\frac{d M(i, k, t)}{n}=-\frac{M(i, k, t)}{T_{S O}(i)}+S(i, k)
$$

where $T_{S O}(i)$, the time constant for simultaneous oxidation and settling/trapping, is given by:

$$
\frac{1}{T_{S O}(i)}=\frac{1}{T_{S T}(i)}+\frac{1}{T_{O X}(i)}
$$

where $T_{O X}(i)$ is the oxidation time constant in control volume $i$. The solution to Eq. A.3 is identical to Eq. A.2 except that $T_{S T}(i)$ is replaced by $T_{S O}(i)$. The airborne masses of $\mathrm{ZrO}_{2}$ and other materials that are products of oxidation reactions are given by:

$$
\frac{d M(i, k, t)}{d t}=-\frac{M(i, k, t)}{T_{S T}(i)}+R \times \frac{M(i, l, t)}{T_{O X}(i)}+S(i, k)
$$

where $R$ is the mass of product $k$ formed by the oxidation of a unit mass of reactant $l$. The solution of Eq. A.5 is:

$$
M(i, k, t)=\left[M\left(i, k, t_{0}\right)-C_{1}-C_{2}\right] \times \exp \left(, \quad,+C_{2} \times \exp \left(\frac{-d t}{T_{S O}(i)}\right)+C_{1}\right.
$$

where

$$
C_{1}=\left[\frac{S(i, k)+R \times S(i, l) \times T_{S O}(i)}{T_{O X}(i)}\right] \times T_{S T}(i)
$$

and

$$
C_{2}=\left[R \times S(i, l) \times T_{S O}(i)\right]-M\left(i, l, t_{0}\right)
$$

The HPME model contains two options for oxidation modeling. The user invokes the sequential oxidation option, in which the order of oxidation is $\mathrm{Zr}$, Al then steel, by specifying a positive value for the oxidation time constant, $T_{O X}(i)$. For control volumes in which the user would prefer simultaneous oxidation of the metals, a negative value of $T_{O X}(i)$ is specified and the time constant will be equal to the absolute value of $T_{O X}(i)$. In the sequential oxidation model a separate oxidation rate is first calculated for each metal independently of all others with the given value of $T_{O X}(i)$. Then the mass of metal 
$B$ consumed will be converted into an equivalent mass of metal $A$, where metal $A$ is assumed to oxidize in preference to metal $\mathrm{B}$, until all of metal $\mathrm{A}$ is consumed. Hence, steel will not be consumed until all the $\mathrm{Zr}$ and $\mathrm{Al}$ have been consumed, and $\mathrm{Al}$ will not be consumed until the $\mathrm{Zr}$ is exhausted. 'I'his implies that the effective time constant for metal A oxidation when metal $B$ is present may be significantly shorter than $\operatorname{tau}_{o x}(\mathrm{i})$. The actual values of the effective oxidation time constants will be used in determining the end of time ster, airborne mass inventories in Eq. A.2 and Eq. A.6 above. Of course both oxidation options are constrained by the availability of oxygen or steam. Steam oxidation will only be calculated if there is insufficient oxygen available in the control volume to support the prescribed oxidation rate. If there is insufficient oxidant to support the calculated rates of oxidation for zirconium and iron, then the zirconium will have first, priority. The oxidation reactions will proceed at the initial time step values of debris temperature in each control volume, and hydrogen formed by the steam reaction will enter the atmosphere at that temperature.

The energy of the airborne debris is given by the solution of the following simple equation:

$$
\frac{d H(i, t)}{d t}=\dot{E}_{O X}(i, t)-\dot{Q}_{G A S}(i, t)+S_{H}(i)
$$

where $\dot{E}_{O X}(i, t)$ is the rate of heat generation by the oxidation reaction, $S_{H}(i)$ is the enthalpy source rate associated with the high pressure melt ejection source, and where the rate of heat transfer to the gas is approximated as:

$$
\dot{Q}_{G A S}(i, t)=\frac{Q_{g}(i, t)}{T_{H T}(i)}=\frac{H\left(i, T_{d b r}\right)-H\left(i, T_{g a s}\right)}{T_{H T}(i)}
$$

where $Q_{g}(i, t)$ is the energy available for transfer to the gas, where $T_{H T}(i)$ is the user specified time constant for heat transfer from the airborne debris to the atmosphere in control volume $i$, where $H\left(i, T_{d b r}\right)$ is the energy content of the debris at its actual temperature, $T_{d b r}$, and $H\left(i, T_{g a s}\right)$ is the energy content of the debris in equilibrium with the gas at temperature, $T_{\text {gas }}$. The solution to Eq. A.7 is given by:

$$
H(i, t)=H\left(i, t_{0}\right)+E_{O X}(i, t)-Q_{G A S}(i, t)
$$

where $H\left(i, t_{0}\right)$ is the energy of the debris following the addition of the integrated enthalpy source, $S_{H}(i) \times d t$, and following adjustments to its composition associated with the oxidation reaction, where $E_{O X}(i, t)$ is the oxidation energy generated between times $t_{0}$ and $t$ and where $Q_{G A S}(i, t)$ is the amount of heat transferred to the gas between times $t_{0}$ and $t$. QGAS(i,t) is given by:

$$
Q_{G A S}(i, t)=\int_{t_{0}}^{t_{0}+d t}\left[\frac{Q_{g}(i, t)}{T_{H T}(i)}\right] d t
$$


where $Q_{g}(i, t)$ satisfies:

$$
\begin{gathered}
\frac{d Q_{g}(i, t)}{d t}=-\frac{Q_{g}(i, t)}{T_{H T}(i)}+\left[Q_{S R C}+\frac{\left(E_{O X}+Q_{O X}\right)}{d t}\right] \\
Q_{S R C}=S_{H}\left(i, T_{s r c}\right)-S_{H}\left(i, T_{g a s}\right)
\end{gathered}
$$

is the available source enthalpy and

$$
Q_{O X}=H_{O X}\left(i, T_{d b r}\right)-H_{O X}\left(i, T_{g a s}\right)
$$

is the available enthalpy created by composition adjustments during oxidation. The solution to Eqs. A.10 and A.11 is:

$$
\begin{aligned}
Q_{G A S}(i, t)= & Q_{O L D} \times\left[1-\exp \left(\frac{-d t}{T_{H T}}\right)\right]+ \\
& {\left[Q_{S R C}+\frac{\left(E_{O X}+Q_{O X}\right)}{d t}\right] \times\left\{d t-T_{H T} \times\left[1-\exp \left(\frac{-d t}{T_{H T}}\right)\right]\right\} }
\end{aligned}
$$

where $Q_{O L D}=H\left(i, T\left(t_{0}\right)\right)-H\left(i, T_{\text {gas }}\right)$ is the initial available energy.

The inclusion of the HPME source terms in Eqs. A.1 through A.12 eliminates timestep dependencies that would arise if the sources were added prior to the calculation of oxidation, heat transfer and settling/trapping. After the total energy at the advanced time, $t$, is determined, it is compared to the enthalpy corresponding to a maximum permissible temperature, $H_{M A X}$. If $H(i, t)$ exceeds $H_{M A X}$, then Eq. A.9 is solved for $Q_{G A S}(i, t)$ with $H(i, t)$ set equal to HMAX as follows:

$$
Q_{G A S}(i, t)=H\left(i, t_{0}\right)+E_{O X}(i, t)-H_{M A X}
$$

so that the heat transferred to the gas is increased sufficiently to limit the advanced time debris temperature to the maximum prescribed value, $T_{M A X} \cdot T_{M A X}$ is given by:

$$
T_{M A X}=\operatorname{MAX}\left(T_{g a s}, T_{d b r}\left(t_{0}\right), T_{d b r}\left(t^{\prime}\right), T 4603\right)
$$

where $T_{g a s}$ is the gas temperature, $T_{d b r}\left(t_{0}\right)$ is the debris temperature at the beginning of the time step, $T_{d b r}\left(t^{\prime}\right)$ is the debris temperature after addition of new source material to the initial inventory and T4603 is the temperature limit prescribed by sensitivity coefficient 4603, which normally exceeds the other arguments in the max function of Eq. A.14. The default value of T4603 is approximately equal to the boiling temperature 
of $\mathrm{UO}_{2}$ - temperatures much in excess of this value would likely result in very rapid fragmentation of debris droplets and significantly increased droplet-to-gas heat transfer.

After an advanced time temperature for the airborne debris has been determined, the projected change in the (VH atmosphere temperature as a result of direct containment. heating during the time step is calculated. If the change exceeds a value prescribed by sensitivity coefficient 4604 (with a default value of $500 \mathrm{~K}$ ), then the FDI package requests a fallback with a decreased time step.

Following the determination of the advanced time temperature for the airborne debris, the advanced time mass equations, Eqs. A.1 through A.6, are used to determine how much material is removed from the atmosphere by settling/trapping. 'The settled material and its energy content are removed from the airborne inventory and deposited on the appropriate surface specified by user input. After the settling calculation has been performed, the advanced time total airborne mass in each control volume is determined by summing over all components. If the advanced time total airborne mass is insignificant compared to the total mass of material sourced into the control volume atmosphere over the duration of the DCH event, then all of the remaining airborne mass in the control volume is immediately deposited on the appropriate settling surface and a message is issued to notify the user that direct containment heating has ceased in that particular control volume. The ratio used to determine when the airborne mass has become insignificant is adjustable through sensitivity coefficient 4606 and has a default value of 0.001 .

Deposited Debris

The mass of material $k$ on surface $i$ at time $t$ is given by

$$
M(i, k, t)=M\left(i, k, t_{0}\right)+S^{\prime}(i, k) \times d t
$$

where

$$
S^{\prime}(i, k)=S(i, k)+\sum_{j}\left[\int_{t_{0}}^{t_{0}+d t} \frac{M\left(j, k, t^{\prime}\right)}{T_{S T}(j)} \times d t^{\prime}\right] / d t
$$

and $S(i, k)$ is the constant mass source rate of component $k$ to surface $i$ from trapping. The second term on the right hand side of Eq. A.16 accounts for settling to the surface, and the sum is over all control volumes that have surface $i$ as the user-specified settling surface. $M(j, k, t)$ and $T_{S T}(j)$ are the airborne mass of component $k$ in control volume $j$ and the settling time constant in control volume $j$, respectively.

For $\mathrm{UO}_{2}$ and other materials not associated with oxidation the settling term is given by

$$
\begin{aligned}
\int_{t_{0}}^{t_{0}+d t} \frac{M\left(j, k, t^{\prime}\right)}{T_{S T}(j)} d t^{\prime}= & M\left(j, k, t_{0}\right) \times\left[1-\exp \left(\frac{-d t}{T_{S T}(j)}\right)\right]+ \\
& S(j, k) \times\left\{d t-T_{S T}(j)\left[1-\exp \left(\frac{-d t}{T_{S T}(j)}\right)\right]\right\}
\end{aligned}
$$


For metals that oxidize the settling term is given by

$$
\begin{aligned}
\int_{t_{0}}^{t) 0+d t} \frac{M\left(j, k, t^{\prime}\right)}{T_{S T}(j)} d t^{\prime}= & {\left[\frac{T_{S O}^{\prime}(j)}{T_{S T}(j)}\right] \times\left\{M\left(j, k, t_{0}\right) \times\left[1-\exp \left(\frac{-d t}{T_{S O}(j)}\right)\right]+\right.} \\
& \left.S(j, k)\left[d t-T_{S O}(j)\left\{1-\exp \left(\frac{-d t}{T_{S O}(j)}\right)\right\}\right]\right\}
\end{aligned}
$$

which reduces to Eq. A.17 if $T_{O X}(j)>>T_{S T}(j)$, because in that case $T_{S O}(j) \sim T_{S T}(j)$ as shown by Eq. A.4. For oxidation products the settling term is given by

$$
\begin{aligned}
\int_{t_{0}}^{t_{0}+d t} \frac{M\left(j, k, t^{\prime}\right)}{T_{S T}(j)} d t^{\prime}= & M\left(j, k, t_{0}\right) \times\left[1-\exp \left(\frac{-d t}{T_{S T}(j)}\right)\right]+ \\
& S(j, k)\left\{d t-T_{S T}(j)\left[1-\exp \left(\frac{-d t}{T_{S T}(j)}\right)\right]\right\}+ \\
& R\left\{\left[\frac{T_{S O}(j)}{T_{O X}(j)}\right]\left[M\left(j, l, t_{0}\right)+S(j, l)\left\{d t-T S O(j)-T_{S T}(j)\right\}\right]-\right. \\
& {\left[M\left(j, l, t_{0}\right)-S(j, l) T_{S T}(j)\right] \exp \left(\frac{-d t}{T_{S T}(j)}\right)+\left[\frac{T_{S O}(j)}{T_{S T}(j)}\right] \times } \\
& {\left.\left[M\left(j, l, t_{0}\right)-S(j, l) T_{S O}(j)\right] \times \exp \left(\frac{-d t}{T_{S O}(j)}\right)\right\} }
\end{aligned}
$$

where material $l$ is the metal from which the oxide is formed and $R$ is the mass of product $k$ formed by the oxidation of a unit mass of reactant $l$.

The energy of the deposited debris is calculated with equations almost identical to Eqs. A.7-A.14 except the source term $S_{H}(i)$ also includes the enthalpy associated with debris settling. It is assumed that the enthalpy of the settled debris is equal to the end of time step value calculated with Eq. A.9. The settled mass with the end of step cuthalpy is applied to the deposition surface during the time step at a constant rate as implied by Eq. A.15. The other difference between the treatment of the energy of airborne and deposited debris concerns heat transfer. As discussed above, the user specifies a ime constant for heat transfer from the airborne debris to the atmosphere. However, for heat transfer from deposited debris to the structure a different approach is taken. Because the CVH package does not recognize the deposited debris temperature as the effective surface temperature, in order to effectively simulate the heat transfer from the hot debris to the CVH pool and/or atmosphere associated with the surface it is necessary to tightly couple the debris temperature to the HS surface temperature that (VH does recognize. Accordingly, a very small time constant equal to the minimum of half the surface oxidation time constant and a value of $.001 \mathrm{~s}$ is used to calculate the amount of heat transfer from the debris to the deposition surface using the analog of Eq. A.12 for heat transfer to surfaces. The value obtained is then used to determine the average heat, 
transfer coefficient between the deposited debris and the surface during the time step as follows.

$$
h_{S U R F}=\frac{Q_{S U R F}(i, t)}{A_{S U R F} \times \Delta T \times d t}
$$

where $A_{S U R F}$ is the surface area of the structure, $\Delta T$ is the difference between the beginning of time step debris temperature and the structure surface temperature and QSURF is the value obtained from the analog of Eq. A.12. If $h_{S U R F}$ exceeds a maximum value, $h_{S U R F, \max }$, specified by sensitivity coefficient 4608 (default value $1000 \mathrm{~W} / \mathrm{m}^{2}-\mathrm{K}$ ), then the value of $Q_{S U R F}$ is reduced by the ratio $h_{S U R F}, \max / h_{S U R F}$ to limit it to the value consistent with $h_{S U R F, \text { max }}$. Whenever the $Q_{S U R F}$ is limited by $h_{S U R F, \max }$ the direction of heat transfer (i.e. debris-to-surface or surface-to-debris) is compared to the direction from the previous time step; if the direction is alternating, that indicates that the surface temperature has probably been driven into an oscillation about the debris temperature because the time step exceeds the stability limit associated with the explicit coupling between the FDI and HS packages. In such cases, FDI requests a system fallback with the time step reduced by a factor of one half. Normally, the value of $h_{S U R F, \text { max }}$ should be chosen large enough to promote rapid equilibration of the debris and surface temperatures, yet not so large as to induce instability in the surface temperature for reasonable values of the time step.

If the MELCOR Radionuclide (RN) package is active, then FDI will call RN1 anytime fuel is moved so that the associated radionuclides can be moved simultaneously. Furthermore, the decay heat associated with the radionuclides will be deposited in the appropriate location.

Specified time constants of less than $10^{-6} \mathrm{~s}$ will be reset to that value to avoid potential numerical problems associated with vanishing time constants. For time scales of interest, a time constant of $10^{-6} \mathrm{~s}$ implies an essentially instantaneous process (i.e., instantaneous complete oxidation, instantaneous thermal equilibration with the atmosphere or instantaneous settling).

The simple direct containment heating model described above is not intended to predict all details of $\mathrm{DCH}$ events from first principles. Nodialization requirements would be much greater than normal MELCOR models. Rather, it is intended to allow users to evaluate the overall effect of varying the relative rates of the most important processes controlling DCH loads. HPME model results are sensitive to the relative values of $\operatorname{tau}_{o x}(\mathrm{i}), \operatorname{tau}_{h t}(\mathrm{i})$ and $\operatorname{tau}_{\text {set }}(\mathrm{i})$ specified by the user for each control volume. Reasonable values for these time constants can be obtained in basically two ways. First, results from mechanistic codes such as CONTAIN can be used to obtain appropriate values; or, second, reasonable assumptions concerning particle sizes and velocities in conjunction with simplified hard calculations can yield a range of time constants in the correct range. In most cases this second method should be adequate for parametric PRA studies. 


\section{B SNL/IET-1 Reference Calculation Input Deck}

*

*eor* melgen

*

allowreplace

$*$

$* * * * * * * * * * * * * * * * * * * * * * * * * * * * * * * * * * * * * * * * * * * * * * * * * * * * * * * * * * * * * * * * * * * * * * * * * *$

$*$

title 'Surtsey IET-1'

*

$* * * * * * * * * * * * * * * * * * * * * * * * * * * * * * * * * * * * * * * * * * * * * * * * * * * * * * * * * * * * * * * * * * * * * * * * * *$

$*$

diagfile 'gen1.dia'

outputfile 'gen1.out'

plotfile 'plot1'

restartfile 'restart1'

*

$* * * * * * * * * * * * * * * * * * * * * * * * * * * * * * * * * * * * * * * * * * * * * * * * * * * * * * * * * * * * * * * * * * * * * * * * * *$

*

* common input

*

$* * * * * * * * * * * * * * * * * * * * * * * * * * * * * * * * * * * * * * * * * * * * * * * * * * * * * * * * * * * * * * * * * * * * * * * * * *$

$*$

***************************************************************************

*

* burn package input

*

$* * * * * * * * * * * * * * * * * * * * * * * * * * * * * * * * * * * * * * * * * * * * * * * * * * * * * * * * * * * * * * * * * * * * * * * * * *$

*

bur000 $0 *$ activate package

$\begin{array}{llllllllllllll}\text { bur001 } & 0.0 & 0.167 & 0.07 & 0.129 & 0.05 & 0.55 & 0.0 & 0.167 & 0.05 & 0.55\end{array}$

$\begin{array}{lllllllll}* \text { bur003 } & 1.0 e-6 & 0.148 & 1.0 e-6 & 0.125 & 1.0 e-6 & 0.138 & 1.0 e-6 & 0.150\end{array}$

$\begin{array}{lllllll}\text { burcc00 } & -1 & -1 & 0.0 & -1 & 0.0\end{array}$

bur100 $010 \quad 86$

bur101 $020 \quad 86$

bur102 $030 \quad 86$

*

$* * * * * * * * * * * * * * * * * * * * * * * * * * * * * * * * * * * * * * * * * * * * * * * * * * * * * * * * * * * * * * * * * * * * * * * * * *$

$*$

* non-condensible gas input

*

$* * * * * * * * * * * * * * * * * * * * * * * * * * * * * * * * * * * * * * * * * * * * * * * * * * * * * * * * * * * * * * * * * * * * * * * * * *$

*

ncg000 n2 4

ncg001 $02 \quad 5$

ncg002 h2 6

ncgOO3 co2 7

ncg004 co 8

ncg005 ar 9

*

$* * * * * * * * * * * * * * * * * * * * * * * * * * * * * * * * * * * * * * * * * * * * * * * * * * * * * * * * * * * * * * * * * * * * * * * * * *$

* 


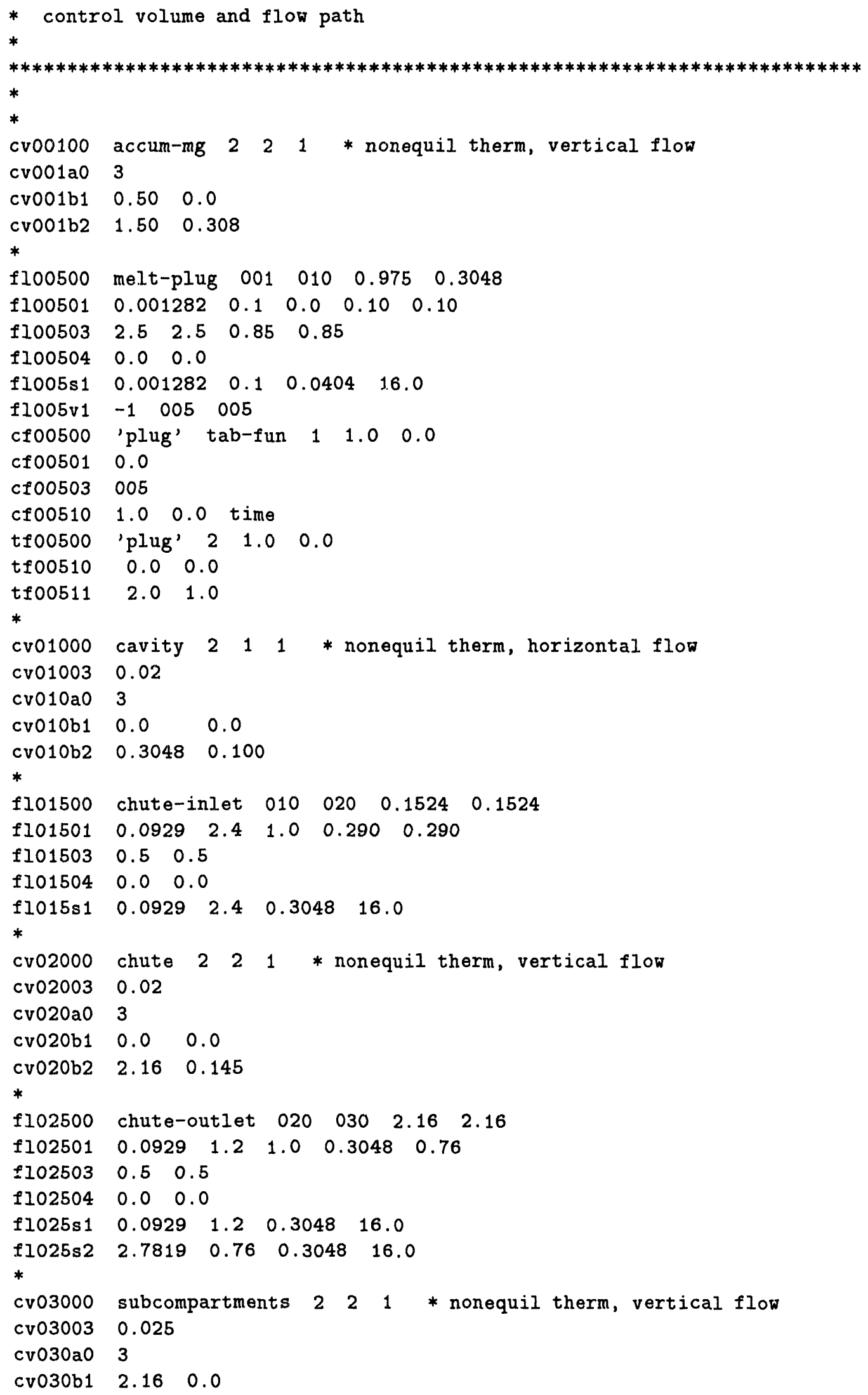




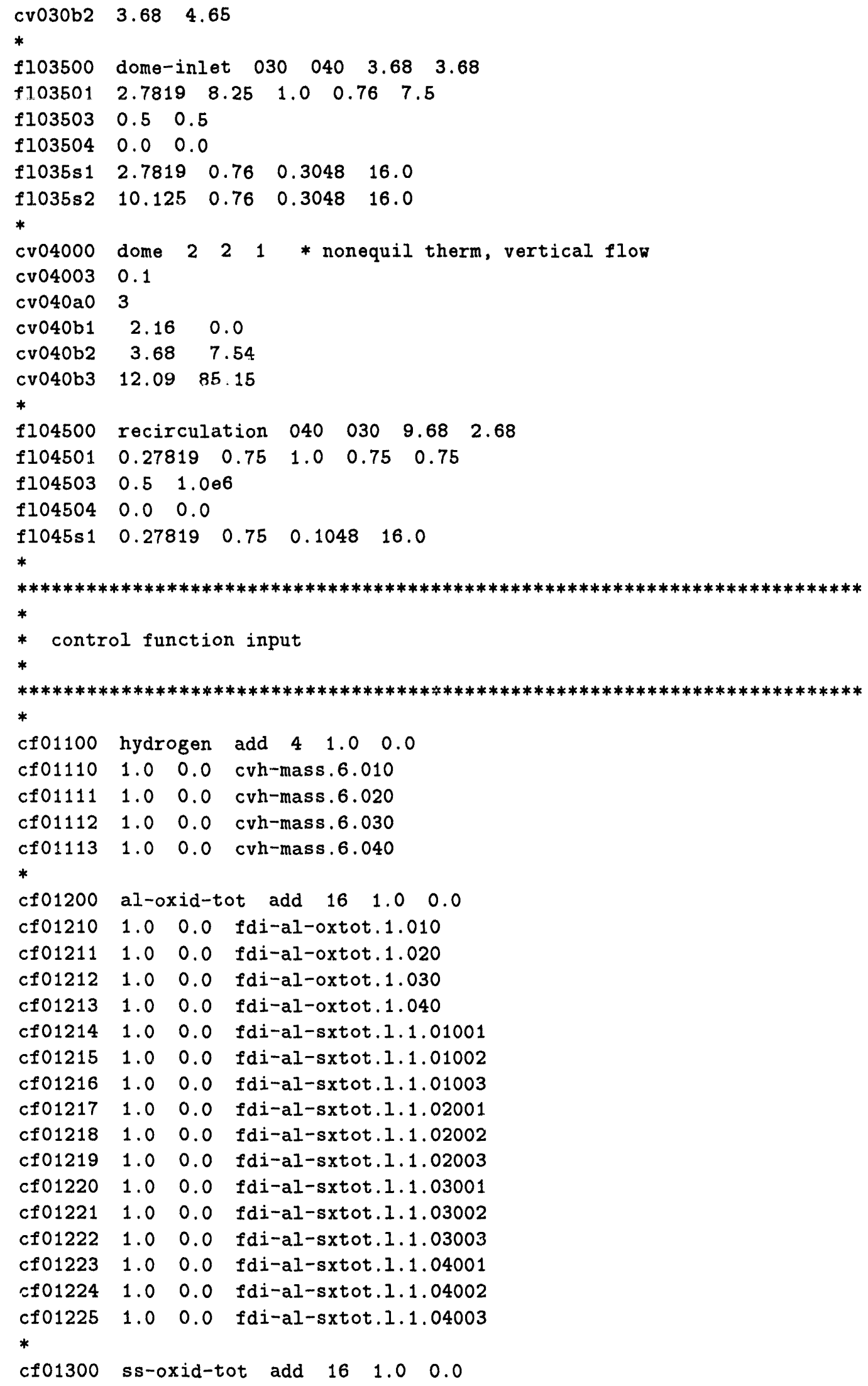




\begin{tabular}{|c|c|c|c|}
\hline 10 & 1.0 & 0.01 & fdi-ss-oxtot. 1.010 \\
\hline $\operatorname{cf01311}$ & 1.0 & 0.0 & fdi-ss-oxtot. 1.020 \\
\hline 101312 & 1.0 & 0.0 & fdi-ss-oxtot. 1.030 \\
\hline 101313 & 1.0 & 0.0 & fdi-ss-oxtot. 1.040 \\
\hline$f 01314$ & 1.0 & 0.0 & fdi-ss-sxtot.1.1.01001 \\
\hline $\operatorname{cf01315}$ & 1.0 & 0.0 & fdi-ss-sxtot.1.1.01002 \\
\hline $\operatorname{cf} 01316$ & 1.0 & 0.0 & fdi-ss-sxtot.1.1.01003 \\
\hline $\operatorname{cf01317}$ & 1.0 & 0.0 & fdi-ss-sxtot.1.1.02001 \\
\hline $\operatorname{cf} 01318$ & 1.0 & 0.0 & fdi-ss-sxtot.1.1.02002 \\
\hline$c f 01319$ & 1.0 & 0.0 & fdi-ss-sxtot.1.1.02003 \\
\hline $\operatorname{cf01320}$ & 1.0 & 0.0 & fdi-ss-sxtot.1.1.03001 \\
\hline $\operatorname{cf} 01321$ & 1.0 & 0.0 & fdi-ss-sxtot.1.1.03002 \\
\hline$c f 01322$ & 1.0 & 0.0 & fdi-ss-sxtot.1.1.03003 \\
\hline $\operatorname{cf} 01323$ & 1.0 & 0.0 & di-ss-sxtot.1.1.04001 \\
\hline $\operatorname{cf} 01324$ & 1.0 & 0.0 & di-ss-sxtot.1.1.04002 \\
\hline$c f 01325$ & 1.0 & 0.0 & $1.40-1$ \\
\hline $\operatorname{cf} 01400$ & $02-0$ & $x i d-$ & add $\quad \begin{array}{lll}16 & 1.0 & 0.0\end{array}$ \\
\hline $\operatorname{cf} 01410$ & 1.0 & 0.0 & fdi-o2-oxtot. 1.010 \\
\hline $\operatorname{cf01411}$ & 1.0 & 0.0 & fdi-o2-oxtot. 1.020 \\
\hline $\operatorname{cf} 01412$ & 1.0 & 0.0 & fdi-o2-oxtot. 1.030 \\
\hline $\operatorname{cf} 01413$ & 1.0 & 0.0 & fdi-02-oxtot. 1.040 \\
\hline cfo1414 & 1.0 & 0.0 & fdi-o2-sxtot.1.1.01001 \\
\hline $\operatorname{cf} 01415$ & 1.0 & 0.0 & fdi-02-sxtot.1.1.01002 \\
\hline 16 & 1.0 & 0.0 & fdi-02-sxtot.1.1.01003 \\
\hline $\operatorname{cf} 01417$ & 1.0 & 0.0 & fdi-02-sxtot.1.1.02001 \\
\hline $\operatorname{cf} 01418$ & 1.0 & 0.0 & fdi-02-sxtot.1.1.02002 \\
\hline $\operatorname{cf01419}$ & 1.0 & 0.0 & fdi-02-sxtot.1.1.02003 \\
\hline $\operatorname{cf} 01420$ & 1.0 & 0.0 & fdi-o2-sxtot.1.1.03001 \\
\hline $\operatorname{cf01421}$ & 1.0 & 0.0 & fdi-o2-sxtot.1.1.03002 \\
\hline $\operatorname{cf} 01422$ & 1.0 & 0.0 & fdi-02-sxtot.1.1.03003 \\
\hline 423 & 1.0 & 0.0 & fdi-02-sxtot.1.1.04001 \\
\hline $\operatorname{cf} 01424$ & 1.0 & 0.0 & fdi-o2-sxtot.1.1.04002 \\
\hline $\begin{array}{l}\text { cf01425 } \\
*\end{array}$ & 1.0 & 0.0 & fdi-02-sxtot.1.1.04003 \\
\hline $\operatorname{cf} 01500$ & st-o & xid-to & ot add $\begin{array}{lll}16 & 1.0 & 0.0\end{array}$ \\
\hline 10 & 1.0 & 0.0 & fdi-st-oxtot. 1.010 \\
\hline $\operatorname{cf} 01511$ & 1.0 & 0.0 & fdi-st-oxtot. 1.020 \\
\hline $\operatorname{cf} 01512$ & 1.0 & 0.0 & fdi-st-oxtot. 1.030 \\
\hline 513 & 1.0 & 0.0 & t-oxtot. 1.040 \\
\hline 514 & 1.0 & 0.0 & fdi-st-sxtot.1.1.01001 \\
\hline $\operatorname{cf} 01515$ & 1.0 & 0.0 & fdi-st-sxtot.1.1.01002 \\
\hline 516 & 1.0 & 0.0 & fdi-st-sxtot.1.1.01003 \\
\hline $\operatorname{cf01517}$ & 1.0 & 0.0 & fdi-st-sxtot.1.1.02001 \\
\hline $\operatorname{cf} 01518$ & 1.0 & 0.0 & fdi-st-sxtot.1.1.02002 \\
\hline $\operatorname{cf01519}$ & 1.0 & 0.0 & fdi-st-sxtot.1.1.02003 \\
\hline $\operatorname{cf01520}$ & 1.0 & 0.0 & fdi-st-sxtot.1.1.03001 \\
\hline 01521 & 1.0 & 0.0 & fdi-st-sxtot.1.1.03002 \\
\hline $\operatorname{cf} 01522$ & 1.0 & 0.0 & fdi-st-sxtot.1.1.03003 \\
\hline f01523 & 1.0 & 0.0 & fdi-st-sxtot.1.1.04001 \\
\hline$c f 01524$ & 1.0 & 0.0 & fdi-st-sxtot.1.1.04002 \\
\hline cf01525 & 1.0 & 0.0 & fdi-st-sxtot.1.1.0.7003 \\
\hline
\end{tabular}




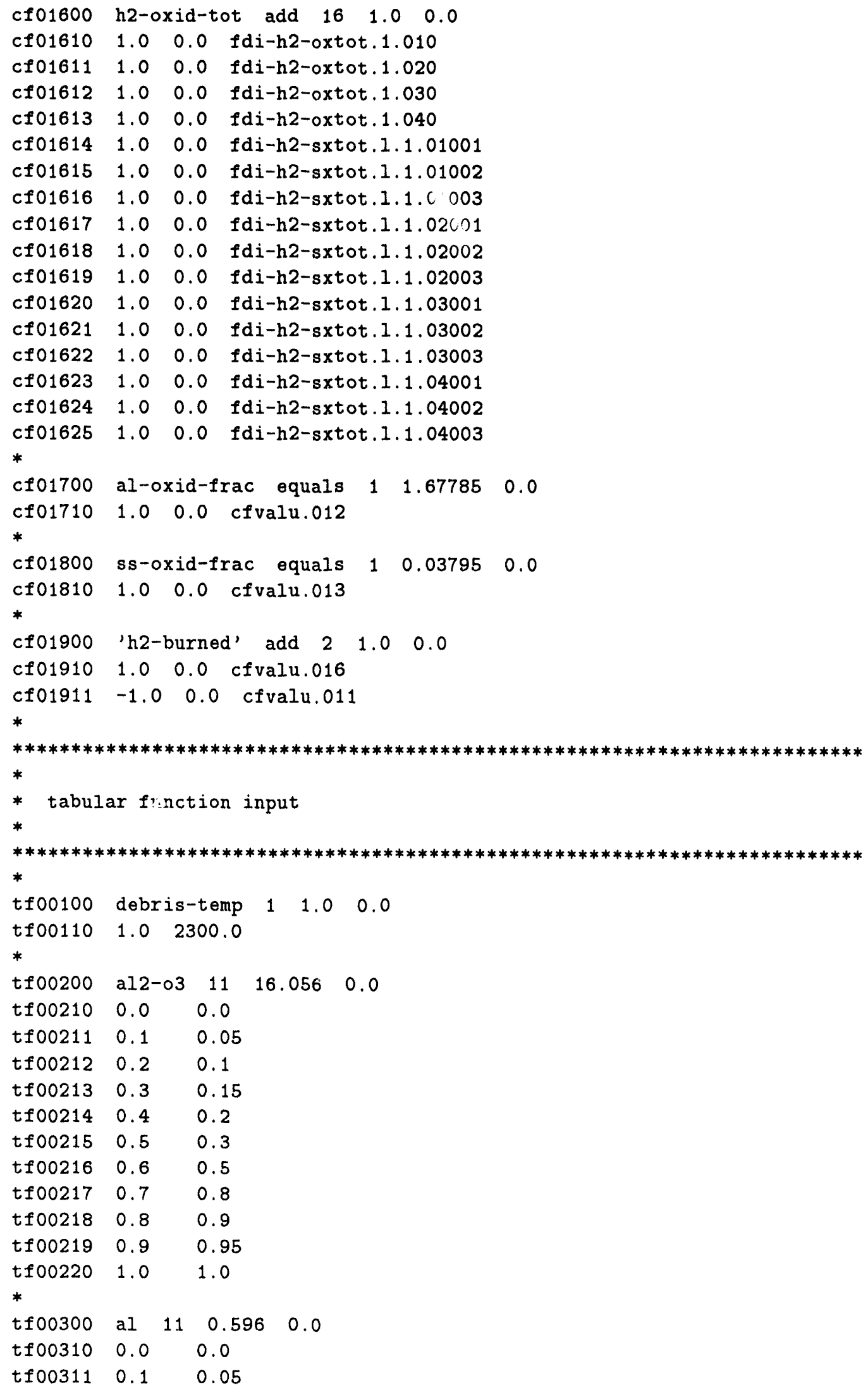




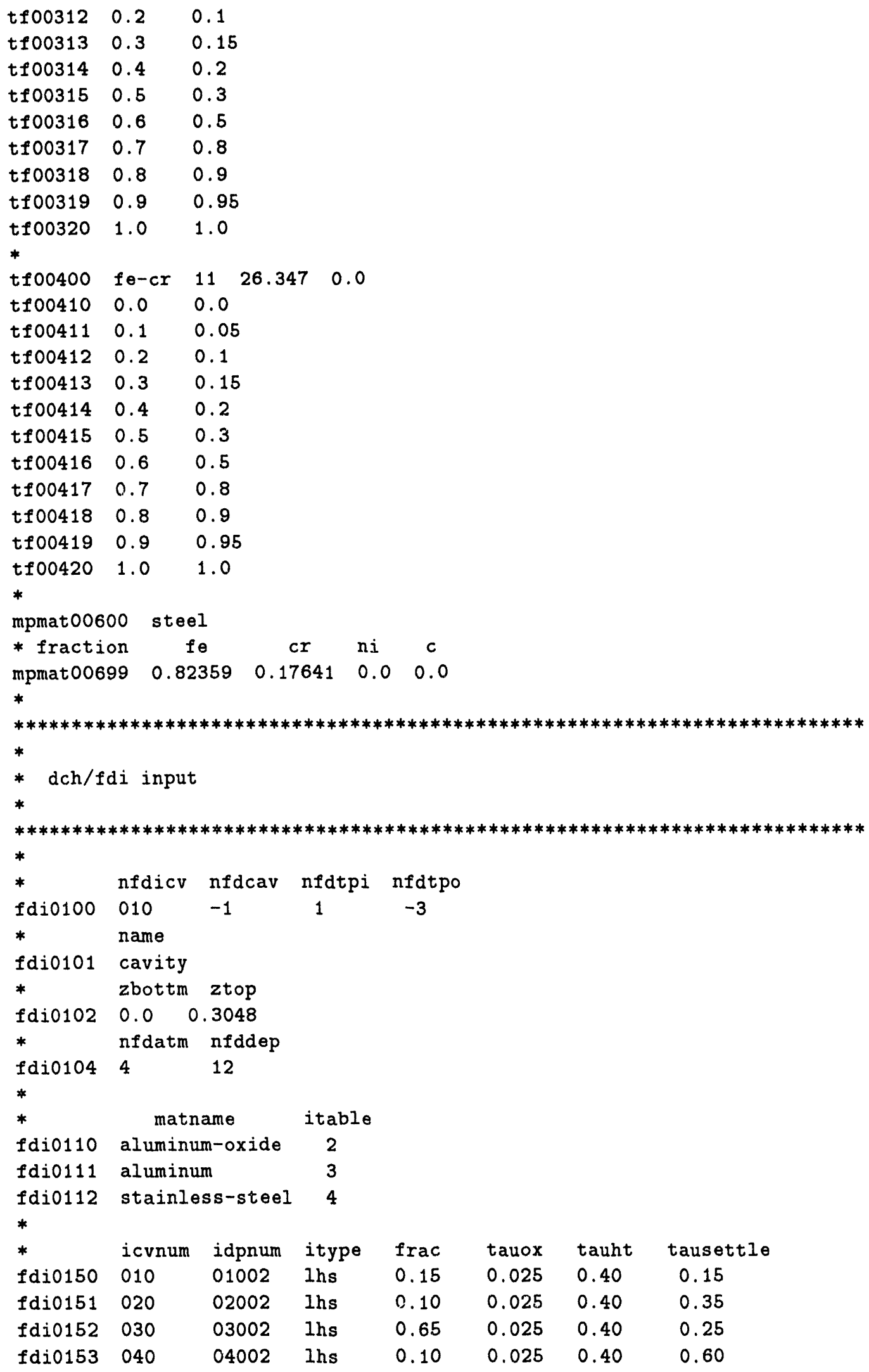




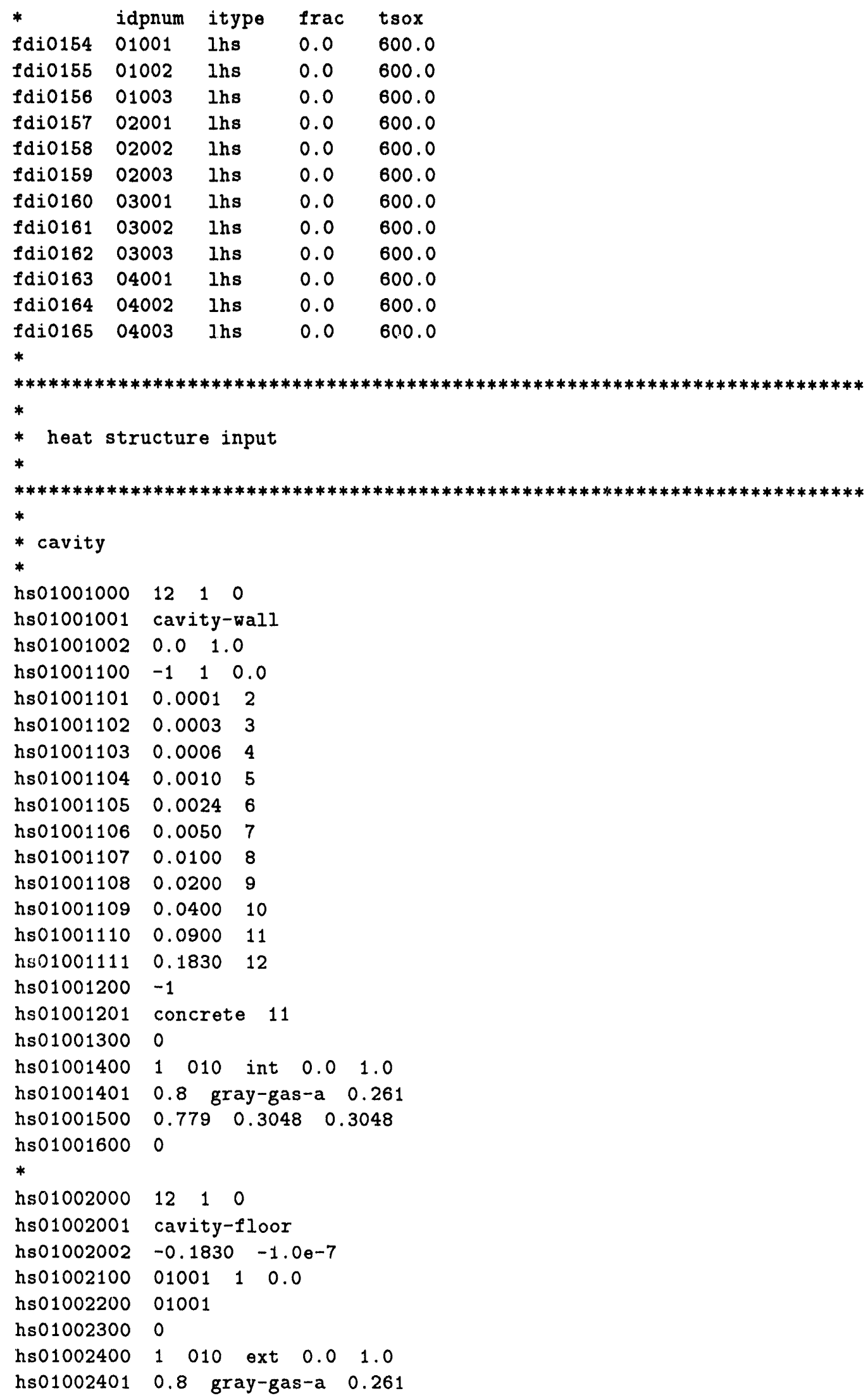




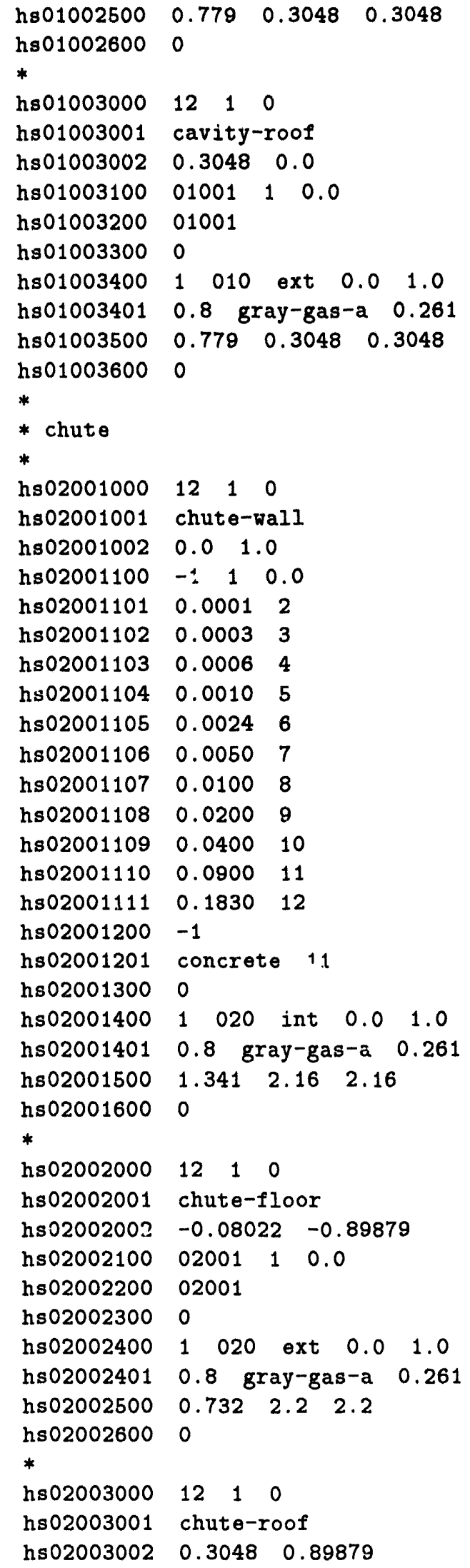




$$
\begin{aligned}
& \text { 震 }
\end{aligned}
$$

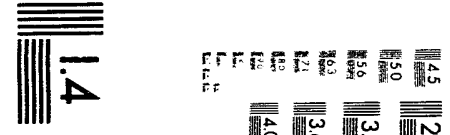

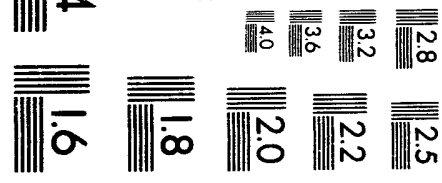




$$
\begin{aligned}
& \omega \\
& \stackrel{\rho}{\rho} \\
& \omega
\end{aligned}
$$




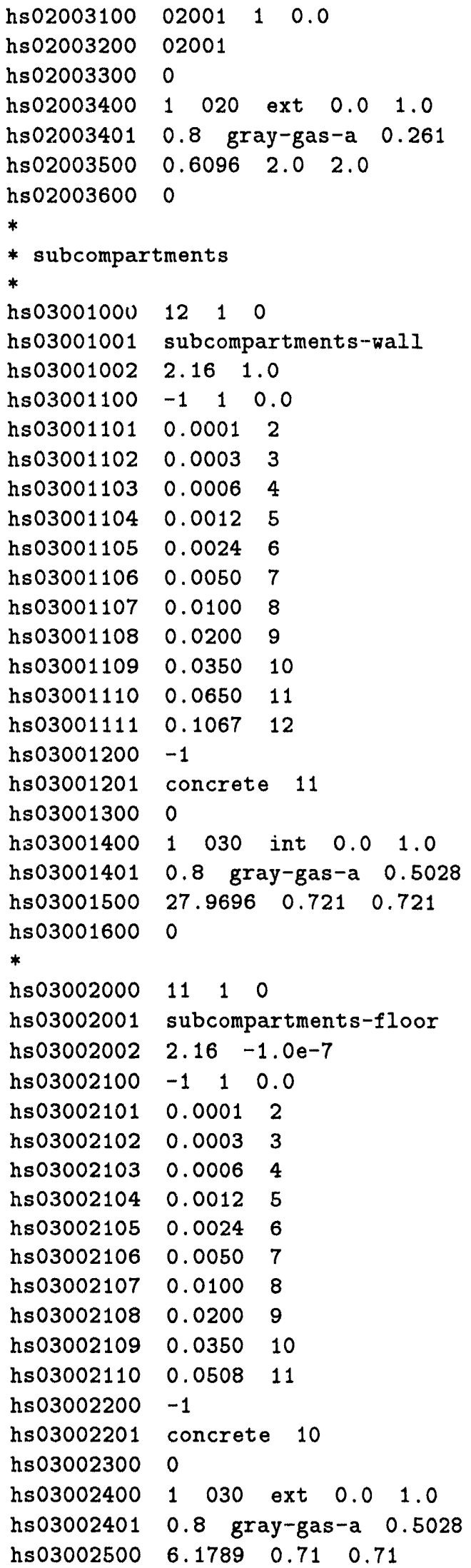




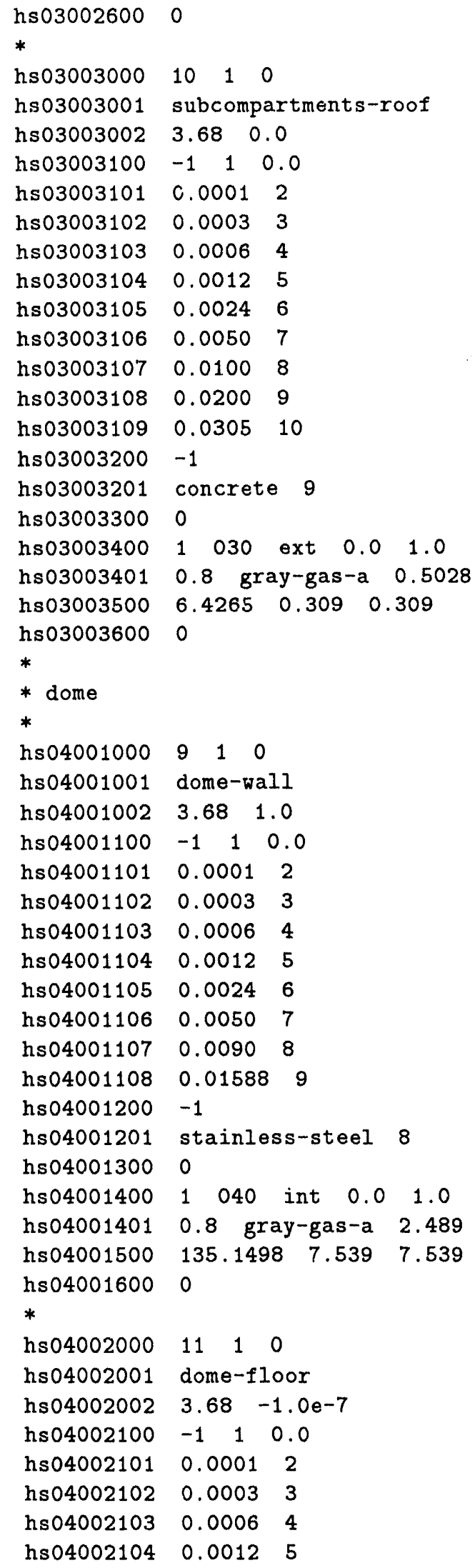




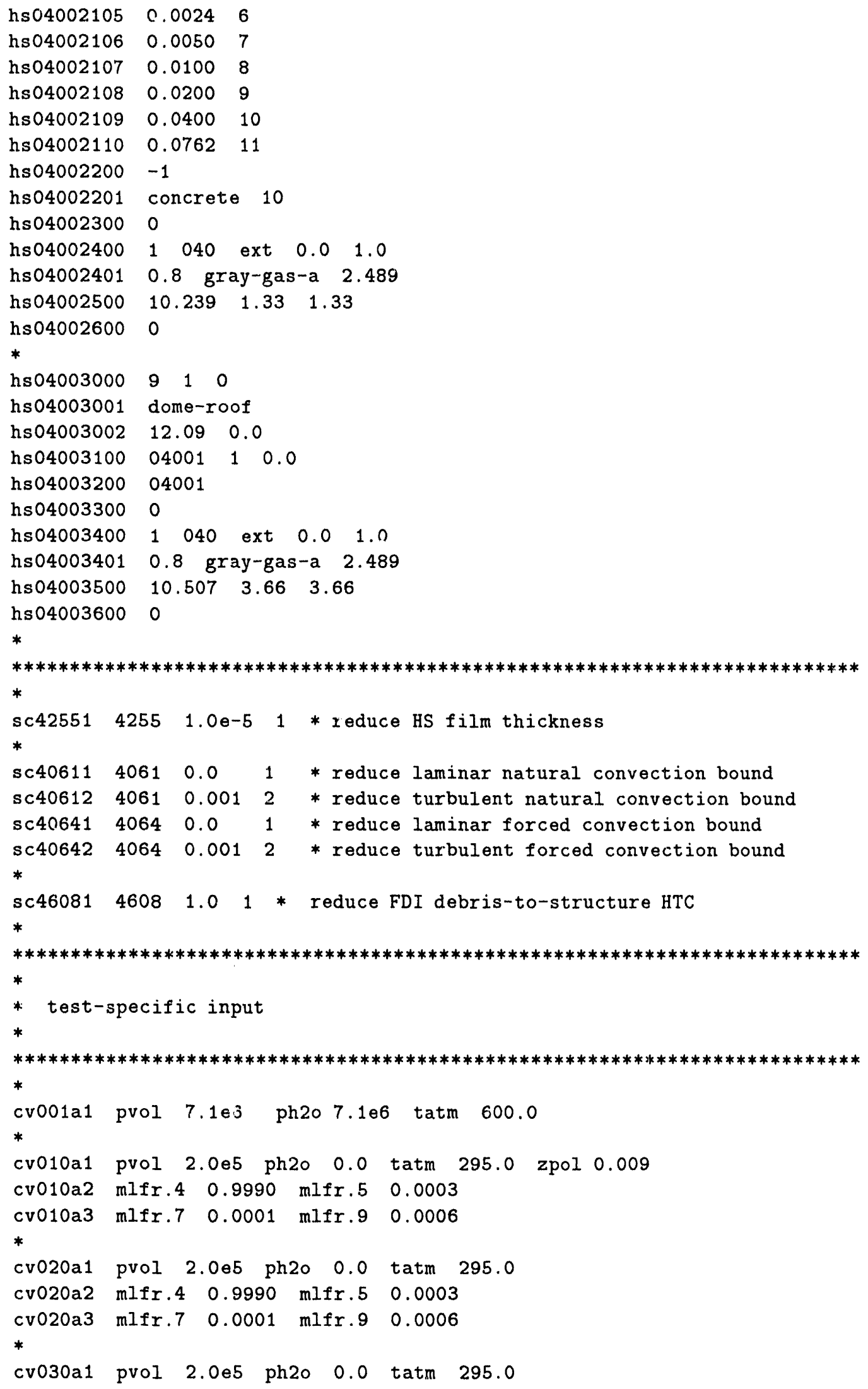




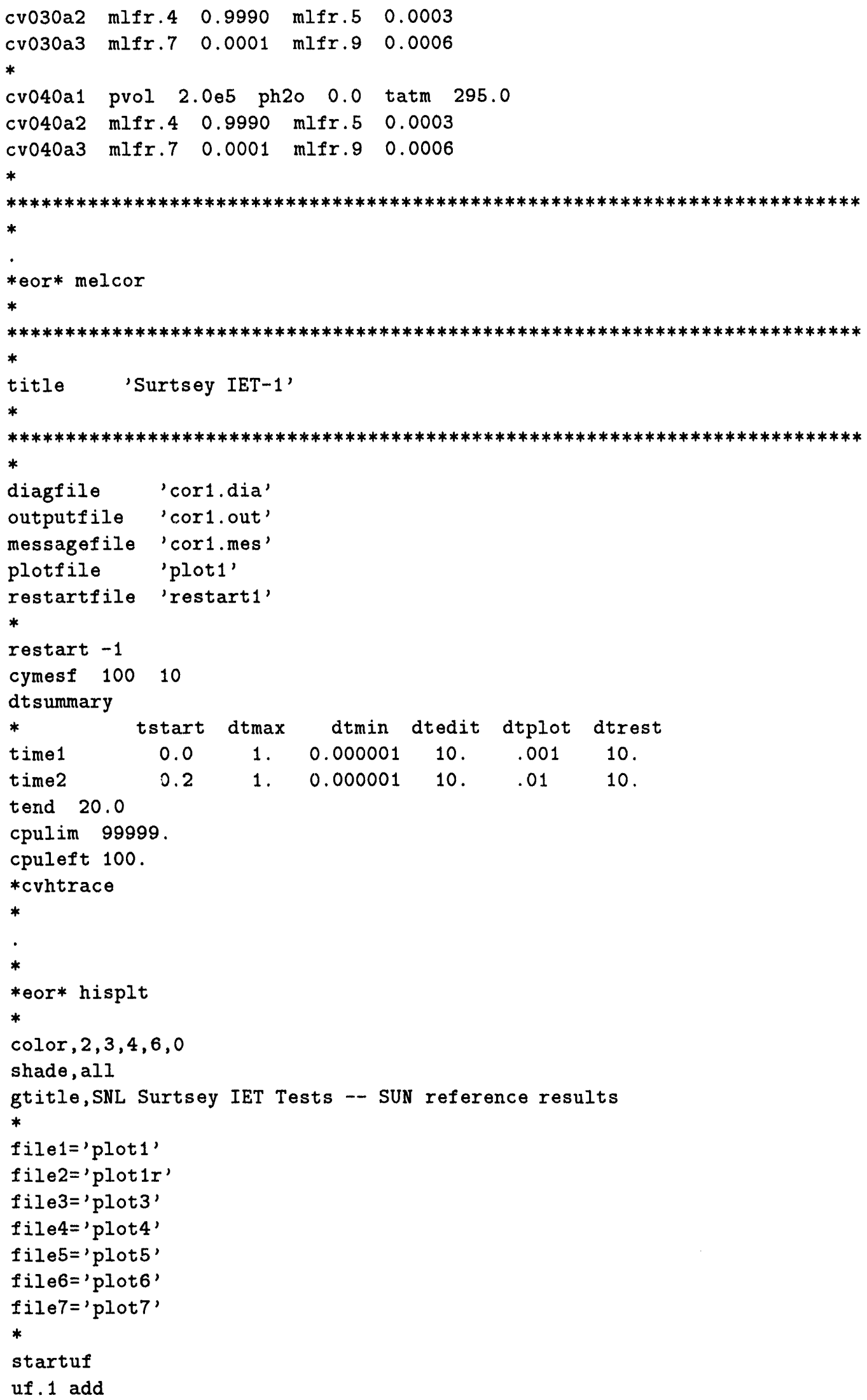




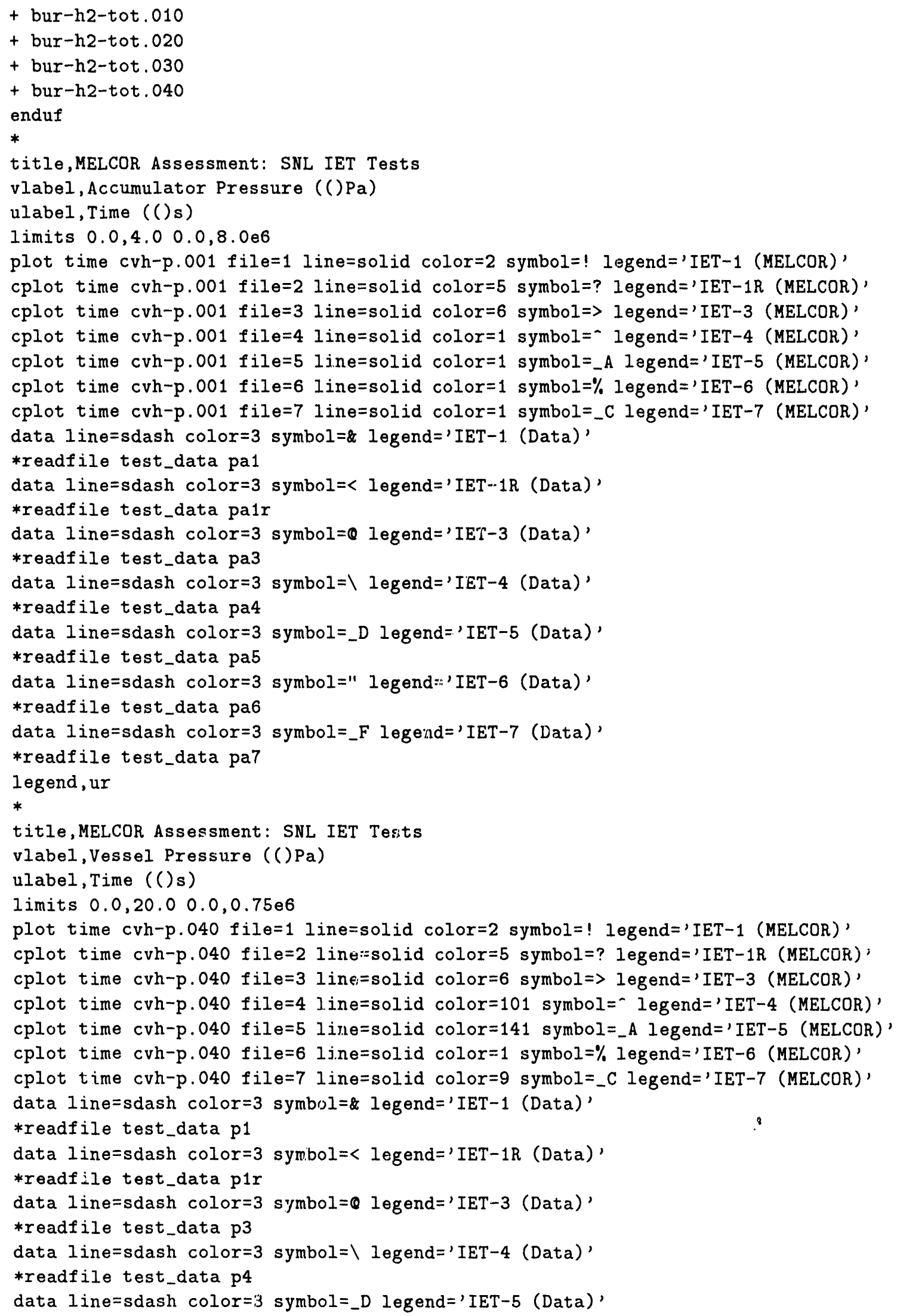




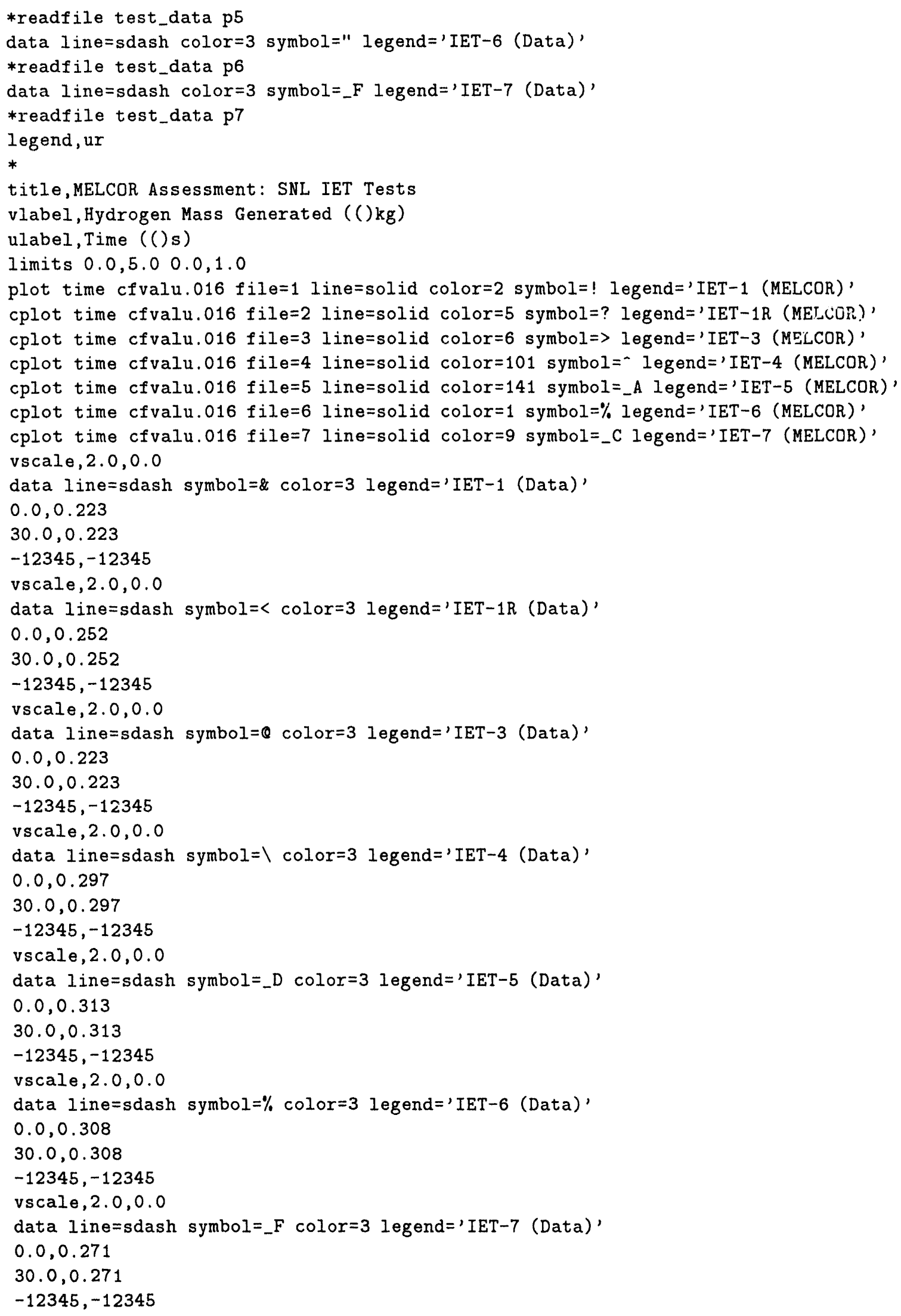


legend, ur

*

tit1e, MELCOR Assessment: SNL IET Tests

vlabel, Hydrogen Mass Burned (() kg)

ulabel, Time (()s)

limits $0.0,20.00 .0,1.0$

plot time uf.1 file=1 line=solid color=2 symbol=! legend='IET-1 (MELCOR)'

cplot time uf. 1 file=2 line=solid color=5 symbol=? legend='IET-1R (MELCOR)'

cplot time uf. 1 file=3 line=solid color $=6$ symbol $\Rightarrow$ legend='IET -3 (MELCOR)'

cplot time uf. 1 file=4 line=solid color=101 symbol=- legend='IET-4 (MELCOR)'

cplot time uf.1 file=5 line=solid color=141 symbol=_A legend='IET-5 (MELCOR)'

cplot time uf.1 file=6 line=solid color=1 symbol=\% legend='IET-6 (MELCOR)'

cplot time uf. 1 file=7 line=solid color $=9$ symbol=_C legend='IET-7 (MELCOR)'

viscale, 2.0,0.0

data 1 ine $=$ sdash symbol=\& color=3 lagend='IET-1 (Data)'

$0.0,0.001$

$30.0,0.001$

$-12345,-12345$

vscale, $2.0,0.0$

data line $=$ sdash symbol $=<$ color $=3$ legend $=$ 'IET $-1 \mathrm{R}$ (Data)'

$0.0,0.012$

$30.0,0.012$

$-12345,-12345$

vscale, $2.0,0.0$

data 1 ine $=$ sdash symbol $=Q$ color $=3$ legend='IET -3 (Data)'

$0.0,0.186$

$30.0,0.186$

$-12345,-12345$

vscale, $2.0,0.0$

data line $=s d a s h$ symbol $=\backslash$ color $=3$ legend='IET-4 (Data)'

$0.0,0.236$

$30.0,0.236$

$-12345,-12345$

vscale, $2.0,0.0$

data $l$ ine=sdash symbol=_D color=3 legend=' IET -5 (Data)'

$0.0,0.050$

3 C. $0,0.050$

$-12345,-12345$

vscale, $2.0,0.0$

data 1 ine=sdash symbol=" color $=3$ legend='IET-6 (Data)'

$0.0,0.335$

$30.0,0.335$

$-12345,-12345$

vscale, $2.0,0.0$

data line=sdash symbol=_F color $=3$ legend='IET-7 (Data)'

$0.0,0.321$

$30.0,0.321$

$-12345,-12345$

legend, ur

*

title, MELCOR Assessment: SNL IET Tests

vlabel, Subcompartment Temperature (()K)

ulabel, Time (()s) 


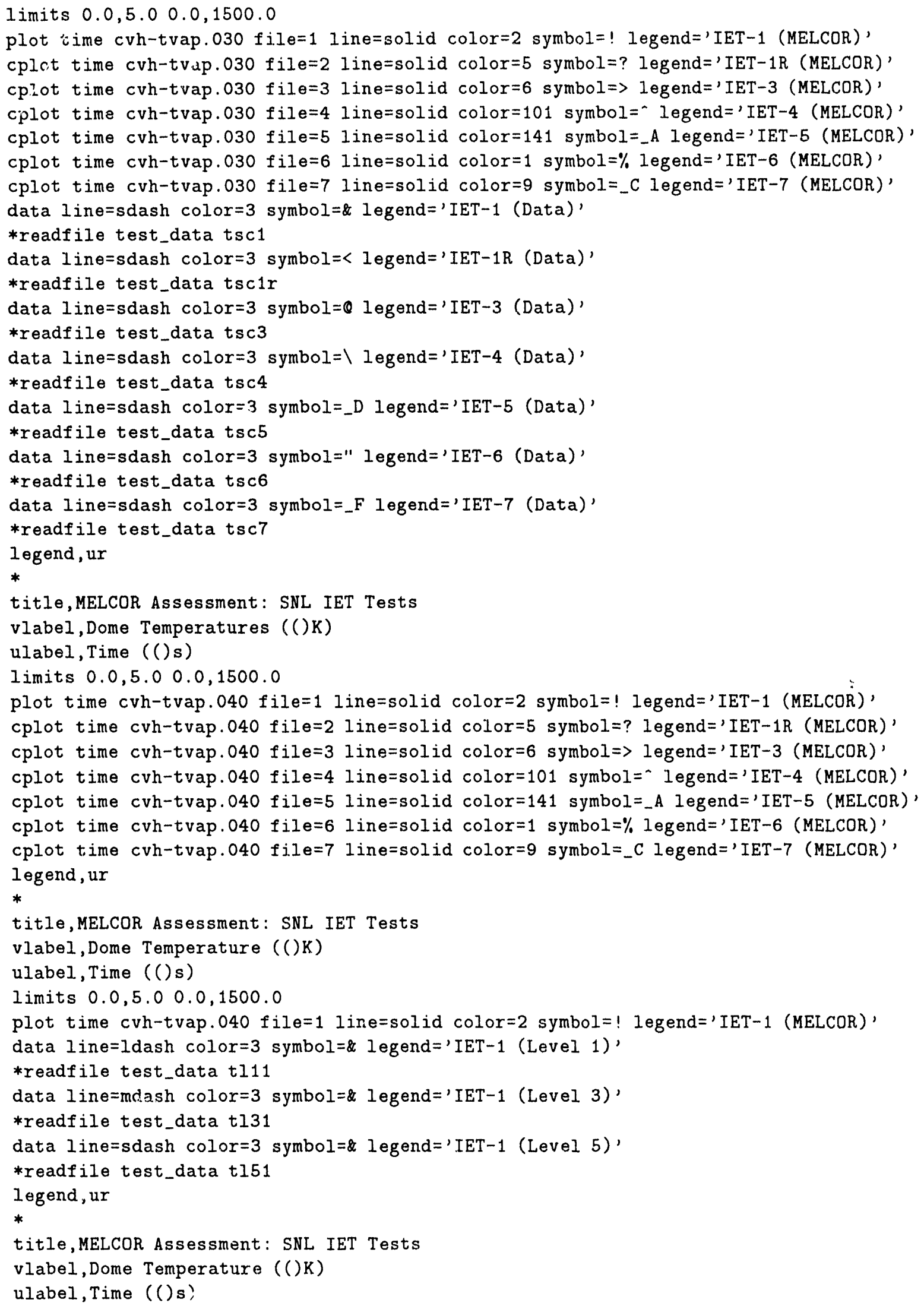




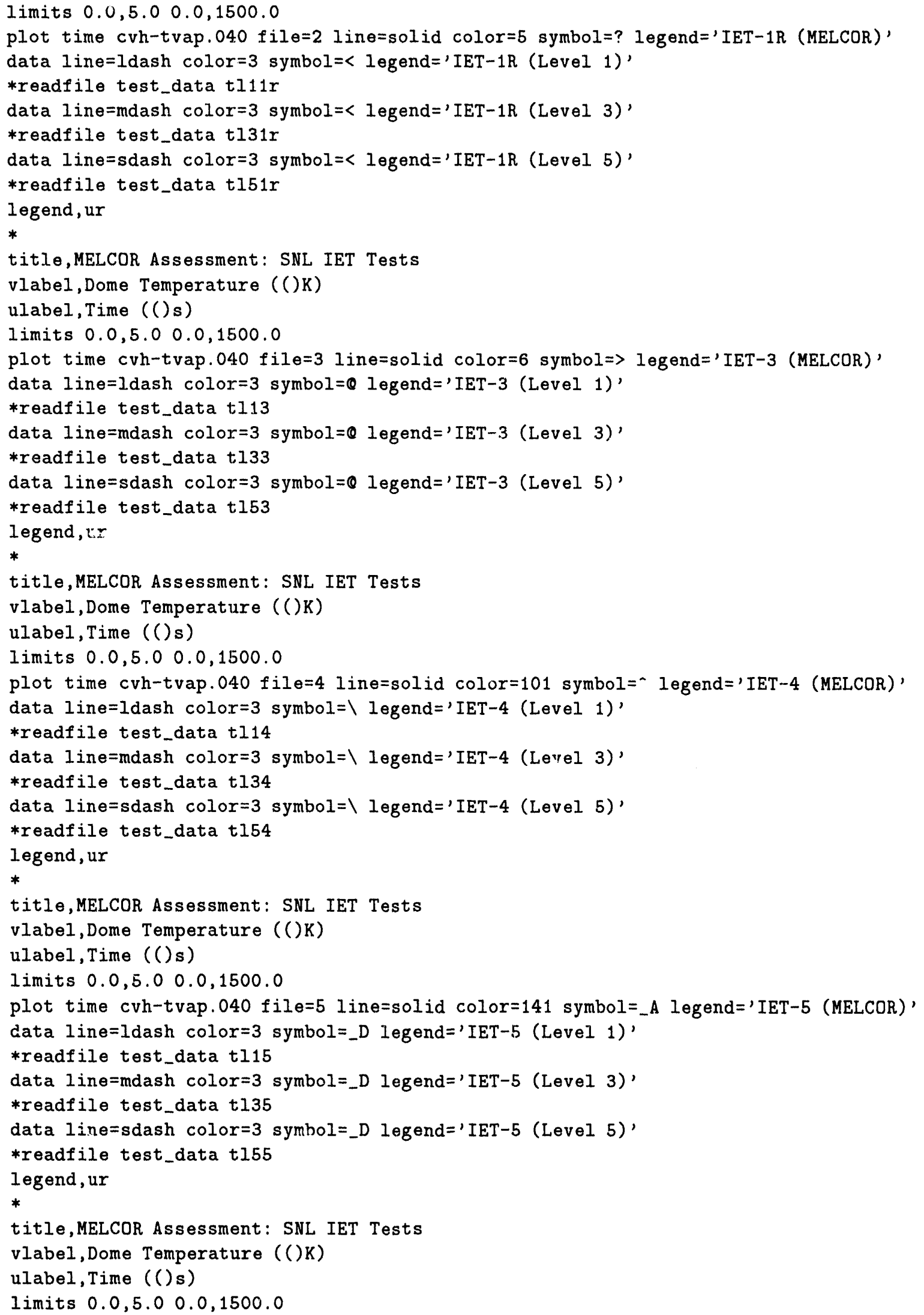




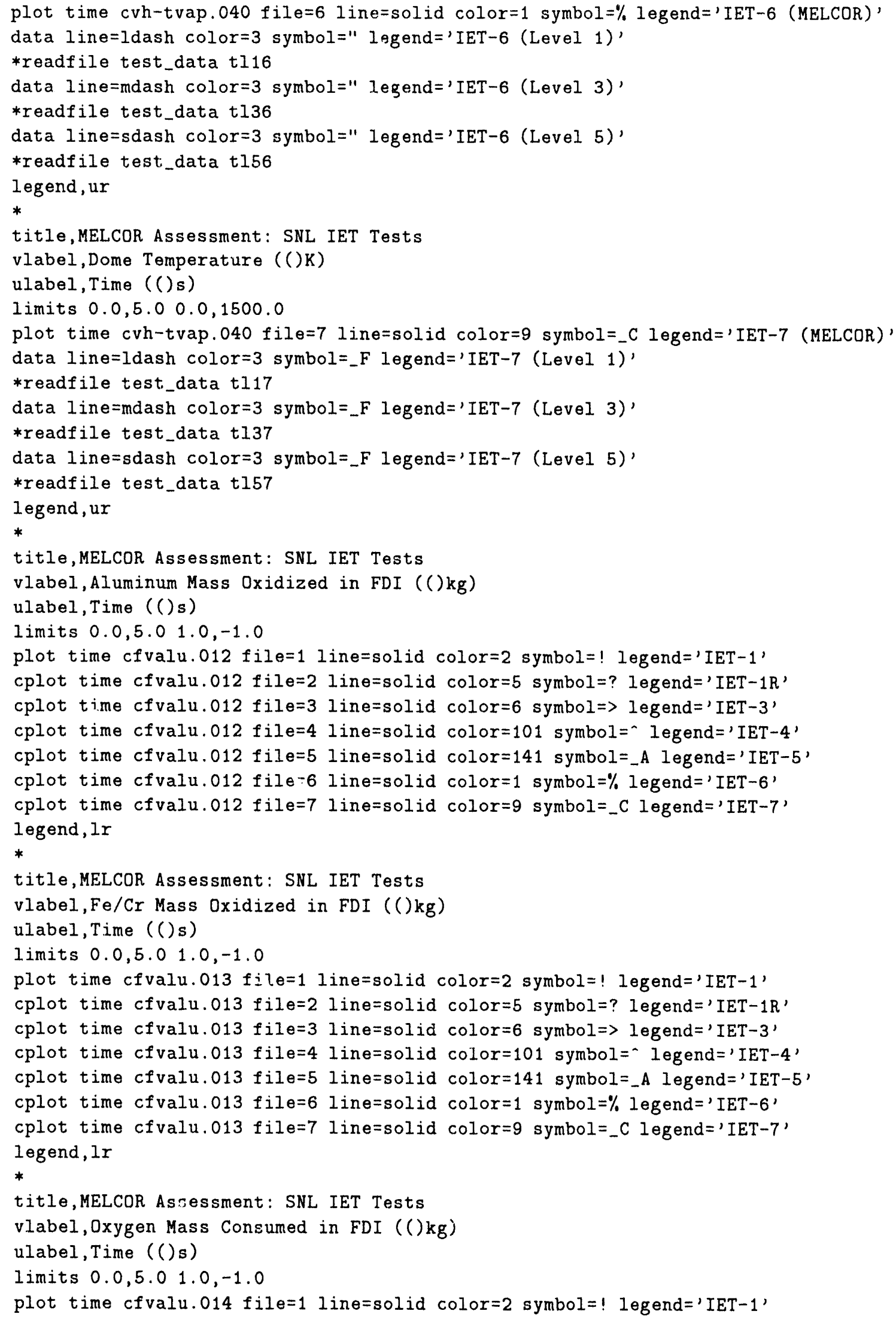


cplot time cfvalu.014 file=? line=solid color $=5$ symbol=? legend=' IET-1R' cplot time cfvalu.014 file=3 line=solid color $=6$ symbol $\Rightarrow$ legend='IET -3 ' cplot time cfvalu.014 file=4 line=solid color=101 symbol=- legend='IET -4 ' cplot time cfvalu. 014 file=5 line=solid color $=141$ symbol=_A legend='IET-5' cplot time cfvalu.014 file=6 line=solid color=1 symbol=\% legend='IET-6' cplot time cfvalu.014 file $=7$ line=solid color $=9$ symbol=_C legend='IET -7 ' legend, ir

*

title, MELCOR Assessment: SNL IET Tests

vlabel, Steam Mass Consumed in FDI (() kg)

ulabel, Time (()s)

limits $0.0,5.01 .0,-1.0$

plot time cfvalu.015 file=1 line=solid color=2 symbol=! legend='JET-1'

cplot time cfvalu.015 file=2 line=solid color=5 symbol=? legend=' IET-1R'

cplot time cfvalu.015 file=3 line=solid color $=6$ symbol => legend=' IET -3 '

cplot time cfvalu.015 file=4 line=solid color $=101$ symbol $=$ - legend $=$ 'IET -4 '

cplot time cfvalu.015 file=5 line=solid color=141 symbol=_A legend='IET-5'

cplot time cfvalu.015 file=6 line=solid color=1 symbol=\% legend='IET-6'

cplot time cfvalu.015 file=7 line=solid color $=9$ symbol=_C legend $=$ ' IET -7 '

legend, Ir

*

title, MELCOR Assessment: SNL IET Tests

vlabel, Hydrogen Mass Generated in FDT ( () $\mathrm{kg}$ )

ulabel, Time (()s)

limits $0.0,5.01 .0,-1.0$

plot time cfvalu.016 file=1 line=solid color=2 symbol=! legend='IET-1'

cplot time cfvalu.016 file=2 line=solid color=5 symbol=? legend='IET-1R'

cplot time cfvalu.016 file=3 line=solid color=6 symbol=> legend='IET -3 '

cplot time cfvalu.016 file=4 line=solid color $=101$ symbol= ${ }^{-}$legend='IET -4 '

cplot time cfvalu.016 file=5 line=solid color=141 symbol=_A legend='IET-5'

cplot time cfvalu.016 file=6 line=solid color $=1$ symbol=\% legend='IET-6'

cplot time cfvalu.016 file=7 line=solid color $=9$ symbol=_C legend=' IET -7 '

legend, Ir

*

title, MELCOR Assessment: SNL IET Tests

vlabel, Hydrogen Mole Fraction in Subcompartments

ulabel, Time (()s)

*limits $0.0,5.01 .0,-1.0$

plot time cvh-x.6.030 file=1 line=solid color=2 symbol=! legend='IET-1 (MELCOR)'

cplot time cvh-x.6.030 file=2 line=solid color=5 symbol=? legend='IET-1R (MELCOR)'

cplot time $c v h-x .6 .030 \mathrm{file=3}$ line=solid color 6 symbol=> legend='IET -3 (MELCOR)'

cplot time cvh-x.6.030 file=4 line=solid color $=101$ symbol=- legend='IET-4 (MELCOR)'

cplot time cvh-x.6.030 file=5 line=solid color=141 symbol=_A legend='IET-5 (MELCOR)'

cplot time cvh-x.6.030 file=6 line=solid color=1 symbol=\% legend='IET-6 (MELCOR)'

cplot time cvh-x.6.030 file=7 line=solid color =9 symbol=_C legend='IET -7 (MELCOR)'

data 1 ine=sdash symbol=\& color=3 legend='IET-1 (Data)'

$0.0,0.0003108$

$2.0,0.208$

$5.0,0.03108$

$30.0,0.03108$

$-12345,-12345$

data 1 ine $=$ sdash symbol=< color $=3$ legend='IET-1R (Data)'

$5.0,0.03077$ 


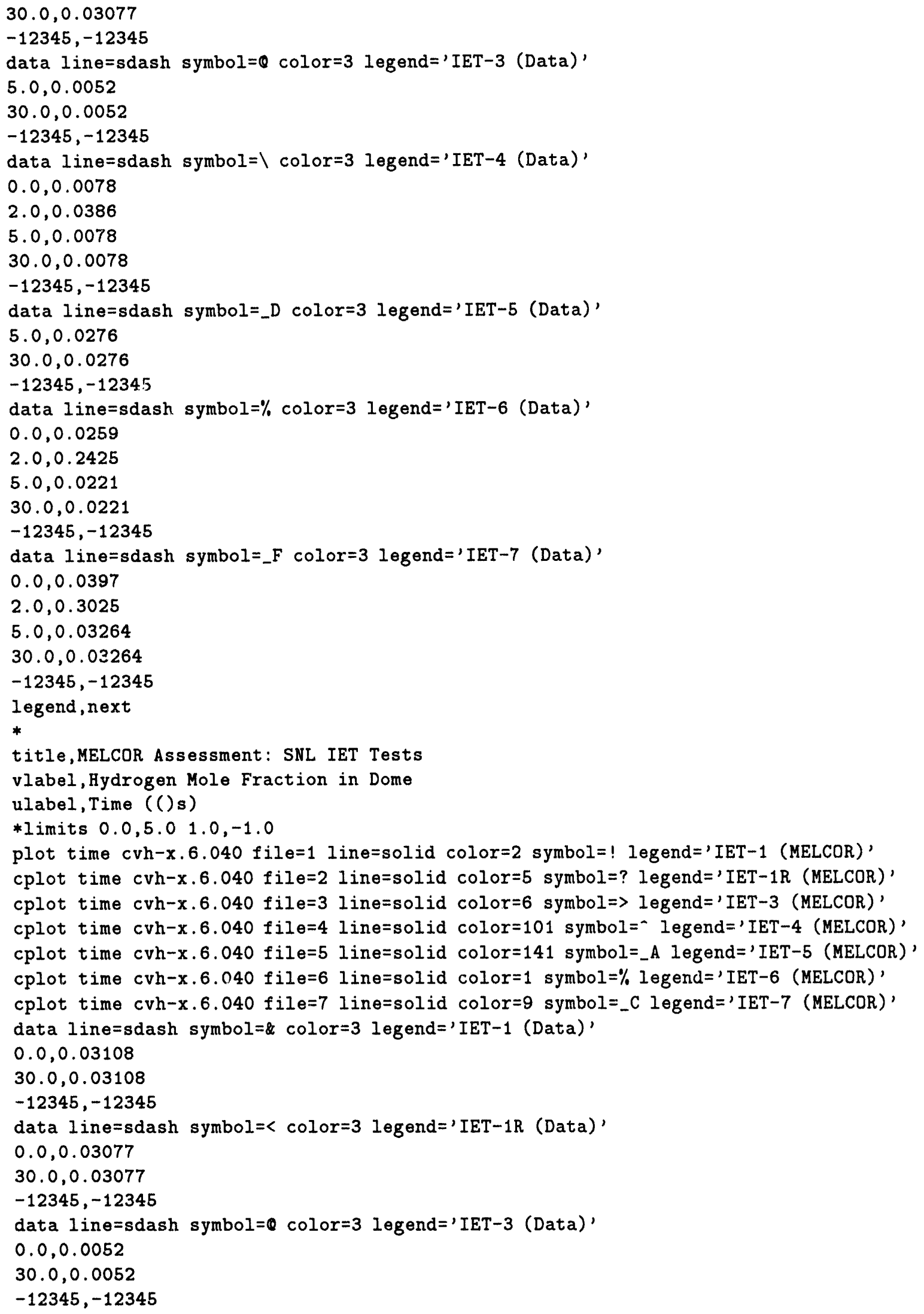




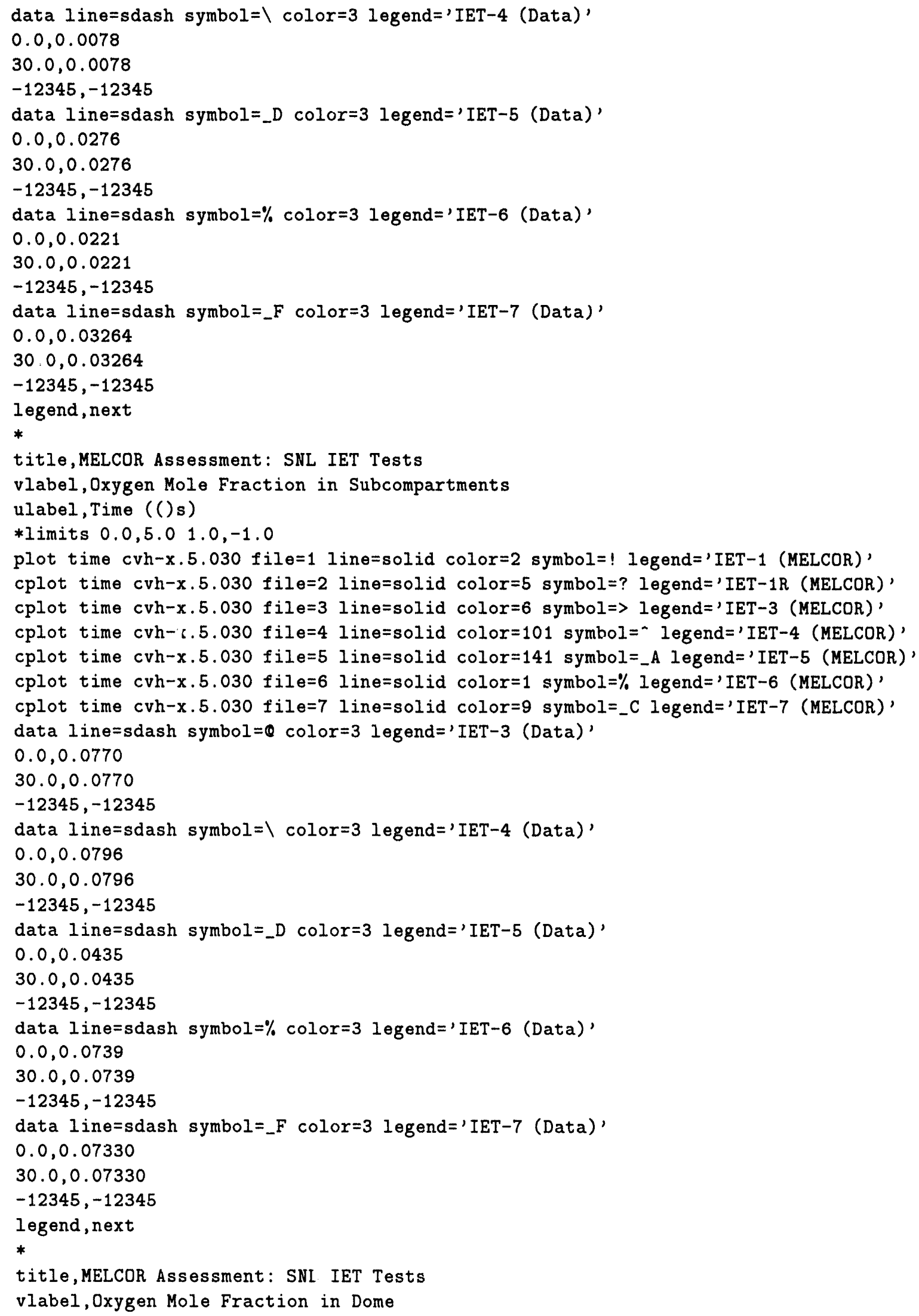




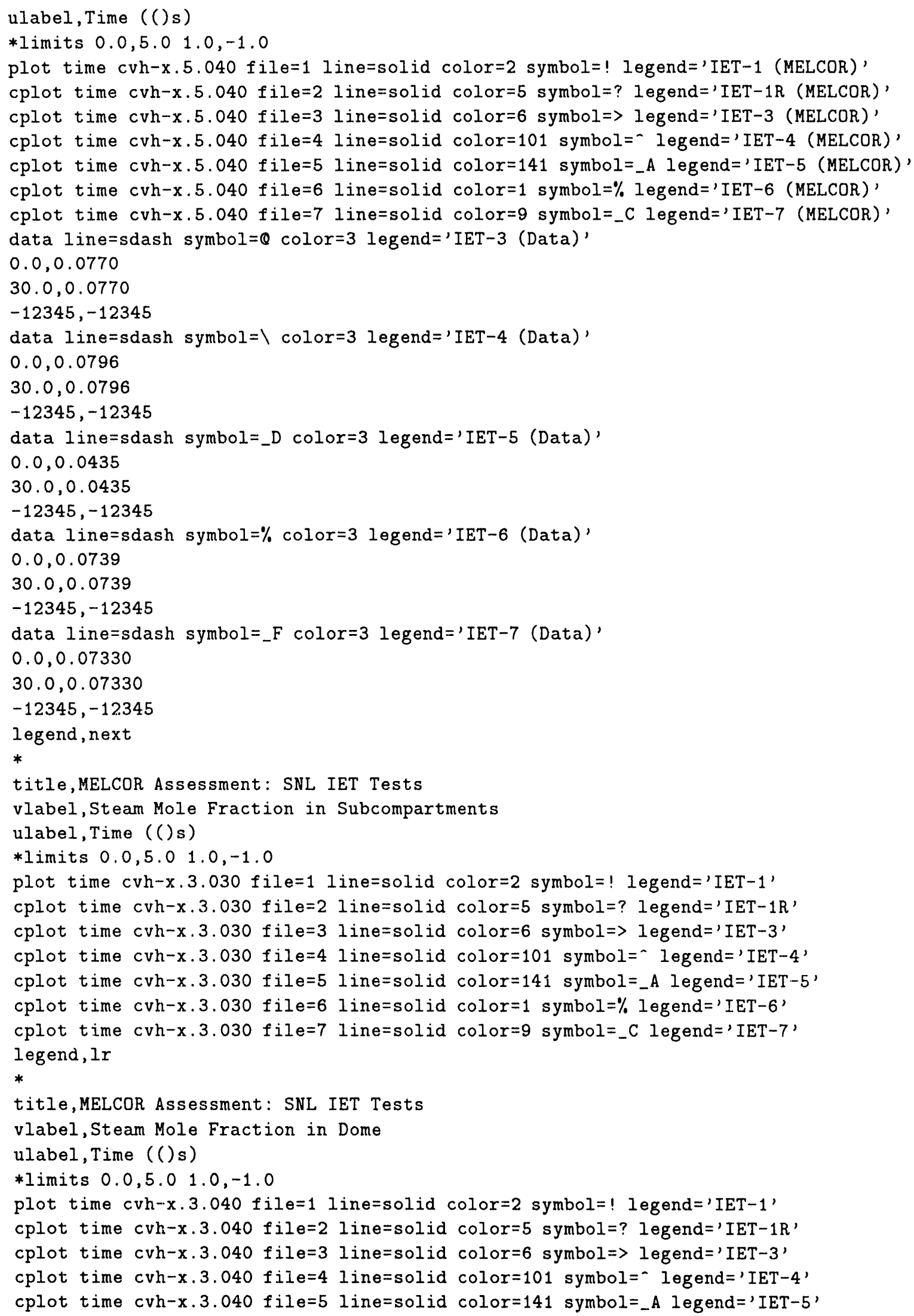


cplot time cvh-x.3.040 file=6 line=solid color=1 symbol=\% legend='IET-6' cplot time cvh-x.3.040 file=7 line=solid color=9 symbol=_C legend='IET -7 ' legend, ir

*

title, MELCOR Assessment: SNL IET Tests

vlabel, Oxygen Burned in Dome $(() \mathrm{kg})$

ulabel, Time (()s)

*Iimits $0.0,5.01 .0,-1.0$

plot time bur-o2-tot.040 file=1 line=solid color=2 symbol=! legend='IET-1'

cplot time bur-02-tot. 040 file=2 line=solid color $=5$ symbol=? legend='IET-1R'

cplot time bur-o2-tot.040 file=3 line=solid color $=6$ symbol $\Rightarrow$ legend='IET-3'

cplot time bur-o2-tot.040 file=4 line=solid color=101 symbol=- legend='IET-4'

cplot time bur-02-tot.040 file=5 line=solid color=141 symbol=_A legend='IET-5'

cplot time bur-o2-tot.040 file=6 line=solid color=1 symbol=\% legend='IET-6'

cplot time bur-o2-tot.040 file $=7$ line=solid color $=9$ symbol=_C legend=' IET -7 '

legend, Ir

*

title,MELCOR Assessment: SNL IET Tests

vlabel, Hydrogen Burned in Dome (() kg)

ulabel, Time (()s)

*Iimits $0.0,5.01 .0,-1.0$

plot time bur-h2-tot.040 file=1 line=solid color=2 symbol=! legend='IET-1'

cplot time bur-h2-tot.040 file=2 line=solid color=5 symbol=? legend=' $I E T-1 R$ '

cplot time bur-h2-tot.040 file=3 line=solid color 6 symbol $\Rightarrow$ legend='IET-3'

cplot time bur-h2-tot.040 file=4 line=solid color=101 symbol= - legend='IET-4'

cplot time bur-h2-tot. 040 file=5 Iine=solid color $=141$ symbol=_A legend='IET-5'

cplot time bur-h2-tot.040 file=6 line=solid color=1 symbol=\% legend=' IET-6'

cplot time bux-h2-tot.040 file=7 line=solid culcr=9 symbol=_C legend='IET -7 '

legend, ir

*

title,MELCOR Assessment: SNL IET Tests

vlabel, Steam Generated in Burns in Dome $(() \mathrm{kg})$

ulabel, Time (()s)

*limits $0.0,5.01 .0,-1.0$

plot time bur-o2-tot.040 file=1 line=solid color=2 symbol=! legend='IET-1'

cplot time bur-o2-tot. 040 file $=2$ line=solid color $=5$ symbol=? legend=' $I E T-1 R$ '

cplot time bur-o2-tot.040 file=3 line=solid color $=6$ symbol $\Rightarrow$ legend='IET-3'

cplot time bur-o2-tot.040 file=4 line=solid color $=101$ symbol=- legend='IET -4 '

cplot time bur-o2-tot.040 file=5 line=solid color=141 symbol=_A legend='IET-5'

cplot time bur-o2-tot.040 file=6 line=solid color=1 symbol=\% legend='IET-6'

cplot time bur-o2-tot.040 file=7 line=solid color $=9$ symbol=_C legend='IET-7'

legend, Ir

*

title, MELCOR Assessment: SNL IET Tests

vlabel, CO Used in Burns in Dome (() kg)

ulabel, Time (()s)

*limits $0.0,5.01 .0,-1.0$

plot time bur-co-tot.040 file=1 line=solid co2lor=2 symbol=! legend='IET-1'

cplot time bur-co-tot.040 file=2 line=solid co2lor=5 symbol=? legend='IET-1R'

cplot time bur-co-tot.040 file=3 line=solid co2lor $=6$ symbol $\Rightarrow$ legend='IET-3'

cplot time bur-co-tot.040 file=4 line=solid co2lor=101 symbol=- legend='IET-4'

cplot time bur-co-tot. 040 file $=5$ line=solid co2lor $=141$ symbol=_A legend='IET-5'

cplot time bur-co-tot. 040 file=6 line=solid co2lor $=1$ symbol=\% legend='IET-6' 
cplot time bur-co-tot. 040 file $=7$ line=solid co2lor $=9$ symbol=_C legend=' IET -7 '

legend, Ir

*

title, MELCOR Assessment: SNL IET Tests

vlabel,CO2 Used in Burns in Dome $(() \mathrm{kg})$

ulabel, Time (()s)

*limits $0.0,5.01 .0,-1.0$

plot time bur-co2-tot.040 file=1 line=solid co2lor=2 symbol=! legend='IET-1'

cplot time bur-co2-tot.040 file=2 line=solid co2lor $=5$ symbol=? legend='IET-1R'

cplot time bur-co2-tot.040 file=3 line=solid co2lor $=6$ symbol $\Rightarrow$ legend ='IET -3 '

cplot time bur-co2-tot.040 file=4 line=solid co2lor $=101$ symbol=- legend=' IET-4'

cplot time bur-co2-tot.040 file=5 line=solid co2lor $=141$ symbol=_A legend='IET-5'

cplot time bur-co2-tot.040 file=6 line=solid co2lor =1 symbol=\% legend='IET-6'

cplot time bur-co2-tot. 040 file=7 line=solid co2lor=9 symbol=_C legend='IET-7'

legend, ir

*

title, MELCOR Assessment: SNL IET Tests

vlabel, BUR Power in Dome (()w)

ulabel, Time (()s)

*Iimits $0.0,5.01 .0,-1.0$

plot time bur-power. 040 file=1 line=solid color $=2$ symbol=! legend='IET-1'

cplot time bur-power. 040 file=2 line=solid color=5 symbol=? legend='IET-1R'

cplot time bur-power. 040 file=3 line=solid color $=6$ symbol=> legend='IET -3 '

cplot time bur-power. 040 file=4 line=solid color=101 symbol=- legend='IET-4'

cplot time bur-power. 040 file=5 line=solid color=141 symbol=_A legend='IET-5'

cplot time bur-power. 040 file $=6$ line=solid color $=1$ symbol=\% legend='IET-6'

cplot time bur-power. 040 file=7 line=solid color=9 symbol=_C legend='IET-7'

legend, $1 r$

*

title, MELCOR Assessment: SNL IET Tests

vlabel, BUR Energy in Dome (() J)

ulabel, Time (()s)

*Iimits $0.0,5.01 .0,-1.0$

plot time bur-energy.040 file=1 line=solid color=2 symbol=! legend='IET-1'

cplot time bur-energy.040 file=2 line=solid color=5 symbol=? legend=' IET-1R'

cplot time bur-energy.040 file=3 line=solid color $=6$ symbol $\Rightarrow$ legend=' IET -3 '

cplot time bur-energy.040 file=4 line=solid color=101 symbol=- legend='IET-4'

cplot time bur-energy.040 file=5 line=solid color=141 symbol=_A legend='IET-5'

cplot time bur-energy.040 file=6 line=solid color =1 symbol=\% legend=' IET-6'

cplot time bur-energy.040 file=7 line=solid color=9 symbol=_C legend='IET -7 '

legend, Ir

* 
External Distribution:

U. S. Nuclear Regulatory Commission (18)

Attn: S. Acharya, NLS-372

Y. S. Chen, NLN-344

M. A. Cunningham, NLS-372

F. Eltawila, NLN-344

R. B. Foulds, NLN-344

S. Basu, NLN-344

C. Gingrich, NLN-344

C. G. Tinkler, NLN-344

L. E. Lancaster, NLS-372

R. O. Meyer, NLS- 007

J. A. Mitchell, NLS-314

C. P. Ryder, NLS-372

L. Soffer, NLS-324

B. Sheron, NLSS-007

J. A. Murphy, NLS-007

L. M. Shotkin, NLN-353

N. Lauben, NLN-353

R. Landry, NLN-344

Washington, DC 20555

S. Y. Chen

Argonne National Laboratory

9700 South Cass Avenue

Argonne, IL 60439

Battelle Columbus Laboratories (3)

Attn: P. Cybulskis

M. Carmel

R. S. Denning

505 King Avenue

Columbus, OH 4.3201

Brookhaven National Laboratory (2)

Attn: I. K. Madni

T. Pratt

Bldg. 130

32 Lewis

Upton, NY 11973 
Idaho National Engineering Laboratory (5)

Attn: A. Brown

R. J. Dallman

D. W. Golden

S. E. Reed

G. W. Johnsen

EG\&G Idaho

P. O. Box 1625

Idaho Falls, ID 83404

D. Jones

EI International

P. O. Box 50736

Idaho Falls, ID 83405

Electric Power Research Institute (3)

Attn: E. Fuller

R. N. Oehlberg

B. R. Sehgal

P. O. Box 10412

Palo Alto, CA 94303

Los Alamos National Laboratory (2)

Attn: B. E. Boyack, K-551

D. R. Liles, K-553

P. O. Box 1663

Los Alamos, NM 87545

Oak Ridge National Laboratory (11)

P. O. Box 2009

Oak Ridge, TN 37831-8057

Attn: S. R. Greene, MS-8057

R. H. Morris, MS- 8057

S. E. Fisher, MS-8057

R. Sanders, MS-8057

T. L. Heatherly, MS-8057

S. A. Hodge, MS- 8057

C. R. Hyman, MS-8057

B. W. Patton, MS-8057

D. B. Simpson, MS- 8057

R. P. Taleyarkhan, MS- 8057

M. L. Tobias, MS- 8088 
Andrzej Drozd

Nuclear Regulatory Commission

OWFN, MS 8E1

11555 Rockville Pike

Rockville, MD 20852

W. P. Barthold

Barthold \& Associates

132 Seven Oaks Drive

Knoxville, TN 37922

K. C. Wagner

Science Applications Intl. Corp.

2109 Air Park Rd. SE

Albuquerque, NM 87106

Savannah River Laboratory (2)

Attn: B. DeWald

D. Allison

Westinghouse Savannah River Co.

Bldg. 773-41A

Aiken, SC 29808-0001

Westinghouse Hanford Co. (2)

Attn: D. Ogden

O. Wang

P. O. Box 1970

Richland, WA 99352

General Electric Company (3)

Knolls Atomic Pwer Laboratory

Attn: D. F. McMuilan

G. H. Epstein

E. Mennard

Bldg. F3, Room 8

P. O. Box 1072

Schenectady, NY 12301-1072

Bettis Atomic Power Laboratory (3)

Attn: Mark Riley

Jow Semanchik

Vincent Baiamonte

P. O. Box 79

West Mifflin, PA 15122 
Mohsen Khatib-Rahbar

Energy Research Inc.

P. O. Box 2034

Rockville, MD 20852

V. K. Dhir

2445 22nd Street

Santa Monica, CA 90403

R. Viskanta

Purdue University

Heat Transfer Laboratory

School of Mechanical Engineering

West Lafayette, IN 47907

Dr. Jim Gieseke

Battelle Memorial Institute

505 King Ave.

Columbus, Ohio 43201

M. A. Kenton

Gabor, Kenton \& Associates

770 Pasquinelli Drive

Suite 426

Westmont, IL 60559

University of California (2)

Attn: W. H. Amarasooriya

$T$. Theofanous

ERC-CRSS

Santa Barbara, CA 93106

F. E. Haskin

University of New Mexico

Department of Chemical and Nuclear Engineering

Albuquerque, NM 87131

J. C. Lee

University of Michigan

Dept. of Nuclear Engineering

Cooley Building, North Campus

College of Engineering

Ann Arbor, MI 48109-2104 
University of Wisconsin (2)

Dept. of Nuclear Engineering

Attn: M. L. Corradini

G. A. Moses

Engineering Research Building

1500 Johnson Drive

Madison, WI 53706

Ramu K. Sundaram

Manager, LOCA Analysis Group

Nuclear Engineering

Yankee Atomic Electric Company

580 Main Street

Bolton, MA 01740

John Bolin

CEGA

P. O. Box 85608

San Diego, CA 92186-9784

M. Plys

Fauske \& Associates

16W070 West 83rd Street

Burr Ridige, II. 60521

Nick Trikouros

GPU Nuclear Corporation

One Upper Pond Road

Parsippany, NJ 07054

B. Raychaudhuri

Nebraska Public Power District

PRA \& Engineering Review Group

P. O. Box 499

Columbus, NE 68601

Frank Elia

Stone \& Webster Engineering Corp.

245 Summer Street

Boston, MA 02210 
Samir S. Girgis

Atomic Energy of Canada Limited

CANDU Operations

Sheridan Park Research Community

Mississagua, Ontario

CANADA I.5K1B2

Paul J. Fehrenbach

Chalk River Nuclear Laboratories

Fuel Engineering Branch, RSR Division

Chalk River, Ontario

CANADA KOJ1J0

Dr. Bohumír Kujal

Department of Reactor Technology

Nuclear Research Institute Re $\mathrm{R}^{-z}$ plc

25068 Řež

CZECH REPUBLIC

Andrej Mitro

Institute of Radioecology and Applied Nuclear Techniques

Garbiarska 2

P. O. Box A-41

04061 Košice

CHECHOSLOVAKIA

Shih-Kuei Cheng

Institute of Nuclear Energy Research

P. O. Box 3-3

Lung-Tan, Taiwan

REPUBLIC OF CHINA

Technical Research Centre of Finland (3)

Nuclear Engineering Laboratory

Attn: Lasse Mattila

Ilona Lindholm

Esko Pekkarinen

P. O. Box 208 (Tekniikantie 4)

SF-002151 Espoo

FINLAND 
Jorma V. Sandberg

Finnish Center Radiation \& Nucl. Safety,

Dept. of Nuclear Safety

P. O. Box 268

SF-00101 Helsinki

FINLAND

Akihide Hidaka

Safety Research Department

Reactor Accident Studies and Modelling Branch

DRS/SEMAR

Cadarache Nuclear Center

13108 Saint-Paul-Lez-Durance Cedex

FRANCE

Dr. Lothar Wolf

Battelle Institute EV

AM Romerhof 35

D-6000

Frankfurt/Main90

GERMANY

Gesellschaft fur Anlagen- und Reaktorsicherheit (3)

Attn: Ulrich Erven

Walter Erdmann

Manfred Firnhaber

Schwertnergasse 1

D-5000 Koln 1

GERMANY

Kernforschungzentrum, Karlsruhe (3)

Attn: P. Hofmann

Werner Scholtyssek

Philipp Schmuck

P. O. Box 3640

D-7500 Karlsruhe 1

GERMANY

Udo Brockmeier

University of Bochum

Energietechnik

IB-4-128

D-4630 Bochum

GERMANY 
György Gyenes

Central Rescarch Institute for Physics

Institute for Atomic Energy Research

H-1525 Budapest, P. O. Box 49

HUNGARY

Joint Research Center

Commission of the European Communities

Attn: Alan Jones

Iain Shepherd

Safety Technology Institute

21020 Ispra (Va)

ITALY

Giovanni Saponaro

ENEA

Natl. Comm. for R\&D of Nuclear Energy

Via Vitaliano Brancati, 48

00144 Rome

ITALY

Japan Atomic Energy Research Institute (3)

Attn: Kunihisa Soda

Jun Sugimoto

Norihiro Yamano

'Tokai-mura, Naka-gun, Ibaraki-ken

319-11, JAPAN

Dr. Masayoshi Shiba, Director General

Institute of Nuclear Safety

Nuclear Power Engineering Corporation

Fujita Kankou Toranoman Bldg. 7F

3-17-1, Toranoman

Minato-Ku, Tokyo, 105

JAPAN

Masao Ogino

Mitsubishi Atomic Power Industries

4-1 Shibakoen 2-Chome

Minatoku Tokyo

JAPAN 
Hidetoshi Okada

Nuclear Power Engineering Corporation

3-17-1, Toranomon Bldg. 5F

Minato-ku, Tokyo 105

JAPAN

Hirohide Oikawa

Toshiba Corporation

8, Shin-Sugita, Isogo-ku

Yokohama

JAPAN

Korea Atomic Energy Research Inst. (3)

Attn: Kun-Joong Yoo

Song-Won Cho

Dong-Ha Kim

P. O. Box 7, Daeduk Danji

Taejon

SOUTH KOREA 305-353

Jae Hong Park

Safety Assessment Department

Korea Atomic Energy Research Institute

P. O. Box 16, Daeduk-Danji

Taejon

SOUTH KOREA 305-353

Netherlands Energy Research Foundation (2)

Attn: Karel J. Brinkmann

E. J. Velema

P. O. Box 1

1755 ZG Petten

THE NETHERLANDS

Dr. Valery F. Strizhov

Russian Academy of Science

Institute of Nuclear Safety

Moscow, G. Tulsky, 52

113191, RUS.IIA 
Universidad Politecnica de Madrid (2)

Attn: Augustin Alonzo Santos

Francisco Martin

E.T.S. Ingenieros Industriales

Jose Gutierrez Abascal, 2

28006 Madrid

SPAIN

Juan Bagues

Consejo de Seguridad Nuclear

Justo Dorado, 11

28040, Madrid

SPAIN

Oddbjörn Sandervåg

Statens Kärnkraftinspektion

Swedish Nuclear Power Inspectorate

Box 2710610252 Stockholm

SWEDEN

L. Hammar, Director

Division of Research

Swedish Nuclear Power Inspectorate

Statens Karnkraftinspektion

Sehlstedtsgatan 11

Box 27106

S-102-50 Stockholm

SWEDEN

Swiss Federal Nuclear Safety Inspectorate (4)

Attn: S. Chakraborty

Sang Lung Chan

U. Schmocker

H. P. Isaak

CH-5232 Villigen-HSK

SWITZERLAND

United Kingdom Atomic Energy Agency (3)

Winfrith Technology Center

Attn: T. Haste

S. R. Kinnersley

D. W. Sweet

Winfrith, Dorchester, Dorset

UNITED KINGDOM, DTS 8DH 
United Kingdom Atomic Energy Authority (2)

Safety \& Reliability Directorate

Attn: M. I. Robertson

C. Wheatley

Wigshaw Lane, Culcheth, Warrington

Cheshire, WA3 4NE

UNITED KINGDOM

Geoffrey A. Brown

Manager, Safety and Accident Analysis

AEA Technology, (SRD)

Thomson House, Risley, Warrington

Cheshire, WA3 6AT

UNITED KINGDOM

Internal Distribution:

6400 N. R. Ortiz

6403 W. A. von Riesemann

6404 D. A. Powers

6412 A. L. Camp

$6412 \mathrm{~S}$. E. Dingman

$6413 \mathrm{~F}$. 'l'. Harper

6414 J. E. Kelly

6418 S. L. Thompson (10)

6418 R. K. Cole

6418 A. A. Elsbernd

6418 L. N. Kmetyk (10)

6418 R. C. Smith

6418 D. S. Stuart

6418 R. M. Summers

6418 'T. J. Tautges

6422 M. D. Allen

6422 T. K. Blanchat

6422 M. Pilch

6429 K. E. Washington

6429 D. C. Williams

7141 Technical Library (5)

7151 'Technical Publications

7613-2 Document, Processing for DOE/OS'TI (10)

8523-2 Central Technical Files 

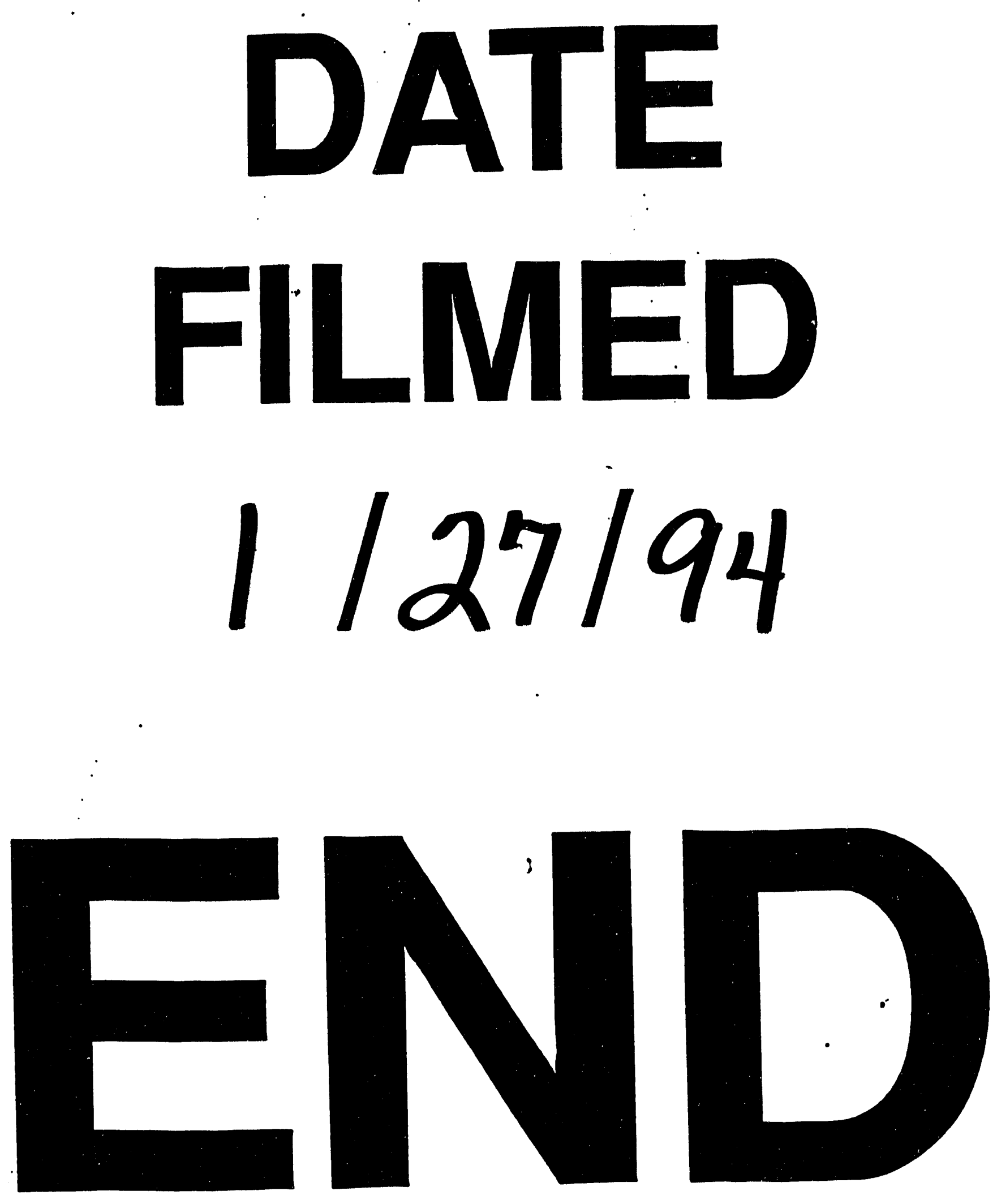
